RESEARCH

SERIES

NUMBER 90

July 2019

\title{
GEOGRAPHIC PROFILE OF HEALTHCARE NEEDS AND NON-ACUTE HEALTHCARE SUPPLY IN IRELAND
}

SAMANTHA SMITH, BRENDAN WALSH, MAEV-ANN WREN, STEVE BARRON, EDGAR MORGENROTH, JAMES EIGHAN AND SEÁN LYONS

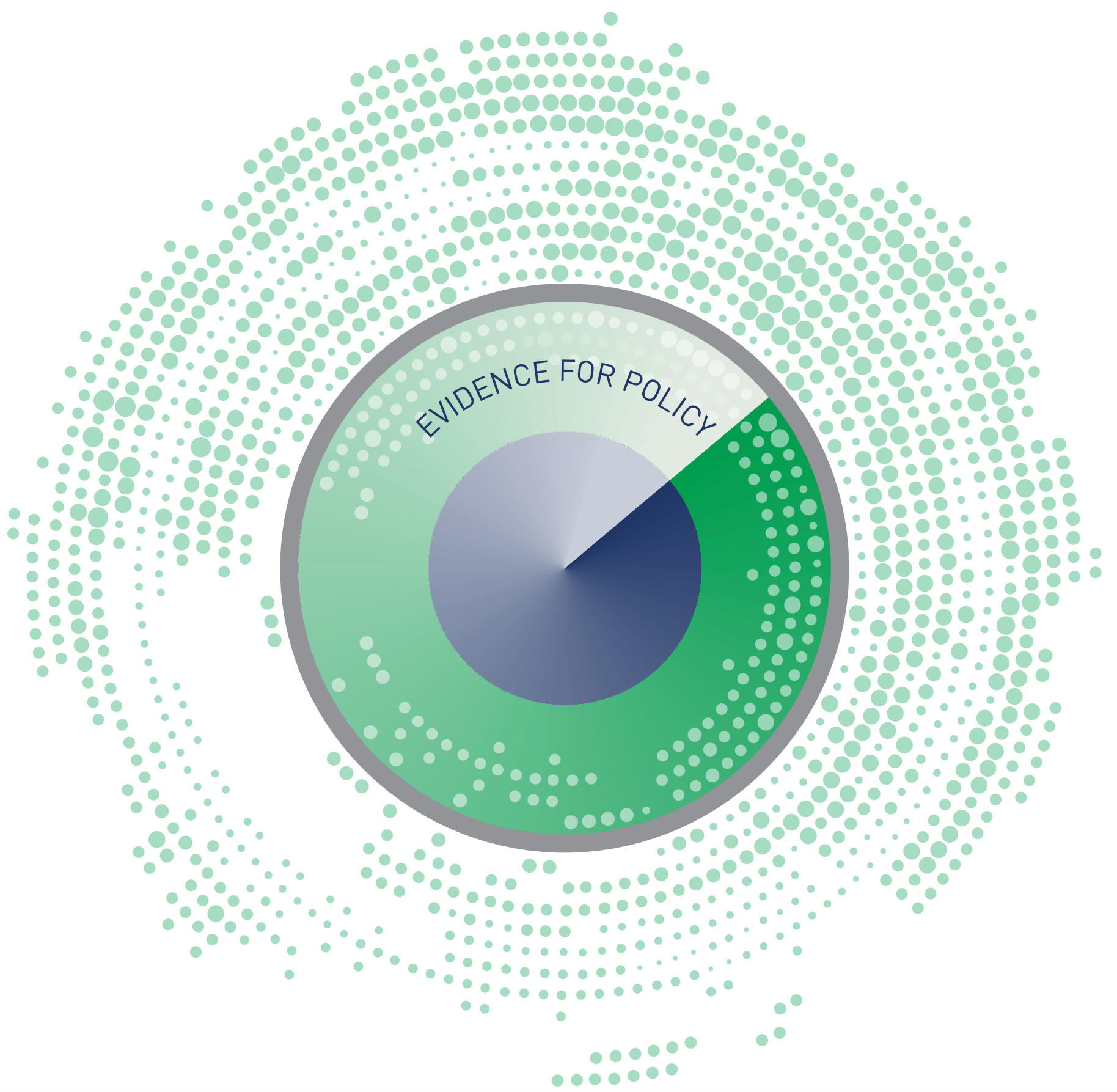




\section{GEOGRAPHIC PROFILE OF HEALTHCARE NEEDS AND NON-ACUTE HEALTHCARE SUPPLY IN IRELAND}

Samantha Smith

Brendan Walsh

Maev-Ann Wren

Steve Barron

Edgar Morgenroth

James Eighan

Seán Lyons

July 2019

\section{RESEARCH SERIES}

\section{NUMBER 90}

Available to download from www.esri.ie

(C) The Economic and Social Research Institute

Whitaker Square, Sir John Rogerson's Quay, Dublin 2

ISBN 978-0-7070-0498-3

DOI: https://doi.org/10.26504/rs90

First report of the project entitled: 'An inter-sectoral analysis by geographic area of the need for and the supply and utilisation of health services in Ireland' HRB Project HRA-HSR-2014-659

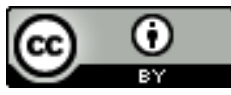

This Open Access work is licensed under a Creative Commons Attribution 4.0 International License (https://creativecommons.org/licenses/by/4.0/), which permits unrestricted use, distribution, and reproduction in any medium, provided the original work is properly credited. 



\section{ABOUT THE ESRI}

The mission of the Economic and Social Research Institute is to advance evidencebased policymaking that supports economic sustainability and social progress in Ireland. ESRI researchers apply the highest standards of academic excellence to challenges facing policymakers, focusing on 12 areas of critical importance to 21st Century Ireland.

The Institute was founded in 1960 by a group of senior civil servants led by $\operatorname{Dr}$ T.K. Whitaker, who identified the need for independent and in-depth research analysis to provide a robust evidence base for policymaking in Ireland.

Since then, the Institute has remained committed to independent research and its work is free of any expressed ideology or political position. The Institute publishes all research reaching the appropriate academic standard, irrespective of its findings or who funds the research.

The quality of its research output is guaranteed by a rigorous peer review process. ESRI researchers are experts in their fields and are committed to producing work that meets the highest academic standards and practices.

The work of the Institute is disseminated widely in books, journal articles and reports. ESRI publications are available to download, free of charge, from its website. Additionally, ESRI staff communicates research findings at regular conferences and seminars.

The ESRI is a company limited by guarantee, answerable to its members and governed by a Council, comprising 14 members who represent a cross-section of ESRI members from academia, civil services, state agencies, businesses and civil society. The Institute receives an annual grant-in-aid from the Department of Public Expenditure and Reform to support the scientific and public interest elements of the Institute's activities; the grant accounted for an average of 30 per cent of the Institute's income over the lifetime of the last Research Strategy. The remaining funding comes from research programmes supported by government departments and agencies, public bodies and competitive research programmes. Further information is available at www.esri.ie

This report has been accepted for publication by the Institute, which does not itself take institutional policy positions. All ESRI Research Series reports are peer reviewed prior to publication. The author(s) are solely responsible for the content and the views expressed. 


\section{THE AUTHORS}

Samantha Smith is a Research Affiliate, Brendan Walsh is a Research Officer, MaevAnn Wren is a Senior Research Officer and Seán Lyons is an Associate Research Professor at the Economic and Social Research Institute (ESRI), Dublin. Steve Barron was a Research Officer and James Eighan was a Research Assistant at the ESRI. Edgar Morgenroth is a full Professor of Economics in DCU Business School, Dublin City University, Dublin. Brendan Walsh, Maev-Ann Wren and Seán Lyons have adjunct research positions at Trinity College Dublin.

\section{ACKNOWLEDGEMENTS}

The authors would like to thank the members of the project Steering Group and collaborators on the project team for their expert advice and input.

The authors would also like to thank people who provided additional analysis for the study. Dr Kathleen Bennett (Department of Pharmacology \& Therapeutics, TCD Centre for Health Sciences, St James's Hospital) and Dr Caitriona Cahir (ESRI) provided the analysis of morbidity among people with Medical Cards. Bryan Coyne (ESRI) assisted with the analysis of physical access to GPs. Nathan Cunningham (ESRI) provided additional analysis of population estimates, GP data and morbidity data.

The authors are very grateful to all those who facilitated the many requests for data for this study and in particular: Alan Cahill, Department of Health; Central Statistics Office; Justin Gleeson, All-Ireland Research Observatory (AIRO), Maynooth University; Dr Howard Johnson and the Health Intelligence Unit, Health Service Executive; Vincent Kennedy, Department of Health; Tom O'Regan, Health Information and Quality Authority; Dr Conor Teljeur and Department of Public Health and Primary Care, Trinity College Dublin; Des Williams, National HR Directorate, Health Service Executive; Michael Fitzgerald and Eithne McAuliffe, Services for Older People, Health Service Executive; and Bob Hennessy and Margaret Cahill, Health Information Quality Authority. 


\section{ABBREVIATIONS}

$\begin{array}{ll}\text { AIRO } & \text { All-Ireland Research Observatory } \\ \text { CHN } & \text { Community Healthcare Network } \\ \text { CHO } & \text { Community Healthcare Organisation } \\ \text { CN } & \text { community nurse } \\ \text { CO\&PSY } & \text { counsellors and psychologists } \\ \text { CRGN } & \text { community registered general nurse } \\ \text { CSO } & \text { Central Statistics Office } \\ \text { DOH } & \text { Department of Health } \\ \text { DOHC } & \text { Department of Health and Children } \\ \text { EA } & \text { Enumeration Area } \\ \text { ED } & \text { Emergency Department } \\ \text { EU } & \text { European Union } \\ \text { GMS } & \text { General Medical Services } \\ \text { GP } & \text { general practitioner } \\ \text { HCH } & \text { home care hour } \\ \text { HCP } & \text { Home Care Package } \\ \text { HIPE } & \text { Hospital In-Patient Enquiry } \\ \text { HIQA } & \text { Health Information and Quality Authority } \\ \text { HRB } & \text { Health Research Board } \\ \text { HSCN } & \text { Health and Social Care Network } \\ \text { HSE } & \text { Health Service Executive } \\ \text { HSPC } & \text { Health Service Personnel Census } \\ \text { ICGP } & \text { Irish College of General Practitioners } \\ \text { IMD } & \text { Irish Medical Directory } \\ \text { ISA } & \text { Integrated Service Area } \\ \text { ISCP } & \text { Irish Society of Chartered Physiotherapists } \\ \text { ISD } & \text { Integrated Services Directorate } \\ \text { LHO } & \text { Local Health Office } \\ \text { LTRC } & \text { long-term residential care } \\ \text { NHI } & \text { Nursing Homes Ireland } \\ \text { NHO } & \text { National Hospital Office } \\ \text { NHSS } & \text { Nursing Homes Support Scheme ('Fair Deal') } \\ \text { NIRSA } & \text { National Institute for Regional and Spatial Analysis } \\ \text { OECD } & \text { Organisation for Economic Co-operation and Development } \\ \text { OT } & \text { occupational therapist } \\ \text { P\&C } & \text { podiatrists and chiropodists } \\ \text { PCCC } & \text { Primary, Community and Continuing Care } \\ \text { PCRS } & \text { Primary Care Reimbursement Service } \\ \text { PCT } & \text { primary care team } \\ \text { PHN } & \text { public health nurse } \\ \text { PT } & \text { physiotherapist } \\ \text { RCSI } & \text { Royal College of Surgeons in Ireland } \\ \text { TILDA } & \text { Regional Integrated Care Organisation } \\ & \text { The Irish Longitudinal Study on Ageing } \\ & \end{array}$


WHO World Health Organization

WTE whole-time equivalent

\section{County codes}

CE

Clare

$\mathrm{CN}$

Cavan

$\mathrm{CO}$

Cork

$\mathrm{CW}$

Carlow

DL

Donegal

DN

Dublin North

DS

Dublin South

G Galway

KY Kerry

KE Kildare

KK Kilkenny

LD Longford

LH Louth

LK Limerick

LM Leitrim

LS Laois

$\mathrm{MH} \quad$ Meath

MN Monaghan

MO Mayo

OY Offaly

RN Roscommon

SO Sligo

TN Tipperary North

TS Tipperary South

WD Waterford

WH Westmeath

WW Wicklow

WX Wexford 


\section{GLOSSARY}

Acute care

Adjustment

Capitation

Co-payment

Disability

Equality

Equity

General Medical

Services Scheme

Gini coefficient

GP Visit Card

Health Boards

Health Information

and Quality Authority

Health Service

Executive

Home Care Package

Home Help

Local Health Office
Curative, rehabilitative or palliative care provided in a hospital setting including day patient, inpatient and outpatient care

Statistical method used to adjust the population in each study area by a specific need indicator (e.g. percentage with disability). Used to re-calculate the ratios of relative supply in an area on the basis of the adjusted population (e.g. number of GPs per person with disability in each area)

A payment method where a healthcare provider receives a set amount for each enrolled person per time period, whether or not that person seeks care

An out-of-pocket payment for care which is partially financed by the state or another source

This term covers impairments, activity limitations and participation restrictions, where an impairment is a problem in body function or structure, an activity limitation is a difficulty encountered by an individual in executing a task or action, and a participation restriction is a problem experienced by an individual in involvement in life situations

\section{Equal dispersion of resources}

Dispersion of resources based on need

A scheme in which individuals who are eligible for a Medical Card receive mostly free access to public health services

Summary measure of relative inequality with the measure laying between 0 (complete equality) and 1 (complete inequality)

A card that allows the eligible recipient free GP visits

The regional devolution of health and social care to local regions from the 1970 Health Act until the establishment of the HSE in 2005

An independent authority established in 2007 to monitor and promote quality and safety in Irish health and social care services

The organisation that administers public health and social care services in Ireland

A publicly provided set of health and domestic services under the Home Care Package Scheme

A service that provides domestic and personal care to individuals in their own home

An HSE administrative geographic division (32 in total) 
Long-stay beds

Lorenz curve

Mean

Medical Card

Morbidity

Non-acute care

Nursing Home

Support (Fair Deal)

Scheme

Primary care team

RICOs

Sláintecare

Substitutability
Residential care beds that include those for extended/continuing care for people who have been assessed as being in need of long-term care; psychiatry of old age, for specialised psychiatric services; and 'young chronic sick' for young people with long-lasting illness which is usually irreversible and may be progressive

A graph presenting relative inequality. Cumulative percentage of total supply is plotted against the cumulative percentage of supply in each area. Areas are ranked from lowest to highest supply

The arithmetic average of a group of numbers

A card that allows the recipient free access to most public health services

The state of being ill or having a disease

Health and social care services provided by medical practitioners outside of the hospital setting; primary care (e.g. general practice), community care (community-based therapy) and long-term care (residential care, home care)

A scheme through which the state funds or subsidises the care of residents in long-term care institutions based on an assessment

A multidisciplinary group of health and social care professionals, including GPs and allied healthcare professionals, focused on the delivery of primary care

Proposed Regional Integrated Care Organisations, to replace $\mathrm{CHOs}$ and Hospital Groups

Cross-party plan for the reform and restructure of the health and social care system in Ireland

Replacement of care from one setting (acute) to another (non-acute) 


\section{FOREWORD}

This report was prepared by researchers at the Economic and Social Research Institute (ESRI) for the Health Research Board funded project titled 'An intersectoral analysis by geographic area of the need for and the supply and utilisation of health services in Ireland'. The report is the first ESRI Research Series Report published from this project. This report examines the geographic distribution of non-acute healthcare services in Ireland in 2014. A second report from this project examines the effect that acute capacity, and home care and long-term residential care, have on inpatient length of stay in public hospitals in Ireland.

The ESRI is responsible for the quality of this research, which has undergone national and international peer review prior to publication. This report was prepared by Dr Samantha Smith, Mr Steve Barron, Dr Brendan Walsh, Dr MaevAnn Wren, Professor Edgar Morgenroth, Mr James Eighan and Dr Seán Lyons, and reflects their expertise and views. The views expressed in this report are not necessarily those of other ESRI researchers, the Health Research Board, or organisations represented on the Steering Group. 


\section{TABLE OF CONTENTS}

EXECUTIVE SUMMARY

Introduction

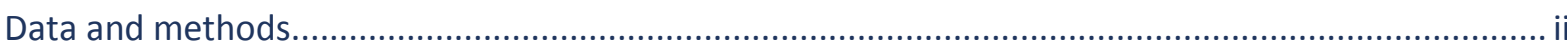

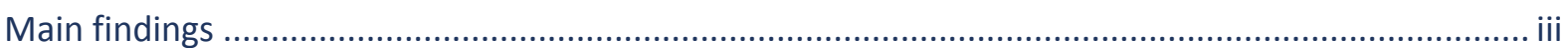

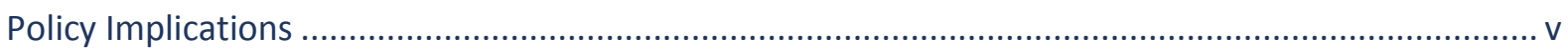

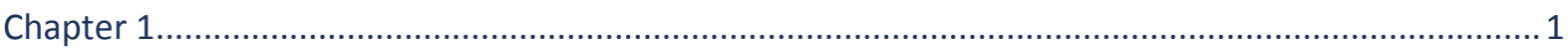

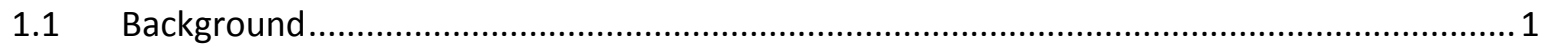

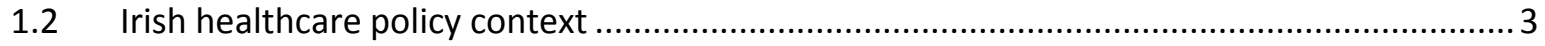

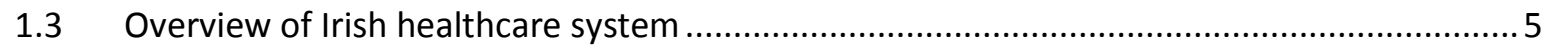

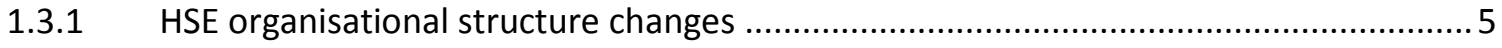

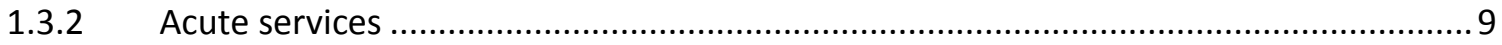

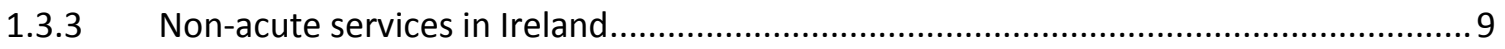

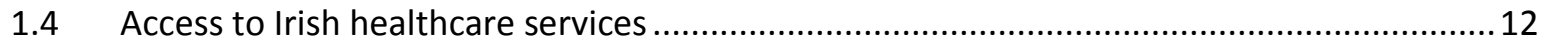

1.4.1 Category I (Medical Card holders) …......................................................................... 12

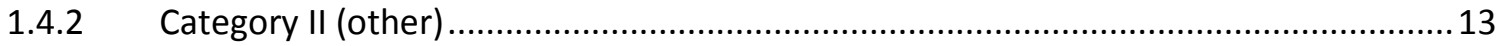

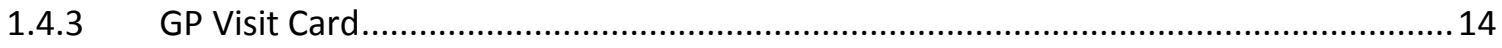

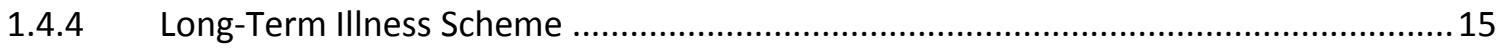

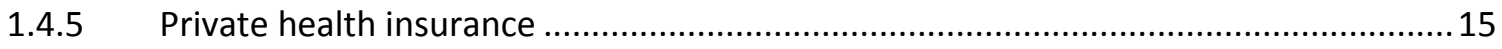

1.4.6 Equity implications of eligibility structures ................................................................. 15

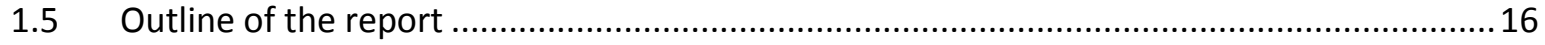

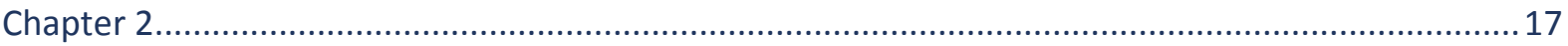

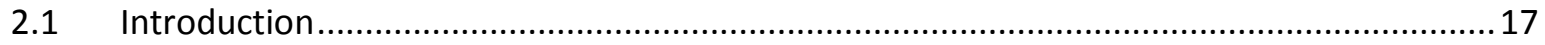

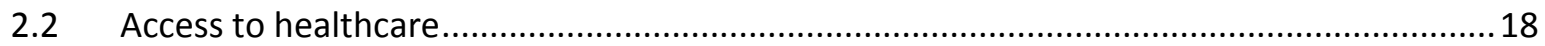

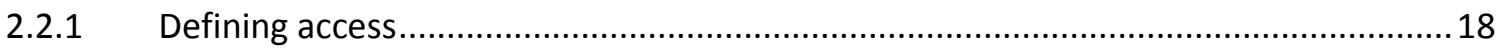

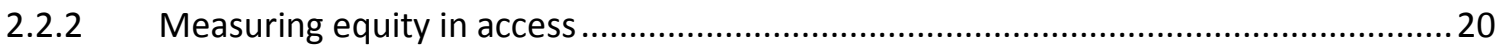

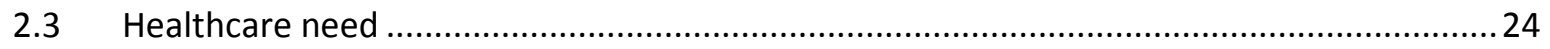

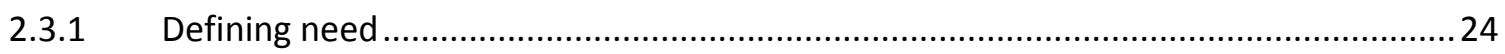

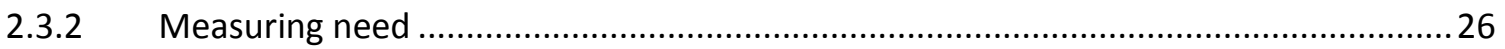

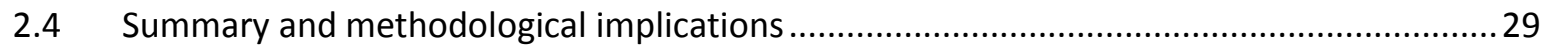

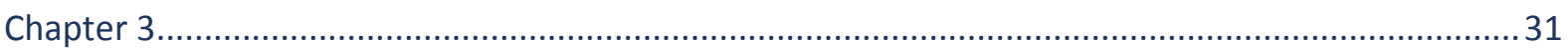

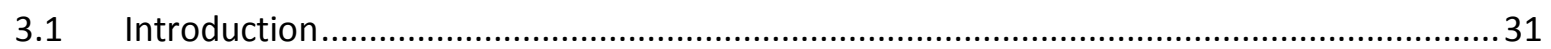

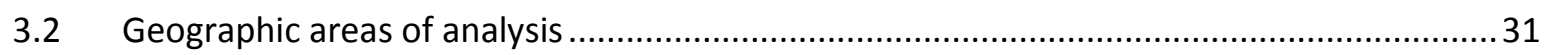

3.2.1 Selection of geographic areas of analysis ................................................................... 31 


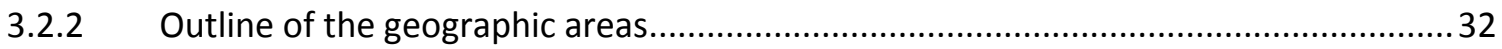

3.2.3 Assigning healthcare supply and need data to geographic areas...............................33

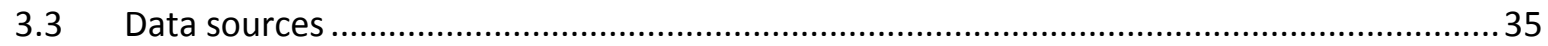

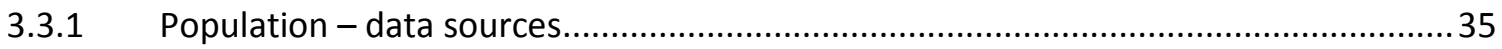

3.3.2 Healthcare need indicators - data sources................................................................. 43

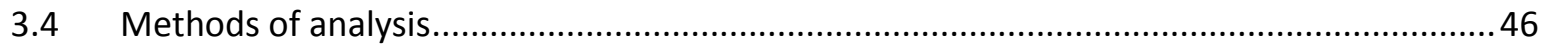

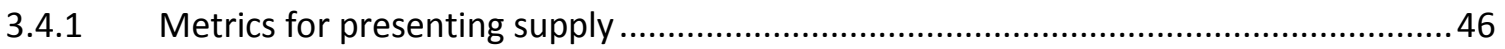

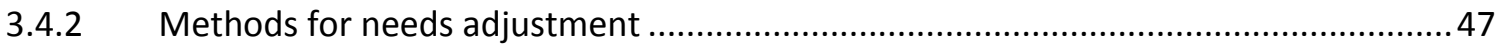

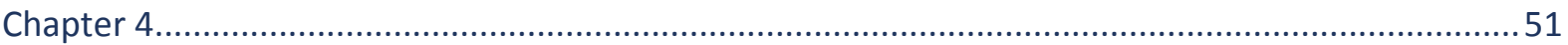

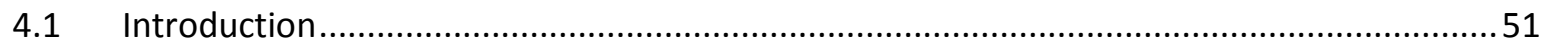

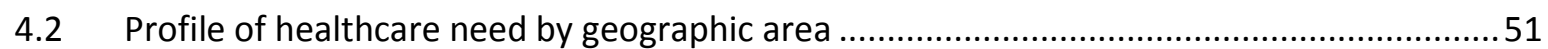

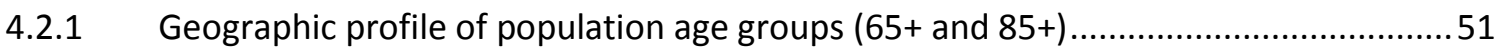

4.2.2 Geographic profile of mortality-adjusted population.....................................................56

4.2.3 Geographic profile of population with disability ...................................................... 58

4.2.4 Geographic profile of Medical Card and GP Visit Card Holders.....................................60

4.2.5 Geographic profile of the number of Medical Card holders with a prescription for a

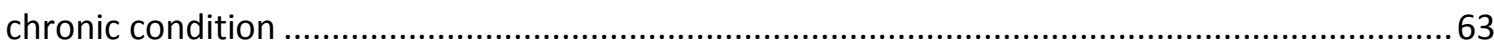

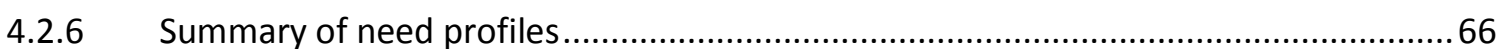

4.3 Profile of non-acute healthcare supply by geographic area - primary care .........................67

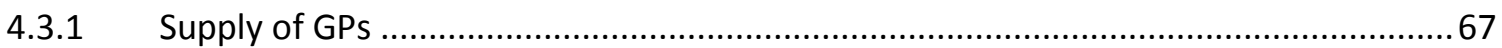

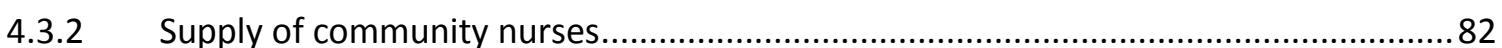

4.4 Profile of non-acute healthcare supply by geographic area - allied health professionals ... 88

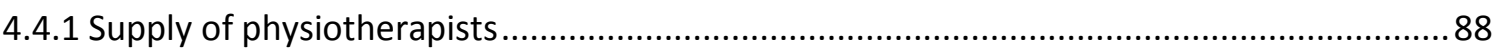

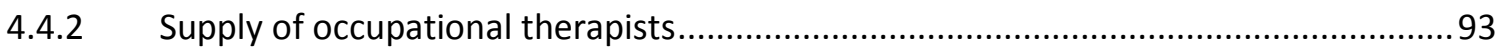

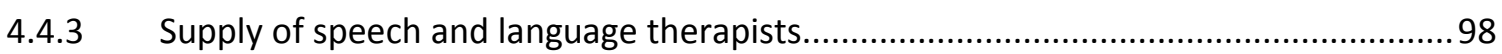

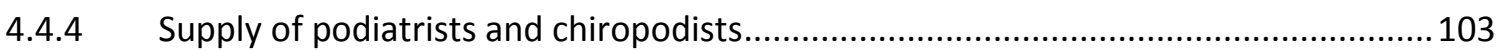

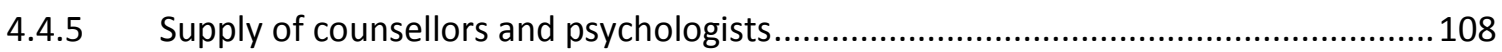

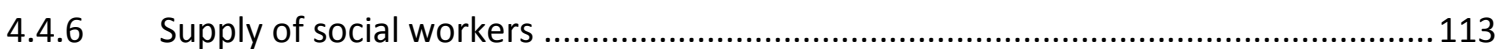

4.5 Profile of non-acute healthcare supply by geographic area - long-term care....................118

4.5.1 Overview of long-term residential care supply in Ireland 2015 .................................118

4.5.2 Geographic patterns of long-term care supply in Ireland in 2015 ............................. 118

4.5.3 Geographic patterns of long-term residential care supply within Dublin 2015 .........120

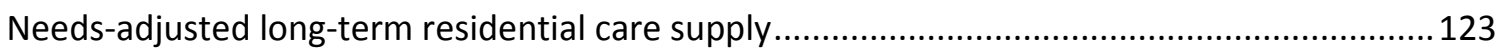

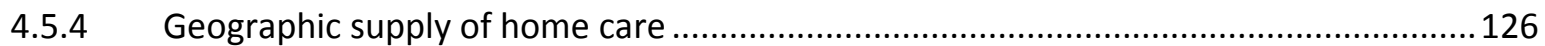

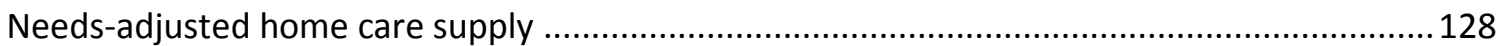




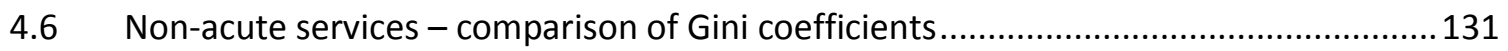

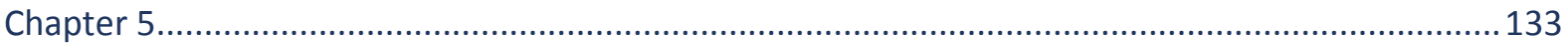

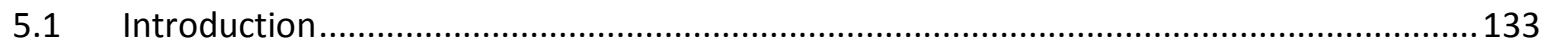

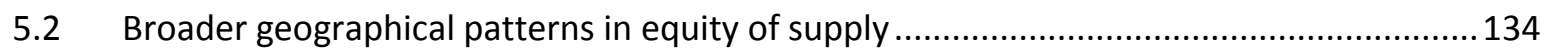

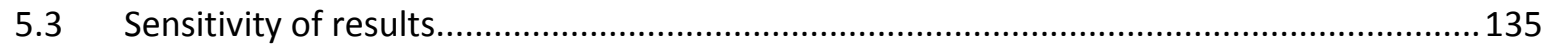

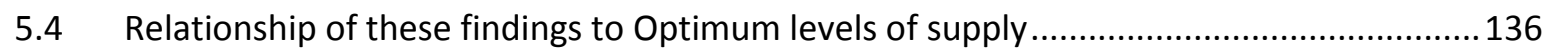

5.5 Discussion of findings on drivers of geographic variations in health and social care supply 137

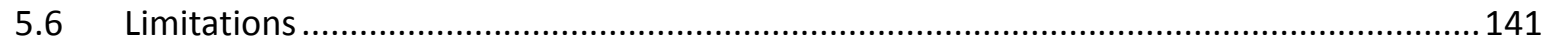

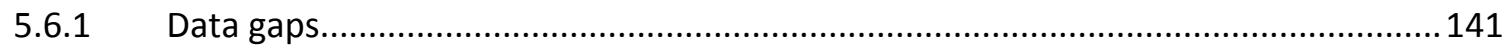

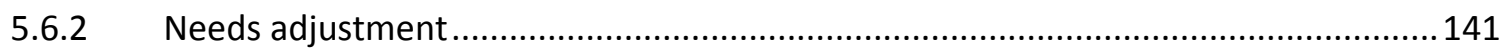

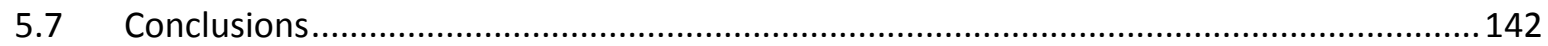

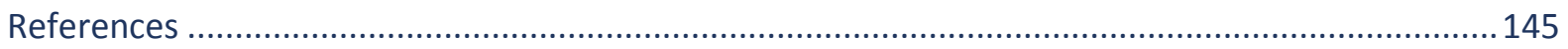

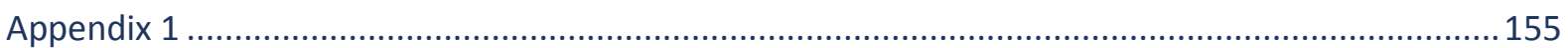

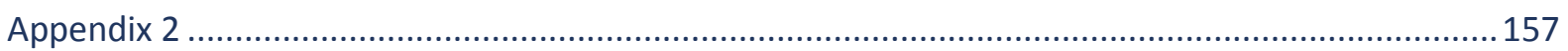

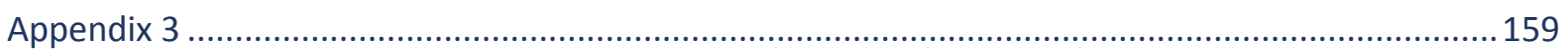

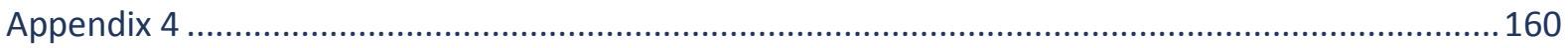






\section{EXECUTIVE SUMMARY}

\section{INTRODUCTION}

This report provides evidence on the supply of and need for non-acute primary, community and long-term care across geographic areas in Ireland in 2014. This is the first report to be published from the Health Research Board-funded project 'An inter-sectoral analysis by geographic area of the need for and the supply and utilisation of health services in Ireland'. This report provides the most comprehensive evidence on the geographic distribution of primary, community and long-term care supply to have been published for Ireland to date. Overall, the report finds significant inequalities in the supply of primary, community and longterm care services across counties in Ireland. ${ }^{1}$ The findings have important implications for future planning of the Irish health system.

The overall objective of the project is to provide evidence to inform policymakers about the shift of care, where appropriate, from the acute hospital setting to nonacute care settings. This project is undertaken in the context of significant system reforms in recent years that aimed to, among other things, achieve greater integration in the Irish healthcare system via shifting care, where appropriate, from acute to non-acute settings and building capacity in primary, community and longterm care. The project sets out to provide detailed evidence on supply of services in the non-acute sector, compares supply across regions to identify where nonacute care supply is particularly scarce, and provides evidence on how acute and non-acute services interact, and substitute, within the Irish health and social care system. Evidence generated from this project is of particular relevance in the context of the current Sláintecare strategy (Houses of the Oireachtas Committee on the Future of Healthcare, 2017), a cross-party plan aimed at delivering sustainable and equitable health and social care services in Ireland.

This project is partitioned into two reports. The aim of this first report is to contribute to the evidence base on the supply of non-acute services around the country. The scope of this report is broad and it sets out the geographic distribution, by county, of ten prominent non-acute health and social care services in Ireland in 2014. To examine inequality in supply, adjustments are made for a range of need indicators, and relative supply is assessed against the benchmark of national average supply.

A major difficulty encountered in this project has been that there is no national dataset that profiles the number, location and catchment population of non-acute

\footnotetext{
1 Supply estimated for 28 'counties' with Dublin and Tipperary split into North and South counties.
} 
healthcare services in Ireland. A major contribution of this report, therefore, was the identification, collation and examination of a range of datasets to inform the analyses. Owing to data limitations, the report mainly focuses on the supply of publicly employed or publicly funded non-acute services, but where data are available, private supply is also examined (e.g. general practitioners (GPs), private physiotherapists and private long-term residential care facilities).

It is important to note at the outset that a geographic profile of services can highlight variations in per capita supply from one area to another but does not in itself answer questions about equity and adequacy. For example, if supply in an area is relatively low but needs for healthcare in that area are also relatively low, the distribution may not be inequitable, and rather the unequal pattern of supply could be matching a similarly unequal pattern of healthcare need. Thus, analyses in this report account for demographic differences and the distribution of healthcare needs across regions to judge whether or not a given unequal distribution of supply is inequitable. Furthermore, the national average supply should not be treated as sufficient for regional healthcare administrators and policymakers to aim for, as it is beyond the scope of this report to assess whether national average supply is a benchmark of adequate supply.

This report demonstrates that without a resource allocation system, there has been great regional inequity in the supply of non-acute services, which cannot be explained on any needs basis. In the context of a national policy objective of moving care from acute hospitals into the community, such inequity may present hospitals and healthcare administrators in some areas with far greater challenges than in other areas, which are better resourced.

\section{DATA AND METHODS}

In this report, ten of the most prominent care services provided outside the hospital setting are examined: primary care - GPs and community and public health nurses; allied health professionals - public and private physiotherapists (PTs), public occupational therapists, public speech and language therapists (SLTs), public social workers (SWs), public chiropodists and podiatrists, and public counsellors and psychologists; and long-term care - long-term residential care and public home care.

In most analyses, the geographic unit of analysis is a county, with some additional disaggregation at postal district level within Dublin. A range of supply metrics are calculated for each geographic area including supply per capita and location quotient (ratio of area supply per capita to national supply per capita). Supply is measured in terms of whole-time equivalents (WTEs) for personnel (GPs, 
community nurses (CNs), etc.), beds for long-term residential care and hours for home care supply.

Inequalities in supply per capita are compared across services using Gini coefficients, a standard way to measure inequality. In order to draw conclusions about equity in supply, the location and volume of supply are also assessed in relation to the location and volume of needs for those services. The adjustment methods used involve adjusting the population in each study area by a specific need indicator (e.g. percentage with disability) and then re-calculating the ratios of supply per capita on the basis of the adjusted population (e.g. number of GPs per person with disability in each area). Andersen's Behavioural Model of Health Service Use is used as a guide to select healthcare needs indicators. Supply per capita in each county is adjusted for the following factors independently: age, mortality, disability rates, Medical Card rates, chronic illness rates. ${ }^{2}$ Supply in each area is assessed against the benchmark of national average supply.

The results in this report refer to supply of care in Ireland in 2014. The authors acknowledge that changes in regional supply and population in the subsequent five years may have altered some of the supply rankings summarised in our findings. However, in the absence of a national resource allocation system that relates supply to population need, it is likely that inequalities persist.

\section{MAIN FINDINGS}

Significant inequalities were observed in the supply of primary, community and long-term care across counties in Ireland in 2014. Table ES.1 provides a high-level synthesis of the report's findings on the geographic variation in the per capita supply of non-acute and long-term care services. Counties with supply of a service 10 per cent lower than the national average are denoted as a red circle. Counties with supply of a service 10 per cent higher than the national average are denoted as a green circle. Where per capita supply of a service is within 10 per cent of the national average, this is denoted as an amber circle. Counties are sorted by the number of services where supply is lower than the national average. 


\begin{tabular}{|c|c|c|c|c|c|c|c|c|c|c|c|}
\hline & \multicolumn{8}{|c|}{ Non-Acute Primary and Community Care } & \multicolumn{2}{|c|}{ Long-Term Care } & \multirow{2}{*}{$\begin{array}{l}\text { Number of services } \\
>10 \text { per cent below } \\
\text { national average }\end{array}$} \\
\hline & GP $^{1}$ & $\mathrm{PHN} / \mathrm{CN}^{2}$ & $\mathbf{P T}^{3}$ & $\mathrm{OT}^{2}$ & $\mathrm{SLT}^{2}$ & $P \& C^{2}$ & CO\&PSY ${ }^{2}$ & $s w^{2}$ & LTRC $^{4}$ & $\mathrm{HCH}^{5}$ & \\
\hline Kildare & & & & & & & & & & & 9 \\
\hline Meath & & & & & & & & & O & & 8 \\
\hline Wexford & & & & & & & & & & & 8 \\
\hline Wicklow & & & & & & & & & & & 8 \\
\hline Clare & & & & & & & & & & & 7 \\
\hline Kilkenny & & & & & & & & & & & 7 \\
\hline Waterford & & & & & & & & & & & 7 \\
\hline Offaly & & & & & & & & & & & 5 \\
\hline Carlow & & & & & & & & & & & 5 \\
\hline Laois & & & & & & & & & & & 4 \\
\hline Limerick & & & & & & & & & & & 3 \\
\hline Mayo & & & 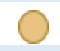 & & & & & & & & 3 \\
\hline Tipperary North & & 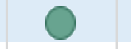 & & & 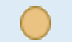 & & & & O & & 3 \\
\hline Dublin North & & & & & & & & & & & 3 \\
\hline Kerry & & & ( & & 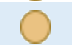 & & & & 0 & & 3 \\
\hline Monaghan & & & & & 0 & & & 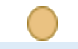 & 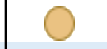 & & 3 \\
\hline Longford & & & & & & & & & & & 3 \\
\hline Roscommon & & 0 & C & & & & & & O & & 3 \\
\hline Dublin South & & O & 0 & & J & & & & 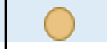 & & 2 \\
\hline Cavan & & & & & & & & & & & 2 \\
\hline Louth & & Л & & & & & & & 0 & & 2 \\
\hline Donegal & & 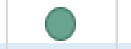 & & & 0 & & & $\checkmark$ & 0 & 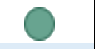 & 2 \\
\hline Tipperary South & & & 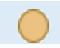 & & & & & & 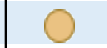 & 0 & 1 \\
\hline Westmeath & & & & & & & & & 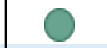 & & 1 \\
\hline Leitrim & & & C & & & & & & ) & & 1 \\
\hline Sligo & & 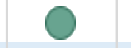 & 0 & & 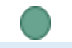 & & 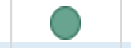 & O & 0 & 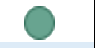 & 1 \\
\hline Cork & & 0 & 0 & 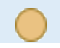 & 0 & & & 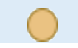 & O & 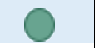 & 0 \\
\hline Galway & & 0 & $\bigcirc$ & 0 & 0 & & 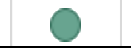 & O & 0 & O & 0 \\
\hline
\end{tabular}

County has supply at least 10 per cent higher than national average.

County has supply at least 10 per cent lower than national average.

County has supply approximately equal to the national average.

Notes: $\quad 1$. The number of GPs is converted to estimated WTEs based on survey evidence on full- and part-time working practices of GPs in Ireland. See Chapter 3 for more details. 2. Publicly employed WTEs. See Chapter 3 for more details. 3. Publicly employed and privately employed WTE PTs. See Chapter 3 for more details. 4. Long-term residential care beds in public and private long-term residential care centres (supply of beds per 1,000 population aged 65+). See Chapter 3 for more details. 5. Publicly funded home care hours from the Home Help and Home Care Package schemes (supply of hours per population aged 65+). See Chapter 3 for more details.

Looking across services in Table ES.1, a consistent pattern in low supply of care for many counties is observed. The Greater Dublin commuter belt and South East counties have lower relative supply of many non-acute primary and community care services than the national average. Kildare and Meath have lower relative supply (at least 10 per cent lower than the national average) for all non-acute community and primary care services. Wexford and Wicklow have lower relative supply (at least 10 per cent lower than the national average) for seven of the eight non-acute community and primary care services examined. 
In contrast to the low relative supply on the East coast, three counties on the West coast - Galway, Sligo and Leitrim - as well as Cork, Westmeath and Tipperary South have higher relative supply for many services, and do not have lower relative supply for more than one of the services examined.

In general in Dublin, the supply of services in Dublin North and Dublin South is similar to the national average. Some variation in supply is seen across some services. Dublin North has low relative supply of GPs, counsellors and psychologists, and long-term residential care. Dublin South has low relative supply of counsellors and psychologists, and publicly funded home care hours.

Table ES.1 does not attempt to assign levels of relative importance to each of the services examined or consider the extent to which lower relative supply of one service could be traded off with higher relative supply of another service. Furthermore, it is important to consider the factors that contribute to variations in supply and test whether results are consistent across different adjustment factors. The report adjusts supply for need factors (age, mortality, disability rates, Medical Card rates, chronic illness rates), with each need indicator adjusted for separately. The results consistently show that needs adjustment does not remove inequities in supply. The finding that counties in the Greater Dublin commuter belt and in the South East have non-acute primary and community service supply that is lower than the national average is not altered by these adjustments. One exception is Kildare: following adjustment, the level of supply in Kildare is higher than the national average for community and public health nurses, PTs, GPs and SLTs for some need indicators. There are a small number of areas where the supply falls from above the national average to below the national average after adjustment. In particular, in Mayo the supply of community and public health nurses, GPs, and SLTs lies above the national average prior to adjustment but below the national average following adjustment for most need indicators. In Roscommon, the supply of PTs, SWs and community and public health nurses changes from above to below the national average following adjustment, and in Sligo and Kerry, the supply of PTs changes from above to below the national average following adjustment for most need indicators.

\section{POLICY IMPLICATIONS}

These findings have important policy implications. There are substantial variations in primary, community and long-term care supply across regions in Ireland. In order to achieve equity in supply, considerable increases in supply of non-acute care would be required in many counties. A subset of counties have low levels of supply across several types of non-acute care, and these include publicly employed, but also some privately provided, services (GPs, private PTs, long-term residential care). Counties in the Greater Dublin commuter belt and South East regions have 
relatively low per-capita levels of service supply across a range of services. By and large, these patterns of low supply of non-acute care remain even after adjusting for needs.

This project has been undertaken in the context of the current impetus towards system reform, including the recent Sláintecare report (Houses of the Oireachtas Committee on the Future of Healthcare, 2017). The analysis contributes to the evidence base required to undertake the policy changes associated with these reforms by providing the most comprehensive evidence to date on the supply of non-acute services around the country. Assessment of supply in each area relative to national average supply highlights areas with consistent under-supply of services relative to the national average. While the adequacy of the national average level of supply of each service itself needs to be assessed, the evidence in this report can help support the goals of the reform programme to build appropriate capacity in primary, community and long-term care. The findings emphasise that without reform of allocation mechanisms, limited levels of provision of non-acute care in many areas could impede progress towards the equity goals of Sláintecare.

This report also shows the importance of accurate and timely collection of health and social care data on not only demand for care but also supply of services. Establishing a consistent and systematic data infrastructure will afford broader scope of research than that presented here and greatly improve the evidence base on which policymakers can make decisions on the efficient and equitable allocation of health and social care resources across areas in Ireland. 


\section{LIST OF TABLES}

Table 2.1 Characteristics of Andersen's Behavioural Model of Health Services Use .......................26

Table 3.1 Estimated levels of activity in Irish health and social care, 2015..................................38

Table 3.2 Data sources for selected healthcare need indicators...................................................4

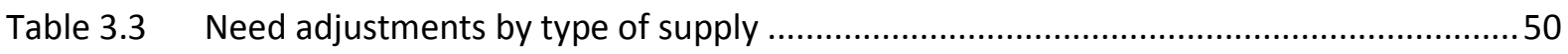

Table 4.1 Estimated number and percentAGE of population aged $65+$ years by geographic area,

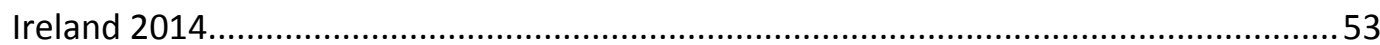

Table 4.2 Estimated number and percentage of population aged $85+$ years by geographic area,

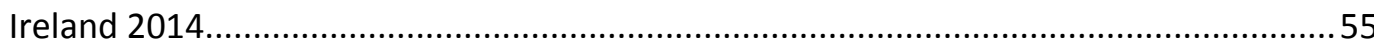

Table 4.3 Number of registered deaths, deaths per 1,000 population and mortality-adjusted population by geographic area, Ireland 2014 ..............................................................5

Table 4.4 Estimated per cent and number of population with disability by geographic area, Ireland 2014

Table 4.5 Number and percentage of population with a Medical Card or GP Visit Card by geographic area, Ireland 2014

Table 4.6 Estimated percentage and number of population with a Medical Card who are receiving a prescription for a chronic health condition by geographic area, Ireland 2014

Table 4.7 Estimated number of WTE GPs per 10,000 population by geographic area, Ireland 20042014 (selected years)

Table 4.8 Number of general practices, number of GPs, and estimated number of WTE GPs by geographic area, Ireland 2014

Table 4.9 Number of general practices, number of GPs and estimated number of WTE GPs by Dublin area, Ireland 2014

Table 4.10 Number of WTE publicy employed community nurses by geographic area, Ireland 2014.

Table 4.11 Number of WTE public and private non-acute physiotherapists by geographic area, Ireland 2014

Table 4.12 Number of WTE publicly employed non-acute occupational therapists by geographic area, Ireland 2014

Table 4.13 Number of WTE publicly employed non-acute speech and language therapists by geographic area, Ireland 2014

Table 4.14 Number of WTE publicly employed non-acute podiatrists and chiropodists by geographic area, Ireland 2014

Table 4.15 Number of WTE publicly employed non-acute counsellors and psychologists by geographic area, Ireland 2014

Table 4.16 Number of WTE publicly employed non-acute social workers by geographic area, Ireland 2014

Table 4.17 Number of long-term residential care centres and long-term Residential care beds by geographic area, Ireland 2014

Table 4.18 Number of long-term residential care centres and long-term residential care beds by Dublin area, Ireland 2014

Table 4.19 Annual average number of publicly financed home care hours per person aged $65+$ by geographic area, Ireland 2014. 
viii I Geographic Profile of Healthcare Needs and Non-Acute Healthcare Supply in Ireland

Table 4.20 Gini coefficients for the geographic distribution of selected non-acute healthcare services, Ireland 2014.

Table 5.1 Summary of relative service supply indicators in Ireland 2014 


\section{LIST OF FIGURES}

Figure 3.1 Method for assigning healthcare supply to the 28 geographic areas at national level ...34

Figure 4.1 Estimated percentage of population aged 65+ years by geographic area, Ireland $2014 \ldots$.

Figure 4.2 Estimated percentage of population aged $85+$ years by geographic area, Ireland $2014 \ldots$.

Figure 4.3 Number of registered deaths per 1,000 population by geographic area, Ireland 2014 .. 58

Figure 4.4 Estimated percentage of population with disability by geographic area, Ireland $2011 . .60$

Figure 4.5 Percentage of population with a Medical Card or GP Visit Card by geographic area, Ireland 2014.

Figure 4.6 Estimated percentage of population with a Medical Card who are receiving a prescription for a chronic health condition by geographic area, Ireland 2014. .66

Figure 4.7 Number of GPs per 10,000 population by OECD country, 2014 ....................................68

Figure 4.8 Estimated number of WTE GPs per 10,000 population by geographic area, Ireland 2014 .

Figure 4.9 Estimated number of WTE GPs per 10,000 population by geographic area, Dublin 2014 ..

Figure 4.10 Scatter plot of location quotients of the estimated number of WTE general practitioners per 10,000 total population and per 10,000 needs-adjusted populations by geographic area, Ireland 2014

Figure 4.11 Number of WTE publicly employed community nurses per 10,000 population by geographic area, Ireland 2014

Figure 4.12 Scatter plot of location quotients of the number of WTE community nurses per 10,000 total population and per 10,000 needs-adjusted populations by geographic area, Ireland 2014

Figure 4.13 Number of WTE public and private non-acute physiotherapists per 10,000 population by geographic area, Ireland 2014.

Figure 4.14 Scatter plot of location quotients of the number of WTE public and private non-acute physiotherapists per 10,000 total population and per 10,000 needs-adjusted populations by geographic area, Ireland 2014 .

Figure 4.15 Number of WTE publicly employed non-acute occupational therapists per 10,000 population by geographic area, Ireland 2014

Figure 4.16 Scatter plot of location quotients of the number of WTE publicly employed non-acute occupational therapists per 10,000 total population and per 10,000 needs-adjusted populations by geographic area, Ireland 2014.

Figure 4.17 Number of WTE publicly employed non-acute speech and language therapists per 10,000 population by geographic area, Ireland 2014

Figure 4.18 Scatter plot of location quotients of the number of WTE publicly employed non-acute speech and language therapists per 10,000 total population and per 10,000 needsadjusted populations by geographic area, Ireland 2014

Figure 4.19 Number of WTE publicly employed non-acute podiatrists and chiropodists per 10,000 population by geographic area, Ireland 2014 
Figure 4.20 Scatter plot of location quotients of the number of WTE publicly employed non-acute podiatrists and chiropodists per 10,000 total population and per 10,000 needs-adjusted populations by geographic area, Ireland 2014

Figure 4.21 Number of WTE publicly employed non-acute counsellors and psychologists per 10,000 population by geographic area, Ireland 2014

Figure 4.22 Scatter plot of location quotients of the number of WTE publicly employed non-acute counsellors and psychologists per 10,000 total population and per 10,000 needsadjusted populations by geographic area, Ireland 2014

Figure 4.23 Number of WTE publicly employed non-acute social workers per 10,000 population by geographic area, Ireland 2014

Figure 4.24 Scatter plot of location quotients of the number of WTE publicly employed non-acute social workers per 10,000 total population and per 10,000 needs-adjusted populations by geographic area, Ireland 2014

Figure 4.25 Number of long-term residential care beds per 1,000 population aged $65+$ years by geographic area, Ireland 2014.

Figure 4.26 Number of long-term residential care beds per 1,000 population aged $65+$ years by geographic area, Dublin 2014

Figure 4.27 Scatter plot of location quotients of the number of long-term residential care beds per 1,000 population aged $65+$ years and per 1,000 needs-adjusted populations aged $65+$ years by geographic area, Ireland 2014

Figure 4.28 Average annual number of publicly financed home care hours per person aged $65+$ by geographic area aged 65+, Ireland 2014

Figure 4.29 Scatter plot of location quotients of the mean number of publicly financed home care hours per person aged $65+$ and needs-adjusted populations aged $65+$ by geographic area, Ireland 2014 


\section{Introduction}

\section{$1.1 \quad$ BACKGROUND}

This report presents findings from the first phase of research for the project 'An inter-sectoral analysis by geographic area of the need for and the supply and utilisation of health services in Ireland'. The overall aim of the project is to inform public policy about the shift of care, where appropriate, from acute to non-acute care settings. For the purpose of this report, acute care refers to services such as outpatient, day patient, emergency and inpatient care that take place in acute hospitals. Non-acute care refers to care services provided outside of an acute hospital setting including in a health centre, a general practitioner (GP) clinic or other community-based facility, a person's home, or a long-term residential care (LTRC) facility.

This analysis is undertaken in the context of current policy priorities to achieve greater integration across the Irish health and social care system (discussed in more detail below). There are a number of challenges to achieving greater integration in the Irish health and social care system. This project focuses on two of these challenges:

- insufficient evidence about whether or not there is adequate capacity in the non-acute sector to meet increased (or even existing) demands should more care be transferred to non-acute services;

- insufficient evidence on the way in which acute and non-acute sectors interact in the system.

To address these challenges, the project has been partitioned into two reports. This report contributes to the evidence base on the supply of non-acute services around the country. A further report will analyse the interaction between acute and non-acute care in the Irish healthcare system and examine substitution effects between acute inpatient activity in public hospitals using the large administrative Hospital In-Patient Enquiry (HIPE) database, and non-acute supply indicators for long-term care (home care and long-term residential care) using administrative data from the Health Service Executive (HSE) and other sources (Walsh et al., 2019b). This second report will also reflect on the findings from both reports to make recommendations about how resource allocation could be improved within Irish health care services (Walsh et al., 2019b). This is an ESRI-led project funded by the Health Research Board, running from 2015 to 2019. 
The aim of this report is to describe the geographic profile of non-acute care services in Ireland. ${ }^{3}$ Specifically, the analysis seeks to:

- identify what non-acute services are available, where they are and how many there are in Ireland;

- examine available supply of non-acute services in relation to needs for care.

The analysis mainly focuses on the supply of publicly employed non-acute services, but where data are available, private supply is also analysed (e.g. private GPs, private physiotherapists (PTs), beds in private LTRC centres).

The project contributes to the evidence base for health policy in Ireland in the following ways. The practice of historical budgeting for community-based care persists in Ireland, and attempts to allocate healthcare resources equitably across areas have been hindered by limitations in available data. This has reduced the ability to develop resource allocation formulas for health and social care (see Vega et al., 2010 for further discussion on resource allocation methods for (reland). This report seeks to contribute to the evidence base on the geographic supply of nonacute healthcare services in Ireland to inform the current policy discussions on expanding community-based care and the development of population-based resource allocation methods (Government of Ireland, 2018). There is no national dataset that profiles the number, location and catchment population of non-acute healthcare services in Ireland. Rather, several disparate data sources provide some information on the supply of publicly provided non-acute services and very limited information on the supply of private non-acute services. This makes it difficult to characterise the current supply of health and social care in the country and to undertake the health research needed to help improve health policy. Therefore, one of the aims of this project has been to collate and combine the available data to provide a more detailed picture of non-acute supply across geographic regions. This forms the basis of the analyses undertaken in this report, which provides the most detailed evidence to date of primary, community and long-term care supply across regions in Ireland.

Section 1.2 discusses the Irish policy context for the project as a whole and for this report in particular. Section 1.3 gives a brief overview of the Irish healthcare system, Section 1.4 summarises current eligibility structures and Section 1.5 outlines the rest of this report.

3 Analysis in this project focuses on the 26 counties of the Republic of Ireland. 


\subsection{IRISH HEALTHCARE POLICY CONTEXT}

Health policy in Ireland has been the focus of several high-level government publications in recent years including the Government's health reform programme 2012-2015 (Department of Health (DOH), 2012), the Sláintecare report by the allparty Committee on the Future of Healthcare (Houses of the Oireachtas Committee on the Future of Healthcare, 2017) and most recently the Sláintecare Implementation Strategy (Government of Ireland, 2018a). ${ }^{4}$

The reform programme preceding Sláintecare was aimed at achieving a single-tier health service, supported by universal health insurance (DOH, 2012). This was the first time in the history of the state that there was a political commitment to the introduction of universal healthcare in Ireland (Connolly and Wren, 2019). Although the plans for universal health insurance were not enacted (Wren et al., 2017), other elements of the reform programme remain in current policies. Of direct relevance to this project, reform of health services focused on the need to shift away from the current 'hospital-centric' model of care to develop a new integrated model of care where patients are treated at the lowest level of complexity that is safe, timely, efficient and as close to home as possible' (DOH, 2012, p. 4).

Increasing integration in the system is particularly important for chronic conditions because health services have a role to play at each stage of the condition (prevention, self-care, primary care, acute care). As outlined in the reform framework, the fragmented nature of the current system means that resources are concentrated on providing acute care when the chronic condition becomes a major problem, rather than on prevention or early management of the condition ( $\mathrm{DOH}$, 2012).

Limited capacity within the non-acute sector was acknowledged as an issue that needs to be addressed in order to facilitate, where appropriate, the transfer of care from acute to non-acute settings. Specifically, the Strategic Framework 2012-2015 noted that integrated care requires the development of capacity in primary, community and social care and that this would involve 'a clear transfer of capacity to non-institutional care and the necessary and consequent downsizing of activity undertaken in acute hospitals and other institutions' (DOH, 2012, p. 18). In this

The all-party parliamentary Committee on the Future of Healthcare set out a ten-year vision for the health sector, outlined in the Sláintecare report (Houses of the Oireachtas Committee on the Future of Healthcare, 2017). The Sláintecare Implementation Strategy, published in 2018, sets out the actions to be taken in the first three years of the Sláintecare implementation process (Government of Ireland, 2018). 
context, it is important to understand capacity at the regional as well as at the national level.

The need for delivering care at the most appropriate and cost-effective level is a fundamental principle in the Sláintecare plan for reform (Houses of the Oireachtas Committee on the Future of Healthcare, 2017). The report acknowledges the importance of developing primary and social care capacity to facilitate integrated care in the system and a move away from a 'hospital-centric' system. One of the ten 'strategic actions' of the Sláintecare implementation strategy focuses on expanding community-based care to bring care closer to home, with more specific actions to increase workforce capacity in general practice, community nursing, and a range of non-acute allied health professional staff. Further points outlined in the plan are aimed at advancing the community-based costing programme to move towards a system of population-based funding in the medium term (Government of Ireland, 2018). However, while it is recognised that enhanced capacity in primary and social care is expected to relieve some pressure on the acute hospital system, the report also notes the importance of adequately resourcing the hospital sector (Houses of the Oireachtas Committee on the Future of Healthcare, 2017). Ireland has one of the lowest rates of acute hospital beds per capita in the OECD (Keegan et al., 2019). As a consequence of an increasing, and ageing, population (Wren et al., 2017), substantial investment in acute hospital capacity, as well as in non-acute care services, is required to meet existing and future demand pressures (PA Consulting, 2018; Wren et al., 2017) even in the context of shifting care to postacute settings (Keegan et al., 2019).

Achievement of greater integrated care does not automatically imply shifting care from acute to non-acute settings, but in fact the issue is more complicated. First, there is a surprising lack of empirical analysis of the substitutability of acute and non-acute care and this needs to be addressed in order to inform policymakers tasked with implementing the goals set out in the current reform programme for Irish healthcare. Thus, this project seeks to contribute to the evidence base on the substitutability between acute and non-acute care (in Report 2 (Walsh et al., 2019b)). To further inform the debate on the transfer of care, there is need for information on what non-acute services are currently available, and how they are dispersed around the country, hence the focus of this report.

Second, there are distinctions between care settings and between the types of care that are required for different healthcare needs. Care can take place in a hospital (e.g. inpatient, day patient) or health centre, other institution (e.g. GP clinic, LTRC facility) or in people's own homes (e.g. community palliative care). Different services are required for patients for preventing, diagnosing and managing chronic conditions, and for a wide range of social and long-term care. While there is a general distinction between the types of care needs that are addressed in different 
care settings, it is important to recognise that complex interfaces are at work in an integrated healthcare system. For example, it is not always the case that ongoing management of a chronic disease takes place outside of a hospital setting. Work on epilepsy care in Beaumont Hospital, Dublin has shown that implementation of a care pathway within the acute care setting involving early specialist advice and follow-up together with nurse-led patient education, telephone and email advice to aid in self-management can contribute to fewer epilepsy-related inpatient admissions and lower length of stay (lyer et al., 2012). These complexities, and the fact that analysts know very little about substitutability between care settings, need to be kept in mind when discussing the high-level objective to see a general shift of care from acute hospitals to the community where appropriate. The current structures of the Irish healthcare system, and the way in which they are organised, are outlined in the next section.

\subsection{OVERVIEW OF IRISH HEALTHCARE SYSTEM}

The health and social care sectors in Ireland are governed by the DOH and the HSE. The DOH provides strategic leadership for the health service and oversees the translation of government health policies into actions. The HSE manages the dayto-day operation of the system. The Health Information and Quality Authority (HIQA) was established in 2007 and is responsible for promoting quality and safety in health and social care services.

\subsubsection{HSE organisational structure changes}

The Irish healthcare system underwent substantial organisational reform with the establishment of the HSE in 2005 and of HIQA in 2007. The HSE was established to co-ordinate public health service delivery at a national level, replacing regionally based Health Boards. ${ }^{5}$ The 11 former regional Health Boards had considerable autonomy in developing local services, with local political representation on the boards. In existence from 1970 to 2005, they succeeded an earlier locally administered and funded system. Thus, the HSE inherited a long-standing system of local services, which had developed in divergent ways. A major motivation of the establishment of the HSE was to remove the influence of localism from policy issues such as hospital location (Wren, 2003).

Since 2005, the HSE has itself been reorganised a number of times, as outlined here. 


\section{HSE organisational structure 2005-2008}

Brick et al. (2010) provide a useful overview of the HSE and its structures over the period 2005-2008:

- When first established, the HSE comprised national directorates including Primary, Community and Continuing Care (PCCC), the National Hospital Office (NHO), Population Health and others managing human resources, finance, procurement and information and communication technology. Administration was divided into four regions (Dublin and Mid Leinster, Dublin and North East, West, and South).

- The PCCC Directorate was responsible for primary care, mental health, disability, children, youth and families, community hospital, continuing care and social inclusion services. PCCC services were co-ordinated and in some cases directly provided by 32 Local Health Offices throughout the country. The NHO was responsible for resource allocation and oversight of acute public hospital services. These acute hospitals were grouped into eight hospital networks (two in each region).

\section{HSE organisational structure 2009-2012}

The establishment of the HSE was intended to achieve economies of scale in terms of standardising processes of procurement, finance and human resources and to implement strategic policies set by the government. However, over time there was concern that certain processes became overly centralised, with a need for more innovation and responsiveness at the local level and more integration in the delivery of care (ISA Review Project Team, 2014). Changes made in 2009 were intended to build stronger links between services and to begin to devolve responsibility for delivery services from national level to the four regions.

Brick et al. (2010) and the ISA Review Project Team (2014) describe the changes that took place in 2009:

- The Integrated Services Directorate (ISD) was established, incorporating the PCCC and NHO Directorates.

- Within the new ISD, one national director was responsible for performance and financial management, and a second director was responsible for reconfiguration of acute hospital services, pre-hospital care and primary care teams.

- Health and social services in the four regions were managed by regional directors.

- In 2010, Integrated Service Areas (ISAs) were established within each region, and ISA managers were responsible for overseeing both hospital services and primary, community and continuing care in their area. In total, 17 ISAs were established but the full ISA structure was never completed due to the changed economic circumstances (ISA Review Project Team, 2014). 
Throughout the period of changes to the HSE structures, the ISA Review Project Team (2014) acknowledges that efforts were continuing to roll out the Primary Care Strategy (Department of Health and Children (DOHC), 2001). The Primary Care Strategy set out a blueprint for how services in the community could be coordinated: including primary care teams (PCTs) and wider Health and Social Care Networks (HSCNs). A PCT was to comprise GPs, community and public health nurses, speech and language therapists (SLTs), occupational therapists, physiotherapists, and administrative support. Within the Local Health Offices (LHOs) (and subsequently the ISAs), it was noted that 'serious efforts' were made to adopt an integrated approach to service delivery, by delivering as many services as possible through the PCTs and HSCNs. Yet despite these efforts it is accepted that the attempts have not been successful and the model has not been implemented in a comprehensive and consistent way across the country (ISA Review Project Team, 2014, p. 22). Many barriers to implementation have been identified including inequitable access to services, uneven patterns across the country (e.g. different management structures), competing demands on existing staff and inadequately resourced and trained teams (ISA Review Project Team, 2014).

\section{HSE organisational structure 2013-2018}

With the launch of a new programme for healthcare reform (DOH, 2012), further changes to HSE structures were made. The Board of the HSE was replaced with the HSE Directorate in 2013, headed by the Director General and accountable to the Minister for Health. The directorate structure was organised along service delivery lines (Primary Care Directorate, Acute Hospitals Directorate, etc.) (Wren et al., 2017).

The reform programme aimed to give greater autonomy to frontline services, moving away from centralised management of health services. This process was supported by the development of seven Hospital Groups (to transition into independent Hospital Trusts over time) and similar structures for the organisation and management of primary and continuing care services (DOH, 2014; ISA Review Project Team, 2014). It was envisaged that these Hospital Groups will evolve to have greater autonomy, with activity-based funding replacing block grants (Wren et al., 2017). The ISA Review Project Team recommended the replacement of the 17 ISAs with nine Community Healthcare Organisations (CHOs) (ISA Review Project Team, 2014). ${ }^{6}$ The primary emphasis of the $\mathrm{CHOs}$ was to implement nationally

\footnotetext{
CHO 1: Donegal, Sligo/Leitrim/West Cavan, Cavan/Monaghan; $\mathrm{CHO}$ 2: Galway, Roscommon, Mayo; CHO 3: Clare, Limerick, North Tipperary/East Limerick; CHO 4: Kerry, North Cork, North Lee, South Lee, West Cork; CHO 5: South Tipperary, Carlow/Kilkenny, Waterford, Wexford; CHO 6: Wicklow, Dún Laoghaire, Dublin South East; CHO 7: Kildare/West Wicklow, Dublin West, Dublin South City, Dublin South West; CHO 8: Laois/Offaly, Longford/Westmeath, Louth/Meath; CHO 9: Dublin North, Dublin North Central, Dublin North West (http://www.hse.ie/eng/services/yourhealthservice/feedback/Complaints/Officers/PCCC/CHOS.html, accessed 26 June 2019).
} 
agreed standardised models of care for each care group (primary care, social care, mental health, health and wellbeing services), but with scope to bring a local community focus to service delivery (ISA Review Project Team, 2014). The nine CHOs are at different stages of development, comprising 96 Community Healthcare Networks (CHNs, former Primary Care Networks) (Houses of the Oireachtas Committee on the Future of Healthcare, 2017). The CHNs are designed to cover an average population of 50,000 and are the main vehicle for ensuring continuity of care between primary and social care. It is important to note that while ISA managers had responsibility for overseeing acute as well as primary and social care, the CHOs no longer have responsibility for hospital services (ISA Review Project Team, 2014).

These reforms and the subsequent 2016 Programme for Government also aimed to introduce a formal purchaser/provider split within the health sector, proposing that the HSE should ultimately be transformed into a Health Commission (Department of the Taoiseach, 2016).

\section{HSE organisational structure 2019+}

The Sláintecare report proposes that the HSE be reformed into a 'more strategic national centre' with an independent board and fewer directorates (Houses of the Oireachtas Committee on the Future of Healthcare, 2017, p. 22). However, the report also acknowledges that structural change should be as simple as possible to avoid negative impacts of system reorganisation. To advance the reform programme outlined in the Sláintecare report, a Sláintecare Implementation Office has been established, located at the Department of Health, led by an executive director and supported by an advisory council. At the beginning of 2019, this office launched the first Sláintecare Action Plan, which outlined the approach for and the delivery of key Sláintecare milestones in 2019 (DoH, 2019).

For integration of services, the Sláintecare report recommends the establishment of Regional Integrated Care Organisations (RICOs) to co-ordinate care across acute, primary and social care at a regional level. These RICOs would be responsible for allocating resources for integrated care, staff recruitment and accountability; in other words, moving towards regional health resource allocation 'with accompanying governance structures to formally connect Hospital Groups and Community Health Organisations for the provision of integrated care, using $\mathrm{CHOs}$ and CHNs as the core unit of health service coordination and provision' (Houses of the Oireachtas Committee on the Future of Healthcare, 2017, p. 89). As of July 2019, it has been proposed to merge Hospital Groups and CHOs into six RICOs with each RICO having its own budget and greater autonomy on decision making at the local level. 


\subsubsection{Acute services}

Acute hospital services are delivered by public and private hospitals (Brick et al., 2010). Public hospitals either are owned and directly managed by the HSE or are owned by voluntary organisations but for many years have received most of their funding from the HSE (Brick et al., 2010). There are over 50 acute care public hospitals in the Republic of Ireland, which receive most of their funding from the HSE (HSE, 2015b). Following a period of reconfiguration since 2005, many of these hospitals have lost much of their emergency inpatient activity and most activity is now undertaken in 29 large hospitals that have Tier 1 (operating 24/7) Emergency Departments (EDs).

In addition there are 18 independent for-profit hospitals (providing acute and mental healthcare services) registered with the Private Hospitals Association. ${ }^{7}$ Private hospitals operate in parallel to public hospitals, providing outpatient, day patient and inpatient services, and some now offer limited ED services (e.g. office hours only), ${ }^{8}$ but there are some complex treatments that are not available in the private sector (Brick et al., 2010). An estimated 31 per cent of all day patient admissions and 15 per cent of inpatient bed days in the acute hospital sector occur in private hospitals (Wren et al, 2017). Most inpatient care in private hospitals is delivered on an elective rather than on an emergency basis.

Acute care utilisation is a key part of the analyses in this project, so a more detailed description of acute public hospital services in Ireland is provided in the next report (Walsh et al., 2019b).

\subsubsection{Non-acute services in Ireland}

\section{Organisation of non-acute services}

Non-acute healthcare encompasses a wide range of services including long-stay residential care facilities, primary care providers (GPs, community and public health nurses), and other community care services (allied health professionals, home care, palliative care nurses, etc.). Services provided by professionals in the community are often co-ordinated in primary care and can be substitutes for care provided in acute hospitals (Wren et al., 2017).

\section{GPs and practice nurses}

GPs in Ireland are self-employed private practitioners, although a large proportion hold a state General Medical Services (GMS) contract to provide GP care that is free at the point of use to Medical Card and GP Visit Card holders (see section 1.5,

http://privatehospitals.ie/members/, accessed 17 January 2019.

For example, the emergency department at the Beacon Hospital in Dublin is open 10am-7pm Monday-Friday, 10am$6 \mathrm{pm}$ Saturdays, and closed Sundays and Bank Holidays (https://www.beaconhospital.ie/emergency-department, accessed 17 January 2019). 
HSE, 2015c). These GPs are paid to provide services under a capitation and fee system. A small number of GPs who do not hold a GMS contract are registered to provide services under alternative state-funded programmes (Primary Childhood Immunisation Scheme, Heartwatch, Methadone Treatment Scheme, etc.) (HSE, 2015c). ${ }^{9}$ GPs work in single- or multi-person practices; a recent survey of members of the Irish College of General Practitioners indicates that more than 75 per cent now work in multi-person practices (Collins and O'Riordan, 2015).

Practice nurses are employed by GP practices to provide nursing care to patients. GP practices are granted subsidies to contribute to the cost of employing a practice nurse (Teljeur et al., 2014). Practice nurses are an increasing component of general practice and in 2015, approximately 82 per cent of general practices employed a practice nurse (O'Kelly et al., 2016).

\section{Community Health Nurses}

The HSE employs public health nurses (PHNs) and community registered general nurses (CRGNs) to provide healthcare services to individuals, families and communities within a geographic area (An Bord Altranais, 2005). These nurses are referred to in this report as community nurses. Community nurses provide a wide range of services including primary care, child and maternal health, health protection and promotion, and acute and continuing care (McDonald et al., 2015) in health centres and in individuals' homes. Older people are one of the main groups to whom community nurses provide services and Ireland's ageing population will lead to increased demand for community nursing services (Wren et al., 2017). Community nurses' responsibility for specific geographic areas allows them to lead on engagement with community health and wellbeing ( $\mathrm{DOH}, 2013)$, so it is important to describe their geographic distribution.

\section{Allied health professionals and other community care services}

Other non-acute services are provided in the community by physiotherapists, occupational therapists, speech and language therapists and others (chiropodists/podiatrists, ${ }^{10}$ social workers, psychologists, etc.). These can include private as well as publicly employed professionals. Services provided by these professionals are delivered to patients in health centres or within individuals'

$9 \quad$ Health promotion and chronic disease management form part of the contract with GPs participating in the under $6 \mathrm{~s}$ GP Visit Card arrangement. The contract for the provision of GP Visit Cards to children under the age of 6 includes measures aimed at promoting wellbeing and disease prevention (i.e. provision of periodic wellness checks for children at ages 2 and 5) and chronic disease management for Asthma. The contract includes a cycle of care for the management of Asthma, requiring GPs to maintain a register of children diagnosed with Asthma and providing services outlined in the cycle of care (http://www.hse.ie/under6contract/).

10 We include all public employees using the title of 'chiropodist' or 'podiatrist', though the title 'podiatrist' has replaced the title 'chiropodist' (Citizens Information, 2018). While the HSE is not legally obliged to provide chiropody or podiatry services, where available these services can be provided by LHOs or voluntary organisations on behalf of the HSE (Citizens Information, 2018). 
homes. These services are often provided within home care packages (Wren et al., 2017).

A range of other primary and social care services are also provided in a community setting, including day care, respite care and others. These services are provided by the HSE or by voluntary organisations operating in conjunction with, or on behalf of, the HSE (Citizens Information, 2015a). It is well documented that there is a wide variation in the level of services available in different parts of the country (Citizens Information, 2015a).

\section{Home care}

Home care refers to health and domestic care provided to individuals in their own homes and is generally delivered to older people and/or those with an illness or disability. Approximately 73 per cent of home care is provided through nonstatutory public home care. From 2006 to 2018, two parallel schemes existed in Ireland: the Home Care Package (HCP) scheme and the Home Help scheme. While differences between the two schemes existed in the past, in practice in recent years they provided similar care and support to aid individuals at home (Care Alliance Ireland, 2018) and were merged into the Home Support Scheme in 2018. Home care is provided by home helps or personal care attendants, and other services, including occupational therapy, may also be provided depending on need (Wren et al., 2017). Home helps and personal care attendants provide domestic and personal care (help with dressing, prompting taking of medicines, etc.) to help support individuals to continue living at home. Home care is often provided following a hospital stay to allow for earlier discharge from acute care, or to act as a substitute for hospital care or LTRC (Wren et al., 2017). Publicly financed home care is provided by employees of the HSE, or contracted from voluntary or private organisations. Home care can also be purchased privately from private organisations and carers as a complementary or substitutable service (Wren et al., 2017).

There have been criticisms of how the home care schemes have been managed, and the variation in supply across regions. In particular, lack of clear eligibility criteria in home care has been criticised for giving rise to 'uneven provision and hence glaring inequity in access to services throughout the country' (Timonen et al., 2012, p. 316).

\section{Long-term residential care}

The LTRC sector has been changing rapidly over recent years and has been described as being mainly privately delivered and publicly financed (Wren et al., 2017). Approximately 75 per cent of LTRC beds in 2014 were provided by private nursing homes (Health Information and Quality Authority, 2014). A further 20 per 
cent of LTRC beds were provided by the HSE, mostly in extended care units, and a small number in welfare homes, and the remaining 5 per cent are provided by nonstatutory/voluntary agencies (Health Information and Quality Authority, 2014). Generally, the residents in welfare homes may have had social needs in addition to medical needs (DOH, 2015a).

The majority of residents are now financed through the Nursing Homes Support Scheme (NHSS) introduced in 2009 (Wren et al., 2017). This scheme, also known as the 'Fair Deal' scheme, governs access to and eligibility for publicly funded residential care. Applicants to the scheme have a care needs assessment carried out by a health professional. Participants in the scheme pay a co-payment that is calculated on the basis of income and assets. ${ }^{11}$

\subsection{ACCESS TO IRISH HEALTHCARE SERVICES}

The extent of healthcare affordability for patients is an important element in facilitating access to healthcare (see Chapter 2 for further discussion of the complex concept of healthcare access). In the Irish system, there are two broad categories of eligibility to public healthcare services, with each group facing different sets of prices for healthcare.

\subsubsection{Category I (Medical Card holders)}

Individuals in Category I are granted a Medical Card. Medical Card holders (individuals and dependants) have access to the following services that are free at the point of use: GP care, approved prescribed drugs and medicines, ${ }^{12}$ inpatient and day patient treatment in public beds in public hospitals, outpatient services in public hospitals, medical and midwifery care for mothers and infants, maternity cash grant for each child born, and dental, ophthalmic and aural services and some personal and social care services (e.g. public health nursing, social work services, other community services) (Expert Panel on Medical Need for Medical Card Eligibility, 2014; HSE, 2015d).

In 2019 the main groups of people eligible for a Medical Card include (HSE, 2019):

11

http://www.citizensinformation.ie/en/health/health_services/health_services_for_older_people/nursing_homes_su pport_scheme_1.html, accessed 22 February 2019.

12 Prescription charges are now levied for Medical Card holders. From January 2018, charges are levied at $€ 2$ per item dispensed, subject to a maximum of $€ 20$ a month for an individual or family. Since April 2019 the prescription charge for Medical Card holders over the age of 70 is $€ 1.50$ per item

(https://www.citizensinformation.ie/en/health/drugs_and_medicines/prescription_charges_for_medical_card_holders.ht $\mathrm{ml}$, accessed 01 July 2019). 
- Applicants (and their dependants) whose assessable income comes within a set of income guidelines. ${ }^{13}$ The majority of Medical Cards are granted on the basis of this means test, which takes account of both income and allowances for specified living expenses (e.g. childcare costs) so that an individual's overall financial situation is assessed (Expert Panel on Medical Need for Medical Card Eligibility, 2014). ${ }^{14}$

- Applicants (and their dependants) whose assessable income exceeds the income guidelines but who have a medical condition or conditions that mean paying for healthcare is difficult and would cause 'undue financial hardship'. In this case the National Medical Card Unit assesses the situation and decides if the person should have a Medical Card or a GP Visit Card (see below) (HSE, 2019).

- Applicants who automatically apply and may not have to do a means test, including individuals who are taking part in certain government work schemes or returning to work, some people affected by the drug Thalidomide, women affected by symphysiotomy, children under 18 who have been diagnosed with cancer within the past five years, children in foster or residential care, people living in direct provision centres, people who qualify under EU Regulations, and children whose parents get a Domiciliary Care Allowance for them. ${ }^{15}$

\subsubsection{Category II (other)}

Individuals in Category II are entitled to public hospital care, subject to inpatient and outpatient charges, and to medical and midwifery care for mothers and infants. ${ }^{16}$

Individuals in Category II can apply for the Drugs Payment Scheme, which covers the cost of prescribed drugs, medicines and certain appliances above a threshold of $€ 124$ per month for the individual and their family. ${ }^{17}$ Individuals in Category II who are not eligible for a GP Visit Card are required to pay privately for GP care (Citizens Information, 2015b) with the exception of maternity and infant GP services, which are provided free of charge for a specific number of visits (Nolan and Smith, 2012). Recent analysis puts the average private GP visit payment at over $€ 50$ (Connolly et al., 2018). Tax relief at the standard tax rate (20 per cent) is

13 Applicants whose weekly incomes are derived solely from social welfare or HSE allowances are entitled to a Medical Card (HSE, 2019).

14 For individuals aged 70 and over, the means test is based on gross income at higher thresholds and expenditure is not taken into account, but these individuals can also apply under the general Medical Card scheme (https://www2.hse.ie/services/medical-cards/medical-card-for-over-70s.html).

15 People who contracted hepatitis C/HIV from the use of human anti-D immunoglobulin blood products qualify for a Health Amendment Act Card. This card entitles the holder to a range of services that are free at the point of use including GP care, prescribed drugs and medicines, home nursing and home help services, and others (HSE, 2019). The Redress for Women Resident in Certain Institutions Scheme makes certain health services available without charge to many women who were admitted to and worked in certain institutions (HSE, 2019).

16 Inpatient charges are levied at $€ 80$ per night up to a maximum of $€ 800$ in a rolling 12-month period, and emergency department visits without referral by a GP are charged at $€ 100$ per visit, although certain exemptions apply (https://www.hse.ie/eng/services/list/3/acutehospitals/hospitals/hospitalcharges.html, accessed 19 January 2019). https://www2.hse.ie/services/drugs-payment-scheme/drugs-payment-scheme-card.html, accessed 5 June 2019. 
available for all medical expenses that are not otherwise reimbursed by public funding or by private health insurance (Nolan and Smith, 2012).

Entitlements for individuals in Category II to community and social services (community nursing, home help, physiotherapy, etc.) are difficult to ascertain and have been described as 'complex and confusing' (Ruane, 2010, p. 45). The Sláintecare report notes that the lack of clarity dates back to the 1970 Health Act, with the result that 'for the whole population, there is a huge variety in access to primary and social care services depending on geographic location and existing supply in that area' (Houses of the Oireachtas Committee on the Future of Healthcare, 2017, p. 45). In practice, while access to community services varies depending on availability in each area (Citizens Information, 2015b), in many cases priority is given to Medical Card holders (Houses of the Oireachtas Committee on the Future of Healthcare, 2017). ${ }^{18}$

\subsubsection{GP Visit Card}

Over time, the above two categories have become more complicated with the introduction of the GP Visit Card. This card was introduced in 2005, granting access to GP visits free at the point of use; for all other healthcare services, GP Visit Card holders fall under Category II.

Eligibility for a GP Visit Card is based on a means test whereby the income thresholds are approximately 50 per cent higher than those set for the full Medical Card (Expert Panel on Medical Need for Medical Card Eligibility, 2014). As with full Medical Cards, discretionary GP Visit Cards may be issued where the assessed means of the applicant exceed the income guidelines but the absence of the GP Visit Card would cause undue financial hardship. In 2015, GP Visit Cards were introduced for all children under the age of six and all individuals aged 70 and older regardless of means (Houses of the Oireachtas Committee on the Future of Healthcare, 2017). The majority of GPs with a GMS contract signed up to provide care to these new groups (Walsh et al., 2019a). There are negotiations ongoing between the DOH and the Irish Medical Organisation to extend GP Visit Cards to children aged between six and 12 in the coming years.

The Sláintecare report outlines recommendations to change the pattern of entitlements in the system with the aim of moving towards a universal system that is delivered on the basis of need and free at the point of delivery (or at the lowest possible cost). The recommendations include phased introduction of universal free

18 For example, access to physiotherapy in a primary care team in Dublin South is prioritised for Medical Card holders and for clients living in the catchment area of the health centre (https://www.hse.ie/eng/services/list/2/primarycare/pcteams/dublinsouthpcts/dunlaoghaireglasthulepct/physio.ht $\mathrm{ml}$, accessed 19 January 2019). 
GP care and substantially increasing public healthcare expenditure and capacity over time (Houses of the Oireachtas Committee on the Future of Healthcare, 2017). The proportion of the population covered by Medical and GP Visit Cards has fluctuated over time due to changes in incomes and in income thresholds for eligibility. Between 2005 and 2015, the proportion of the population covered by Medical Cards and GP Visit Cards increased from 29 to 47 per cent (Wren et al., 2017).

\subsubsection{Long-Term IIIness Scheme}

Individuals with one or more of a list of specified illnesses ${ }^{19}$ qualify for the LongTerm Illness Scheme, which grants access to drugs, medicines, and medical and surgical appliances directly related to the treatment of the illness, free of charge. The scheme is not means tested and an individual may also be eligible for a Medical Card or GP Visit Card. ${ }^{20}$

\subsubsection{Private health insurance}

A large proportion of the population (45 per cent in 2018) ${ }^{21}$ is covered by supplementary private health insurance. ${ }^{22}$ Key motivating factors for coverage include potentially faster access to hospital care, superior accommodation and a greater selection of providers (Smith, 2010; Keegan et al., 2016). Many policies offer insurance for primary care services but this is generally subject to large deductibles (Keegan et al., 2016).

Until 2015, the private health insurance market was governed by single-rate community rating regulations, whereby companies were required to charge individuals the same premium per plan (i.e. varying premiums based on insurees' risk profiles was not permitted) (Keegan et al., 2016). In May 2015, the government introduced lifetime community rating for private health insurance. A late entry loading of 2 per cent per year is now charged to individuals aged 35 and older who postpone taking out private health insurance (Keegan et al., 2016).

\subsubsection{Equity implications of eligibility structures}

The eligibility and financing structures in the Irish healthcare system give rise to a number of equity concerns and these have been widely discussed (e.g. Smith and Normand, 2009; Smith, 2010). The arrangements also establish complicated

19 Acute leukaemia, cerebral palsy, cystic fibrosis, diabetes insipidus, diabetes mellitus, epilepsy, haemophilia, hydrocephalus, intellectual disability (mental handicap), mental illness (under the age of 16 years), muscular dystrophy, multiple sclerosis, parkinsonism, phenylketonuria (PKU), spina bifida and Thalidomide conditions (https://www2.hse.ie/services/long-term-illness-scheme/long-term-illness.html, accessed 1 July 2019).

20 http://www.citizensinformation.ie/en/health/drugs_and_medicines/long_term_illness_scheme.html, accessed 1 July 2019.

21 https://www.hia.ie/publication/market-statistics, accessed 1 July 2019.

2244 per cent in 2014 (Keegan et al., 2016), the reference year for this study. 
incentive structures (Brick et al., 2012) that have direct implications for delivering integrated care, and for transferring care (where appropriate) from an acute to a non-acute setting. As discussed by Ruane (2010), for some individuals, shifting care from an acute hospital setting where services are 'effectively free at the point of use would be replaced by services in the community which currently involve significant charges for those without Medical Cards or GP Visit cards' (Ruane, 2010, p. 45). Achievement of integrated care is inhibited because the incentives facing many Category II patients are to focus on finding care that does not involve high charges, rather than finding care in the most appropriate setting. This point is illustrated by Ruane (2010), whereby patients with 'long-term illnesses may need regular health checks or monitoring (which can be done in the primary care setting), but this is expensive for most patients under current entitlements. Once a private [non-Medical Card] patient has been referred to a hospital service it is in his or her financial interest to avoid being discharged back to primary care' (Ruane, 2010, p. 45).

As discussed above, the eligibility structures are further complicated by the fact that access to community care services is variable and confusing (Ruane, 2010). While full Medical Card holders are entitled to receive community care services (e.g. public health nursing, home help, physiotherapy) free of charge, non-Medical Card holders may also receive these services depending on availability in their local area (Citizens Information, 2015a). Overall, the Sláintecare report acknowledges 'widespread inequities' (Houses of the Oireachtas Committee on the Future of Healthcare, 2017, p. 94) in geographic access to care, including community care, hence the recommendation to develop a geographic resource allocation formula to ensure 'equitable allocation of resources based on both population characteristics and activity levels' (Houses of the Oireachtas Committee on the Future of Healthcare, 2017, p. 95).

\subsection{OUTLINE OF THE REPORT}

Chapter 2 discusses the motivation and background of the report, introducing and discussing the concepts (e.g. equity in access) that underpin the analysis. Chapter 3 outlines the data sources and methods of analysis for presenting a geographic profile of non-acute services in Ireland (using 2014 data). Findings are presented in Chapter 4 and discussed in Chapter 5. 


\section{Motivation and background}

\subsection{INTRODUCTION}

Improved supply of non-acute services, in terms of ensuring adequate quantity and equitable distribution, is a current priority for health policymakers in Ireland, as discussed in Chapter 1. However, published evidence on the patterns of supply of non-acute services across the country is limited. This limitation seems to be largely due to the lack of data collected and collated on the demand and supply of health and social care services in Ireland.

A historical failure to invest in health information and data systems, and until recently the lack of broad population-based survey-level data, has severely hindered the ability to draw a comprehensive picture of health and social care in Ireland. Some databases, such as the administrative Hospital In-Patient Enquiry (HIPE) database on public acute hospital activity, the Growing Up in Ireland survey, The Irish Longitudinal Study on Ageing (TILDA) and the recent Healthy Ireland Survey, have aided the understanding of health, healthcare demand and healthcare utilisation in Ireland. However, there are still data gaps concerning the supply of primary, community and long-term care. For example, there is as yet no complete central register of general practitioners (GPs) practising in Ireland. Inadequate data make it harder for health research to inform health policy decision making and curtail the development of effective resource allocation decisions. In other health systems, such as the NHS in the UK, where many of the data lacking in Ireland are routinely collected, health research and policy integration is seen as vital (NHS England, 2017). Furthermore, the availability of data to the NHS allows for the development of resource allocation formulas based on methods proposed by Carr-Hill et al. (1994), where service supply can be allocated based on the factors that influence healthcare demand.

This report uses a broad array of administrative and survey-based datasets that were gathered following an extensive scoping exercise. The aim of the identification and collation of these data is to present the most comprehensive depiction of non-acute care supply in Ireland that has been prepared to date. Many of the datasets included in this report were not designed, or have not previously been used, for the purpose of health research. Considerable time was spent on cleaning and quality assurance of these data to ensure accuracy in the report's estimates. It is important to note at the outset that a geographic profile of services can highlight variations in per capita supply from one area to another but does not in itself answer questions about equity and adequacy. The geographic distribution of non-acute healthcare supply may be unequal, but these variations are not 
necessarily considered inequitable or unfair. For example, if supply in an area is relatively low but needs for healthcare in that area are also relatively low, the distribution may not be inequitable; rather the unequal pattern of supply could reflect a similarly unequal pattern of healthcare need. Thus, to judge whether or not a given unequal distribution of supply is inequitable, other factors, such as the distribution of healthcare needs, should be taken into account.

In this report, the geographic distribution of non-acute services in Ireland is examined, adjusting for the distribution of healthcare needs. To judge whether or not a given level of supply is adequate would require assessment against a set of agreed criteria (e.g. clinical guidelines, national or international benchmarks). In this report, supply in each geographic area is assessed against national average supply (and where feasible, comparisons with international averages are made), but it is beyond the scope of the report to assess whether national average supply is a benchmark of adequate supply.

Assessment of the supply of non-acute services, and of the degree of equity in the distribution across the country, ties in with policy priorities to ensure fair access to healthcare (e.g. Sláintecare), but it should be noted that supply is just one component of a broad, and variably defined, concept of access (Mclntyre et al., 2009). Similarly, defining and measuring need for healthcare is not straightforward, and it is argued that healthcare needs are not directly observable (Morris et al., 2007). Thus, in order to guide the methodology and interpretation of findings, this chapter examines these core concepts that underpin the analysis in this report.

Section 2.2 discusses the definition and measurement of equity in access to healthcare, Section 2.3 focuses on defining and measuring healthcare need, and Section 2.4 concludes.

\subsection{ACCESS TO HEALTHCARE}

\subsubsection{Defining access}

In Ireland and elsewhere, ensuring equitable access to healthcare is frequently identified as a goal for healthcare policy but the definition of access, and how to measure it, remains unclear (McIntyre et al., 2009), although useful advances were made by Penchansky and Thomas (1981), McIntyre et al. (2009), Andersen (1995) and Andersen et al. (2013).

Penchansky and Thomas (1981) defined access as a general concept that represents the degree of 'fit' between individuals and the healthcare system. This general concept summarises more specific areas of fit between the patient and the system. These areas or dimensions include: 
- availability (relationship of volume and types of services to the patients' volume and types of needs, i.e. adequacy of supply of services);

- accessibility (relationship between location of supply and location of patients, taking account of transportation, travel time, distance, cost, etc.);

- accommodation (how the services are organised to accommodate patients in terms of opening hours, appointment arrangements, walk-in facilities, etc.);

- affordability (relationship between prices of services and ability to pay);

- acceptability (attitudes of patients and providers).

These five dimensions can be related to, but are not identical to, the enabling factors outlined in Andersen's Behavioural Model of Health Services Use (described in Section 2.3) (Penchansky and Thomas, 1981).

McIntyre et al. (2009) built on the idea of access as a concept concerned with the degree of fit between individuals and the healthcare system. The authors proposed that access to healthcare represents the empowerment of individuals to use services, reflecting their capacity to benefit from healthcare given their own circumstances and experiences in relation to the healthcare system. Thus, policies to improve access to care must not only make services available, but also actively empower individuals to use those services when needed. For example, problems with empowerment could be due to the service not being available in the community, or available for limited hours of service only, or individuals not being aware of the effectiveness of the service, etc. McIntyre et al. (2009) identified three dimensions of access including availability (encompassing Penchansky and Thomas' dimensions of accommodation, accessibility and availability), affordability and acceptability, and the interaction between these three dimensions determines access. Availability focuses on whether the appropriate healthcare services are provided in the right place, at the right time, to meet the needs of the population. Affordability focuses on the degree of fit between the full cost (i.e. direct (formal and any 'under the counter' costs) and indirect costs (e.g. lost income while seeking and receiving care)) and individuals' ability to pay. Acceptability focuses on the degree of fit between the provider and patient in terms of attitudes to and expectations of each other.

Andersen et al. (2013) also acknowledge the importance of the link between health services and individuals in defining access. The authors emphasise that access is not achieved simply when an individual visits a healthcare provider, but when they get the right services at the right time: a point that links in with and expands on the concept of acceptability outlined by Mclntyre et al. (2009).

Carrillo et al. (2011) adopted a more focused definition of access, concentrating on 
'modifiable' healthcare access barriers rather than on a comprehensive model of all determinants of access. Their model outlines three categories of modifiable healthcare access barriers: financial (cost of care and health insurance), structural (availability, proximity, transport, etc.) and cognitive (knowledge and communication) barriers.

\subsubsection{Measuring equity in access}

Equity in healthcare can be examined across population groups defined in various ways including economic status, geographic location, social status, demographics, etc. For example, much of the recent empirical literature on equity in healthcare has focused on developing robust measures of socioeconomic-related equity in healthcare utilisation (van Doorslaer and Masseria, 2004; van Doorslaer et al., 2007).

Given the challenges in defining access, it is not surprising that many empirical studies on access focus on one aspect of this multifaceted concept. There is a large body of work that interprets access as a supply concept, concentrating on the geographic availability of services using provider-population ratios. McIntyre et al. (2009) identified three other strands of research on healthcare access wherein access is interpreted as a utilisation concept (e.g. studies of equity in utilisation controlling for needs), a demand concept (focusing on the affordability of services), or as the full cost of using a service, including travel costs, waiting costs, childcare costs, etc.

Many studies acknowledge the limitations of focusing on narrow definitions of access. For example, in their study of primary care, Ryvicker et al. (2012) found that variations in primary care supply cannot fully explain variations in realised access to care, and other access factors such as accessibility of public transport need to be taken into account.

Given the focus of this report on analysing geographic patterns of healthcare supply, it is useful to identify why this can be valuable, notwithstanding the important caveat that supply alone does not capture the full picture of access to a healthcare system. Rice and Smith (2001) outlined three reasons for considering geography when assessing equity in healthcare. First, healthcare systems, including Ireland, are organised on a geographic basis: for example, Health Boards (in the past), Local Health Offices and Regional Integrated Care Organisations (RICOs). Equity across geographic areas is a central concern in the distribution of resources. The focus on the geographic distribution of resources is encompassed in the widely cited 'inverse-care law', introduced by Tudor Hart in the 1970s, which highlighted the concern that 'availability of good medical care tends to vary inversely with the need of the population served' (Tudor Hart, 1971, p. 412). 
Second, Rice and Smith (2001) pointed out that healthcare facilities are concentrated at specific locations, and thus geographic considerations come into play in determining access to healthcare (e.g. distance to healthcare facility). Third, there is evidence that geographic inequalities in health status can exist over and above socioeconomic variations. There may be specific 'area effects' (e.g. physical environment, local economic conditions, local social support systems) that directly influence an individual's health and healthcare needs. In addition to the direct effects of geography on health, there may also be area effects on healthcare production. For example, input prices can vary from one area to another; service provision can be more costly in rural than in urban areas (Rice and Smith, 2001). Thus, geography can play a role in determining the nature of healthcare provided in different areas. Geographic access can also directly affect utilisation whereby individuals may be induced to make more use of services in areas with relatively high provision compared with less well-resourced areas.

\section{Measuring geographic equity in supply}

Simple comparisons of supply to population ratios across different areas give a good indication of patterns of geographic inequality, and this is the most common way in which geography is used in assessing equality and/or equity in healthcare access (WHO et al., 2010). For example, supply of doctors is expressed as the number of doctors per population in each area, where 'area' is a specific geographic unit of analysis (e.g. county, region). This allows for organisations such as Eurostat, the OECD and the Commonwealth Fund to undertake international comparisons of health and social care supply. Supply ratios are useful for broad comparisons of supply across large areas and are used by policymakers to set minimal standards of supply and to identify underserved areas (Guagliardo, 2004).

Researchers in the UK (Gravelle and Sutton, 2001; Hann and Gravelle, 2004; Goddard et al., 2010) have used this approach to examine the geographic distribution of GPs from the mid-1970s to the early 2000s, with some modifications to the supply ratios to take account of geographic variations in healthcare needs. Their methods are based on calculating Gini coefficients (see Section 3.4.1) on the geographic supply of whole-time equivalent GPs per needs-adjusted population for each time period.

As comparisons of raw GP per capita ratios do not allow for differences in needs across areas, Gravelle and Sutton (2001) used alternative indicators to adjust area populations for needs. These include age-related capitation weights, ${ }^{23}$ age- and sex-specific GP consultation rate adjustments, mortality rate adjustments and morbidity measures. For example, for mortality adjustment, area populations are

23 Capitation payments to GPs varied by age groups to reflect workload generated by different population groups. 
weighted by their crude death rate relative to the national crude death rate. ${ }^{24}$ For morbidity, area age- and sex-specific limiting long-term illness rates have been used to adjust the populations. Results for England and Wales indicate that inequality in the geographic distribution of GPs increased over time, with very few areas changing from having a below-average GP:population ratio to having an above-average ratio from the 1990s to the early 2000s (Hann and Gravelle, 2004). Gini coefficients for the supply of GPs in England and Scotland increased over time (indicating an increase in inequality) between the mid-1970s and 2006 (Goddard et al., 2010). More recent work examining GP supply at more granular geographic levels has shown a small increase in supply, and a reduction in socioeconomic inequities in supply from 2004 to 2014 (Asaria et al., 2016). Similar work from Japan has been used to project physician shortages in the future (Ishikawa et al., 2017). Supply ratios are used in this report to examine patterns of supply of non-acute services across counties in Ireland (see Chapter 3), drawing on the methods used in the UK to adjust for healthcare needs. Supply is measured at the most granular level in which the data are available.

Many studies have focused on what Guagliardo (2004) refers to as spatial accessibility. These involve methods, such as gravity models, that move beyond provider-to-population ratios to combine the dimensions of availability (level of supply) and accessibility (distance/time between patient location and healthcare supply), within the broader concept of access. Advances made in geocoding have facilitated this type of research in many countries, including Ireland (Mohan et al., 2019).

Siegel et al. (2016) used an 'improved gravity model' to examine spatial accessibility of a range of ambulatory and inpatient services in Germany. For each type of healthcare service, the model measured the provider to population ratios in a given district, but also incorporated supply and demand potential in all other districts (allowing for the fact that individuals living in one area can travel to other areas to receive services), while taking account of travel times between regions. A distance decay function was used to ensure that the more distant providers and potential users contribute less to the measure of spatial accessibility than those who are closer.

Other studies report links between spatial accessibility and how the healthcare system is used (Guagliardo, 2004). For example, Gulliford (2009) found that lower primary care availability is associated with higher rates of hospital admissions for ambulatory care sensitive conditions. Some studies have also demonstrated an association between access (e.g. supply of services) and health outcomes. Shi et al. (2002) observed a positive association between physician supply levels and self-

24 The crude death rates are based on raw numbers rather than on age-standardised rates. 
rated health. Okumura et al. (2013) used survey data to examine changes in health status and access to care over time in adolescents with special healthcare needs. Access is measured using supply variables (e.g. whether the adolescents had a usual source of care, a personal doctor or nurse) and insurance status. Results showed that significant deterioration in access factors over time was associated with decline in health status among adolescents with special healthcare needs.

\section{Measuring equity in access in the Irish context}

One common concern in studies of equity in the Irish healthcare system is the extent to which the eligibility structures influence the patterns of healthcare use. A number of studies have shown that individuals with a Medical Card or GP Visit Card have higher rates of use of non-acute and acute care services, ceteris paribus (Nolan and Layte, 2017; Hudson and Nolan, 2015; O'Callaghan et al.,2018; Walsh et al., 2012, 2019a). As outlined in Chapter 1, there are complex eligibility structures in the Irish system, with different payment mechanisms for different parts of the system and for different groups of the population. There has been widespread discussion of two-tier access to acute care in the system, with privately financed patients getting preferential access to public hospital care, and long waiting lists for public patients (Wren and Connolly, 2016). In primary care, for those without a Medical Card there are high user charges and although some community services may in principle be available free at the point of use, in areas where there is limited supply, Medical Card holders are granted priority (Citizens Information, 2019).

Studies of equity in access in the Irish context include studies on socioeconomic equity in utilisation (interpreting access as utilisation) (Layte and Nolan, 2004; Layte 2007) and assessments of geographic profiles and inequalities in healthcare supply, in particular of GPs (e.g. Layte et al., 2009; Teljeur et al., 2010, 2014). There has also been analysis of spatial accessibility in the supply of GPs in Ireland (Mohan et al., 2019; Teljeur et al., 2010; Morrissey et al., 2008) but to date extending this type of analysis to other non-acute healthcare services in Ireland is hindered by the absence of adequately geocoded data. Teljeur et al. (2010) used a gravity model to examine the geographic distribution of GPs in Ireland taking account of the distribution of deprivation. The authors found a relatively equitable distribution of GP practices, but less equity in the distribution of the GP workforce. Rural areas with the highest deprivation scores had the longest average travel times to GPs, but in general the study found only modest variation in travel times across levels of the deprivation proxy. Estimated GP workloads increased with the deprivation proxy in cities, villages and rural areas, with a more complicated pattern in towns.

Mohan et al. (2019) estimated individual-level regression models of GP utilisation using data from TILDA and three accessibility indicators based on the physical proximity of each household to nearby GPs. They found no evidence of a general 
effect on utilisation from accessibility to GP services. However, for respondents able to exercise significant choice about which GP to use (those without a Medical Card), the study found that the number of nearby GPs was positively associated with utilisation.

\subsection{HEALTHCARE NEED}

\subsubsection{Defining need}

As outlined above, in order to examine the fairness of a given distribution of services across geographic areas, analysts require some way of controlling for variations in healthcare needs across those areas. Similar to healthcare access, healthcare need is difficult to define and measure (Allin et al., 2010). In one sense healthcare need can be captured by poor health status. Assuming the presenting complaint is amenable to healthcare, healthcare need could be defined in terms of ill health. However, it is difficult to see how preventive healthcare fits into this definition: an individual does not need to be sick in order to benefit from preventive healthcare measures.

Alternatively, healthcare need could be defined by capacity to benefit from healthcare (Allin et al., 2010). This definition of need accommodates the role of preventive healthcare, accepting that individuals have capacity to benefit from health promotion and other preventive measures. Healthcare resources may be allocated very differently where two individuals with similar states of ill health have different capacities to benefit from healthcare. However, in practice, proxy measures are often used to capture need, so while capacity to benefit might be a more widely accepted definition of healthcare need (Allin et al., 2010; Birch et al., 2013), empirical analysis often relies on measures of poor health status and other indicators that are associated with health status and the demand for healthcare.

Theoretical models examining healthcare demand help to identify the factors that might give rise to healthcare needs, how those needs are translated into demands for healthcare and how those demands for healthcare are translated into use of healthcare (e.g. Grossman, 1972; Pohlmeier and Ulrich, 1995; Andersen, 1995). These models are useful for identifying appropriate proxy measures for healthcare need. In particular, Andersen's 'Behavioral Model of Health Services Use' (Phase 4, Andersen, 1995) provides an overview of a wide range of factors involved in the decisions to use healthcare services. The framework is particularly useful for highlighting the linkages between health status and healthcare need, use, and supply.

The Andersen model describes how population characteristics and wider system factors influence personal health practices and use of health services, which in turn 
influence outcomes (including perceived and evaluated health status as well as consumer satisfaction (see Table 2.1 for detail on the components of the framework). Population characteristics include predisposing factors, enabling factors and need factors. Pre-disposing factors describe the innate propensity of individuals to use services prior to the onset of illness (i.e. age, sex, marital status, season of admission). Need factors refer to the most immediate causes of health service use, while enabling factors refer to the means available for individuals to make use of health services. Broader health system factors (e.g. policy priorities and resources) as well as factors external to the health system (e.g. political and economic environment) can also influence healthcare-seeking behaviour. Health outcomes such as perceived health status and quality of life are included in the model to reflect the fact that healthcare use is a means to an end rather than an end in itself. Moreover, the more recent iterations of the model specifically acknowledge a feedback loop between health outcomes and subsequent predisposing factors, perceived need for healthcare and health behaviour (Andersen, 1995a; Andersen et al., 2013).

This model has been used in several studies to examine the determinants of healthcare utilisation and, as discussed below, it is helpful for identifying and categorising indicators of healthcare need. 


\begin{tabular}{|c|c|c|}
\hline Characteristic & \multicolumn{2}{|r|}{ Details } \\
\hline \multirow[t]{3}{*}{$\begin{array}{l}\text { Population } \\
\text { characteristics }\end{array}$} & Demographic & $\begin{array}{l}\text { Age, gender, representing 'biological imperatives suggesting } \\
\text { the likelihood that people will need health services' (Andersen, } \\
1995, \text { p. 2) }\end{array}$ \\
\hline & Social structure & $\begin{array}{l}\text { Factors that represent the status of a person in the community, } \\
\text { reflecting their ability to cope with presenting problems, and } \\
\text { the quality of the physical environment }\end{array}$ \\
\hline & Health beliefs & $\begin{array}{l}\text { Attitudes, values and knowledge that people have about health } \\
\text { and health services. These beliefs might influence perceptions } \\
\text { of need and use of health services }\end{array}$ \\
\hline \multirow[t]{2}{*}{ Enabling factors } & $\begin{array}{l}\text { Community } \\
\text { resources }\end{array}$ & $\begin{array}{l}\text { Organisation of healthcare services and availability of } \\
\text { personnel }\end{array}$ \\
\hline & $\begin{array}{l}\text { Personal } \\
\text { resources }\end{array}$ & $\begin{array}{l}\text { Income, health insurance, proximity to services, and transport } \\
\text { (i.e. the means and knowledge of how to access services) }\end{array}$ \\
\hline \multirow[t]{2}{*}{ Need } & Perceived need & $\begin{array}{l}\text { Individual's view of own general health, experience of illness } \\
\text { and pain, and judgement as to whether or not the problem is of } \\
\text { 'sufficient importance and magnitude to seek professional help' } \\
\text { (Andersen, 1995, p. 3) }\end{array}$ \\
\hline & Evaluated need & $\begin{array}{l}\text { Professional judgement about health status and need for } \\
\text { medical care (e.g. specific disease or pathology) }\end{array}$ \\
\hline \multirow[t]{2}{*}{ Environment } & $\begin{array}{l}\text { Healthcare } \\
\text { system }\end{array}$ & $\begin{array}{l}\text { Influence of national health policy and healthcare resources } \\
\text { (quantity and organisation) on people's use of the system }\end{array}$ \\
\hline & $\begin{array}{l}\text { External } \\
\text { environment }\end{array}$ & $\begin{array}{l}\text { Influence of physical, political and economic factors on people's } \\
\text { behaviour }\end{array}$ \\
\hline Health behaviour & $\begin{array}{l}\text { Personal health } \\
\text { practices }\end{array}$ & $\begin{array}{l}\text { Diet, exercise and self-care are included, recognising the fact } \\
\text { that health outcomes are influenced by these behaviours as } \\
\text { well as by use of formal health services }\end{array}$ \\
\hline Outcomes & Health outcomes & $\begin{array}{l}\text { Perceived health status, evaluated health status, consumer } \\
\text { satisfaction and quality of life }\end{array}$ \\
\hline
\end{tabular}

Source: $\quad$ Extracted from Andersen, 1995; Andersen et al., 2013.

\subsubsection{Measuring need}

As noted above, in practice it is generally accepted that needs for healthcare are not directly observed and proxy measures are used instead. Proxy measures for healthcare needs are used in a wide range of studies. This section gives an overview of typical measures of healthcare need that have been adopted in the empirical literature on resource allocation and in the broader literature on modelling determinants of healthcare utilisation. A review of this literature can inform the selection of variables to describe healthcare need and demand in Ireland for analysis in this report (see Chapter 3).

The broad literature on determinants of healthcare utilisation is useful for identifying indicators of need and non-need factors that contribute to healthcare demand. Several studies have used Andersen's Health Behaviour Model to categorise determinants of healthcare utilisation (Chen and Thompson, 2010; Jahangir et al., 2012; Lindamer et al., 2012; Keegan and Smith, 2013; Morrissey, 2019). Despite the wide variation in the analytic focus of these studies, common 
factors are used to capture population characteristics in the Andersen framework. In addition to age and sex, predisposing factors typically include marital status, and sometimes education and ethnicity. Enabling factors include private health insurance status or Medical Card status in the Irish case (Keegan and Smith, 2013), employment status and ability to pay. In one study of acute service utilisation, outpatient visits were included as an enabling factor, justified on the basis that more outpatient care may be associated with lower use of acute care (Lindamer et al., 2012) although the question of reverse causality would need to be considered here. Need factors have been measured by specific diagnoses but also by selfreported health indicators (e.g. EQ5D quality of life ratings) (Jahangir et al., 2012). The classification of indicators is not always consistent. For example, living situation (living alone or with others, homeless, etc.) has been categorised as predisposing by Jahangir et al. (2012) and enabling by Lindamer et al. (2012). Other studies, although not specifically adopting the Andersen framework, include similar population characteristics outlined above (Merikangas et al., 2011; Cardoso et al., 2012). Other studies have focused on the role of perceived needs in healthcare utilisation (Martins et al., 2013).

Examples of characteristics that capture other elements of the Andersen Model tend to be more study-specific. Jahangir et al. (2012) included a range of behavioural factors (level of physical activity, smoking status, alcohol abuse, etc.) in their analysis of factors associated with blood pressure measurement in Argentina. Keegan and Smith (2013) included a range of healthcare system factors in the analysis of inpatient length of stay for stroke discharges in Irish public hospitals (hospital type, stroke unit type, etc.).

\section{Resource allocation models}

The next report from this project (Walsh et al., 2019b) discusses the importance of resource allocation decision making in greater depth than this report. It also outlines the key factors that need to be addressed to allow for efficient resource allocation decision making. One of these key factors is accurate information on supply of and demand for health and social care, which is examined in this report.

The literature on healthcare resource allocation is concerned with allocating resources across a health system in line with healthcare needs. This is a useful literature for identifying common proxy measures of healthcare need. The resource allocation model for the English National Health Service (NHS) has received international attention, with many countries adopting a similar approach (Asthana et al., 2004; Morris et al., 2007). The weighted capitation formula for hospital and community health services comprises an age index, an additional needs index, an adjustment for unmet need and health inequalities, and other adjustments for costs (National Health Service, 2016). Needs indicators are the health status and socioeconomic variables that are most closely correlated with 
the national average pattern of hospital utilisation, controlling for the effects of supply (Asthana et al., 2004, Morris et al., 2007). Drawing on data on the levels of the needs variables in different areas, the resource allocation model estimates needs in each area and allocates resources accordingly (Morris et al., 2007).

However, the legitimacy of deriving needs indicators from existing patterns of healthcare utilisation has been criticised. It is argued that this approach assumes that the historical patterns of care delivered to each type of person are appropriate and reflect a desired package of care (Rice and Smith, 2001; Asthana et al., 2004). Interest is growing in a new approach to health resource allocation, whereby resources are distributed on the basis of direct measures of morbidity. The Welsh healthcare system adopts this epidemiological approach, drawing on available survey data on morbidity. Expenditure on any health condition is shared across geographic areas on the basis of the relative incidence of that condition in each area (Morris et al., 2007). The epidemiological approach requires detailed data on morbidity and the methodology has also been criticised. One issue of concern is the assumption of proportionality that applies to the relationship between morbidity and need. This condition requires that the mean level of need is the same for every geographic area and does not allow for geographic variations in mean severity levels (Morris et al., 2007).

To date, in Ireland, the practice of historical budgeting for community-based care persists and attempts to allocate healthcare resources equitably across areas have been hindered by limitations in available data (see Vega et al., 2010 for further discussion on resource allocation methods for Ireland). This report seeks to contribute to the evidence base on the geographic supply of non-acute healthcare services in Ireland to feed into the current policy discussions on expanding community-based care and the development of population-based resource allocation methods (Government of Ireland, 2018).

\section{Indicators of need for healthcare}

The current weighted capitation model in the English NHS draws on analysis by Carr-Hill et al. (1994), who identified three types of population characteristics that influence demand for healthcare: demography, morbidity and material socioeconomic conditions. Health status indicators include standardised mortality rates (SMRs), long-term limiting illness rates, permanent sickness indicators and low birth weight. Carr-Hill et al. (1994) also considered indicators of accessibility of healthcare services (e.g. number of inpatient beds per capita weighted for distance and competition from other areas, GP accessibility) as important factors influencing the demand for healthcare.

In a review of resource allocation formulas in seven jurisdictions (New Zealand, 
England, Scotland, the Netherlands, New South Wales (Australia), Ontario (Canada), and Stockholm (Sweden)), Penno et al. (2013) identified common factors that are deemed to reflect need for healthcare. Key indicators observed in some/all of the formulas include age, sex, socioeconomic status (e.g. welfare dependency, education level, income, and housing), ethnicity, geography (e.g. rural/urban) and disease status (e.g. premature mortality and morbidity indicators).

In Ireland, the need for a transparent resource allocation model that is based on population need was recommended by the Expert Group on Resource Allocation and Financing in the Health Sector (Ruane, 2010). The Group noted that the volume of non-historic budgeting for primary and community care services remained low and proposed that moving from historic funding patterns towards a population health allocation was central to addressing objectives of equity in access and responsiveness of healthcare delivery. As discussed, policymakers in Ireland have plans to develop population-based resource allocation methods (Government of Ireland, 2018). Within the current healthcare system, there are limited examples where resource allocation formulas are adjusted for population characteristics. For example, GPs are paid a capitation fee by the HSE to treat Medical Card and GP Visit Card holders. These capitation payments are adjusted for age and sex (Primary Care Reimbursement Service, 2017).

\subsection{SUMMARY AND METHODOLOGICAL IMPLICATIONS}

The focus of this report is on geographic patterns of supply of non-acute healthcare services in Ireland. It is clear from the discussion of the definition of access that supply is just one component contributing to the degree of fit between individuals and the healthcare system. Moreover, if any conclusions about equity in the geographic distribution of non-acute supply are to be drawn, the location and volume of supply of services should be assessed in relation to the location and volume of needs for those services.

Drawing on available data, this report aims to assess geographic patterns of healthcare supply in Ireland, adjusting for geographic patterns of healthcare needs. Andersen's (1995) theoretical framework of healthcare use, and available literature on resource allocation and utilisation in healthcare, provide guidance for selecting appropriate indicators of healthcare need. Chapter 3 introduces the methods and data used to undertake this analysis 
30 | Geographic Profile of Healthcare Needs and Non-Acute Healthcare Supply in Ireland 


\section{CHAPTER 3}

\section{Data and methods}

\subsection{INTRODUCTION}

This chapter outlines the data and methods used to examine the geographic distribution of non-acute healthcare services in Ireland. Geographic analyses can be undertaken at different levels of aggregation. This study assesses the distribution of non-acute healthcare supply across counties, with some additional disaggregation at postal district level within Dublin where data are available. Data for the year 2014 (unless otherwise stated) are analysed in this report.

As discussed in Chapter 2, if any conclusions about equity in supply are to be drawn, the location and volume of supply should be assessed in relation to the location and volume of needs for those services. Data and methods for assessing the geographic profile of needs in relation to supply are outlined in this chapter.

Section 3.2 outlines the geographic areas of analysis. Section 3.3 presents data required for examining non-acute healthcare supply and healthcare need indicators by geographic area. Section 3.4 outlines methods for analysing geographic variations in supply and for adjusting the analysis of supply for geographic variations in healthcare needs.

\subsection{GEOGRAPHIC AREAS OF ANALYSIS}

\subsubsection{Selection of geographic areas of analysis}

The supply and need for non-acute healthcare services in Ireland are assessed across counties. There are 26 administrative counties in Ireland, ranging in population size from just over 32,000 (Leitrim) to $1.35 \mathrm{~m}$ (Dublin City and County). This level of aggregation is selected for four reasons:

- Counties provide historical administrative boundaries as they distinguish areas of local government and administration.

- Counties reflect definitions of catchment areas for these services. Acute hospitals are likely to have catchment areas that incorporate more than one county and cross county borders (examined in the next report of the project (Walsh et al., 2019b)). This is less likely to be the case for non-acute services, which are more likely to be community-based services, serving clients in their immediate locality. Border areas remain problematic (regardless of the size of the catchment definition) and these are discussed where relevant. 
- To align with the geography of available data sources. The way in which public health and social care services are organised within the Health Service Executive (HSE) has implications for assessing the spatial distribution of healthcare services in Ireland. Public healthcare supply data are available at varying levels of aggregation, often reflecting older organisational structures (HSE Regions, Local Health Offices (LHOs), etc.). These data need to be converted to the geographic areas selected for this study and are most closely aligned with counties. As illustrated in the description of organisational changes within HSE structures in Chapter 1, a number of administrative structural changes have occurred in recent years. Thus, counties have the advantage of being stable across time and independent of the impacts of potentially changing HSE administrative structures, but at the same time align well with previous and current regional structures within the HSE (e.g. LHOs, Integrated Service Areas (ISAs), Community Healthcare Organisations (CHOs), Regional Integrated Care Organisation (RICOs)). ${ }^{25}$

- To align with data analysis in the second report from this project (Walsh et al., 2019b). Analysis in the second report examines substitution effects between acute and non-acute supply using the Hospital In-Patient Enquiry (HIPE) database (see Chapter 1). The geographic areas for this report have been selected to match areas of residence as recorded in HIPE.

Below we present the geographic areas used in this analysis. Methods for estimating levels of non-acute healthcare supply, and levels of need, in each geographic area are also presented.

\subsubsection{Outline of the geographic areas}

The geographic distribution of non-acute healthcare supply and need is described for the following 28 areas in Ireland:

- 26 areas outside the Dublin region: 25 counties, with Tipperary disaggregated as Tipperary North and Tipperary South;

- two areas within the Dublin region: Dublin North (of Liffey river) and Dublin South (of Liffey river).

Where data availability allows, the geographic distribution of non-acute healthcare supply and need is also described for the following:

- 24 smaller areas within the Dublin region - 22 postal districts, Dublin Other North (of Liffey river) and Dublin Other South (of Liffey river).

$25 \quad$ However, when presenting data and tracking potential reasons for observed geographical patterns in healthcare supply (in particular public healthcare services), regrouping the data in accordance with an older set of administrative structures might assist interpretation. 


\subsubsection{Assigning healthcare supply and need data to geographic areas}

\section{National supply (28 areas)}

The process of assigning healthcare supply data to the 28 areas identified above involves one or more of the following steps (outlined in Figure 3.1):

- If a healthcare service is supplied at a specific address (e.g. a GP surgery, a nursing home), the area in which that address is located is identified using boundary files for counties. Boundary files for counties were provided by the CSO.

- If the service provider name indicates that the service is supplied to one of the 28 areas (e.g. community nurses working in the programme for 'Older Person Home Care Packages Mayo'), the service provider is assigned to that area (i.e. Mayo in this example).

- Where the service is provided to more than one of the 28 areas, the supply data (e.g. number of nurses) are redistributed from the aggregated area to the relevant study areas based on share of population. For example, some supply data are available at LHO rather than at county level. Cross-classification of Census 2011 population counts by county, LHO and age were provided by the Health Intelligence unit of the HSE. These data are used to redistribute supply data from LHO to county level based on population shares of counties within LHOs (see Appendix 2).

\section{Dublin supply (24 areas)}

Healthcare supply data are assigned to the 24 smaller areas within Dublin only where the source data are already disaggregated by these areas.

\section{National healthcare needs and Dublin healthcare needs}

The process of assigning healthcare need data to the 28 areas is more straightforward than for supply. Need data are available at county or LHO level and are assigned to the 28 areas in the same way as outlined above for supply. Healthcare need data are assigned to the 24 smaller areas within Dublin only where the source data are already disaggregated by these areas. 
FIGURE 3.1 METHOD FOR ASSIGNING HEALTHCARE SUPPLY TO THE 28 GEOGRAPHIC AREAS AT NATIONAL LEVEL

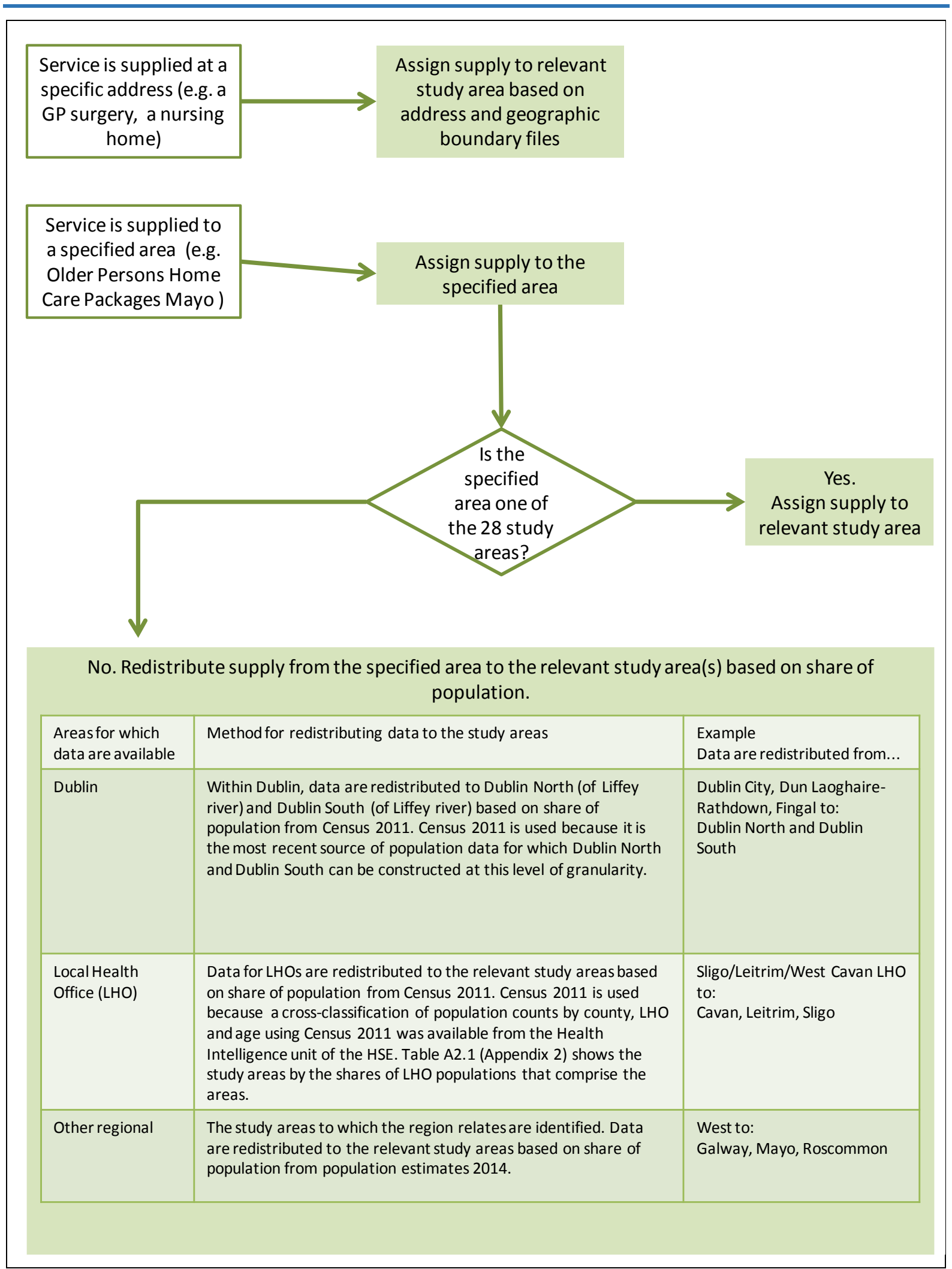




\subsection{DATA SOURCES}

Data on supply of non-acute healthcare services and on healthcare needs, by geographic area in Ireland, are required for this analysis. In addition, population data are needed to align geographic distributions of available data sources on supply and healthcare needs with the study geographic areas, and to control for population size when comparing supply and needs across areas.

\subsubsection{Population - data sources}

\section{Population by county, 2014}

The year 2014 falls between the 2011 and 2016 Censuses (Central Statistics Office (CSO), 2012a, 2016). While the CSO reports population counts for counties by single year of age and sex in census years (e.g. 2006, 2011, 2016), it does not report estimates for intercensal years by single year of age and sex. Therefore, estimated population counts for 2014 were generated by the research team at the ESRI using the fundamental balancing equation of population growth. Further details on the methods used to generate these population estimates are given in Morgenroth $(2008,2014)$. The balancing equation forms the basis of the cohort component method conventionally used to construct population projections. Population growth is defined as the result of births minus deaths plus net migration for each county, outlined in equation 1 :

$$
\text { (1) } P_{1}=P_{0}+B_{0-1}-D_{0-1}+N M_{0-1}
$$

where $P_{1}$ is the population estimate for 2014, $P_{0}$ is the enumerated population count in Census 2011, $B_{0-1}$ is births during the period 2011-2014, $D_{0-1}$ is deaths during the period 2011-2014, and $\mathrm{NM}_{0-1}$ is net migration during the period 20112014.

This formula has been used to construct 2014 population estimates by age, sex and county using published data on births, deaths and net migration as follows:

- Number of deaths by single year of age and sex in each county was constructed using the mortality rates contained in the CSO Life Tables (CSO, 2015a). ${ }^{26}$

- Net migration numbers by county were constructed using international migration estimates from the CSO (CSO, 2015b). International migration was distributed according to the patterns observed in Census 2011 (CSO, 2012a). Internal migration was projected using traditional patterns of internal migration (CSO, 2013).

26 In contrast with population projections produced using a cohort component model, which generates births and deaths based on mortality and fertility assumptions, actual births and deaths were used in this analysis. 
This method was used to construct age-/sex-specific 2014 population estimates for 27 areas:

- 26 counties with Tipperary estimated as two areas and the Dublin region estimated as one area;

- the Dublin region was subsequently disaggregated to Dublin North and Dublin South using age-specific proportions from Census 2011.

\section{Dublin population by postal district, 2014}

The 24 geographic areas within Dublin (22 postal districts, 'Dublin Other North' and 'Dublin Other South') do not correspond to the administrative boundaries used to collect population data in the Census. However, Census Enumeration Areas (EAs) can be assigned to postal districts using GIS files supplied by the All-Ireland Research Observatory (AIRO) within the National Institute for Regional and Spatial Analysis (NIRSA) based at Maynooth University.

Population estimates for the 24 geographic areas within Dublin could not be calculated directly from the available data and have been constructed using population estimates for the Census 2011 Small Areas that constitute the geographic areas (CSO, 2012b). Population estimates for these Small Areas are calculated by first allocating EAs to each postal district on the basis of the largest area share. In total 3,392 EAs are matched to Dublin postal areas. Only population totals were available for each EA, and the age and sex distribution of the electoral district in which each EA is located is imposed on this to generate EA populations by sex and age. These are then aggregated to the 24 geographic areas, and the 2014 population estimates for the Dublin region are then attributed to each area on the basis of the 2011 population by sex and age shares.

\section{Non-acute healthcare supply - data sources}

This section presents the data sources for each of the non-acute healthcare services included in the geographic analysis. There is no national dataset that profiles the number, location and catchment population of non-acute healthcare services in Ireland. Rather, there are several disparate data sources that provide some information on the supply of publicly provided non-acute services, and very limited information on the supply of private non-acute services. Therefore, one of the aims of this project has been to collate and combine the available data to provide a more detailed picture of non-acute supply across geographic regions.

Available evidence indicates important gaps and potentially inequitable geographic variations in supply of specific non-acute services in Ireland. GP supply has been examined by Layte et al. (2009) and more recently by Teljeur et al. (2014) and allied health supply in the community (with specific focus on stroke patients) 
has been examined by Wren et al. (2014). In other work, a model of demand for and supply of GP and practice nurse services has been developed for the Department of Health (DOH) to examine implications of population growth, ageing and changes in epidemiology on demand/supply of these services. Further phases of the model are expected to examine supply of and demand for allied health professionals and other members of the primary care team (DOH, 2012; HSE, 2015a). The model projects future supply of and demand for GP services and links these projections with training requirements, but does not consider the spatial distribution of the services. There is a growing interest in the spatial distribution of services and analysis is undertaken by a number of bodies including the Health Atlas $^{27}$ and the AIRO. ${ }^{28}$

In this report, we examine the most central non-acute healthcare services in Ireland:

- GPs;

- community nurses including public health nurses (PHNs) and other registered nurses working in the community;

- allied health professionals - physiotherapists (public and private), occupational therapists, speech and language therapists, podiatrists and chiropodists, counsellors and psychologists, and social workers;

- long-term residential care beds;

- home care hours (Home Help and Home Care Packages).

This is not an exhaustive list of all the non-acute services available in the country, but is representative of the key professions that make up (notional or actual) primary care teams and wider community healthcare networks. These services account for the vast majority of non-acute services examined in a recent ESRI health and social care demand projection report (Wren et al., 2017). The importance of these services in Table 3.1. This illustrates the estimated total activity (e.g. GP visits, home care hours) for each service in Ireland in 2015 (Wren et al., 2017). 


\begin{tabular}{|l|l|r|}
\hline \multicolumn{1}{|c|}{ Non-acute healthcare service } & \multicolumn{1}{|c|}{ Measure of activity } & \multicolumn{1}{c|}{$\begin{array}{c}\text { Activity volume 2015 } \\
\text { ('000s) }\end{array}$} \\
\hline General practice & GP visits & 17,551 \\
\hline \multirow{2}{*}{ Community health nursing ${ }^{\mathbf{1}}$} & Practice nurse visits & 5,944 \\
\hline Long-term care ${ }^{2}$ & Community health nursing & 1,362 \\
\hline Home care & Residents/places & 29 \\
\hline & Long-term residential care bed days & 10,460 \\
\hline Public health nursing and community & Public Home Care Package & 15 \\
\hline therapy & recipients & 10,300 \\
\hline & Public Home Help scheme hours & 760 \\
\hline & Public physiotherapy visits & 347 \\
\hline
\end{tabular}

Source: Wren et al. (2017).

Notes: $\quad$ 1. Excludes schools vaccination programme. 2. Long-term care residents' places are estimated at end 2015; other measures are for total activity in 2015.

\section{General practitioners (GPs)}

GPs play a central role in the overall running of the Irish healthcare system. However, unlike other countries, there is no central register of GPs practising in Ireland. Data on GP supply for this report are based on extracts from two GP databases in September 2014: the Irish College of General Practitioners (ICGP) database and the Irish Medical Directory (IMD). The ICGP is responsible for education, training and standards in general practice. To be a registered member of the ICGP, a GP is required to have completed recognised GP specialist training (or a recognised alternative route to membership). ICGP membership covered more than 85 per cent of practising GPs in Ireland in 2019. ${ }^{29}$ The IMD collates professional profiles (names, practice address, specialty, etc.) of consultant doctors and GPs working in Ireland. Registration with the IMD is voluntary and in 2019 approximately 2,800 GP specialists were included..$^{30} \mathrm{GPs}$ from either or both extracts are included in this report. The extracts were compiled by researchers from the Department of Public Health and Primary Care, Trinity College Dublin and made available to this study. Previous estimates of the supply of GPs have also used these data sources (Teljeur et al., 2010; Thomas et al., 2012). The extracts include GP name and GP practice location. ${ }^{31}$

Given the absence of a central register, it is important to note that in this report there may be some underestimation of the total number of GPs available to patients. There are two sources of underestimation. First, GPs in training are not

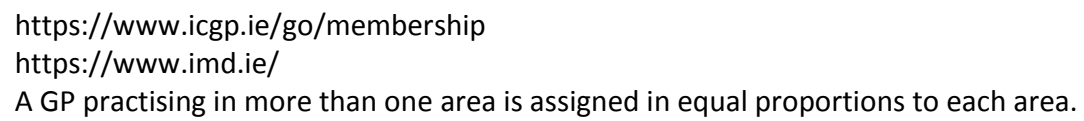


included in the above extracts, although trainees may be working in GP practices around the country. As at March 2015, there were 668 GP trainees (Mansfield et al., 2015) and approximately half of trainees (i.e. those in the final two years of the four-year training programme) were in supervised general practice (Irish College of General Practitioners, 2015) but data on their location are not available. Second, the National Doctors Training and Planning unit in the HSE estimated a total number of 3,923 doctors working in general practice in Ireland in 2014 (HSE, 2015a). This estimate includes doctors who are on the specialist register of the Medical Council (specifying GP as the specialty), and other doctors indicating that they work in general practice but who are not on the specialist register (e.g. general registration, specialist registration for another specialty). It is likely that the main source of discrepancy in the number of GPs between this study and the HSE estimates (HSE, 2015a) is the exclusion in this study of GPs who have not completed recognised specialist GP training. Furthermore, the HSE data are not reported by geographic area and so are not available for geographic analysis.

The number of GPs in each area is calculated based on the practice location given in the data extract. However, headcount-based measures can only give the maximum available capacity of a given healthcare system (Girasek et al., 2016) and do not take account of variations in full-time and part-time practice. A whole-time equivalent (WTE) measure can adjust for actual volume of available resources. The headcount numbers of GPs in each area have been converted to WTEs based on survey evidence on full- and part-time working practices of GPs in Ireland (O'Kelly et al., 2016a). The WTE adjustment factor adjusts for separate male and female working practices given the lower rates of full-time practice amongst female GPs and the increasing proportion of female GPs in Ireland in recent years (the proportion of female GPs is estimated to have increased from 12 per cent in the 1980s to 42 per cent in 2015) (O'Kelly et al., 2016b).

The following WTE adjustment factors have been applied using the survey evidence from O'Kelly et al. (2016) on full and part-time working rates by sex:

- males - 91 per cent work full-time (1 WTE), 9 per cent work part-time $(0.5 \mathrm{WTE}){ }^{32}$ giving an adjustment factor of $(0.91 \times 1)+(0.09 \times 0.5)=0.96$;

- females -72 per cent work full-time ( 1 WTE), 28 per cent work part-time (0.5 WTE), giving an adjustment factor of $(0.72 \times 1)+(0.28 \times 0.5)=0.86$.

\section{Health Service Personnel Census}

Data on the supply of non-acute personnel in the public health service were obtained from the HSE's Health Service Personnel Census (HSPC) (HSE, 2015c). The

32 The assumption that part-time input is equivalent to 0.5 WTE is consistent with the approach taken in the literature (Teljeur et al., 2014). 
HSE uses this dataset to collate employment data for the HSE and 39 agencies (23 non-acute agencies and 16 voluntary acute hospitals) that are funded under Section 38 of the Health Act, $2004 .{ }^{33}$ Data are available on the number of people and WTEs employed in the public health service by grade, gender, functional area, LHO and specific agency (if relevant) on a monthly basis.

Personnel working in acute services, ambulance services, corporate and health business services, and management/administration and general support staff were excluded from the data reported here. Thus, the following personnel (number and WTE, including personnel on maternity leave and excluding personnel on career break) were extracted from the HSPC as at December 2014:

- Community nurses including - PHNs, nurses working in primary care or social inclusion areas, and nurses working with older people in a community setting. These were extracted as follows:

- Grade Group = 'Public Health Nursing'

- OR (Staff Category = 'Nursing' AND Care Group = 'Primary Care')

- OR (Staff Category = 'Nursing' AND Care Group = 'Social Inclusion')

- OR (Staff Category = 'Nursing' AND Care Group = 'Older People' AND Agency = Community/home based).

- Allied health professionals including - physiotherapists (PTs), occupational therapists (OTs), speech and language therapists (SLTs), podiatrists and chiropodists, counsellors and psychologists, ${ }^{34}$ and social workers. These professionals were extracted from the database based on the Grade Group associated with their specialty (e.g. physiotherapists were extracted using the selection Grade Group = 'Physiotherapists').

\section{Private physiotherapists}

Owing to data availability, this report examined the supply of both public and private physiotherapists. A more comprehensive analysis of physiotherapy supply in Ireland than that provided in this report, where supply in both the acute and non-acute sectors was examined, was also published as part of this project (Eighan et al., 2019). Data on the supply of private physiotherapists are based on two sources: the database of physiotherapists registered with the Irish Society of Chartered Physiotherapists (ISCP) and an online survey of members registered with the ISCP.

\footnotetext{
33 Agencies funded under Section 39 of the Health Act, 2004 are not included in the HSPC. Section 39 agencies are all voluntary/non-statutory agencies excluding those listed under Section 38.

34 Student clinical psychologists that are listed in the HSPC are excluded from the analysis to ensure consistency with data on other professionals (students are not included for any of the other professions).
} 


\section{ISCP database}

The ISCP is the national professional body representing chartered physiotherapists in Ireland. Membership is not a statutory requirement, but in order to use the title 'chartered physiotherapist' in the private sector, recognition of qualifications and membership of the ISCP is required. ${ }^{35}$ As the ISCP is the only designated authority that has the approval of the Minister for Health to recognise physiotherapy qualifications in Ireland, ${ }^{36}$ its membership is expected to be representative of current private physiotherapy supply in the country. ${ }^{37}$

For each member, the ISCP records data on primary work category (public, private, etc.), work address(es), physiotherapy grade and other administrative data. Anonymised data for currently practising members were extracted from the database in order to obtain a geographic profile of private physiotherapists working in non-acute settings in Ireland. Data were extracted in April 2016 and reflect the membership for the year July 2015-June 2016. ${ }^{38}$

\section{ESRI physiotherapist survey}

Data on working hours were required to adjust the number of physiotherapists to give WTE estimates, but this information is not available in the ISCP membership database. Data on working hours (i.e. full-time, part-time) were drawn from an online survey of ISCP members.

The short online survey of the supply of public and private physiotherapy in Ireland was generated by the project team and approved for circulation to ISCP members. The survey was anonymous and asked questions about public and/or private physiotherapy activity in 2014 and where in the country (i.e. county/city/Dublin areas) the respondent undertook their work.

The survey was generated in SurveyMonkey and a web link to the survey was emailed by the ISCP to members registered in November 2015. There were 576 respondents, giving a response rate of approximately 20 per cent. Data were extracted to and analysed in MS Excel.

Data on the proportion of respondents working full-time and part-time were used to generate a WTE adjustment factor to convert the number of private physiotherapists into WTE estimates. Overall, approximately 60 per cent of private

\footnotetext{
35 In order to work as a physiotherapist in the public health system, it is necessary for individuals to have their physiotherapy qualifications recognised by the ISCP.

36 http://www.iscp.ie/membership-and-renewals/qualification-recognition

37 Statutory registration with the new multi-profession health and social care regulator, CORU, commenced in 2017 (CORU, 2017).

38 Data on work address(es) were not available for 2014.
} 
PTs work full-time (1 WTE - over and above 1500 hours per year) and 40 per cent work part-time (0.5 WTE), giving an adjustment factor of $0.8=(0.6 \times 1+0.4 \times 0.5)$.

\section{Long-term residential care beds}

Data on the supply of long-term residential care (LTRC) beds are based on combined datasets maintained by the Health Information and Quality Authority (HIQA), the DOH and Nursing Homes Ireland (NHI):

- HIQA is responsible for the regulation of designated centres for older people and it maintains a database of publicly owned and privately owned LTRC centres.

- The DOH conducted surveys of activity in long-stay units up to 2014 and maintains a database of LTRC centres.

- $\mathrm{NHI}$ is the representative body for private and voluntary LTRC centres in Ireland. NHI conducted surveys of activity in long-stay units up to 2014.

LTRC centres and beds from either or both of the HIQA and DOH databases, dated February $2015,{ }^{39}$ are included in this study. Supplementary information on centres not covered in the larger databases are included from the NHI surveys. The databases and surveys include the centre's name, address and number of beds. The number of LTRC beds reported in this study reflects the maximum number of people that a service is registered to accommodate. Although at any given time there may be fewer residents than this at a site, the maximum number is considered by the $\mathrm{DOH}$ to be the most accurate reflection of capacity in long-term care services. ${ }^{40}$ The measure of beds includes long-stay beds for the elderly, limited-stay or intermediate care beds, respite beds, rehabilitation beds and condition-specific beds such as dementia-specific beds in line with previous analysis of this area (Wren et al., 2017).

\section{Home care}

Data on the supply of publicly financed home care were provided by the Social Care Division of the HSE. These data cover services provided across the 32 LHOs by the two home care schemes running in 2014: the Home Help scheme and the Home Care Package (HCP) scheme. Metrics include the number of home care hours provided as part of the Home Help scheme and the number of HCP recipients. The average number of hours provided within an HCP was multiplied by the number of recipients in the scheme. This allowed for the aggregation of home care hours across the two schemes. As a new merged Home Support scheme was established

39 February 2015 was an opportune time to compile data on supply of long-term care because the DOH was reconciling its list of long-stay units with HIQA's list of designated centres for older people at that time.

40 For example, when submitting data to Eurostat, the Organisation for Economic Co-operation and Development (OECD) and the World Health Organization, the $\mathrm{DOH}$ reports the number of registered long-term residential care beds (rather than e.g. the number of beds that are open, or in use). 
in 2018 , combining both schemes in this report should provide a more accurate reflection of the current home care system in place in Ireland as of 2019.

\subsubsection{Healthcare need indicators - data sources}

This section outlines the set of indicators that have been selected to reflect need for healthcare (drawing on the discussion of how need is defined in Chapter 2). The indicators can be categorised using Andersen's Behavioural Model of Health Services Use and include predisposing characteristics (i.e. age), need (i.e. indicators of ill health) and enabling factors (i.e. Medical Card and GP Visit Card coverage). For ease of presentation these are collectively referred to as 'needs' indicators. Table 3.2 presents the indicators together with their definitions and data sources. 


\begin{tabular}{|c|c|c|}
\hline $\begin{array}{l}\text { Classification as per } \\
\text { Andersen's Model of } \\
\text { Healthcare Utilisation }\end{array}$ & Variable & Definition and notes \\
\hline $\begin{array}{l}\text { Population } \\
\text { characteristic/ } \\
\text { demographic }\end{array}$ & Age & $\begin{array}{l}\text { Percentage of area population aged } 65+\text { years in } 2014 \\
\text { Percentage of area population aged } 85+\text { years in } 2014\end{array}$ \\
\hline $\begin{array}{l}\text { Population } \\
\text { characteristic/ } \\
\text { need/evaluated }\end{array}$ & Mortality & $\begin{array}{l}\text { Ratio of area crude mortality rate to national crude mortality rate: } \\
\text { - The CSO is responsible for reporting mortality data. The number of deaths registered } \\
\text { during } 2014 \text { by county and city areas were taken from Table } 10 \text { of the CSO's Vital } \\
\text { Statistics Yearly Summary. } \\
\text { - Deaths by year of registration are used in this study instead of deaths by year of } \\
\text { occurrence because the registration data are more timely and, since } 2014 \text {, include all } \\
\text { deaths registered during the year. (Previously the practice was not to include deaths } \\
\text { in the annual summary statistics until the cause of death had been definitely } \\
\text { established.) }\end{array}$ \\
\hline
\end{tabular}

Population
characteristic/
need/perceived

Percentage of area population with disability:

- Census data were used to estimate the proportion of people with disability in each study area in 2014.

- A person with disability is defined as someone who responded 'yes' to any of the seven categories on long-lasting conditions (question 16) or 'yes' to any of the four categories on difficulties (question 17) in Census 2011 (see Appendix 1 for the full text of the questions).

- The number of people enumerated in an area was used instead of the number of people usually resident in an area because healthcare services may be needed and/or used by people who are present in an area but not usually resident in that area or not usually resident in Ireland. The date of the census is chosen to coincide with a period when movements are at a minimum and, consequently, the figures for the enumerated population closely approximate those for the normally resident population (CSO, 2012c). The total enumerated population is $101.4 \%$ of the total usually resident population and, at county level, the difference ranges from $100.5 \%$ to $102.3 \%$.

- The proportion of people with disability in an area has been applied to the 2014 population estimate for that area.

\section{Data source}

ESRI population estimates

2014

Table 10 CSO Vital Statistics Yearly Summary (CSO, 2015a)

Census 2011 (CSO, 2012c),

ESRI population estimates 2014 
Enabling factor/

personal resource

Medical Card

(and GP Visit

card) coverage

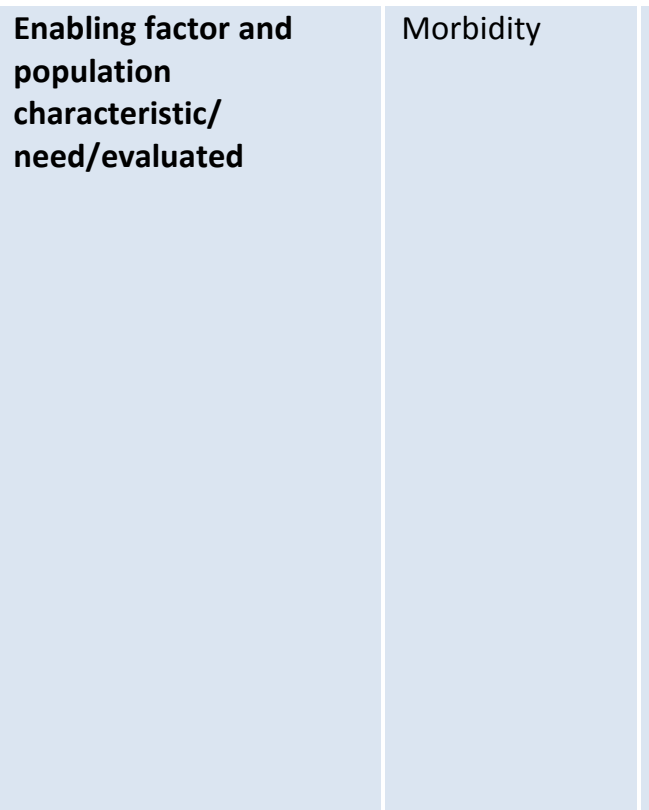

Percentage of area population with a Medical Card (and GP Visit Card where relevant):

- Data on the number and geographic distribution of Medical Card holders and GP Visit Card holders are recorded by the Primary Care Reimbursement Service (PCRS). The number of people with a Medical Card by age, sex and LHO at December 2014 were made available for this analysis by the $\mathrm{DOH}$.

Percentage of area population with a Medical Card and in receipt of a prescription relating to a chronic health condition:

- Prescription data have been used to estimate the proportion of people with a Medical Card who have a chronic health condition.

- The majority of pharmacists in Ireland have a contract with the HSE to dispense prescribed medication to Medical Card holders. The HSE reports that there were 1,778 agreements with pharmacists at December 2014 as part of the PCRS (HSE, 2014). The PCRS of the HSE processes monthly payments to pharmacists based on prescriptions dispensed to people with a Medical Card. Access to the prescription data was provided by the Department of Pharmacology and Therapeutics, Trinity Centre for Health Sciences in St James's Hospital, Dublin.

- RxRisk is an algorithm that classifies prescriptions dispensed by ambulatory pharmacies into chronic disease classes based on the WHO Anatomical Therapeutic Chemical (ATC) classification system. There are separate algorithms for children aged 0-15 years (Fishman and Shay, 1999), adults aged 16-64 years (Fishman et al., 2003) and adults aged $65+$ years (Sloan et al., 2003). The three algorithms were run on PCRS prescription data for 2014 to identify the number of children, adults and older adults in LHOs of the HSE with a Medical Card and a prescription relating to a chronic health condition.
$\mathrm{DOH}$

PCRS prescription data 2014

(Department of Pharmacology and Therapeutics, TCD Centre for Health Sciences, St James's Hospital, Dublin) 


\subsection{METHODS OF ANALYSIS}

\subsubsection{Metrics for presenting supply}

To facilitate analysis and interpretation of the geographic distribution of supply, a number of supply metrics are adopted from available literature on spatial accessibility in healthcare. The following supply metrics are calculated for each geographic area.

\section{Supply per capita (e.g. GP WTEs per capita)}

As discussed in Chapter 2, this is a standard metric used to facilitate assessment of geographic inequality within and between countries. Results are presented in terms of supply per 10,000 population for all except long-term residential care and home care. Long-term residential care is presented in terms of number of beds per 1,000 population aged 65 and over. Home care is presented in terms of home care hours per person aged 65 and over.

The distribution of supply per capita is presented in detailed bar charts to show the spread of supply per capita from highest to lowest across the 28 areas and in maps (to identify any specific geographic patterns in supply).

\section{Location quotient (equation 2)}

(2) location quotient $=$ (area supply/area population $) /($ national supply/national population)

The location quotient gives the ratio of the area value of supply per capita to the national value (national average) of supply per capita. It shows how individual areas compare with the national value and is a useful simple measure to examine the relative levels of supply (Robinson, 1998; Foley, 2008). For example, a location quotient of 2.0 indicates that supply in that area is twice the national average supply, while a score of 0.5 indicates that supply in that area is half the national average level of supply.

However, it is important to note that comparison against national average supply does not assume that the latter represents an optimal level of supply. Location quotients could be calculated using different benchmarks (e.g. the highest/lowest levels of supply per capita in the distribution, or an objective measure of optimal supply per capita). The location quotient allows the calculation of an area's excess or deficit of supply relative to national average, supply as per equation 3 :

(3) excess or deficit of supply = area supply - (area supply/location quotient) Where supply per capita in an area is lower than the national average supply per 
capita, this measure calculates the absolute number of units (e.g. number of GPs) that would be needed to bring supply in that area up to the national average supply per capita. Conversely, where supply per capita in an area is greater than the national average, this measure calculates the degree to which supply in that area is in excess of the national value, in absolute terms.

\section{Gini coefficients}

The Gini coefficient is a summary measure of relative inequality (see Appendix 3 for a description of how the Gini is calculated). It is useful for making broad comparisons of the degree of inequality across different non-acute healthcare services and for making international comparisons, and is widely used in the literature on measuring inequality in healthcare supply (Gravelle et al., 2001; Morris et al., 2005). The Gini lies between 0 (complete equality) and 1 (complete inequality).

The ease of interpretation of Gini coefficients is advantageous when comparing inequalities in supply across services. For example, a Gini coefficient of 0.2 implies twice as much inequality in supply exists compared to a Gini coefficient of 0.1. As a rule of thumb, a Gini coefficient of more than 0.1 can be regarded as describing considerable inequality (Koolman and van Doorslaer, 2004). In order to remove inequality, the redistribution required depends on the estimated coefficient, with a Gini coefficient of 0.1 requiring 10 per cent redistribution from regions with higher average supply to regions with lower average supply.

It is important to note that the Gini coefficient is only a summary measure (e.g. two very different Lorenz curve shapes could yield similar Ginis) and hides important information about the shape of the underlying distributions. Thus, this report presents the distributions of non-acute services across the 28 areas in detailed bar charts and maps, and presents the Gini coefficients as supplementary rather than core metrics.

\subsubsection{Methods for needs adjustment}

This section outlines the methods for adjusting the analysis of geographic patterns of supply for geographic variations in healthcare needs.

The adjustment methods draw on those used in analyses of GP and nursing supply in the UK (Gravelle and Sutton, 2001; Hann and Gravelle, 2004; Goddard et al., 2010). The general approach involves adjusting the population in each study area by a specific need indicator (e.g. percentage with disability), and then recalculating the ratios of supply per capita on the basis of the adjusted population (e.g. number of GPs per person with disability in each area). This process has been repeated for different need indicators, reflecting the complexity of the concept of need and the 
challenges in measuring need. In this study, the population in each study area has been adjusted in turn for the need indicators outlined in Table 3.2, namely age, mortality, disability, Medical Card status and a measure of morbidity among Medical Card holders.

The ratios of supply per capita in each area are recalculated on the basis of each of the following adjusted populations (see Table 3.2 for details):

- age - population aged $65+$ in each area;

- age - population aged $85+$ in each area;

- mortality - the population in each study area is weighted by the ratio of the area's crude mortality rate to the national crude mortality rate (see Table 3.2 for details). The ratios of supply per capita are recalculated on the basis of the mortality-weighted population;

- disability - population with disability in each area;

- enabling - population with a Medical Card in each area;

- enabling and morbidity - population with a Medical Card and in receipt of prescription relating to a chronic health condition.

\section{Need adjustments by type of supply}

The above adjustments were made, where relevant, for each of the supply variables. For example, GP Visit Cards do not cover anything other than GP fees and thus adjustment for the GP Visit Card population (together with Medical Card holders) was only undertaken for GP supply. Medical Cards do not cover LTRC fees and thus the ratio of supply of LTRC beds to the Medical Card population is not presented. Conversely, it does not make sense to present the ratio of LTRC beds to the full population given that the proportion of individuals under the age of 65 using long-term care is very small (Wren et al., 2017). ${ }^{41}$ Table 3.3 summarises the adjustments made for each of the supply variables presented in the analysis.

Scatter plots are used to compare the ratios of supply per total population with the ratios of supply per needs-adjusted populations for each needs-adjustment indicator. Box 3.1 outlines how to interpret these scatter plots. 
BOX 3.1 Interpretation of scatter plots

Scatter plots are used to compare the ratios of supply per total population with the ratios of supply per needs-adjusted population. Gravelle and Sutton (2001) used similar plots to compare GP supply per capita by area across two time periods.

1) The vertical axis shows supply for the total population. The horizontal axis shows supply for a needs-adjusted population. The values on the axes are location quotients (i.e. supply per capita in an area relative to national supply per capita). If the level of supply in an area is equal to the national value, the location quotient is equal to 1 .

2) Each area is plotted as a data point.

3) If the needs adjustment does not change the relative supply in any area, then all the area data points lie on the diagonal 'line of no change'.

4) If the needs adjustment accounts for all the unequal distribution in supply across the areas, then all the area data points lie along the vertical line at 1.0.

5) The position of an area data point in one of the quadrants created by the intersecting lines at $(1,1)$ shows whether an area is same as, above, or below the national value before and after needs adjustment.
Example: The marker represents an area where supply per population is:

1) higher than the national value when the total populations are compared (1.4 > 1.0 on the vertical axis), but

2) lower than the national value when the needs-adjusted populations are compared $(0.9<1.0$ on the horizontal axis).

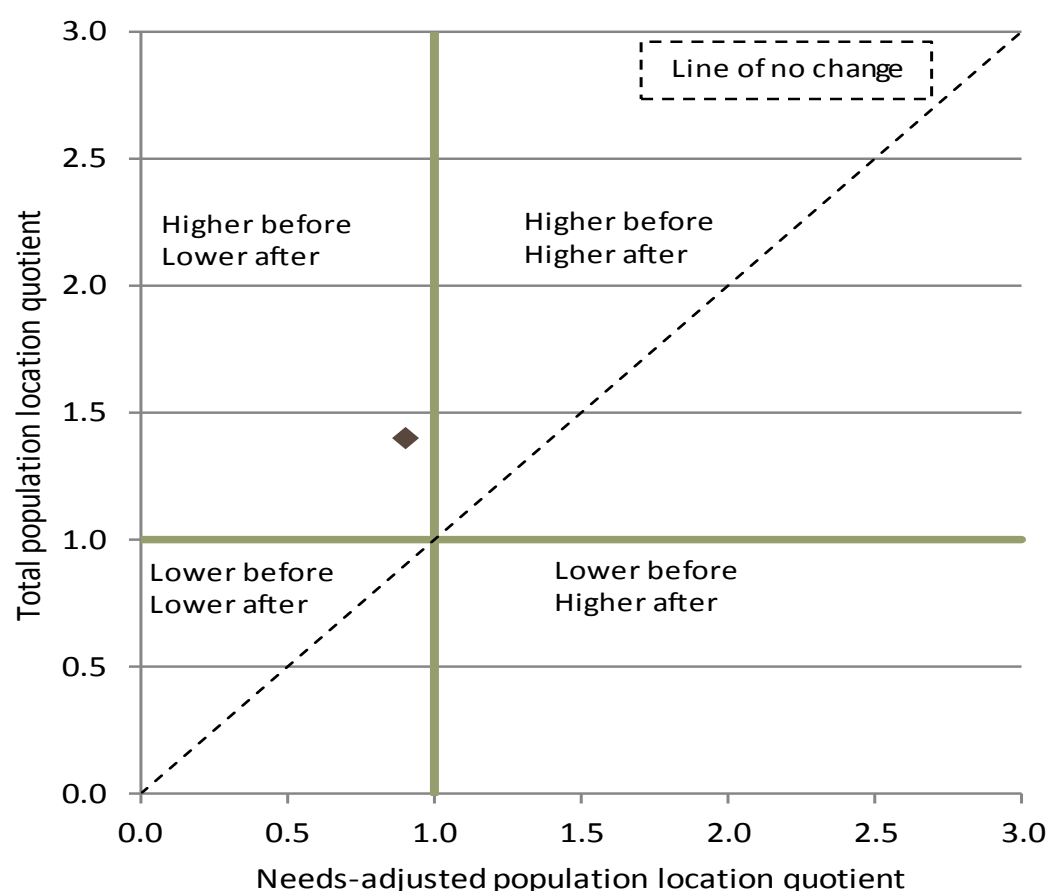


TABLE 3.3 NEED ADJUSTMENTS BY TYPE OF SUPPLY

\begin{tabular}{|c|c|c|c|c|c|c|c|}
\hline \multirow[t]{2}{*}{ Supply variable } & \multirow{2}{*}{$\begin{array}{c}\text { Baseline } \\
\text { population }\end{array}$} & \multicolumn{6}{|c|}{ Adjusted populations } \\
\hline & & Age $65+$ years & Age $85+$ years & Mortality & Disability & Enabling & $\begin{array}{l}\text { Enabling and } \\
\text { morbidity }\end{array}$ \\
\hline GP & $\begin{array}{l}\text { GPs per } 10,000 \\
\text { total population }\end{array}$ & $\begin{array}{l}\text { GPs per } 10,000 \\
\text { population }\end{array}$ & $\begin{array}{l}\text { GPs per } 10,000 \\
\text { population }\end{array}$ & $\begin{array}{l}\text { GPs per } 10,000 \\
\text { mortality adjusted } \\
\text { population }\end{array}$ & $\begin{array}{l}\text { GPs per } 10,000 \\
\text { population with } \\
\text { disability }\end{array}$ & $\begin{array}{l}\text { GPs per } 10,000 \\
\text { population with } \\
\text { Medical Card or GP } \\
\text { Visit Card }\end{array}$ & $\begin{array}{l}\text { GPs per } 10,000 \\
\text { population with } \\
\text { Medical Card and } \\
\text { prescription for } \\
\text { chronic condition }\end{array}$ \\
\hline $\begin{array}{l}\text { Community } \\
\text { nursing }\end{array}$ & $\begin{array}{l}\text { Nurses per } \\
10,000 \text { total } \\
\text { population }\end{array}$ & $\begin{array}{l}\text { Nurses per } 10,000 \\
\text { population }\end{array}$ & $\begin{array}{l}\text { Nurses per } \\
10,000 \\
\text { population }\end{array}$ & $\begin{array}{l}\text { Nurses per } 10,000 \\
\text { mortality adjusted } \\
\text { population }\end{array}$ & $\begin{array}{l}\text { Nurses per } \\
10,000 \\
\text { population with } \\
\text { disability }\end{array}$ & $\begin{array}{l}\text { Nurses per } 10,000 \\
\text { population with } \\
\text { Medical Card }\end{array}$ & $\begin{array}{l}\text { Nurses per } 10,000 \\
\text { population with } \\
\text { Medical Card and } \\
\text { prescription for } \\
\text { chronic condition }\end{array}$ \\
\hline $\begin{array}{l}\text { Allied health } \\
\text { professionals }\end{array}$ & $\begin{array}{l}\text { Professionals } \\
\text { per } 10,000 \text { total } \\
\text { population }\end{array}$ & $\begin{array}{l}\text { Professionals per } \\
10,000 \text { population }\end{array}$ & $\begin{array}{l}\text { Professionals } \\
\text { per } 10,000 \\
\text { population }\end{array}$ & $\begin{array}{l}\text { Professionals per } \\
10,000 \text { mortality } \\
\text { adjusted } \\
\text { population }\end{array}$ & $\begin{array}{l}\text { Professionals } \\
\text { per } 10,000 \\
\text { population with } \\
\text { disability }\end{array}$ & $\begin{array}{l}\text { Professionals per } \\
10,000 \text { population } \\
\text { with Medical Card }\end{array}$ & $\begin{array}{l}\text { Professionals per } \\
10,000 \text { population } \\
\text { with Medical Card } \\
\text { and prescription for } \\
\text { chronic condition }\end{array}$ \\
\hline $\begin{array}{l}\text { Long-term } \\
\text { residential care } \\
\text { beds }\end{array}$ & $\begin{array}{l}\text { Beds per } 1,000 \\
\text { population aged } \\
65+\end{array}$ & As per baseline & $\begin{array}{l}\text { Beds per } 1,000 \\
\text { population }\end{array}$ & $\begin{array}{l}\text { Beds per } 1,000 \\
\text { mortality adjusted } \\
\text { population }\end{array}$ & $\begin{array}{l}\text { Beds per } 1,000 \\
\text { population with } \\
\text { disability }\end{array}$ & No adjustment & No adjustment \\
\hline Home care & $\begin{array}{l}\text { Hours per } \\
\text { person aged } 65+\end{array}$ & As per baseline & $\begin{array}{l}\text { Hours per } \\
\text { person aged } \\
85+\end{array}$ & $\begin{array}{l}\text { Hours per } \\
\text { mortality adjusted } \\
\text { population }\end{array}$ & $\begin{array}{l}\text { Hours per } \\
\text { person with } \\
\text { disability }\end{array}$ & No adjustment & No adjustment \\
\hline
\end{tabular}




\section{Findings}

\subsection{INTRODUCTION}

This chapter presents findings on the geographic distribution of the main nonacute health and social care services in Ireland in 2014. As outlined in Chapters 2 and 3 , the geographic distribution of supply is assessed in relation to the distribution of needs for those services, and supply in each geographic area is assessed against national average supply. This chapter is laid out as follows.

Section 4.2 presents an overview of the geographic profile of a selection of healthcare need indicators and the number of Medical Card holders (and general practitioner (GP) Visit Card holders) in Ireland in 2014. Section 4.3 presents the geographic profile of primary care services. The geographic profile of additional non-acute services in the wider community network is presented in Section 4.4. Long-term residential and home care supply are presented in Section 4.5. Section 4.6 details a comparison of inequalities across services.

Throughout the report, bar charts and maps are colour coded into two sub-groups relative to the national value. For example, in Figure 4.1, blue refers to areas with values that are higher than the national value and green refers to areas with values that are lower than the national value. These colour codes are only intended as a general summary indicator and it is important to look at the wider variation in the underlying geographic patterns.

\subsection{PROFILE OF HEALTHCARE NEED BY GEOGRAPHIC AREA}

The geographic patterns of non-acute supply are adjusted for geographic variations in a number of indicators. As outlined in Chapter 3, these indicators have been selected in line with Andersen's Behavioural Model of Health Services Use and capture characteristics including predisposing factors (e.g. age 65+ and 85+), need (e.g. mortality, disability, morbidity) and enabling factors (e.g. Medical Card and GP Visit Card coverage). For ease of presentation these are collectively referred to as 'needs' indicators. This section presents the geographic profiles of each of these indicators so as to understand better the patterns of needs-adjusted supply.

\subsubsection{Geographic profile of population age groups (65+ and $85+)$}

Table 4.1 and Figure 4.1 present the geographic profile of the estimated number and proportion of the population aged 65 years and older in Ireland in 2014. Table 4.2 and Figure 4.2 present the geographic profile of the estimated number and 
proportion of the population aged 85+ and older in Ireland in 2014. In Tables 4.1 and 4.2 and Figures 4.1 and 4.2 , areas are ranked by the proportion of population aged $65+/ 85+$ from lowest to highest.

\section{Geographic profile of population aged 65+}

Overall, 12.8 per cent of the population in Ireland in 2014 were aged 65+, ranging from 9.0 per cent in Kildare to 16.5 per cent in Mayo.

- The areas with the lowest proportions aged 65+ include Kildare, Meath, Laois and Dublin North. In these areas, the proportion of the population aged $65+$ is lower than the national value by between 12-29 per cent. For example, 9.0 per cent of the population in Kildare are aged $65+$, and this is 29 per cent lower than the national value (i.e. ratio of area value to national value is 0.71 ; see Table 4.1 ).

- The areas with the highest proportions of those aged 65+ include Mayo, Leitrim, Roscommon, Kerry, Sligo, Donegal, Tipperary South, Tipperary North and Waterford. The ratio of the area value to the national value ranges from 1.29 down to 1.12 .

\section{Geographic profile of population aged $85+$}

Overall, 1.4 per cent of the population in Ireland in 2014 were aged 85+, ranging from 0.8 per cent in Kildare to 2.2 per cent in Roscommon (see Table 4.2).

There is greater variation in the geographic distribution of the population aged $85+$ (ranging from 0.58 to 1.61 relative to the national value) than for the population aged $65+$ (ranging from 0.71 to 1.29 relative to the national value). In four areas the proportion of the population aged $85+$ is higher than the national value by more than 50 per cent: Roscommon, Leitrim, Mayo and Sligo. 
TABLE 4.1 ESTIMATED NUMBER AND PERCENTAGE OF POPULATION AGED 65+ YEARS BY GEOGRAPHIC AREA, IRELAND 2014

\begin{tabular}{|c|c|c|c|c|}
\hline Geographic area & Population & $\begin{array}{c}\text { Population aged } \\
65+\text { years }\end{array}$ & Percentage & $\begin{array}{c}\text { Ratio of area } \\
\text { percentage to } \\
\text { national } \\
\text { percentage }\end{array}$ \\
\hline Kildare & 219,570 & 19,814 & 9.0 & 0.71 \\
\hline Meath & 191,931 & 18,900 & 9.8 & 0.77 \\
\hline Laois & 80,166 & 8,951 & 11.2 & 0.88 \\
\hline Dublin North & 594,002 & 66,781 & 11.2 & 0.88 \\
\hline Louth & 123,082 & 14,907 & 12.1 & 0.95 \\
\hline Dublin South & 704,937 & 85,457 & 12.1 & 0.95 \\
\hline Westmeath & 86,854 & 10,623 & 12.2 & 0.96 \\
\hline Wicklow & 138,421 & 17,015 & 12.3 & 0.96 \\
\hline Carlow & 53,957 & 6,794 & 12.6 & 0.99 \\
\hline Galway & 254,959 & 32,231 & 12.6 & 0.99 \\
\hline Offaly & 75,561 & 9,817 & 13.0 & 1.02 \\
\hline Cork & 524,199 & 68,704 & 13.1 & 1.03 \\
\hline Cavan & 72,750 & 9,639 & 13.2 & 1.04 \\
\hline Limerick & 192,681 & 25,591 & 13.3 & 1.04 \\
\hline Kilkenny & 96,050 & 12,931 & 13.5 & 1.06 \\
\hline Monaghan & 59,822 & 8,161 & 13.6 & 1.07 \\
\hline Clare & 119,027 & 16,379 & 13.8 & 1.08 \\
\hline Wexford & 144,373 & 20,311 & 14.1 & 1.10 \\
\hline Longford & 37,559 & 5,288 & 14.1 & 1.10 \\
\hline Waterford & 113,792 & 16,291 & 14.3 & 1.12 \\
\hline Tipperary North & 69,861 & 10,200 & 14.6 & 1.14 \\
\hline Tipperary South & 87,672 & 12,916 & 14.7 & 1.15 \\
\hline Donegal & 159,358 & 23,728 & 14.9 & 1.17 \\
\hline Sligo & 65,104 & 9,916 & 15.2 & 1.19 \\
\hline Kerry & 144,259 & 23,135 & 16.0 & 1.26 \\
\hline Roscommon & 63,296 & 10,281 & 16.2 & 1.27 \\
\hline Leitrim & 30,925 & 5,043 & 16.3 & 1.28 \\
\hline Mayo & 129,395 & 21,330 & 16.5 & 1.29 \\
\hline Ireland & $4,633,563$ & 591,134 & 12.8 & 1.00 \\
\hline
\end{tabular}

Source: $\quad$ SRI population estimates 2014. 
FIGURE 4.1 ESTIMATED PERCENTAGE OF POPULATION AGED 65+ YEARS BY GEOGRAPHIC AREA, IRELAND 2014

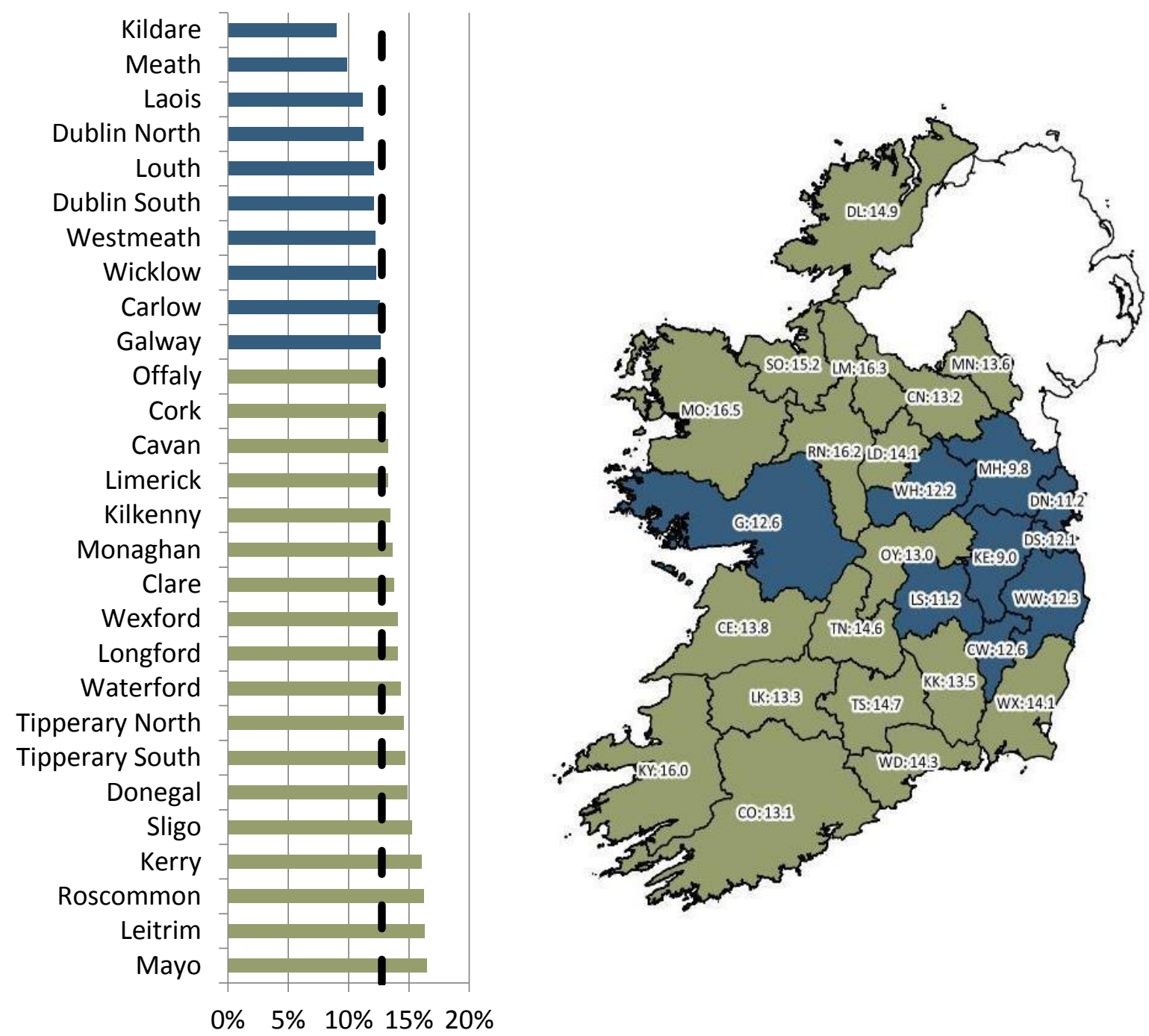


TABLE 4.2 ESTIMATED NUMBER AND PERCENTAGE OF POPULATION AGED 85+ YEARS BY GEOGRAPHIC AREA, IRELAND 2014

\begin{tabular}{|c|c|c|c|c|}
\hline Geographic area & Population & $\begin{array}{c}\text { Population aged } \\
85+\text { years }\end{array}$ & Percentage & $\begin{array}{l}\text { Ratio of area per } \\
\text { cent to national } \\
\text { percentage }\end{array}$ \\
\hline Kildare & 219,570 & 1,777 & 0.8 & 0.58 \\
\hline Meath & 191,931 & 1,752 & 0.9 & 0.66 \\
\hline Wicklow & 138,421 & 1,559 & 1.1 & 0.81 \\
\hline Dublin North & 594,002 & 6,814 & 1.1 & 0.82 \\
\hline Laois & 80,166 & 980 & 1.2 & 0.88 \\
\hline Carlow & 53,957 & 667 & 1.2 & 0.89 \\
\hline Limerick & 192,681 & 2,453 & 1.3 & 0.91 \\
\hline Louth & 123,082 & 1,574 & 1.3 & 0.92 \\
\hline Wexford & 144,373 & 1,859 & 1.3 & 0.93 \\
\hline Dublin South & 704,937 & 9,582 & 1.4 & 0.98 \\
\hline Cork & 524,199 & 7,344 & 1.4 & 1.01 \\
\hline Westmeath & 86,854 & 1,231 & 1.4 & 1.02 \\
\hline Longford & 37,559 & 538 & 1.4 & 1.03 \\
\hline Offaly & 75,561 & 1,096 & 1.5 & 1.04 \\
\hline Waterford & 113,792 & 1,661 & 1.5 & 1.05 \\
\hline Clare & 119,027 & 1,767 & 1.5 & 1.07 \\
\hline Galway & 254,959 & 3,909 & 1.5 & 1.10 \\
\hline Kilkenny & 96,050 & 1,513 & 1.6 & 1.13 \\
\hline Monaghan & 59,822 & 965 & 1.6 & 1.16 \\
\hline Tipperary North & 69,861 & 1,134 & 1.6 & 1.17 \\
\hline Tipperary South & 87,672 & 1,449 & 1.7 & 1.19 \\
\hline Kerry & 144,259 & 2,519 & 1.7 & 1.25 \\
\hline Cavan & 72,750 & 1,274 & 1.8 & 1.26 \\
\hline Donegal & 159,358 & 2,846 & 1.8 & 1.28 \\
\hline Sligo & 65,104 & 1,362 & 2.1 & 1.50 \\
\hline Mayo & 129,395 & 2,762 & 2.1 & 1.53 \\
\hline Leitrim & 30,925 & 661 & 2.1 & 1.54 \\
\hline Roscommon & 63,296 & 1,422 & 2.2 & 1.61 \\
\hline Ireland & $4,633,563$ & 64,470 & 1.4 & 1.00 \\
\hline
\end{tabular}

Source: $\quad$ ESRI population estimates 2014. 


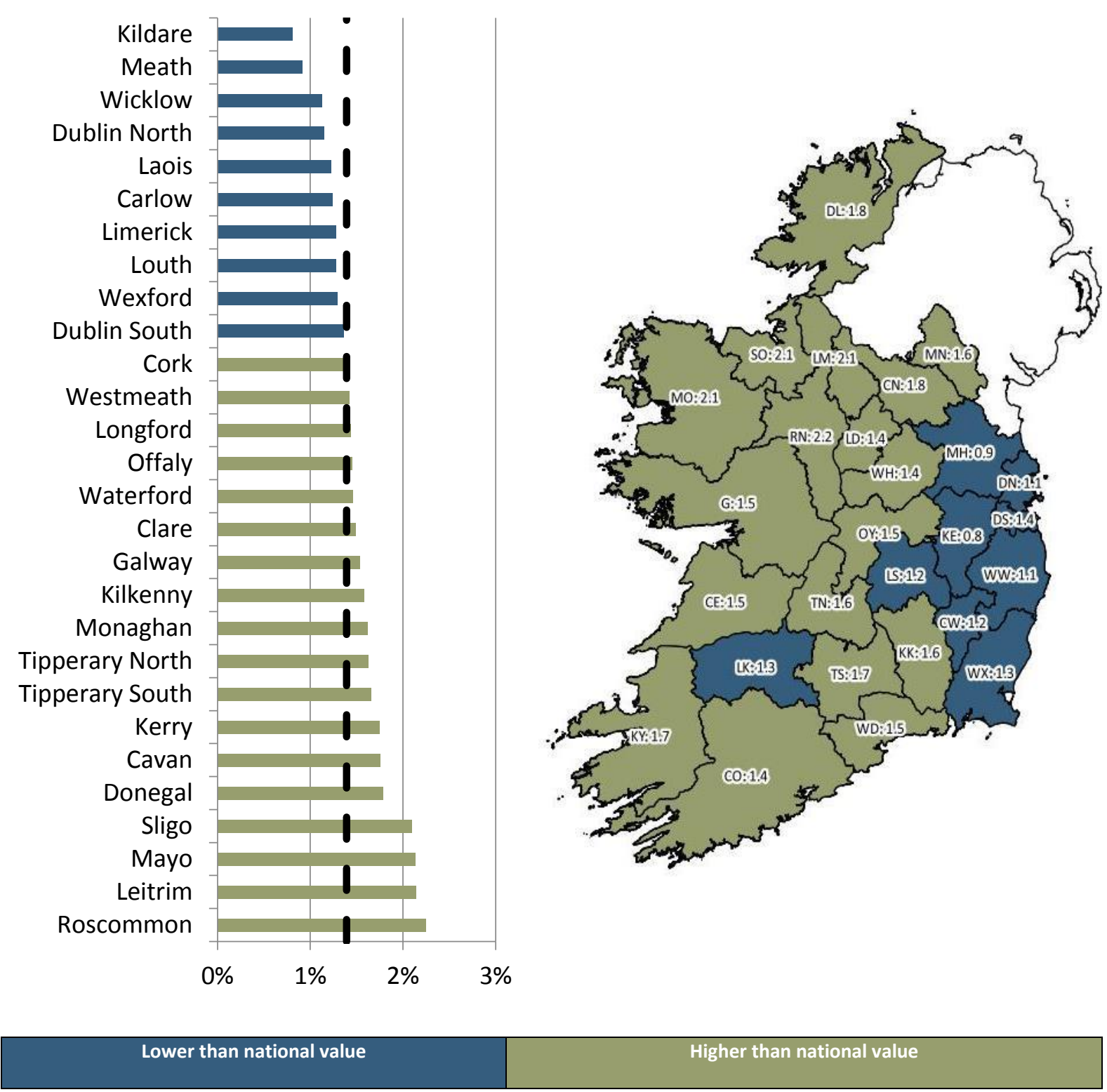

\subsubsection{Geographic profile of mortality-adjusted population}

Table 4.3 and Figure 4.3 present the geographic profile of the number of registered deaths per 1,000 population and mortality-adjusted population by geographic area in Ireland in 2014. In Table 4.3 and Figure 4.3, areas are ranked by the rate of mortality per 1,000 population from lowest to highest.

At the national level, there were 6.3 registered deaths per 1,000 population in Ireland in 2014. The mortality rate varies across the country, ranging from 4.2 deaths per 1,000 in Kildare to 8.2 deaths per 1,000 in Mayo. 
While a number of factors are important in explaining observed geographic variations in mortality rates, there is some correlation between mortality and age, particularly at the extreme ends of the distributions.

- Kildare and Meath have the lowest mortality rates in the country and the smallest proportions of people aged 65+ (Table 4.1).

- Mayo has the highest mortality rate in the country and the largest proportion of people aged $65+$.

TABLE 4.3 NUMBER OF REGISTERED DEATHS, DEATHS PER 1,000 POPULATION AND MORTALITYADJUSTED POPULATION BY GEOGRAPHIC AREA, IRELAND 2014

\begin{tabular}{|c|c|c|c|c|c|}
\hline Geographic area & $\begin{array}{l}\text { Number of } \\
\text { registered } \\
\text { deaths }\end{array}$ & Population & $\begin{array}{c}\text { Deaths per } \\
1,000 \\
\text { population }\end{array}$ & $\begin{array}{c}\text { Ratio of area } \\
\text { value to } \\
\text { national value }\end{array}$ & $\begin{array}{c}\text { Mortality- } \\
\text { adjusted } \\
\text { population }^{a}\end{array}$ \\
\hline Kildare & 926 & 219,570 & 4.2 & 0.67 & 147,471 \\
\hline Meath & 877 & 191,931 & 4.6 & 0.73 & 139,668 \\
\hline Laois & 436 & 80,166 & 5.4 & 0.87 & 69,436 \\
\hline Wicklow & 775 & 138,421 & 5.6 & 0.89 & 123,424 \\
\hline Kilkenny & 555 & 96,050 & 5.8 & 0.92 & 88,387 \\
\hline Dublin & 7,612 & $1,298,939$ & 5.9 & 0.93 & $1,212,259$ \\
\hline Dublin North & & 594,002 & 5.9 & 0.93 & 554,363 \\
\hline Dublin South & & 704,937 & 5.9 & 0.93 & 657,896 \\
\hline Offaly & 444 & 75,561 & 5.9 & 0.94 & 70,710 \\
\hline Louth & 724 & 123,082 & 5.9 & 0.94 & 115,302 \\
\hline Galway & 1,502 & 254,959 & 5.9 & 0.94 & 239,203 \\
\hline Cork & 3,378 & 524,199 & 6.4 & 1.03 & 537,968 \\
\hline Clare & 797 & 119,027 & 6.7 & 1.07 & 126,927 \\
\hline Carlow & 363 & 53,957 & 6.7 & 1.07 & 57,810 \\
\hline Longford & 255 & 37,559 & 6.8 & 1.08 & 40,610 \\
\hline Donegal & 1,083 & 159,358 & 6.8 & 1.08 & 172,475 \\
\hline Wexford & 994 & 144,373 & 6.9 & 1.1 & 158,301 \\
\hline Cavan & 502 & 72,750 & 6.9 & 1.1 & 79,947 \\
\hline Westmeath & 600 & 86,854 & 6.9 & 1.1 & 95,554 \\
\hline Tipperary South & 623 & 87,672 & 7.1 & 1.13 & 99,217 \\
\hline Monaghan & 430 & 59,822 & 7.2 & 1.14 & 68,480 \\
\hline Waterford & 824 & 113,792 & 7.2 & 1.15 & 131,227 \\
\hline Limerick & 1,401 & 192,681 & 7.3 & 1.16 & 223,118 \\
\hline Sligo & 488 & 65,104 & 7.5 & 1.19 & 77,717 \\
\hline Roscommon & 490 & 63,296 & 7.7 & 1.23 & 78,036 \\
\hline Leitrim & 240 & 30,925 & 7.8 & 1.24 & 38,222 \\
\hline Kerry & 1,151 & 144,259 & 8 & 1.27 & 183,304 \\
\hline Tipperary North & 560 & 69,861 & 8 & 1.28 & 89,184 \\
\hline Mayo & 1,065 & 129,395 & 8.2 & 1.31 & 169,608 \\
\hline Ireland & 29,095 & $4,633,563$ & 6.3 & 1 & $4,633,563$ \\
\hline
\end{tabular}

Source: ESRI population estimates 2014. 


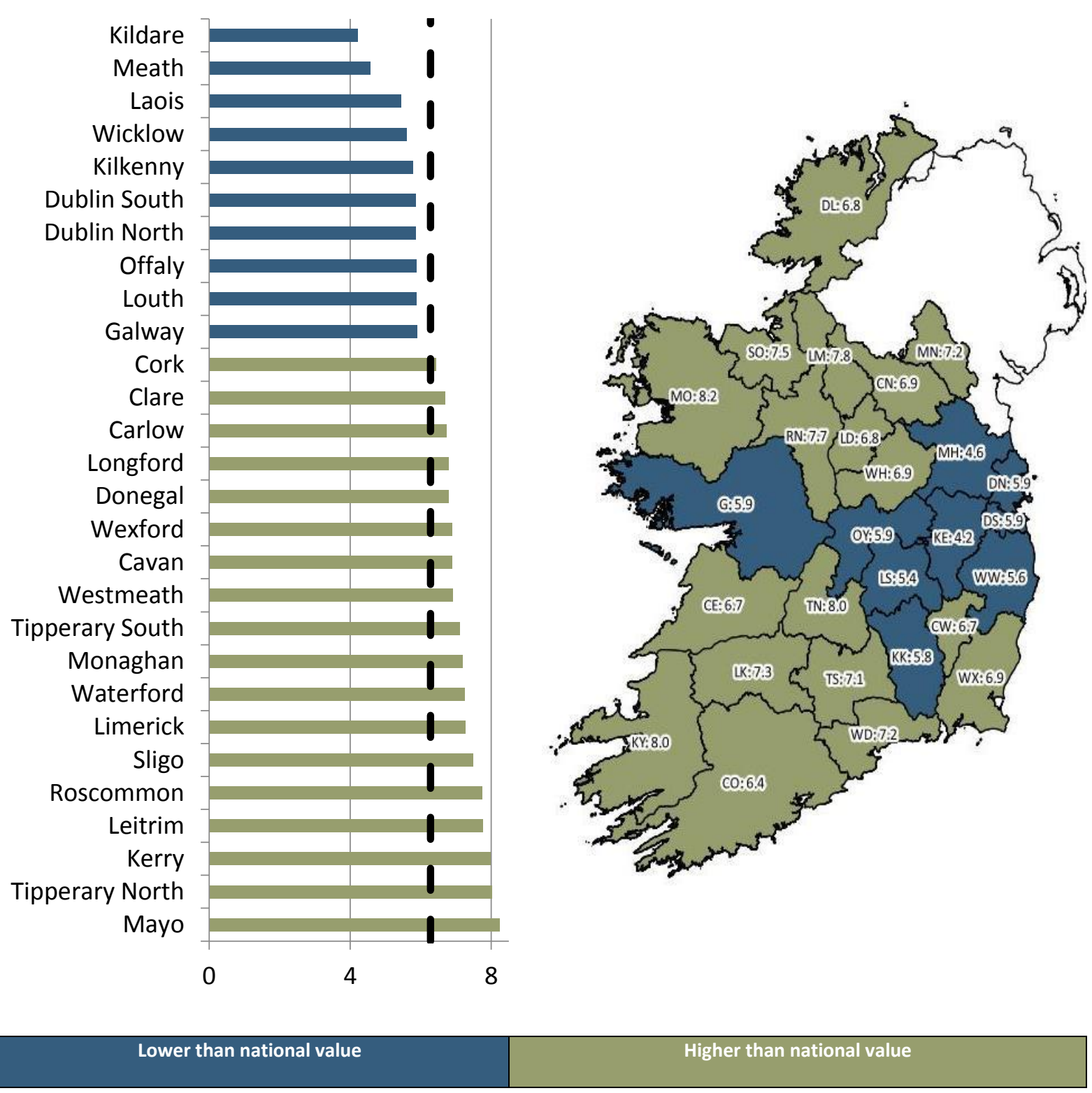

\subsubsection{Geographic profile of population with disability}

Table 4.4 and Figure 4.4 present the geographic profile of the estimated number and proportion of the population with disability in Ireland in 2014. Disability is based on a self-report measure taken from questions included in Census 2011 (see Table 3.2 and Appendix 1). In Table 4.4 and Figure 4.4, areas are ranked by the proportion of population with disability from lowest to highest.

Overall, 13 per cent of the population report the presence of a disability (as defined in Chapter 3), ranging from 10.7 per cent in Meath to 14.7 per cent in Tipperary South. There is some correlation with age in areas at the lower end of the distribution (i.e. lowest levels of disability): 
- The lowest levels of disability are observed in Meath and Kildare and these areas also have the lowest proportions of population aged $65+$.

Compared with the mortality and age indicators used in this analysis, the variation in disability rates across areas is low. The proportion of the population with disability is close to (within 5 per cent) or equal to the national value in a large number of areas.

TABLE 4.4 ESTIMATED PER CENT AND NUMBER OF POPULATION WITH DISABILITY BY GEOGRAPHIC AREA, IRELAND 2014

\begin{tabular}{|c|c|c|c|c|}
\hline Geographic area & Population 2014 & $\begin{array}{l}\text { Percentage of } \\
\text { population with } \\
\text { disability } \\
2011\end{array}$ & $\begin{array}{c}\text { Estimated number } \\
\text { of population with } \\
\text { disability } \\
2014\end{array}$ & $\begin{array}{l}\text { Ratio of area } \\
\text { percentage to } \\
\text { national } \\
\text { percentage }\end{array}$ \\
\hline Meath & 191,931 & 10.7 & 20,502 & 0.82 \\
\hline Kildare & 219,570 & 11.6 & 25,442 & 0.89 \\
\hline Monaghan & 59,822 & 11.9 & 7,105 & 0.91 \\
\hline Cavan & 72,750 & 11.9 & 8,662 & 0.92 \\
\hline Galway & 254,959 & 12.0 & 30,697 & 0.93 \\
\hline Kilkenny & 96,050 & 12.5 & 12,018 & 0.96 \\
\hline Clare & 119,027 & 12.6 & 15,006 & 0.97 \\
\hline Laois & 80,166 & 12.7 & 10,167 & 0.98 \\
\hline Wicklow & 138,421 & 12.9 & 17,846 & 0.99 \\
\hline Louth & 123,082 & 13.0 & 15,956 & 1 \\
\hline Dublin North & 594,002 & 13.0 & 77,220 & 1 \\
\hline Dublin South & 704,937 & 13.0 & 91,642 & 1 \\
\hline Westmeath & 86,854 & 13.1 & 11,394 & 1.01 \\
\hline Cork & 524,199 & 13.2 & 68,959 & 1.01 \\
\hline Kerry & 144,259 & 13.2 & 19,004 & 1.01 \\
\hline Offaly & 75,561 & 13.4 & 10,102 & 1.03 \\
\hline Leitrim & 30,925 & 13.5 & 4,171 & 1.04 \\
\hline Mayo & 129,395 & 13.6 & 17,541 & 1.04 \\
\hline Roscommon & 63,296 & 13.7 & 8,654 & 1.05 \\
\hline Carlow & 53,957 & 13.7 & 7,392 & 1.05 \\
\hline Waterford & 113,792 & 13.7 & 15,625 & 1.06 \\
\hline Tipperary North & 69,861 & 13.7 & 9,596 & 1.06 \\
\hline Wexford & 144,373 & 13.9 & 20,003 & 1.07 \\
\hline Longford & 37,559 & 13.9 & 5,204 & 1.07 \\
\hline Donegal & 159,358 & 14.1 & 22,396 & 1.08 \\
\hline Sligo & 65,104 & 14.1 & 9,207 & 1.09 \\
\hline Limerick & 192,681 & 14.2 & 27,448 & 1.1 \\
\hline Tipperary South & 87,672 & 14.7 & 12,889 & 1.13 \\
\hline Ireland & $4,633,563$ & 13.0 & 601,849 & 1 \\
\hline
\end{tabular}

Source: $\quad$ ESRI population estimates 2014. Disability percentages are from Census 2011. 
FIGURE 4.4 ESTIMATED PERCENTAGE OF POPULATION WITH DISABILITY BY GEOGRAPHIC AREA, IRELAND 2011

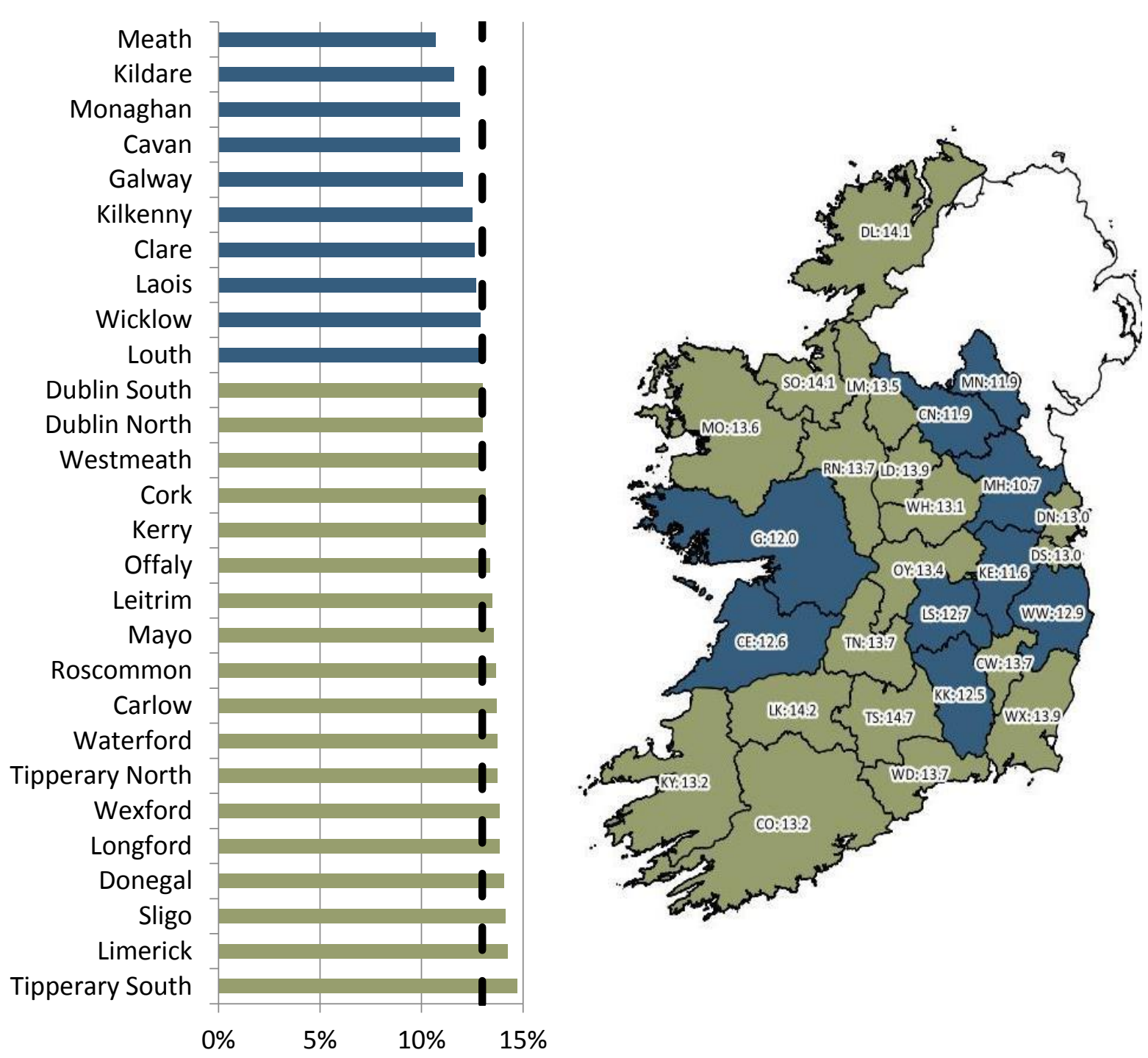

\subsubsection{Geographic profile of Medical Card and GP Visit Card Holders}

The Medical Card (and GP Visit Card) is a key enabling factor for receiving publicly funded healthcare in the Irish system. Medical Card (and GP Visit Card) status is often also used as an indicator of lower socioeconomic status (Coughlan et al., 2013) because of the fact that eligibility is largely determined on the basis of an income-based means test. Moreover, given the well-established link between lower socioeconomic status and poorer health (CSO, 2010, 2012; Marmot, 2010; Layte et al., 2015), Medical Card (and GP Visit Card) status can indicate healthcare need. In addition, the fact that a number of Medical Cards and GP Visit Cards are allocated on a discretionary basis to people whose healthcare needs would cause 
them undue financial hardship (see Chapter 1) strengthens the link between Medical Card/GP Visit Card status and healthcare need.

Table 4.5 and Figure 4.5 illustrate the geographic distribution of the number and percentage of the population with a Medical Card or GP Visit Card in Ireland in 2014. In Table 4.5 and Figure 4.5, areas are ranked by the percentage of population with a Medical Card or a GP Visit Card from highest to lowest.

At December 2014, 38.2 per cent of the population held a Medical Card and a further 3.4 per cent of the population held a GP Visit Card..$^{42}$ The distribution of Medical/GP Visit Card coverage is uneven across the country, ranging from 32.1 per cent of the population in Dublin South to 57 per cent in Donegal. Relative to the national value, Dublin South and Dublin North and the surrounding commuter belt areas of Kildare and Meath have low levels of Medical Card/GP Visit Card coverage (32.1-36.4 per cent). ${ }^{43}$

There is greater variation in the geographic distribution of Medical Card coverage (ranging from 0.77 to 1.39 relative to the national value) than for GP Visit Card coverage (ranging from 0.81 to 1.26 relative to the national value).

As expected, there is some consistency in the geographic distribution of other need indicators with that of Medical Card coverage. In particular, the proportion of the population over the age of 85 is lower than the national value in Meath and Kildare (commuter belt areas around Dublin), consistent with a lower level of Medical Card coverage. These areas also have low levels of disability relative to the national value, consistent with a lower level of Medical Card coverage.

42 The data for Medical Cards and GP Visit Cards are from end December 2014 and so do not include GP Visit Cards that are now available to all children aged 0-5 years (introduced in July 2015) and adults aged 70+ years (introduced in August 2015). See Chapter 1 for eligibility criteria for Medical Cards and GP Visit Cards.

43 Wicklow also had low levels of Medical Card/GP Visit Card coverage relative to the national value, with a location quotient of 0.96 . However, throughout the text a conservative approach is adopted whereby location quotients in the range $0.95-1.05$ are considered to be near the national average and the main focus is on areas with location quotients that fall outside that range. 


\begin{tabular}{|c|c|c|c|c|c|c|c|c|c|c|}
\hline \multirow[b]{2}{*}{$\begin{array}{c}\text { Geographic } \\
\text { area }\end{array}$} & \multirow[b]{2}{*}{$\begin{array}{c}\text { Total } \\
\text { population }\end{array}$} & \multicolumn{3}{|c|}{ Medical Card } & \multicolumn{3}{|c|}{ GP Visit Card } & \multicolumn{3}{|c|}{ Medical Card and GP Visit Card } \\
\hline & & Number & Percentage & $\begin{array}{c}\text { Ratio of area } \\
\text { percentage to } \\
\text { national percentage }\end{array}$ & Number & Percentage & $\begin{array}{c}\text { Ratio of area } \\
\text { percentage to } \\
\text { national percentage }\end{array}$ & Number & Percentage & $\begin{array}{c}\text { Ratio of area } \\
\text { percentage to } \\
\text { national percentage }\end{array}$ \\
\hline Donegal & 159,358 & 84,899 & 53.3 & 1.39 & 5,896 & 3.7 & 1.09 & 90,794 & 57.0 & 1.37 \\
\hline Louth & 123,082 & 59,888 & 48.7 & 1.27 & 4,741 & 3.9 & 1.13 & 64,629 & 52.5 & 1.26 \\
\hline Mayo & 129,395 & 62,712 & 48.5 & 1.27 & 4,567 & 3.5 & 1.04 & 67,279 & 52.0 & 1.25 \\
\hline Wexford & 144,373 & 68,952 & 47.8 & 1.25 & 5,798 & 4.0 & 1.18 & 74,750 & 51.8 & 1.24 \\
\hline Longford & 37,559 & 17,496 & 46.6 & 1.22 & 1,538 & 4.1 & 1.2 & 19,034 & 50.7 & 1.22 \\
\hline Carlow & 53,957 & 24,466 & 45.3 & 1.19 & 2,313 & 4.3 & 1.26 & 26,779 & 49.6 & 1.19 \\
\hline Leitrim & 30,925 & 14,051 & 45.4 & 1.19 & 1,248 & 4.0 & 1.18 & 15,299 & 49.5 & 1.19 \\
\hline Roscommon & 63,296 & 28,698 & 45.3 & 1.19 & 2,188 & 3.5 & 1.01 & 30,886 & 48.8 & 1.17 \\
\hline Monaghan & 59,822 & 26,655 & 44.6 & 1.17 & 2,408 & 4.0 & 1.18 & 29,063 & 48.6 & 1.17 \\
\hline Kilkenny & 96,050 & 42,648 & 44.4 & 1.16 & 3,971 & 4.1 & 1.21 & 46,619 & 48.5 & 1.17 \\
\hline Offaly & 75,561 & 33,603 & 44.5 & 1.16 & 2,943 & 3.9 & 1.14 & 36,546 & 48.4 & 1.16 \\
\hline Westmeath & 86,854 & 38,282 & 44.1 & 1.15 & 3,369 & 3.9 & 1.14 & 41,651 & 48.0 & 1.15 \\
\hline Cavan & 72,750 & 31,915 & 43.9 & 1.15 & 2,899 & 4.0 & 1.17 & 34,814 & 47.9 & 1.15 \\
\hline Clare & 119,027 & 51,518 & 43.3 & 1.13 & 4,330 & 3.6 & 1.07 & 55,848 & 46.9 & 1.13 \\
\hline Sligo & 65,104 & 28,004 & 43.0 & 1.13 & 2,513 & 3.9 & 1.13 & 30,517 & 46.9 & 1.13 \\
\hline Waterford & 113,792 & 49,075 & 43.1 & 1.13 & 4,260 & 3.7 & 1.1 & 53,335 & 46.9 & 1.13 \\
\hline Laois & 80,166 & 34,452 & 43.0 & 1.12 & 3,079 & 3.8 & 1.13 & 37,531 & 46.8 & 1.12 \\
\hline Limerick & 192,681 & 81,381 & 42.2 & 1.1 & 7,136 & 3.7 & 1.09 & 88,518 & 45.9 & 1.1 \\
\hline Kerry & 144,259 & 59,010 & 40.9 & 1.07 & 5,452 & 3.8 & 1.11 & 64,462 & 44.7 & 1.07 \\
\hline Galway & 254,959 & 98,081 & 38.5 & 1.01 & 8,835 & 3.5 & 1.02 & 106,916 & 41.9 & 1.01 \\
\hline Cork & 524,199 & 193,280 & 36.9 & 0.96 & 19,939 & 3.8 & 1.12 & 213,219 & 40.7 & 0.98 \\
\hline Tipp. South & 87,672 & 32,412 & 37.0 & 0.97 & 2,737 & 3.1 & 0.92 & 35,149 & 40.1 & 0.96 \\
\hline Tipp. North & 69,861 & 25,788 & 36.9 & 0.97 & 2,191 & 3.1 & 0.92 & 27,978 & 40.0 & 0.96 \\
\hline Wicklow & 138,421 & 50,821 & 36.7 & 0.96 & 4,531 & 3.3 & 0.96 & 55,352 & 40.0 & 0.96 \\
\hline Meath & 191,931 & 64,066 & 33.4 & 0.87 & 5,804 & 3.0 & 0.89 & 69,870 & 36.4 & 0.87 \\
\hline Dublin North & 594,002 & 195,080 & 32.8 & 0.86 & 17,489 & 2.9 & 0.86 & 212,569 & 35.8 & 0.86 \\
\hline Kildare & 219,570 & 67,382 & 30.7 & 0.8 & 6,286 & 2.9 & 0.84 & 73,668 & 33.6 & 0.81 \\
\hline Dublin South & 704,937 & 206,755 & 29.3 & 0.77 & 19,452 & 2.8 & 0.81 & 226,207 & 32.1 & 0.77 \\
\hline Ireland & $4,633,563$ & $1,771,368$ & 38.2 & 1 & 157,913 & 3.4 & 1 & $1,929,281$ & 41.6 & 1 \\
\hline
\end{tabular}

Source: Data on Medical Card holders and GP Visit Card holders are recorded by the PCRS and December 2014 data were made available for this analysis by the DOH. 


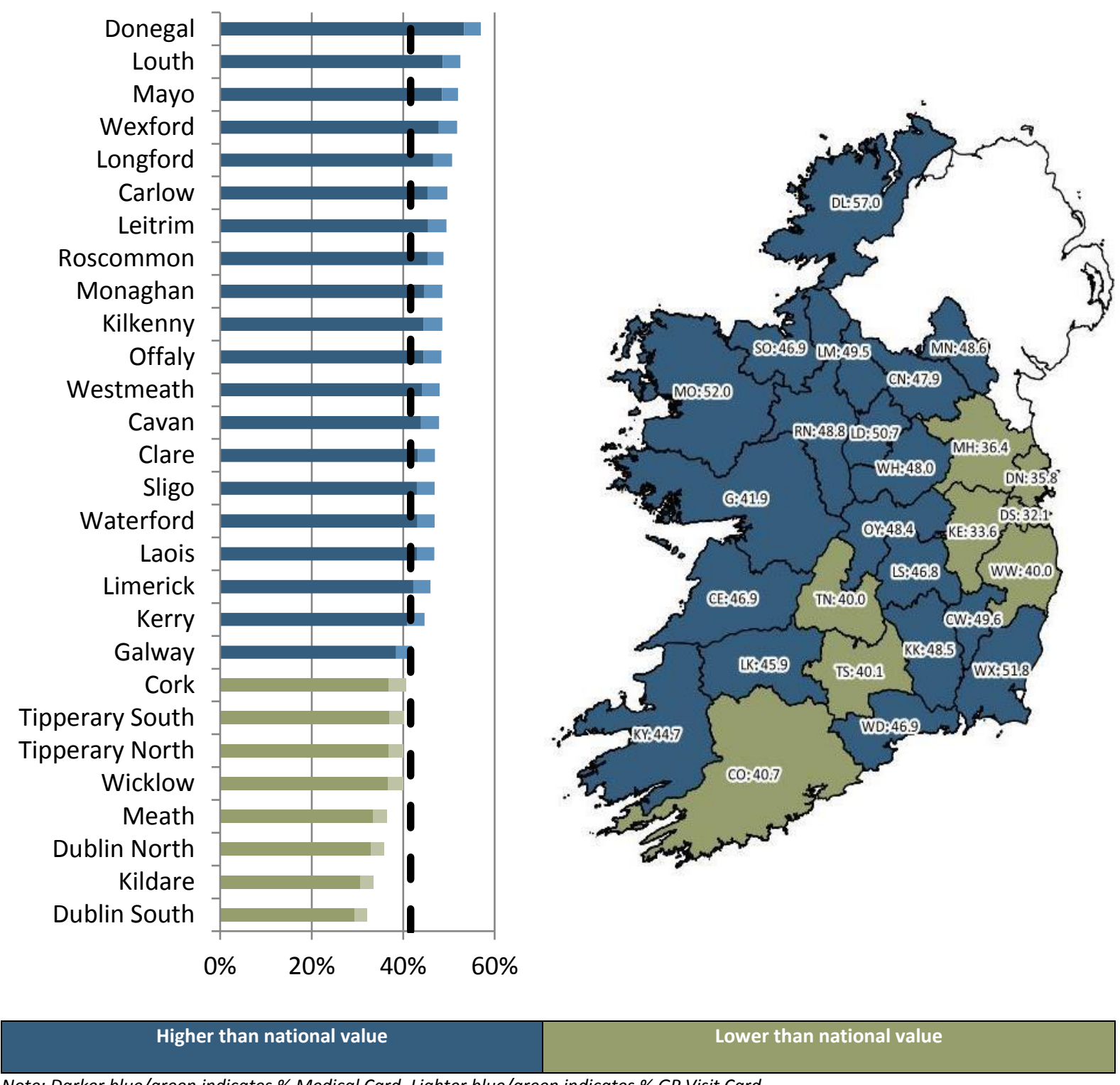

Note: Darker blue/green indicates \% Medical Card. Lighter blue/green indicates \% GP Visit Card.

\subsubsection{Geographic profile of the number of Medical Card holders with a prescription for a chronic condition}

Table 4.6 and Figure 4.6 present the geographic profile of the estimated number and percentage of the population with a Medical Card and receiving a prescription for a chronic health condition in Ireland in 2014. In Table 4.6 and Figure 4.6, areas are ranked by the percentage of population with a Medical Card who are receiving a prescription for a chronic condition from lowest to highest.

Overall, almost 50 per cent of Medical Card holders are receiving a prescription for a chronic condition (as defined in Chapter 3), ranging from 45.5 per cent in Meath 
to 53.6 per cent in Tipperary South.

The distribution of the Medical Card population with a prescription for a chronic condition is different to that for the Medical Card population. Overall, the former is more even than the latter. The percentage of the population with a Medical Card and a prescription for a chronic condition is close to (within 5 per cent) or equal to the national value in most areas. 
TABLE 4.6 ESTIMATED PERCENTAGE AND NUMBER OF POPULATION WITH A MEDICAL CARD WHO ARE RECEIVING A PRESCRIPTION FOR A CHRONIC HEALTH CONDITION BY GEOGRAPHIC AREA, IRELAND 2014

\begin{tabular}{|c|c|c|c|c|c|c|}
\hline Geographic area & $\begin{array}{l}\text { Population } \\
\text { with a } \\
\text { Medical } \\
\text { Card, } \\
\text { Dec 2014 }\end{array}$ & $\begin{array}{l}\text { Percentage of } \\
\text { population with a } \\
\text { Medical Card who are } \\
\text { receiving a prescription } \\
\text { for a chronic health } \\
\text { condition, } \\
\text { Jan-Dec } 2014\end{array}$ & $\begin{array}{c}\text { Ratio of } \\
\text { area } \\
\text { percentage } \\
\text { to national } \\
\text { percentage }\end{array}$ & $\begin{array}{l}\text { Estimated number of } \\
\text { population with a } \\
\text { Medical Card who are } \\
\text { receiving a prescription } \\
\text { for a chronic health } \\
\text { condition, } \\
\text { Dec } 2014\end{array}$ & $\begin{array}{c}\text { Total } \\
\text { population }\end{array}$ & $\begin{array}{l}\text { Percentage of } \\
\text { total } \\
\text { population } \\
\text { with a Medical } \\
\text { Card and a } \\
\text { prescription for } \\
\text { a chronic } \\
\text { health } \\
\text { condition }\end{array}$ \\
\hline Meath & 64,066 & 45.5 & 0.91 & 29,182 & 191,931 & 15.2 \\
\hline Laois & 34,452 & 45.6 & 0.91 & 15,709 & 80,166 & 19.6 \\
\hline Louth & 59,888 & 46.3 & 0.93 & 27,757 & 123,082 & 22.6 \\
\hline Donegal & 84,899 & 46.5 & 0.93 & 39,483 & 159,358 & 24.8 \\
\hline Kildare & 67,382 & 46.6 & 0.93 & 31,375 & 219,570 & 14.3 \\
\hline Westmeath & 38,282 & 47.2 & 0.94 & 18,058 & 86,854 & 20.8 \\
\hline Offaly & 33,603 & 47.6 & 0.95 & 15,996 & 75,561 & 21.2 \\
\hline Carlow & 24,466 & 48.2 & 0.96 & 11,781 & 53,957 & 21.8 \\
\hline Longford & 17,496 & 48.2 & 0.96 & 8,426 & 37,559 & 22.4 \\
\hline Cavan & 31,915 & 48.4 & 0.97 & 15,451 & 72,750 & 21.2 \\
\hline Galway & 98,081 & 48.4 & 0.97 & 47,498 & 254,959 & 18.6 \\
\hline Monaghan & 26,655 & 48.8 & 0.98 & 13,019 & 59,822 & 21.8 \\
\hline Dublin North & 195,080 & 49.0 & 0.98 & 95,533 & 594,002 & 16.1 \\
\hline Wexford & 68,952 & 49.1 & 0.98 & 33,827 & 144,373 & 23.4 \\
\hline Mayo & 62,712 & 49.4 & 0.99 & 30,975 & 129,395 & 23.9 \\
\hline Kilkenny & 42,648 & 49.4 & 0.99 & 21,087 & 96,050 & 22.0 \\
\hline Clare & 51,518 & 50.1 & 1.00 & 25,804 & 119,027 & 21.7 \\
\hline Sligo & 28,004 & 50.8 & 1.02 & 14,233 & 65,104 & 21.9 \\
\hline Leitrim & 14,051 & 50.9 & 1.02 & 7,158 & 30,925 & 23.1 \\
\hline Wicklow & 50,821 & 51.3 & 1.03 & 26,076 & 138,421 & 18.8 \\
\hline Limerick & 81,381 & 51.7 & 1.03 & 42,043 & 192,681 & 21.8 \\
\hline Waterford & 49,075 & 51.7 & 1.04 & 25,386 & 113,792 & 22.3 \\
\hline Roscommon & 28,698 & 51.8 & 1.04 & 14,860 & 63,296 & 23.5 \\
\hline Dublin South & 206,755 & 52.4 & 1.05 & 108,349 & 704,937 & 15.4 \\
\hline Kerry & 59,010 & 52.5 & 1.05 & 30,962 & 144,259 & 21.5 \\
\hline Cork & 193,280 & 52.8 & 1.06 & 102,038 & 524,199 & 19.5 \\
\hline Tipperary North & 25,788 & 53.2 & 1.07 & 13,719 & 69,861 & 19.6 \\
\hline Tipperary South & 32,412 & 53.6 & 1.07 & 17,359 & 87,672 & 19.8 \\
\hline Ireland & $1,771,368$ & 49.9 & 1.00 & 883,145 & $4,633,563$ & 19.1 \\
\hline
\end{tabular}

Source: $\quad$ The PCRS records data on Medical Card holders and prescriptions dispensed to Medical Card holders. Access to the prescription data was provided by the Department of Pharmacology and Therapeutics, Trinity Centre for Health Sciences in St James's Hospital, Dublin.

Notes: $\quad$ The table is ranked by the percentage of the Medical Card population who are receiving a prescription for a chronic health condition. However, the needs adjustment is based on the percentage of the total population who have a Medical Card and are receiving a prescription for a chronic health condition. For example, Donegal has low morbidity (46.5\%) among its Medical Card population but a high proportion of its total population has a Medical Card $(53.3 \%$, see Table 4.5). Therefore, the percentage of total population with a Medical Card and a prescription for a chronic health condition in Donegal is $53.3 \% \times 46.5 \%=24.8 \%$. 


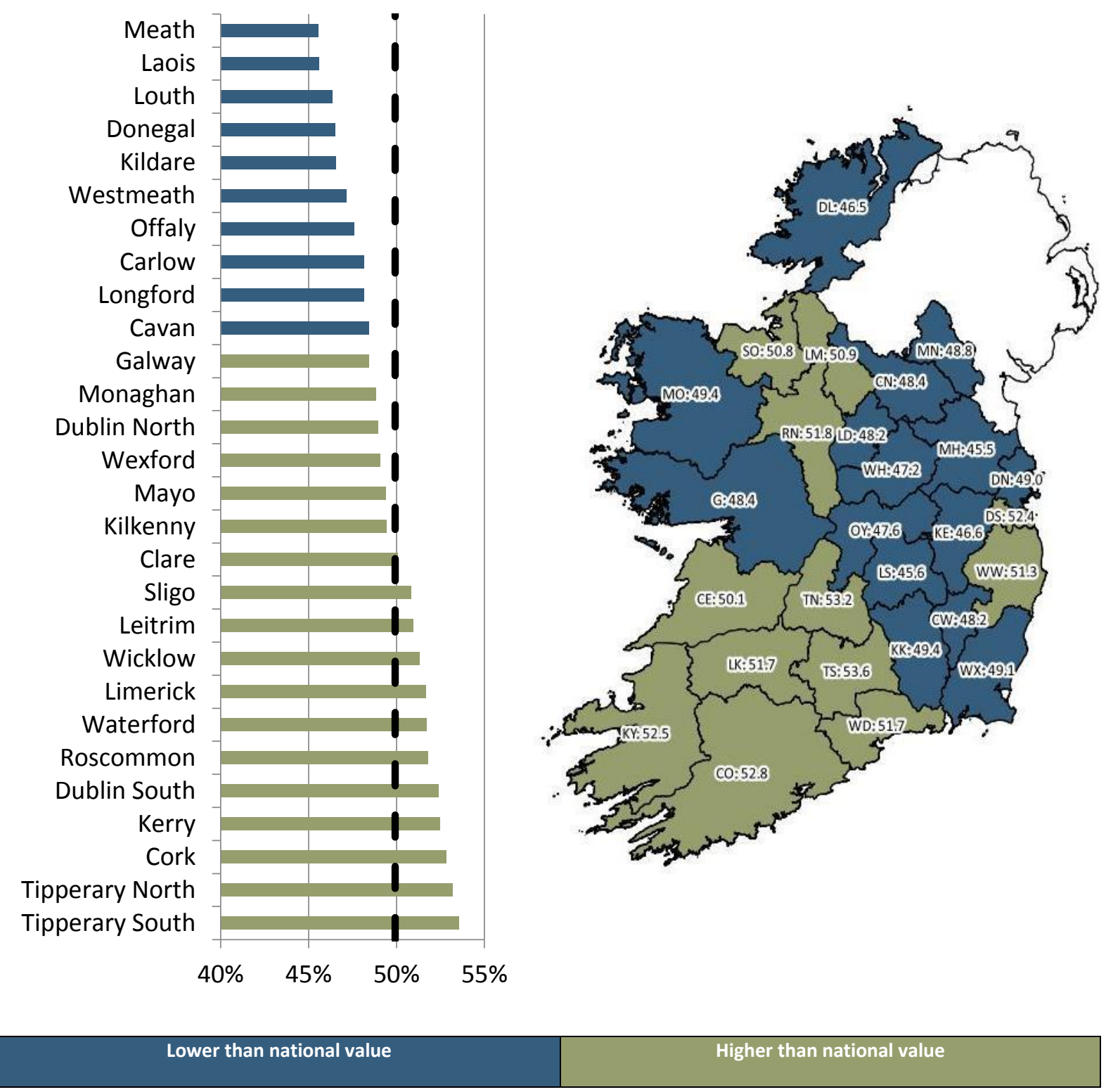

\subsubsection{Summary of need profiles}

This section has outlined the geographic variations in the distribution of older age populations, mortality rates, disability rates, Medical Card (and GP Visit Card) holders and a measure of morbidity (Medical Card plus a prescription for a chronic illness): ${ }^{44}$

- The analysis shows that there is variation in need indicators across the country and thus it is important to control for these variations when assessing supply. In Sections 4.3-4.6,

44 For ease of presentation, the need-adjustment indicator that is based on the population that have both a Medical Card and a prescription for a chronic condition is referred to as the morbidity indicator. 
the geographic profiles of non-acute healthcare services are presented with and without adjustment for each of these indicators (where relevant).

- The degree of variation across the country is different for each need indicator (e.g. the distribution of disability is relatively even across the country compared with other indicators).

- There is some collinearity across adjustment indicators (e.g. age and mortality) and interpretation of geographic profiles of supply following adjustment should be undertaken in this context.

\subsection{PROFILE OF NON-ACUTE HEALTHCARE SUPPLY BY GEOGRAPHIC AREA - PRIMARY CARE}

To link with policy objectives on how non-acute healthcare services are organised in the Irish system, the geographic profiles of these services are grouped in terms of primary care and community care. LTRC and home care are presented separately. This section presents data on the following primary care services: GPs, community nurses (CNs), publicly employed and private non-acute physiotherapists (PTs), publicly employed non-acute occupational therapists (OTs) and publicly employed non-acute speech and language therapists (SLTs).

\subsubsection{Supply of GPs}

An estimated total of 2,868 GPs (i.e. 6.2 per 10,000) were practising in Ireland in 2014. This estimate is very similar to the totals of 2,848 (Thomas et al., 2012) and 2,841 (Teljeur et al., 2014) reported in the most recently published studies of GP supply in Ireland that use comparable methods. This analysis expands on these studies by reporting data separately for Dublin postal districts as well as for counties.

Internationally, OECD data for 2014 indicate that Ireland ranks just above the middle of the distribution of OECD countries (for which data are available), with 7.8 GPs per 10,000 (see Figure 4.7). However, caution should be taken with any international comparison, and valid international comparisons are difficult due to different roles of GPs and different definitions of what each country includes in its count of GPs. For example, the estimates provided by some countries to the OECD include GPs in training but others do not. GPs in training are included in the number of GPs reported for Ireland by the OECD since 2011. The total headcount of 3,585 GPs in Ireland reported by the OECD for 2014 is thus greater than the estimate of 2,868 reported for this study, because the latter does not include GPs in 
training. ${ }^{45,46}$ Removal of the GPs in training reduces Ireland to below Sweden in

Figure 4.7, with $6.3 \mathrm{GPs}$ per 10,000 .

\section{FIGURE 4.7 NUMBER OF GPS PER 10,000 POPULATION BY OECD COUNTRY, 2014}

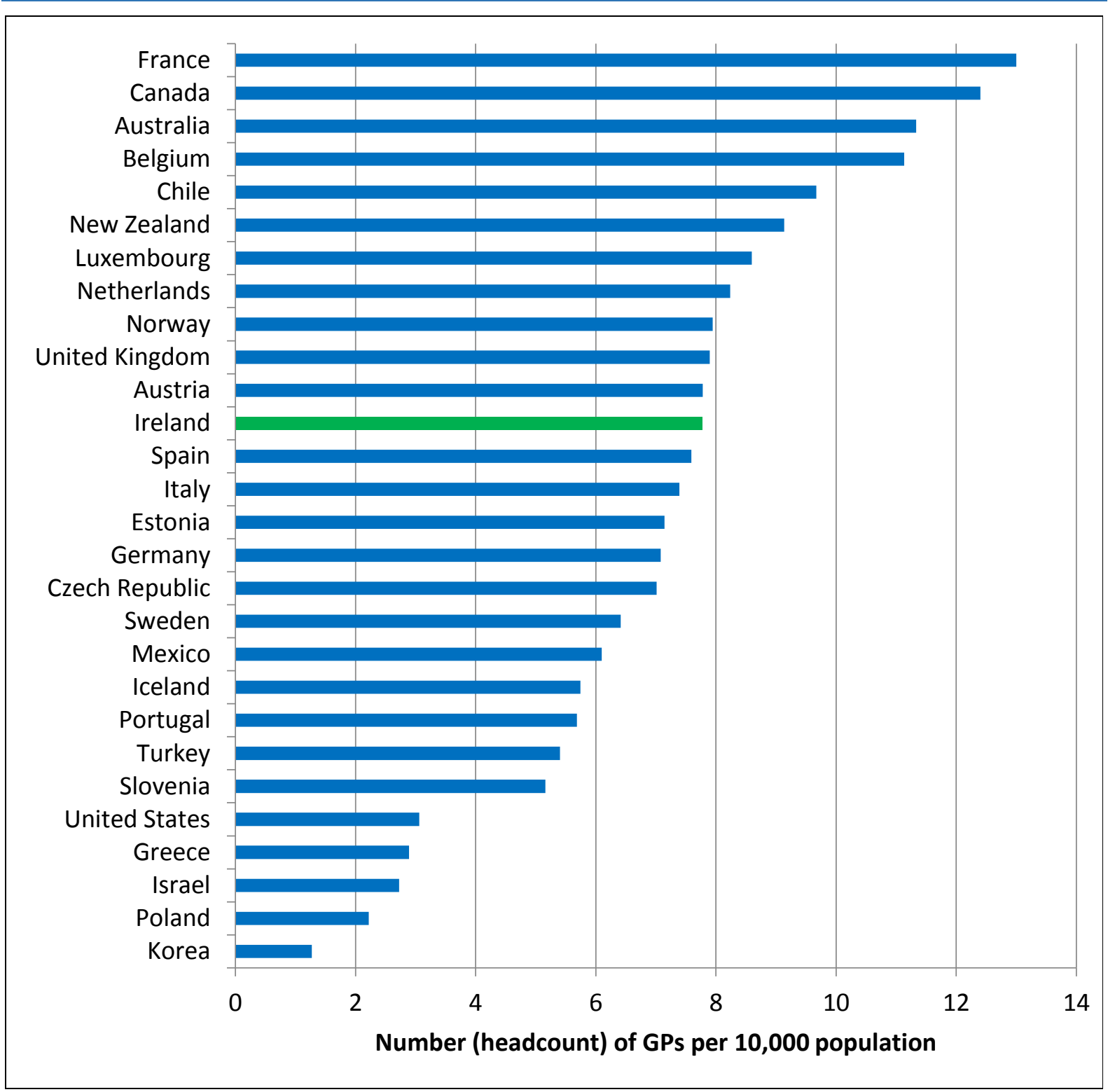

Source: OECD Health Statistics 2019 https://stats.oecd.org/

Notes: (a) Data for Ireland include GPs in training. (b) Data for Czech Republic, Luxembourg and Portugal are for the year 2013.

\section{Trends in GP supply in Ireland 2004-2014}

Table 4.7 compares the estimated number of WTE GPs per 10,000 population in Ireland in 2014 with previous analyses for the years 2004-2008 (Layte et al., 2009)

45 There were 668 GPs in training in Ireland in 2015 (Irish College of General Practitioners, 2015). As a rough guide, adding the number of GPs in training to the headcount of 2,868 gives a total of 3,536 , which is similar to the OECD GP headcount for Ireland in 2013. Further information on the location and WTE activity of GPs in training is required before they can be included in a geographic profile of GP supply in Ireland.

46 Source: OECD Health Statistics 2019 https://stats.oecd.org/ 
and 2010/11 (Teljeur et al., 2014). Caution is required in interpreting the trend over time because of differences in methodologies and in data sources. ${ }^{47}$

The estimated numbers of WTE GPs for the period 2004-2008 and in 2014 are based on the same data sources and are thus broadly comparable. Overall, the estimated number of WTE GPs showed a small increase over the period, from 5.6 per 10,000 population in 2004 to 5.7 in 2014.

Data for 2010/2011 draw on an additional dataset not used in the other years. In addition, the numbers have been adjusted upwards using a capture-recapture method to estimate the number of GPs that may not have been captured by the available datasets (see Teljeur et al., 2014). The estimated number of WTE GPs in $2010 / 2011(6.1 / 10,000)$ is higher than in 2014 and this is more likely to reflect differences in methods than a real decline in numbers from 2010/11 to 2014 .

The largest increases in the estimated number of WTE GPs per 10,000 population between 2004 and 2014 were observed in Sligo (+38 per cent) and three areas in the midlands: Offaly ( +33 per cent), Longford ( +20 per cent) and Laois $(+18$ per cent). Other areas experienced a decrease over this period including Leitrim $(-16$ per cent), Wexford (-11 per cent), Meath (-8 per cent), Wicklow (-8 per cent), Westmeath ( -7 per cent), and Kildare ( -5 per cent). Meath had the lowest estimated number of WTE GPs per 10,000 population in 2014.

Further analysis of changes in the underlying population numbers in each geographic area is required in order to identify the main drivers behind the observed changes in per capita GP supply over time.

47 To facilitate comparison of data over the period 2004-2014, the WTE adjustment factor in 2014 does not distinguish male and female full-/part-time working practices in Table 4.7. However, for the remainder of the analysis of 2014 data, the WTE adjustment factor adjusts for separate male and female working practices, as outlined in Chapter 3. 
TABLE 4.7 ESTIMATED NUMBER OF WTE GPS PER 10,000 POPULATION BY GEOGRAPHIC AREA, IRELAND 2004-2014 (SELECTED YEARS)

\begin{tabular}{|c|c|c|c|c|c|c|c|c|}
\hline Geographic area & 2004 & 2005 & 2006 & 2007 & 2008 & $\begin{array}{c}2010 / \\
2011\end{array}$ & 2014 & $\begin{array}{c}\% \text { change } \\
2004-2014\end{array}$ \\
\hline Carlow & 5.9 & 5.6 & 5.2 & 4.9 & 5.0 & 5.8 & 6.3 & 7 \\
\hline Cavan & 4.8 & 4.6 & 4.4 & 4.2 & 4.3 & 5.0 & 5.1 & 6 \\
\hline Clare & 4.5 & 4.4 & 4.4 & 4.5 & 4.2 & 4.6 & 4.8 & 7 \\
\hline Cork & 7.0 & 7.0 & 6.9 & 6.7 & 6.5 & 7.6 & 7.0 & 0 \\
\hline Donegal & 5.3 & 5.5 & 5.2 & 4.9 & 4.8 & 5.3 & 5.9 & 11 \\
\hline Dublin & 5.6 & 5.5 & 5.6 & 5.3 & 5.4 & 6.5 & 5.5 & -2 \\
\hline Dublin North & & & & & & & 4.9 & \\
\hline Dublin South & & & & & & & 6.0 & \\
\hline Galway & 6.9 & 6.8 & 6.5 & 6.3 & 6.2 & 7.1 & 6.8 & -1 \\
\hline Kerry & 5.9 & 5.9 & 5.8 & 5.6 & 5.3 & 7.3 & 6.5 & 10 \\
\hline Kildare & 4.2 & 4.1 & 3.8 & 3.7 & 3.5 & 4.5 & 4.0 & -5 \\
\hline Kilkenny & 4.4 & 4.6 & 4.7 & 4.0 & 4.3 & 4.5 & 4.6 & 5 \\
\hline Laois & 4.0 & 4.1 & 4.2 & 3.8 & 3.8 & 5.1 & 4.7 & 18 \\
\hline Leitrima $^{a}$ & 5.6 & 5.4 & 5.9 & 5.4 & 5.7 & 5.7 & 4.7 & -16 \\
\hline Limerick & 5.9 & 6.1 & 5.9 & 5.3 & 5.6 & 6.1 & 6.0 & 2 \\
\hline Longford $^{b}$ & 4.6 & 4.6 & 4.6 & 4.2 & 4.3 & 4.4 & 5.5 & 20 \\
\hline Louth & 5.2 & 4.9 & 5.0 & 4.9 & 4.5 & 5.7 & 5.9 & 13 \\
\hline Mayo & 5.7 & 5.8 & 5.9 & 5.4 & 5.8 & 6.1 & 6.4 & 12 \\
\hline Meath & 4.0 & 3.8 & 3.7 & 3.4 & 3.5 & 3.6 & 3.7 & -8 \\
\hline Monaghan & 4.2 & 4.1 & 4.0 & 4.0 & 3.8 & 4.6 & 4.2 & 0 \\
\hline Offaly & 3.9 & 3.4 & 3.6 & 3.4 & 4.0 & 4.3 & 5.2 & 33 \\
\hline Roscommon ${ }^{b}$ & 4.6 & 4.6 & 4.6 & 4.2 & 4.3 & 6.1 & 5.0 & 9 \\
\hline Sligo ${ }^{a}$ & 5.6 & 5.4 & 5.9 & 5.4 & 5.7 & 6.8 & 7.7 & 38 \\
\hline Tipperary North ${ }^{c}$ & 5.0 & 4.8 & 4.9 & 5.1 & 5.4 & 6.4 & 5.5 & 10 \\
\hline Tipperary South ${ }^{c}$ & 5.9 & 5.9 & 5.6 & 5.5 & 6.0 & 6.4 & 5.7 & -3 \\
\hline Waterford & 6.6 & 6.4 & 6.4 & 5.8 & 6.2 & 6.5 & 6.5 & -2 \\
\hline Westmeath & 6.7 & 6.4 & 6.2 & 6.0 & 5.9 & 8.3 & 6.2 & -7 \\
\hline Wexford & 5.5 & 5.1 & 5.0 & 4.6 & 4.8 & 5.1 & 4.9 & -11 \\
\hline Wicklow & 6.1 & 5.7 & 5.6 & 5.3 & 5.4 & 6.1 & 5.6 & -8 \\
\hline Ireland & 5.6 & 5.5 & 5.5 & 5.2 & 5.2 & 6.1 & 5.7 & 2 \\
\hline
\end{tabular}

Sources: 2004-2008, Layte et al. (2009). 2010/2011, Teljeur et al. (2014).

Notes: (a) Leitrim and Sligo, and (b) Longford and Roscommon, have the same rates for 2004-2008 because they were reported as one combined area. (c) Tipperary North and Tipperary South have the same rate for 2010/2011 because they were reported as one combined area. (d) Comparisons between the three time periods (2004-2008, 2010/11 and 2014) should be made with caution due to differences in data sources and methodologies applied. Geographic data were not compiled for the years 2009, 2012 and 2013.

\section{Overview of GP supply in Ireland 2014}

Table 4.8 and Figure 4.8 show the number of practices, number of GPs and estimated number of WTE GPs by geographic area in 2014, ranked by WTEs per 10,000 population from highest to lowest.

The distribution of WTE GPs is not uniform across the country, as illustrated by the Gini coefficient of 0.096 . As outlined in Chapter 3, the Gini coefficient ranges from 0 (complete equality) to 1 (complete inequality) and is a useful summary measure of inequality for making broad comparisons of inequality across different types of services and countries. Analysis of the distribution of WTE GPs in Scotland and England indicates Gini coefficients of $0.074-0.076$ (based on raw unadjusted populations) for the year 2006 (Goddard et al., 2010), suggesting that the distribution of GPs in Ireland may be more unequal than in the UK (earlier analysis 
indicated a Gini coefficient of $<0.05$ for the supply of WTE GPs in England and Wales in 2001; Hann and Gravelle, 2004). Taking an international perspective, there were an estimated 8 WTE GPs per 10,000 population in the UK in 2014 (OECD, 2015), higher than observed in Ireland overall. ${ }^{48}$

\section{Geographic patterns of GP supply in Ireland 2014}

Table 4.8 and Figure 4.8 show substantial geographic variation in the estimated number of WTE GPs per 10,000 population: area values range from 3.7 in Meath to 7.7 in Sligo.

A more detailed examination of the geographic patterns shows that:

- Compared with the national value, there are fewer estimated WTE GPs per 10,000 population in Dublin commuter areas - Meath $(3.7 / 10,000)$, Kildare $(4.0 / 10,000)$ and Dublin North (4.9/10,000). Previous analyses of the distribution of GPs (Layte et al., 2009; Teljeur et al., 2014) also observed a relative deficit in counties around the Dublin region.

- Compared with the national value, there are more estimated WTE GPs per 10,000 population in areas along the west coast apart from Clare.

- Table 4.8 also shows the excess or deficit of estimated WTE GPs in each area when compared with the national value. Substantial numbers of WTE GPs would be required in some areas to increase supply to the national level. These relative deficits are highest in Dublin North (-48.0 WTE GPs), Meath (-38.3 WTE GPs) and Kildare (-35.8 WTE GPs). In contrast, the neighbouring area of Wicklow does not have a relative deficit and Dublin South has a relative excess (22.2 WTE GPs).

48 In Figure 4.8, 100 per cent of the population in Ireland fall under that benchmark, although it should be remembered that at a more granular level of analysis, for example at the level of postal districts in Dublin, there are small areas where the number of WTE GPs per capita is greater than the UK national benchmark. 
TABLE 4.8 NUMBER OF GENERAL PRACTICES, NUMBER OF GPS, AND ESTIMATED NUMBER OF WTE GPS BY GEOGRAPHIC AREA, IRELAND 2014

\begin{tabular}{|c|c|c|c|c|c|c|c|}
\hline Geographic area & $\begin{array}{c}\text { Number of } \\
\text { practices }\end{array}$ & $\begin{array}{c}\text { Number of } \\
\text { GPs }\end{array}$ & $\begin{array}{l}\text { Estimated } \\
\text { WTE GPs }\end{array}$ & Population & $\begin{array}{l}\text { Estimated } \\
\text { WTE GPs } \\
\text { per 10,000 } \\
\text { population }\end{array}$ & $\begin{array}{c}\text { Ratio of } \\
\text { area value } \\
\text { to national } \\
\text { value }\end{array}$ & $\begin{array}{l}\text { Excess or deficit } \\
\text { of estimated } \\
\text { WTE GPs } \\
\text { compared with } \\
\text { national value }\end{array}$ \\
\hline Sligo & 34 & 55 & 50.1 & 65,104 & 7.7 & 1.36 & 13.2 \\
\hline Cork & 217 & 401 & 366.4 & 524,199 & 7.0 & 1.23 & 69.5 \\
\hline Galway & 110 & 190 & 173.1 & 254,959 & 6.8 & 1.20 & 28.7 \\
\hline Waterford & 38 & 81 & 74.4 & 113,792 & 6.5 & 1.15 & 10.0 \\
\hline Kerry & 56 & 103 & 93.8 & 144,259 & 6.5 & 1.15 & 12.1 \\
\hline Mayo & 69 & 89 & 82.6 & 129,395 & 6.4 & 1.13 & 9.3 \\
\hline Carlow & 19 & 37 & 33.9 & 53,957 & 6.3 & 1.11 & 3.4 \\
\hline Westmeath & 33 & 59 & 53.6 & 86,854 & 6.2 & 1.09 & 4.4 \\
\hline Limerick & 82 & 127 & 115.8 & 192,681 & 6.0 & 1.06 & 6.6 \\
\hline Dublin South & 260 & 463 & 421.5 & 704,937 & 6.0 & 1.06 & 22.2 \\
\hline Louth & 40 & 80 & 73.0 & 123,082 & 5.9 & 1.05 & 3.3 \\
\hline Donegal & 51 & 102 & 94.2 & 159,358 & 5.9 & 1.04 & 3.9 \\
\hline Tipperary South & 29 & 54 & 50.1 & 87,672 & 5.7 & 1.01 & 0.4 \\
\hline Wicklow & 40 & 86 & 77.9 & 138,421 & 5.6 & 0.99 & -0.5 \\
\hline Tipperary North & 27 & 42 & 38.4 & 69,861 & 5.5 & 0.97 & -1.2 \\
\hline Longford & 13 & 23 & 20.6 & 37,559 & 5.5 & 0.97 & -0.6 \\
\hline Offaly & 27 & 43 & 39.4 & 75,561 & 5.2 & 0.92 & -3.4 \\
\hline Cavan & 22 & 41 & 37.4 & 72,750 & 5.1 & 0.91 & -3.9 \\
\hline Roscommon & 24 & 35 & 31.6 & 63,296 & 5.0 & 0.88 & -4.3 \\
\hline Wexford & 39 & 77 & 70.9 & 144,373 & 4.9 & 0.87 & -10.9 \\
\hline Dublin North & 187 & 316 & 288.4 & 594,002 & 4.9 & 0.86 & -48.0 \\
\hline Clare & 48 & 61 & 56.9 & 119,027 & 4.8 & 0.84 & -10.5 \\
\hline Leitrim & 10 & 16 & 14.6 & 30,925 & 4.7 & 0.83 & -2.9 \\
\hline Laois & 22 & 41 & 37.5 & 80,166 & 4.7 & 0.83 & -7.9 \\
\hline Kilkenny & 24 & 48 & 44.6 & 96,050 & 4.6 & 0.82 & -9.8 \\
\hline Monaghan & 14 & 27 & 24.8 & 59,822 & 4.2 & 0.73 & -9.0 \\
\hline Kildare & 61 & 97 & 88.6 & 219,570 & 4.0 & 0.71 & -35.8 \\
\hline Meath & 39 & 77 & 70.4 & 191,931 & 3.7 & 0.65 & -38.3 \\
\hline Ireland & 1,635 & 2,868 & $2,624.3$ & $4,633,563$ & 5.7 & 1.00 & 0.0 \\
\hline Gini coefficient & & & & & 0.096 & & \\
\hline
\end{tabular}

Sources: Data on the number and location of GPs are from the ICGP and the IMD at September 2014 and were made available by Department of Public Health and Primary Care, Trinity College Dublin.

Notes: (a) A GP practising in more than one area is assigned in equal proportions to each area. The number of GPs is converted to estimated WTEs based on survey evidence on full-and part-time working practices of GPs in Ireland; see Chapter 3 for more details. (b) Excess or deficit of WTE GPs compared with national value is calculated as: area WTE GPS - (area WTE GPS/ratio of area value to national value). (c) The Gini coefficient summarises inequality in the distribution of GPs across areas, with 0 representing complete equality across areas and 1 representing complete inequality across areas. 


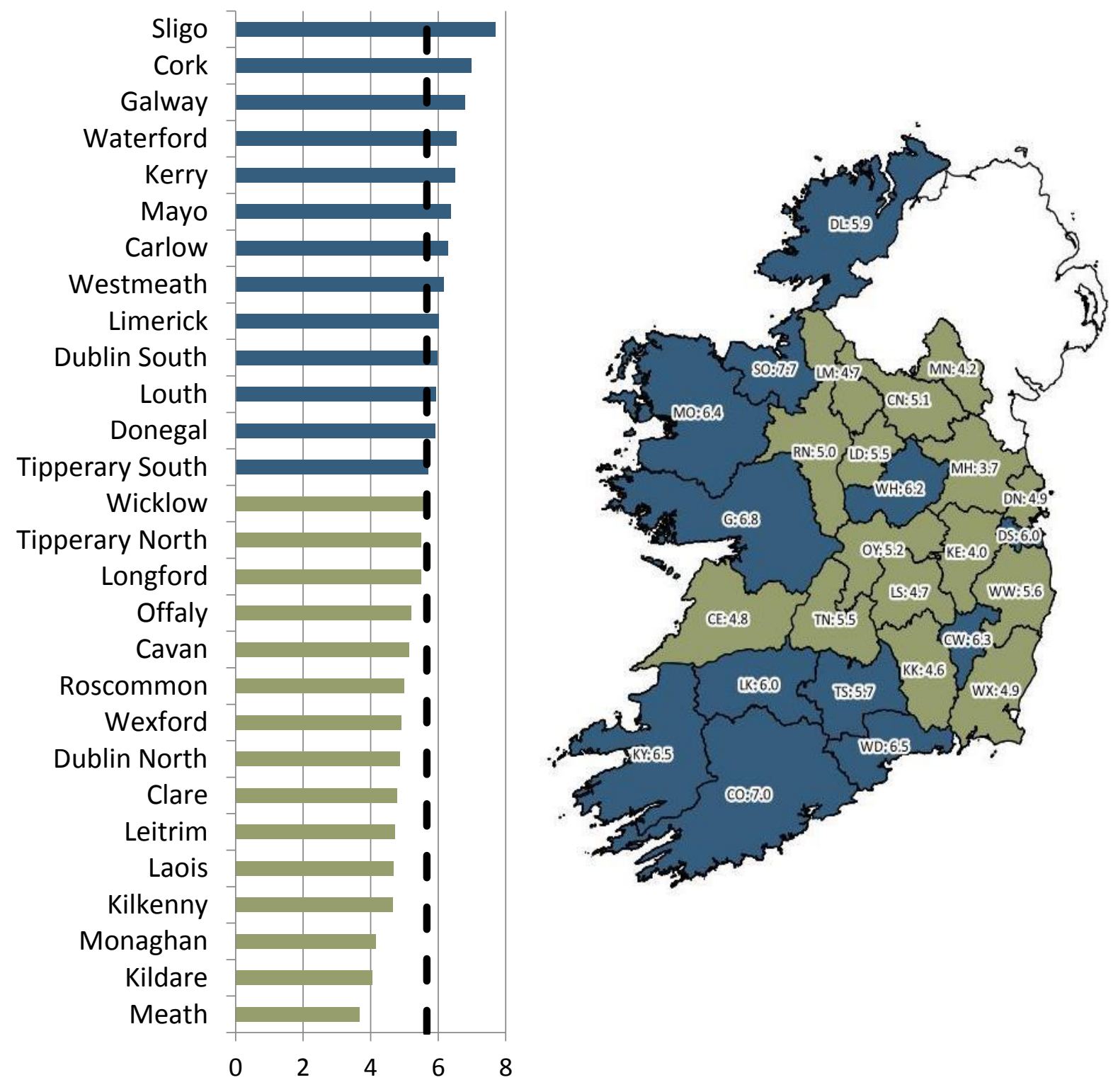

Analysis at county level hides variation in supply that can be observed across smaller areas. This section examines the distribution of GPs at a more disaggregated level within Dublin to highlight the variations in supply that occur across smaller areas (Table 4.9 and Figure 4.9).

The estimated number of WTE GPs per 10,000 population for the Dublin region $(5.5 / 10,000)$ is lower than the national value $(5.7 / 10,000)$ and the range of values is larger in the Dublin region, from 0.9/10,000 in Dublin 17 to 19.6/10,000 in Dublin 2. The Gini coefficient for the distribution of GPs across areas is higher for the 
Dublin region (0.266) than for the national profile (0.096), indicating greater inequality in the geographic distribution of GPs within Dublin than across the country.

There are some notable findings in specific areas:

- The three areas with the highest population in the Dublin region have relatively low numbers of estimated WTE GPs per 10,000 population - Dublin Other North $(3.2 / 10,000)$, Dublin Other South $(3.6 / 10,000)$ and Dublin $24(4.0 / 10,000)$.

- The relatively high number of estimated WTE GPs per 10,000 population in Dublin 2 (city centre) $(19.1 / 10,000)$ may reflect additional demand for GP services from a nonresidential working population in the area.

Table 4.9 also shows the excess or deficit of estimated WTE GPs in each Dublin area when compared with the national value. Overall the Dublin region has a deficit of 25.8 WTE GPs compared with the national value and this deficit is mainly driven by the two areas outside the postal districts: Dublin Other South (-55.4 WTE GPs) and Dublin Other North (-48.9 WTE GPs).

It is important to note that the patterns of GP supply at this level of disaggregation need to be interpreted with caution given the overlapping catchment areas for practices located within small geographic distances. 
TABLE 4.9 NUMBER OF GENERAL PRACTICES, NUMBER OF GPS AND ESTIMATED NUMBER OF WTE GPS BY DUBLIN AREA, IRELAND 2014

\begin{tabular}{|c|c|c|c|c|c|c|c|}
\hline Geographic area & $\begin{array}{l}\text { Number of } \\
\text { practices }\end{array}$ & $\begin{array}{l}\text { Number } \\
\text { of GPs }\end{array}$ & $\begin{array}{l}\text { Estimated } \\
\text { WTE GPs }\end{array}$ & Population & $\begin{array}{l}\text { Estimated } \\
\text { WTE GPs } \\
\text { per } 10,000 \\
\text { population }\end{array}$ & $\begin{array}{c}\text { Ratio of } \\
\text { area value } \\
\text { to national } \\
\text { value }\end{array}$ & $\begin{array}{l}\text { Excess or deficit } \\
\text { of estimated } \\
\text { WTE GPs } \\
\text { compared with } \\
\text { national value }\end{array}$ \\
\hline Dublin 2 & 21 & 42 & 37.6 & 19,189 & 19.6 & 3.46 & 26.8 \\
\hline Dublin 15 & 31 & 44 & 40.1 & 28,810 & 13.9 & 2.46 & 23.8 \\
\hline Dublin 14 & 23 & 42 & 38.0 & 40,515 & 9.4 & 1.66 & 15.1 \\
\hline Dublin 16 & 14 & 25 & 22.2 & 25,607 & 8.7 & 1.53 & 7.7 \\
\hline Dublin 13 & 16 & 27 & 24.4 & 28,330 & 8.6 & 1.52 & 8.4 \\
\hline Dublin 20 & 5 & 10 & 9.3 & 10,925 & 8.5 & 1.50 & 3.1 \\
\hline Dublin 5 & 23 & 38 & 35.3 & 46,010 & 7.7 & 1.36 & 9.3 \\
\hline Dublin 4 & 19 & 31 & 27.7 & 37,539 & 7.4 & 1.30 & 6.4 \\
\hline Dublin 8 & 19 & 42 & 38.5 & 53,235 & 7.2 & 1.28 & 8.4 \\
\hline Dublin 9 & 25 & 38 & 34.6 & 50,884 & 6.8 & 1.20 & 5.8 \\
\hline Dublin 6 & 17 & 29 & 26.0 & 38,715 & 6.7 & 1.19 & 4.1 \\
\hline Dublin 3 & 15 & 26 & 23.6 & 35,317 & 6.7 & 1.18 & 3.6 \\
\hline Dublin 18 & 13 & 23 & 21.1 & 32,239 & 6.5 & 1.16 & 2.9 \\
\hline Dublin 12 & 17 & 30 & 27.2 & 51,898 & 5.2 & 0.93 & -2.2 \\
\hline Dublin 10 & 8 & 14 & 12.8 & 24,692 & 5.2 & 0.92 & -1.2 \\
\hline Dublin 1 & 10 & 18 & 16.0 & 31,019 & 5.1 & 0.91 & -1.6 \\
\hline Dublin 6w & 11 & 14 & 13.1 & 26,109 & 5.0 & 0.88 & -1.7 \\
\hline Dublin 7 & 17 & 29 & 26.1 & 54,691 & 4.8 & 0.84 & -4.9 \\
\hline Dublin 11 & 14 & 25 & 22.9 & 51,107 & 4.5 & 0.79 & -6.0 \\
\hline Dublin 24 & 21 & 33 & 30.6 & 73,630 & 4.2 & 0.73 & -11.1 \\
\hline Dublin 22 & 14 & 22 & 20.4 & 50,572 & 4.0 & 0.71 & -8.2 \\
\hline Dublin Other South & 58 & 107 & 96.9 & 268,924 & 3.6 & 0.64 & -55.4 \\
\hline Dublin Other North & 35 & 70 & 63.5 & 198,445 & 3.2 & 0.57 & -48.9 \\
\hline Dublin 17 & 1 & 2 & 1.8 & 20,537 & 0.9 & 0.16 & -9.8 \\
\hline Total & 447 & 778 & 709.8 & $1,298,939$ & 5.5 & 0.96 & -25.8 \\
\hline Gini coefficient & & & & & 0.266 & & \\
\hline
\end{tabular}

Sources: Data on the number and location of GPs are from the ICGP and the IMD at September 2014 and were made available by Department of Public Health and Primary Care, Trinity College Dublin.

Notes: (a) A GP practising in more than one area is assigned in equal proportions to each area. The number of GPs is converted to estimated WTEs based on survey evidence on full- and part-time working practices of GPs in Ireland; see Chapter 3 for more details. (b) Excess or deficit of WTE GPs compared with national value is calculated as: area WTE GPS - (area WTE GPS/ratio of area value to national value). (c) The Gini coefficient summarises inequality in the distribution of GPs across areas, with 0 representing complete equality across areas and 1 representing complete inequality across areas. 


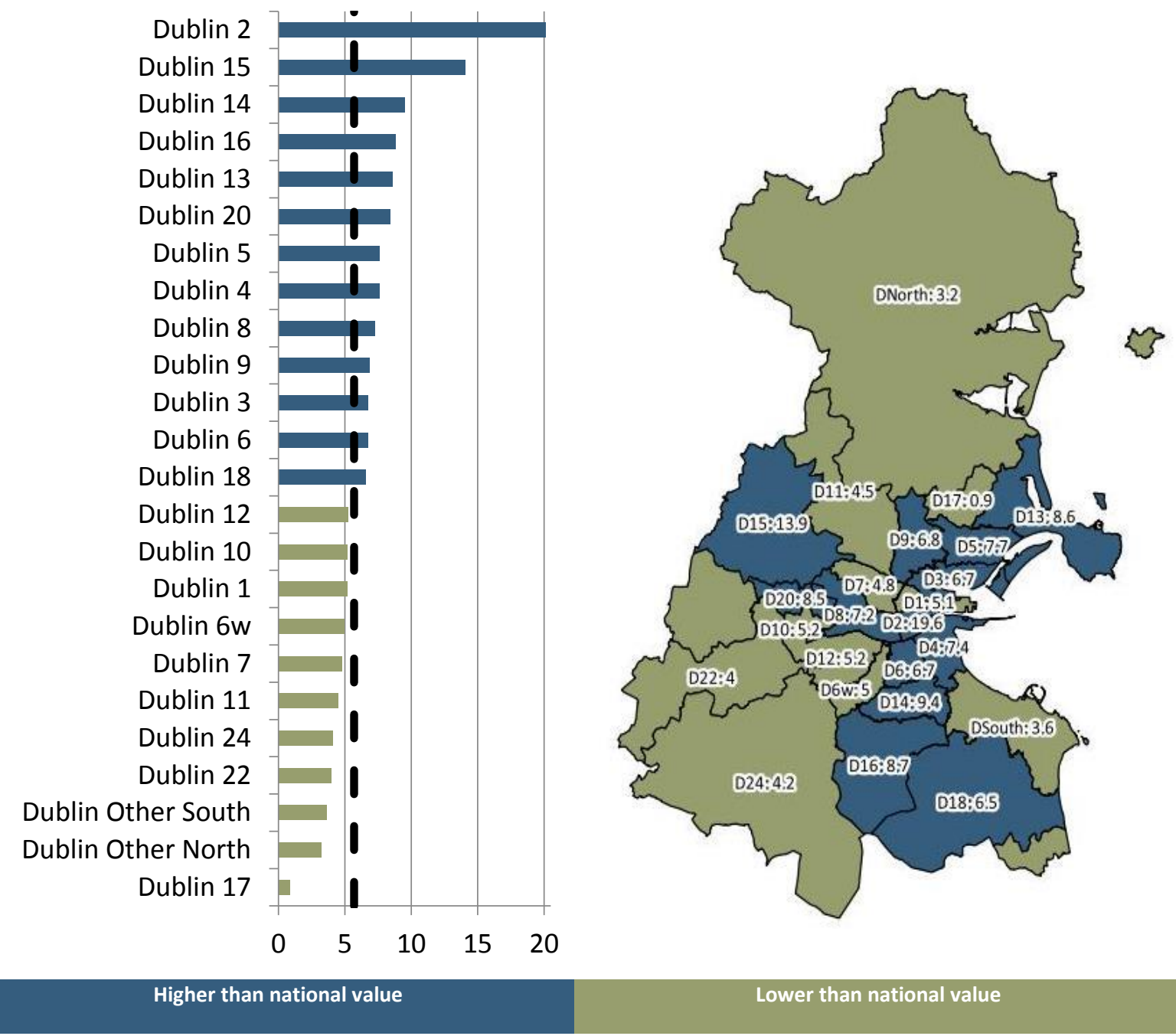

\section{Needs-adjusted GP supply}

This section reassesses the geographic distribution of GP supply following adjustment for a range of healthcare need indicators, using the methods outlined in Section 3.4.2. Further details can be found in Appendices 4 and 5.

Figure 4.10 illustrates the impact on the geographic pattern of GP supply following adjustment of the population for the following need indicators:

- population aged $65+$ years;

- population aged $85+$ years;

- area mortality rates;

- population with a disability; 
- population with a Medical Card or GP Visit Card;

- population with a Medical Card and receiving a prescription for a chronic health condition.

Comparing the Gini coefficients for the equality of the distribution of estimated WTE GPs across areas suggests that the distribution is:

- more equal for the population with disability (0.082) than for the total population (0.096);

- approximately the same for the older population aged $65+$ years $(0.093)$, the mortality adjusted population (0.093) and the total population (0.096);

- less equal for the older population aged 85+ years (0.122), the population with a Medical Card/GP Visit Card (0.115), and the population with a Medical Card and a chronic health condition (0.103) than for the total population (0.096).

The adjustment of GP supply for disability (Figure 4.10d) shows the least change in the position of areas relative to the national value: the data points in the scatter plot lie very close to the 'line of no change'.

Box 4.1 provides some guidance on how to interpret the findings following adjustment for healthcare needs. 
Box 4.1 How does healthcare supply change when populations are adjusted for needs?

For each geographic area, the supply of a non-acute service is measured in terms of supply per capita (e.g. number of community nurses in area $A$ divided by the population in area A). Supply per capita in each area is compared with national supply per capita (i.e. the location quotient: ratio of area supply per capita to national supply per capita).

When the area populations are adjusted for needs (e.g. population aged $85+$ ), supply per capita is recalculated on the basis of the adjusted population in each area. The effect of needs adjustment on the location quotient (i.e. ratio of area supply per capita to national supply per capita) can be described in two ways:

1. whether the area's relative supply is above the national value before adjustment and below the national value after adjustment, or vice versa;

2. the magnitude of change in the area's relative supply.

\section{Ratio of area supply relative to national supply before and after adjustment}

Whether an area's relative supply (i.e. location quotient) is higher/lower than national supply before/after adjustment is different for each type of supply. This is because, even though the area's magnitude of change is the same, the national level of supply is different for each type of supply.

Scatter plots are used to illustrate the position of an area's location quotient before and after adjustment (e.g. low level of supply per capita relative to the national value before adjustment, but higher level of supply per capita relative to the national value after adjustment), for each type of adjustment, for each non-acute service included in the report. These data are summarised in Appendix 5. See Box 3.1 for guidance on how to interpret the scatter plots.

The location quotient centres on 1 (the national value) and throughout the text a conservative approach is adopted whereby location quotients in the range 0.95-1.05 are considered to be near the national value and the main focus is on areas with location quotients that fall outside of this range (before and after needs adjustment).

\section{Magnitude of change in an area's relative supply}

The ratio of area supply to national supply can change substantially in some areas following needs adjustment. For example, when the population is adjusted to include only those aged 85+, the ratio of GP supply in Kildare to national supply increases from 0.71 based on the total population to 1.22 based on the age-adjusted population, a change of $72 \%$. This is because Kildare has a low number of people aged $85+$ compared with the rest of the country. Conversely, Mayo has a relatively high proportion of people aged $85+$ compared with the rest of the country. The ratio of GP supply in Mayo to national supply falls from 1.13 based on the total population to 0.73 based on the age-adjusted population, a change of $35 \%$.

For a given need indicator, it is important to note that the magnitude of change in an area's relative supply is exactly the same for each type of supply. This is because the area's level of need (as measured by a given need indicator) is the same for each type of supply. For example, Kildare has relatively few people aged $85+$ and for each type of supply (GPs, community nurses, long-term residential care beds, etc.); the age-adjusted supply in Kildare increases by the same proportion relative to the national value. Therefore, the magnitude of change following each needs-adjustment is reported only for GP supply and is not repeated for the other non-acute services presented in this report. 


\section{Ratio of area supply relative to national supply before and after adjustment}

Focusing on the change in an area's relative supply, notable area-specific patterns include the following.

- With the exception of Kildare, all areas that have a lower level of GP supply relative to the national value prior to adjustment continue to have a lower level relative to the national value following adjustment, for all need indicators (i.e. bottom left quadrant in Figure 4.10a-4.10f). ${ }^{49}$

- Kildare is in the bottom right quadrant (i.e. lower before, higher after) of Figure $4.10 \mathrm{~b}$ and $4.10 \mathrm{c}$ following adjustment for age $(85+)$ and mortality respectively.

- A number of areas fall in the top left quadrant (i.e. higher before, lower after) following adjustment of GP supply for some of the need indicators:

- Mayo is in the top left quadrant of Figure 4.10a-4.10c, 4.10e and 4.10f after each separate adjustment for age (65+ and 85+), mortality, Medical Card/GP Visit Card coverage and morbidity.

- Kerry is in the top left quadrant of Figures 4.10a-4.10c following each separate adjustment for age (65+ and $85+)$ and mortality.

- Limerick is in the top left quadrant of Figures $4.10 \mathrm{c}$ and $4.10 \mathrm{f}$ following each separate adjustment for mortality and morbidity.

- Carlow and Westmeath are in the top left quadrant of Figure 4.10e after adjustment for Medical Card/GP Visit Card cover.

- Sligo is in the top left quadrant of Figure 4.10b after adjustment for age (85+).

\section{Magnitude of change in area's relative supply}

- In some areas, large changes are observed in the estimated ratio of WTE GPs per 10,000 population following adjustment of the population for different need indicators. In the following areas the estimated ratio of WTE GPs per 10,000 population changes by 20 per cent or more (but not necessarily shifting the position relative to the national value) following adjustment of the population for different need indicators. ${ }^{50}$ The largest effects of the adjustment for the population aged 65+ years on the supply of estimated WTE GPs are observed in Kildare and Meath (where supply increases relative to other areas) and in Mayo, Leitrim, Roscommon and Kerry (where supply decreases relative to other areas).

- The largest effects of the adjustment for the population aged 85+ years on the supply of estimated WTE GPs are observed in Kildare, Meath, Wicklow and Dublin North (where

$49 \quad$ As noted in Section 4.1, the location quotient centres on 1 (the national value) and throughout the text a conservative approach is adopted whereby location quotients in the range $0.95-1.05$ are considered to be near the national value and the main focus is on areas with location quotients that fall outside of this range (before and after needs adjustment). See Box 4.1 for further guidance on how to interpret the findings. 
supply increases relative to other areas) and in Roscommon, Leitrim, Mayo, Sligo, Donegal, Cavan and Kerry (where supply decreases relative to other areas).

- The largest effects of the mortality adjustment on the supply of estimated WTE GPs are observed in Kildare and Meath (where supply increases relative to other areas) and in Mayo, Tipperary North and Kerry (where supply decreases relative to other areas).

- The largest effects of the adjustment for disability on the supply of estimated WTE GPs are observed in Meath (where supply increases relative to other areas).

- The largest effects of the adjustment for Medical Card/GP Visit Card coverage are observed in Dublin South and Kildare (where supply increases relative to other areas) and in Donegal and Louth (where supply decreases relative to other areas).

- The largest effects of the adjustment for population with a Medical Card and receiving a prescription for a chronic health condition on the supply of estimated WTE GPs are observed in Kildare, Meath and Dublin South (where supply increases relative to other areas) and in Donegal and Mayo (where supply decreases relative to other areas). 
FIGURE 4.10 SCATTER PLOT OF LOCATION QUOTIENTS OF THE ESTIMATED NUMBER OF WTE GENERAL PRACTITIONERS PER 10,000 TOTAL POPULATION AND PER 10,000 NEEDS-ADJUSTED POPULATIONS BY GEOGRAPHIC AREA, IRELAND 2014

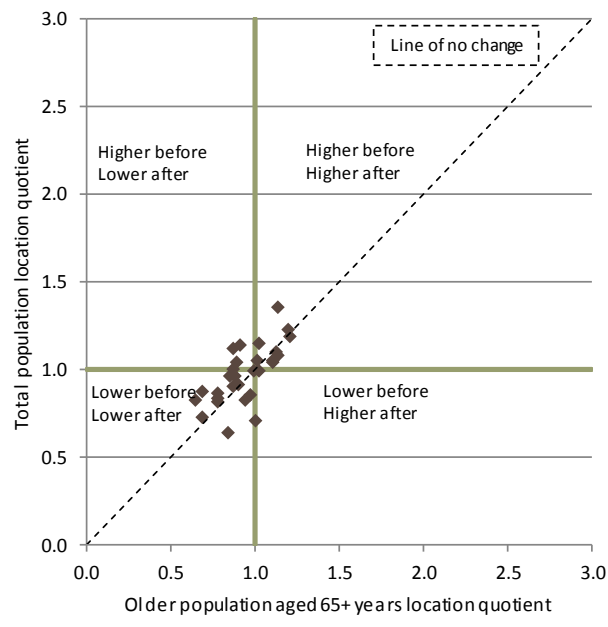

d

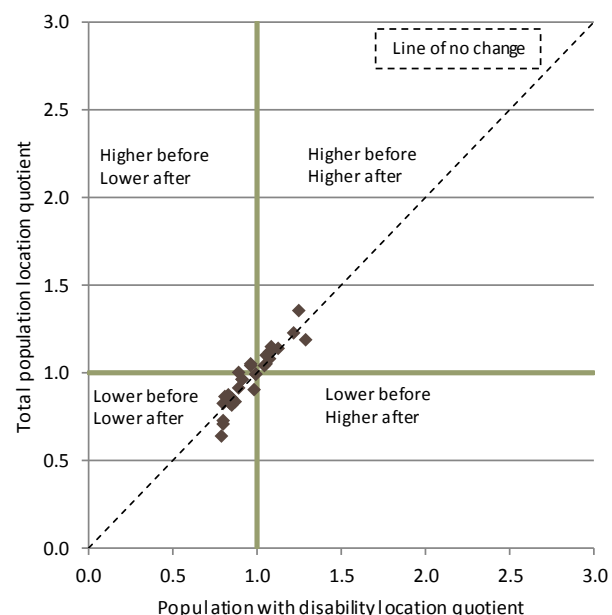

b

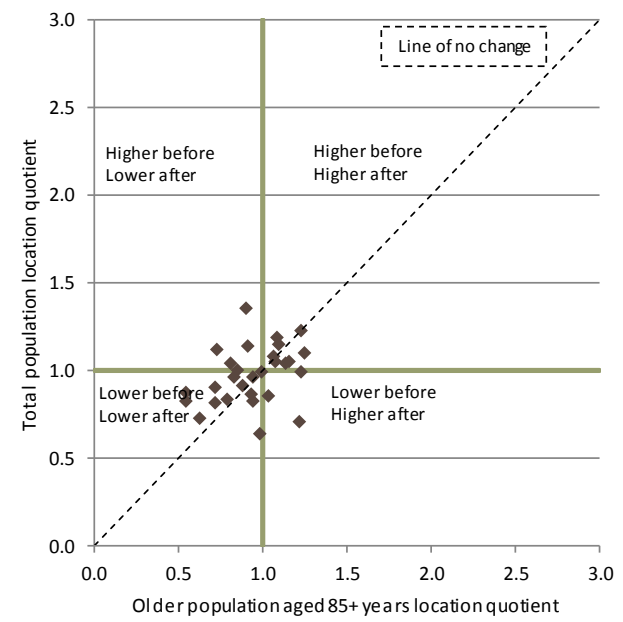

e

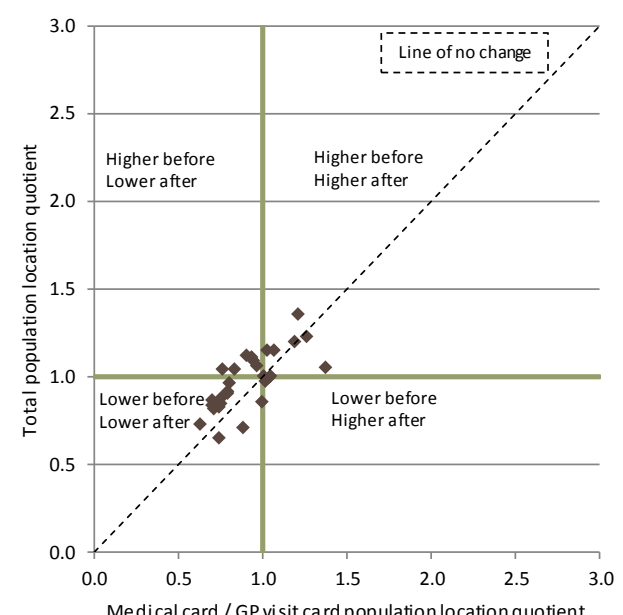

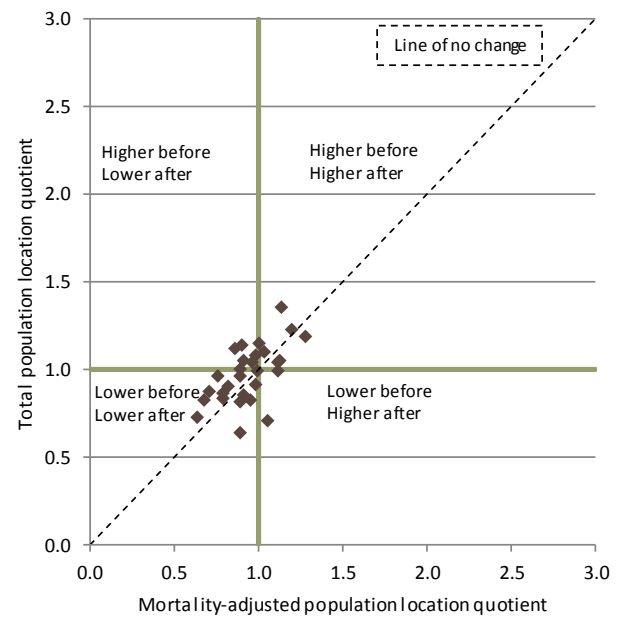

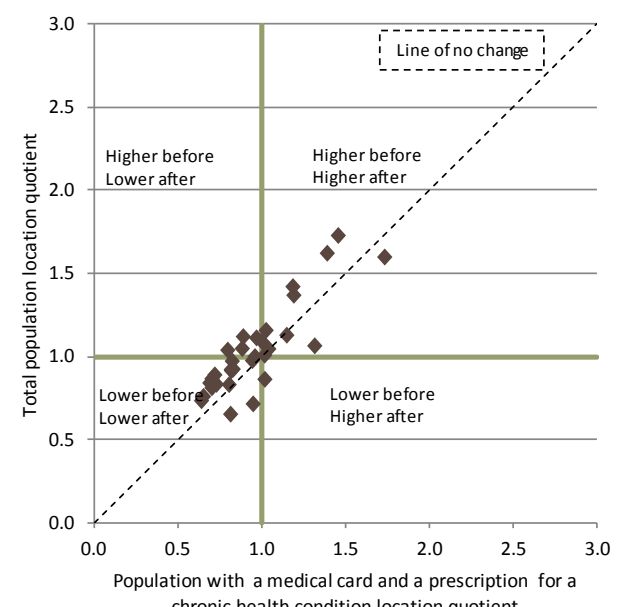

Thesciction for

Notes: $\quad$ An area's location quotient is the area value divided by the national value. 'Higher before' means higher than the national value before adjustment. 'Lower before' means lower than the national value before adjustment. 'Higher after' means higher than the national value after adjustment. 'Lower after' means lower than the national value after adjustment. See Box 3.1 for help on interpreting the scatter plots. 


\subsubsection{Supply of community nurses}

\section{Overview of community nurse supply in Ireland 2014}

It is estimated that there are 2,480 (5.4 per 10,000 population) WTE community nurses nationally. This consists of 1,460 (3.2 per 10,000 population) public health nurses (PHNs) and 1,020 (2.2 per 10,000 population) other CNs. Table 4.10 and Figure 4.11 show the number of WTE CNs by geographic area in 2014 .

The distribution of CNs is not uniform across the country and the Gini coefficient is 0.125 .

\section{Geographic patterns of community nurse supply in Ireland 2014}

Table 4.10 and Figure 4.11 show substantial geographic variation in the number of WTE CNs per 10,000 population: area values range from 3.6 in Meath to 10.0 in Longford.

A more detailed examination of the geographic patterns shows that:

- Compared with the national value, areas in the north, west and midlands appear to be better supplied while areas in the east and south appear to be more poorly supplied. Some of the counties with more WTE CNs per 10,000 population are more rural, with more dispersed populations (e.g. Donegal, Sligo, Kerry) and so may require more CNs.

- Counties in the commuter areas around Dublin have a low number of WTE CNs relative to the national value. When coupled with the relatively low supply of estimated WTE GPs, the data point to potential problems with the availability of primary and community care in Dublin and commuter areas.

- In almost all areas the majority of CNs are PHNs. Exceptions include Kildare and the two areas with the highest numbers of WTE CNs per 10,000 population: Longford and Westmeath..$^{51}$

- Table 4.10 also shows the excess or deficit of WTE CNs in each area when compared with the national value. Substantial numbers of WTE CNs would be required in some areas to increase supply to the national level. In general, these relative deficits are highest in the east and south and in particular: Meath (-34.2 WTEs), Dublin South (-25.6 WTEs), Dublin North (-23.1 WTEs), Cork (-23.0 WTEs) and Kildare (-19.5 WTEs).

51 The values for these two areas were derived from data from a single larger area - Longford Westmeath Local Health Office. 
TABLE 4.10 NUMBER OF WTE PUBLICY EMPLOYED COMMUNITY NURSES BY GEOGRAPHIC AREA, IRELAND 2014

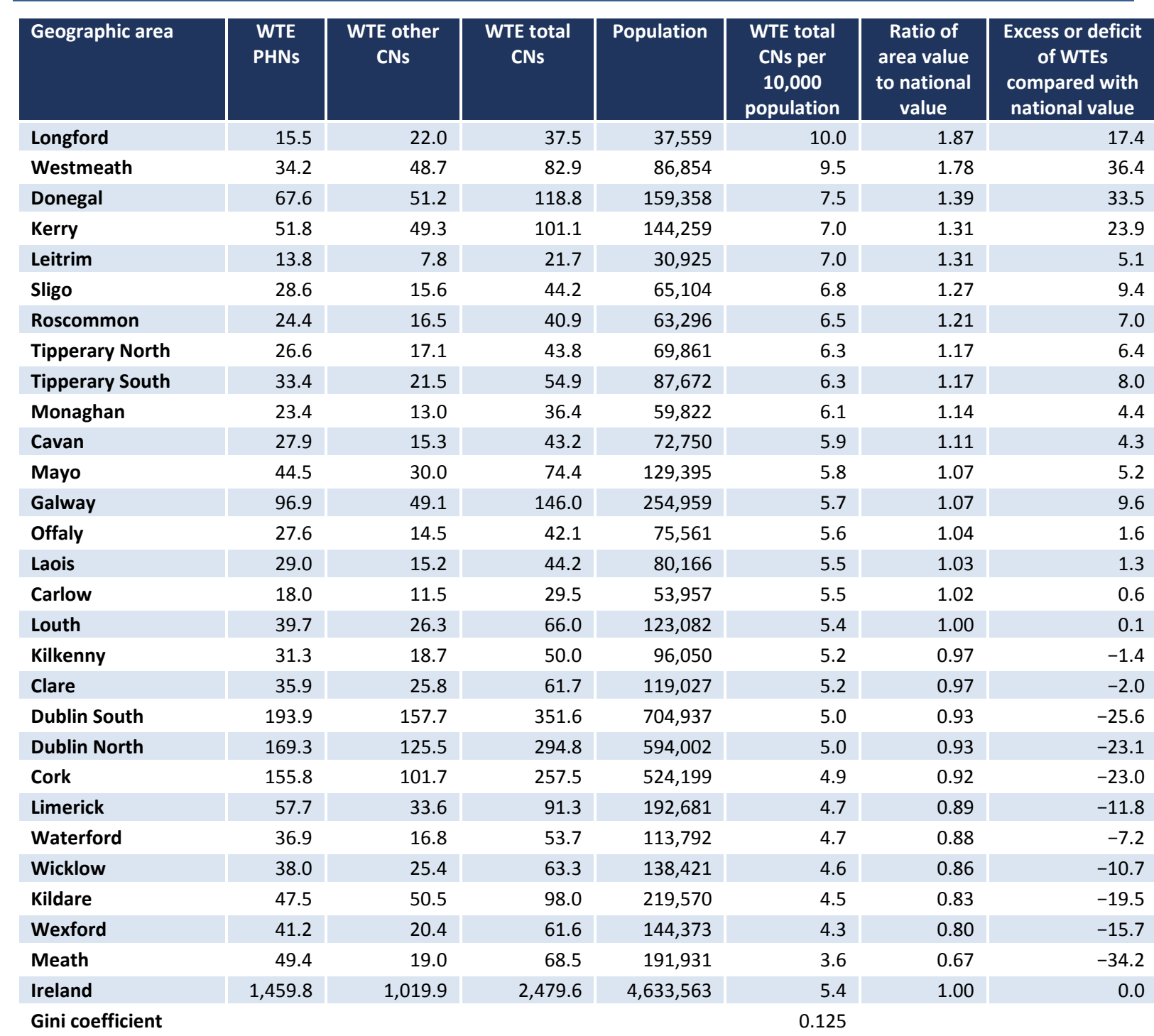

Source: $\quad$ Data on the number of CNs are from the HSE's Health Services Personnel Census (HSPC) December 2014.

Notes: (a) Excess or deficit of WTEs compared with national value is calculated as: area WTEs - (area WTEs/ratio of area value to national value). (b) The Gini coefficient summarises inequality in the distribution of CNs across areas, with 0 representing complete equality across areas and 1 representing complete inequality across areas. (c) Tipperary North and Tipperary South have the same WTE per population value because data were not available separately for Tipperary North and Tipperary South. 


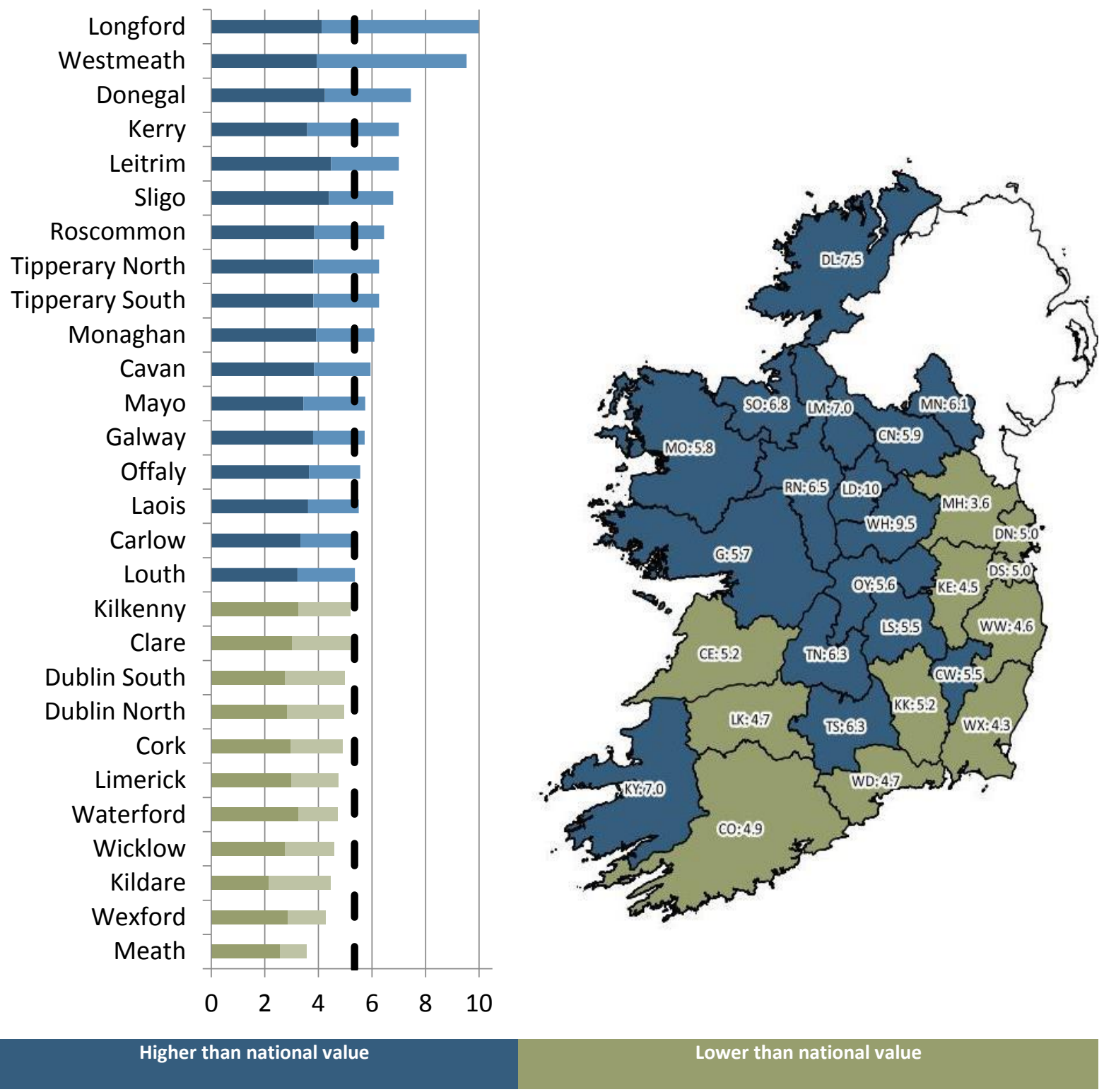

Note: Darker blue/green indicates PHNs; lighter blue/green indicates other community nurses.

\section{Needs-adjusted community nurse supply}

Figure 4.12 illustrates the impact on the geographic pattern of community nursing supply following adjustment of the population for a range of need indicators. ${ }^{52}$ Further details can be found in Appendices 4 and 5.

The adjustment of community nursing supply for disability (Figure 4.12d) shows the least change in the position of areas relative to the national value; the data points in the scatter plot lie very close to the 'line of no change'.

52 See Section 3.4.2 for the definitions of the need indicators and how they were used to adjust supply. 
Comparing Gini coefficients for the equality of the distribution of WTE CNs across areas (Table 4.20) shows that the distribution is:

- more equal for the older population aged $65+$ years $(0.105)$ and $85+(0.117)$, the mortality-adjusted population (0.106), the Medical Card population (0.114), the population with a Medical Card and a chronic health condition (0.110) and the population with disability (0.115) than for the total population (0.125).

\section{Ratio of area supply relative to national supply before and after adjustment}

Some notable area-specific patterns are:

- Most of the areas that have a lower level of community nursing supply relative to the national value prior to adjustment continue to have a lower level relative to the national value following adjustment, for all need indicators (i.e. bottom left quadrant in Figure 4.12a-4.12f).

- Some areas that have a lower level of community nursing supply relative to the national value before adjustment are positioned in the bottom right quadrant (i.e. lower before, higher after) following adjustment for some of the need indicators:

- Kildare lies in the bottom right quadrant of Figure 4.12a-4.12c and $4.12 \mathrm{f}$ following adjustment of the population for age $(65+$ and $85+)$, mortality and morbidity respectively.

- Dublin North lies in the bottom right quadrant of Figure 4.12a-4.12b, 4.12e and 4.12f following adjustment of the population for age $(65+$ and $85+)$, Medical Card coverage and morbidity.

- Wicklow lies in the bottom right quadrant of Figure $4.12 \mathrm{~b}$ after adjustment of the population for age (85+).

- Dublin South lies in the bottom right quadrant of Figure $4.12 \mathrm{e}$ and $4.12 \mathrm{f}$ after adjustment of the population for Medical Card coverage and for morbidity.

- A number of areas fall in the top left quadrant (i.e. higher before, lower after) following adjustment of community nursing supply for some of the need indicators:

- Mayo is in the top left quadrant of Figure 4.12a-4.12c and 4.12e-4.12f after each separate adjustment for age $(65+$ and $85+)$, mortality, Medical Card coverage and morbidity.

- Roscommon is in the top left quadrant of Figure $4.12 a$ and $4.12 b$ after each separate adjustment for age $(65+$ and $85+)$.

- Leitrim, Sligo and Cavan are in the top left quadrant of Figure 4.12b following adjustment for age (85+). 
- Tipperary North is in the top left quadrant of Figure $4.12 \mathrm{c}$ after adjustment for mortality.

However, it is interesting to note that almost all of the areas with the highest supply of WTE CNs per 10,000 population show a decrease in relative supply when adjusted for need.

- The number of areas in the bottom right quadrant (i.e. moving from lower than the national value to higher than the national value) or in the top left quadrant (i.e. higher than the national value to lower than the national value) is small, but greater than observed in the analysis of needs-adjusted GP supply.

- Adjusting for the older population aged $85+$ years has the biggest impact on the pattern of WTE community nursing supply: a larger number of areas are positioned in the bottom right and top left quadrants in the scatter plot for older population aged $85+$ years than in the scatter plots for the other needs-adjusted populations. 
FIGURE 4.12 SCATTER PLOT OF LOCATION QUOTIENTS OF THE NUMBER OF WTE COMMUNITY NURSES PER 10,000 TOTAL POPULATION AND PER 10,000 NEEDS-ADJUSTED POPULATIONS BY GEOGRAPHIC AREA, IRELAND 2014
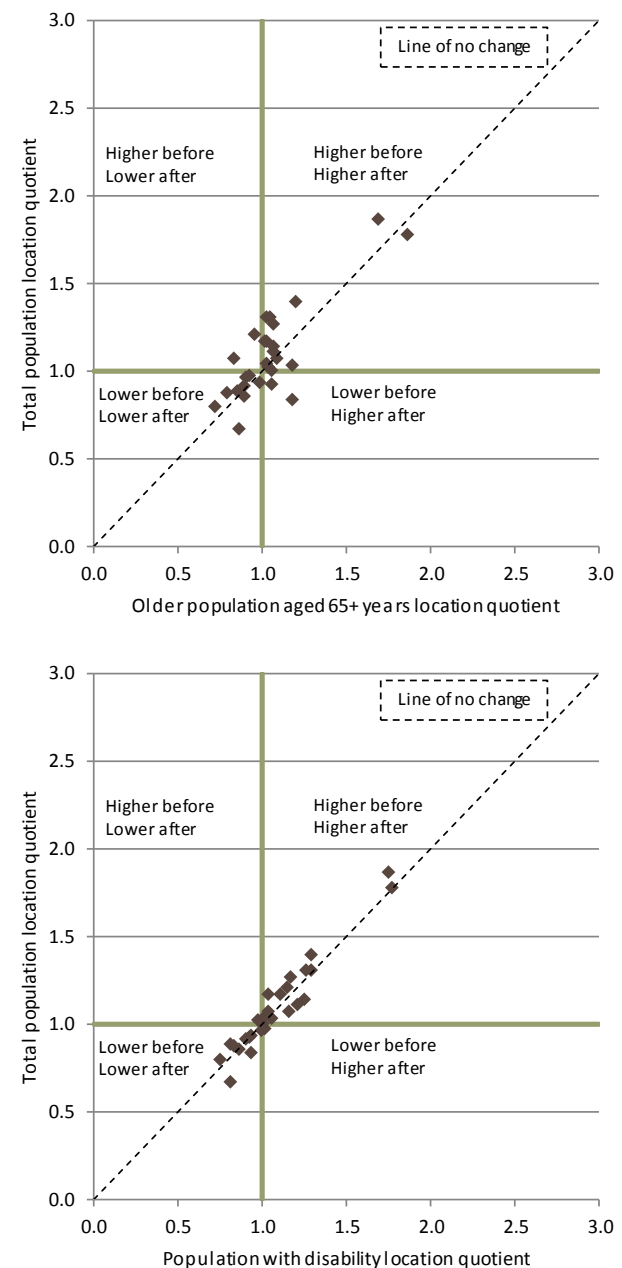
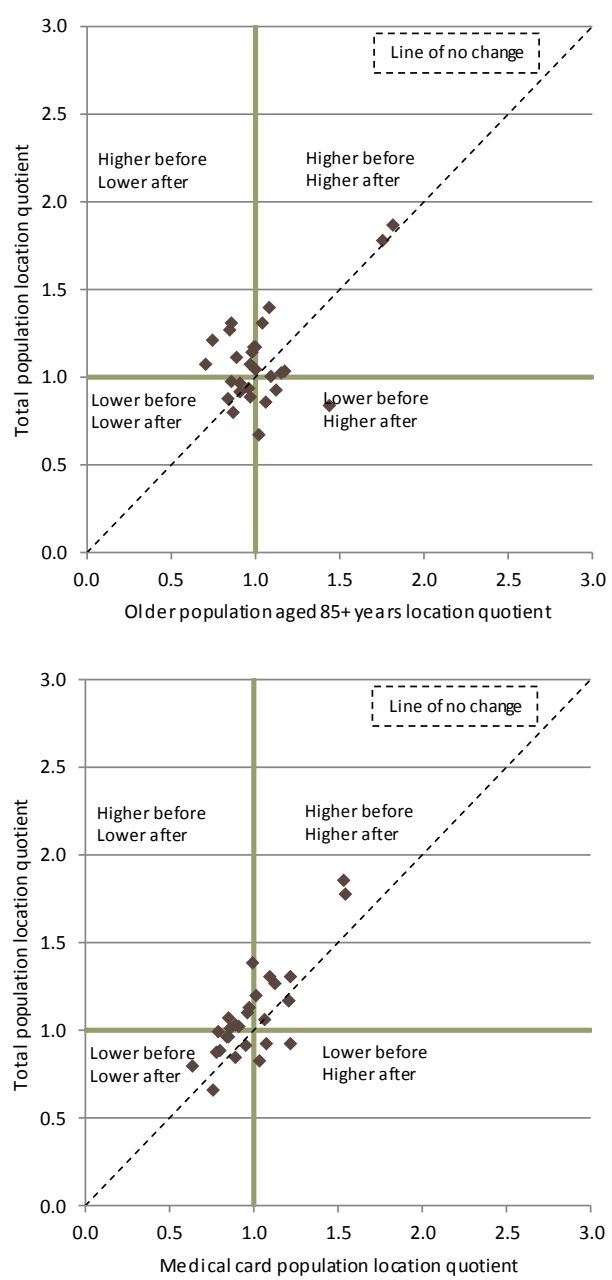

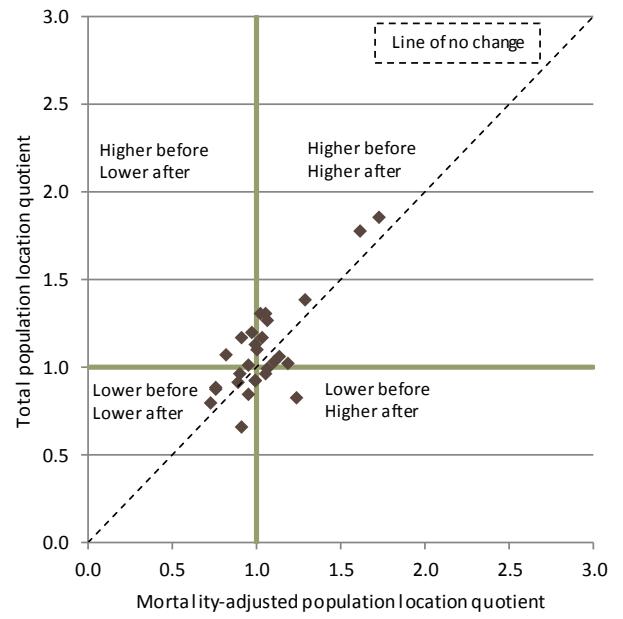

$f$

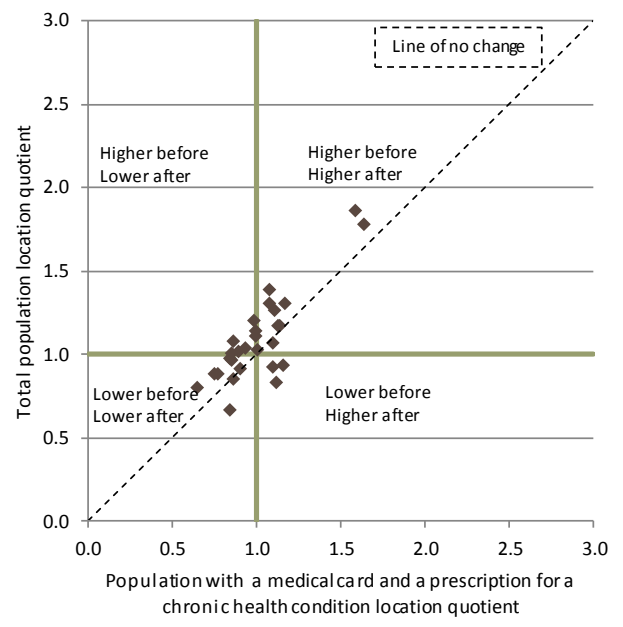

Notes: An area's location quotient is the area value divided by the national value. 'Higher before' means higher than the national value before adjustment. 'Lower before' means lower than the national value before adjustment. 'Higher after' means higher than the national value after adjustment. 'Lower after' means lower than the national value after adjustment. See Box 3.1 for help on interpreting the scatter plots. 


\subsection{PROFILE OF NON-ACUTE HEALTHCARE SUPPLY BY GEOGRAPHIC AREA - ALLIED HEALTH PROFESSIONALS}

\subsubsection{Supply of physiotherapists}

Table 4.11 and Figure 4.13 illustrate the geographic distribution of the number of publicly employed and private non-acute PTs in Ireland in 2014. ${ }^{53}$ Areas are ranked by WTEs of total (public and private) PTs per 10,000 population from highest to lowest. ${ }^{54}$ We are able to include data on private non-acute PT supply here for the first time.

The Gini coefficient for the distribution of public and private PTs is 0.116 , indicating an unequal distribution, and area values range from 2.4 PTs per 10,000 population in Meath to 5.1 PTs per 10,000 in Leitrim (national average 3.6/10,000)..$^{55}$

A more detailed examination of the geographic patterns indicates:

- The supply of PTs in two of the commuter areas around Dublin is among the lowest in the country: Meath $(2.4 / 10,000)$ and Wicklow $(2.5 / 10,000)$. Kildare $(3.2 / 10,000)$ has more PTs per 10,000 population than in the other commuter counties, but is still below the national value.

- There are more PTs per 10,000 population relative to the national value in the north and north west of the country (with the exception of Donegal), but also in other pockets of the country including Dublin South, Kerry and Limerick.

- Some areas would require between 8 and 22 additional WTE PTs to increase supply to the national level: Meath (-22.3 WTE PTs), Wicklow (-15.4 WTE PTs), Dublin North (-15.0 WTE PTs), Wexford (-14.8 WTE PTs), Waterford (-10.2 WTE PTs), Kildare (-9.1 WTE PTs), Clare (-8.5 WTE PTs) and Donegal (-8.0 WTE PTs). In contrast, Dublin South has an excess of 99.5 WTE PTs relative to the national level of supply. ${ }^{56}$ Interestingly, Dublin North and Dublin South have similar supplies of public WTE PTs, but Dublin South has much greater supply of private WTE PTs.

More detail on this analysis is provided in an accompanying research paper (Eighan et al., 2019).

53 Private PTs include PTs who work in voluntary institutions and who are not funded by the State.

$54 \quad$ Note that data are available on publicly employed WTE PTs while data on the number of private PTs are converted to WTEs using evidence from a survey of members of the Irish Society of Chartered Physiotherapists (ISCP).

55 The Gini coefficient for the distribution of publicly employed PTs is 0.167 and the Gini coefficient for private PTs is 0.199 .

56 The number for Dublin South excludes 32.5 WTE PTs in the National Rehabilitation Hospital in Dún Laoghaire, which is a national service rather than a local community service. 
TABLE 4.11 NUMBER OF WTE PUBLIC AND PRIVATE NON-ACUTE PHYSIOTHERAPISTS BY GEOGRAPHIC AREA, IRELAND 2014

\begin{tabular}{|c|c|c|c|c|c|c|c|}
\hline $\begin{array}{c}\text { Geographic } \\
\text { area }\end{array}$ & $\begin{array}{l}\text { Publicly } \\
\text { employed } \\
\text { PT WTE }\end{array}$ & $\begin{array}{c}\text { Private } \\
\text { PT } \\
\text { WTE }^{c, e}\end{array}$ & $\begin{array}{l}\text { Total } \\
\text { public } \\
\text { and } \\
\text { private } \\
\text { WTE }\end{array}$ & Population & $\begin{array}{c}\text { Total WTE PTs } \\
\text { per } 10,000 \\
\text { population }\end{array}$ & $\begin{array}{c}\text { Total PT } \\
\text { ratio of } \\
\text { area value } \\
\text { to national } \\
\text { value }\end{array}$ & $\begin{array}{c}\text { Excess or } \\
\text { deficit of total } \\
\text { PT WTEs } \\
\text { compared } \\
\text { with national } \\
\text { value }^{\text {a }}\end{array}$ \\
\hline Leitrim & 10.5 & 5.3 & 15.8 & 30,925 & 5.1 & 1.43 & 4.7 \\
\hline Dublin South & 135.9 & 216.4 & 352.3 & 704,937 & 5.0 & 1.39 & 99.5 \\
\hline Longford & 10.4 & 6.0 & 16.4 & 37,559 & 4.4 & 1.22 & 2.9 \\
\hline Kerry & 29.1 & 31.2 & 60.3 & 144,259 & 4.2 & 1.17 & 8.6 \\
\hline Westmeath & 21.7 & 13.8 & 35.5 & 86,854 & 4.1 & 1.14 & 4.4 \\
\hline Limerick & 32.6 & 44.5 & 77.1 & 192,681 & 4.0 & 1.12 & 8.0 \\
\hline Louth & 26.9 & 21.3 & 48.2 & 123,082 & 3.9 & 1.09 & 4.1 \\
\hline Sligo & 12.4 & 12.7 & 25.1 & 65,104 & 3.9 & 1.08 & 1.8 \\
\hline Galway & 36.7 & 60.5 & 97.2 & 254,959 & 3.8 & 1.06 & 5.8 \\
\hline Roscommon & 17.1 & 6.8 & 23.9 & 63,296 & 3.8 & 1.05 & 1.2 \\
\hline Mayo & 24.7 & 23.8 & 48.5 & 129,395 & 3.7 & 1.05 & 2.1 \\
\hline Cork & 68.2 & 113.9 & 182.1 & 524,199 & 3.5 & 0.97 & -5.9 \\
\hline Tipperary North & 11.0 & 13.0 & 24.0 & 69,861 & 3.4 & 0.96 & -1.0 \\
\hline Dublin North & 118.1 & 79.9 & 198.0 & 594,002 & 3.3 & 0.93 & -15.0 \\
\hline Tipperary South & 13.8 & 15.0 & 28.8 & 87,672 & 3.3 & 0.92 & -2.6 \\
\hline Carlow & 8.4 & 9.1 & 17.5 & 53,957 & 3.2 & 0.90 & -1.9 \\
\hline Kildare & 21.3 & 48.4 & 69.7 & 219,570 & 3.2 & 0.88 & -9.1 \\
\hline Donegal & 34.9 & 14.3 & 49.2 & 159,358 & 3.1 & 0.86 & -8.0 \\
\hline Kilkenny & 13.1 & 16.4 & 29.5 & 96,050 & 3.1 & 0.86 & -5.0 \\
\hline Laois & 15.0 & 8.7 & 23.7 & 80,166 & 3.0 & 0.82 & -5.1 \\
\hline Clare & 14.7 & 19.5 & 34.2 & 119,027 & 2.9 & 0.80 & -8.5 \\
\hline Cavan & 15.9 & 4.9 & 20.8 & 72,750 & 2.9 & 0.80 & -5.3 \\
\hline Offaly & 13.9 & 6.9 & 20.8 & 75,561 & 2.7 & 0.77 & -6.3 \\
\hline Waterford & 17.0 & 13.6 & 30.6 & 113,792 & 2.7 & 0.75 & -10.2 \\
\hline Wexford & 18.3 & 18.7 & 37.0 & 144,373 & 2.6 & 0.71 & -14.8 \\
\hline Monaghan & 13.6 & 1.5 & 15.1 & 59,822 & 2.5 & 0.70 & -6.4 \\
\hline Wicklow & 15.3 & 19.0 & 34.3 & 138,421 & 2.5 & 0.69 & -15.4 \\
\hline Meath & 22.3 & 24.2 & 46.5 & 191,931 & 2.4 & 0.68 & -22.3 \\
\hline Ireland & 792.5 & 869.3 & $1,661.8$ & $4,633,563$ & 3.6 & 1.00 & 0.0 \\
\hline Gini coefficient ${ }^{b}$ & & & & & 0.116 & & \\
\hline
\end{tabular}

Source: Data on the number of WTE publicly employed non-acute physiotherapists are from the HSE's HSPC December 2014. Data on the number of WTE privately non-acute physiotherapists are from the register of the ISCP.

Notes: (a) Excess or deficit of WTEs compared with national value is calculated as: area WTEs - (area WTEs/ratio of area value to national value). (b) The Gini coefficient summarises inequality in the distribution of non-acute physiotherapists across areas, with 0 representing complete equality across areas and 1 representing complete inequality across areas. (c) The number of private PTs is converted to WTEs using information from a survey of ISCP members, namely that $60 \%$ of PTs work full-time (1 WTE: over and above 1500 hours per year) and $40 \%$ work parttime (0.5 WTE), giving an adjustment factor of $0.8=(0.6 \times 1+0.4 \times 0.5)$. The survey was conducted by the ESRI in November 2015. (d) 32.5 WTE PTs based in the National Rehabilitation Hospital (NRH) in Dún Laoghaire have been deducted from the number of PTs in Dublin South because the NRH operates a national service rather than a local community service. (e) Seventeen individuals are registered as working in a voluntary organisation but the source of funding is unclear (i.e. public or private). These are excluded from this analysis to avoid potential double counting. Including these PTs increases the total number of WTE PTs to 1,710 WTE PTs in Ireland (3.69 per 10,000 population). 


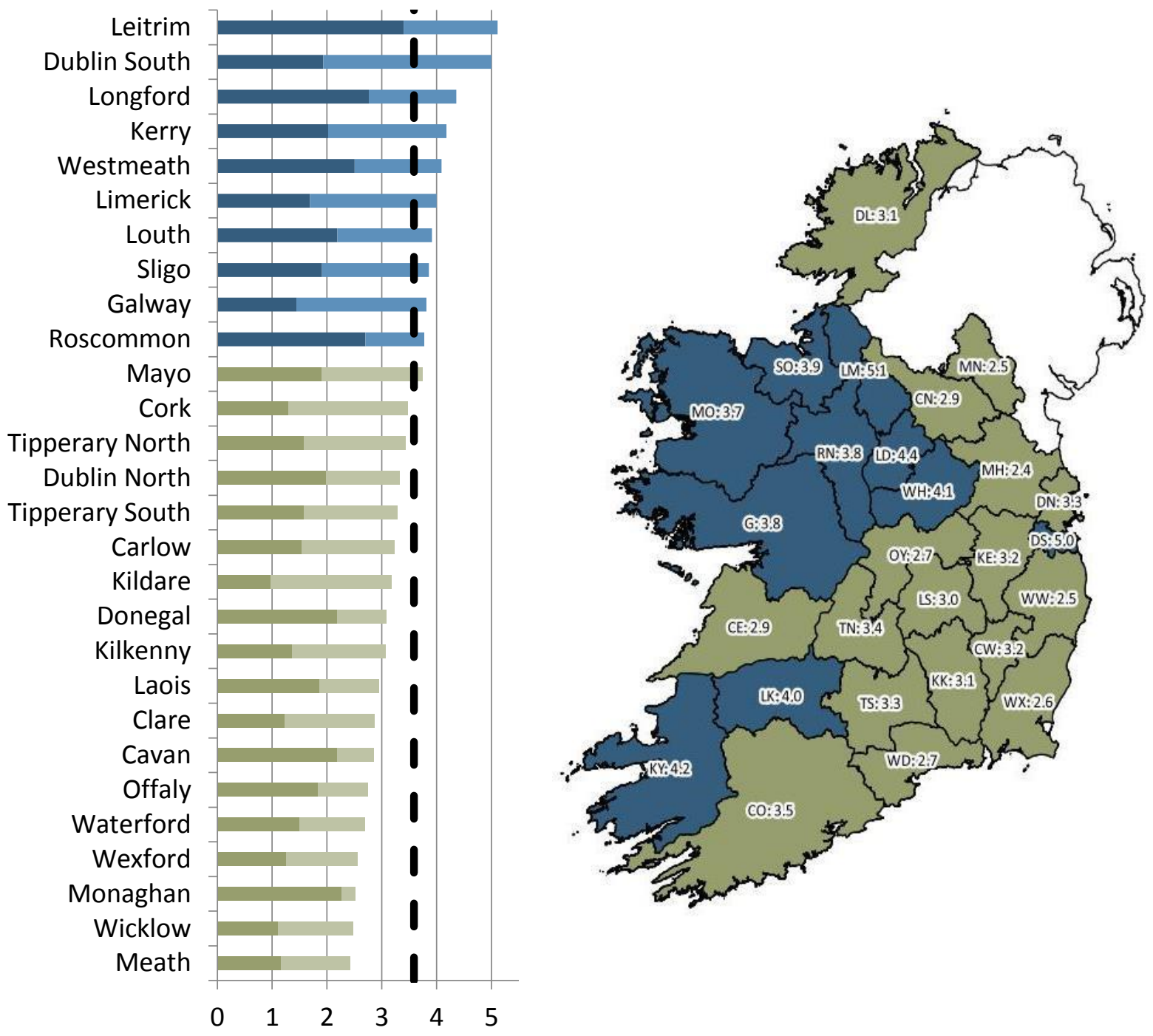

\section{Needs-adjusted total (public and private) physiotherapist supply}

Figure 4.14 illustrates the impact on the geographic pattern of PT supply following adjustment of the population for a range of need indicators..$^{57}$ Figure $4.14 a-4.14 \mathrm{~d}$ illustrates the impact of adjustment for age, mortality and disability on the geographic pattern of total public and private PT supply, while Figure $4.14 \mathrm{e}-4.14 \mathrm{f}$ shows the impact of adjustment for Medical Card coverage and morbidity on public PT supply. ${ }^{58}$ The scatter plots illustrate the extent to which the supply of PTs (i.e. WTE PTs per capita) in an area changes relative to the national value, following

\footnotetext{
57 See Section 3.4.2 for the definitions of the need indicators and how they were used to adjust supply.

58 Medical cards do not cover private PT care, but Medical Card holders often get priority access to publicly funded nonacute services including public physiotherapy, community nursing and others.
} 
adjustment for a specific need indicator. Further details can be found in Appendices 4 and 5.

For total PT supply, the majority of the areas are positioned close to the line of no change', and fall in the top right or bottom left quadrant, following adjustment for each of older age groups, mortality and disability. In other words, the majority of areas have a higher (or lower) level of WTE PTs per 10,000 population relative to the national value before adjustment and continue to have a higher (or lower) level of WTE PTs per 10,000 population relative to the national value following adjustment for each need indicator. The adjustment for disability (Figure 4.14d) shows the least change in the position of areas relative to the national value; the data points in the scatter plot lie very close to the 'line of no change'.

For public PT supply, the majority of the areas are close to the line of no change following adjustment for Medical Card coverage and for morbidity (i.e. top right and bottom left quadrants in Figure 4.14e and 4.14f).

\section{Ratio of area supply relative to national supply before and after adjustment}

Some notable area-specific patterns for total PT supply are:

- With the exception of Kildare and Dublin North, all areas that have a lower level of total WTE PTs per 10,000 population relative to the national value before adjustment continue to have a lower level relative to the national value following adjustment, for all need indicators (i.e. bottom left quadrant in Figures 4.14a-4.14d).

- Kildare lies inside the bottom right quadrant of Figure 4.14a-4.14c (i.e. lower before, higher after) following each separate adjustment of the population for age (65+ and 85+) and mortality. Dublin North lies just inside the bottom right quadrant of Figure 4.14a and $4.14 \mathrm{~b}$ following adjustment for age (65+ and $85+)$.

- A small number of areas fall in the top left quadrant (i.e. higher before, lower after) following adjustment for some of the need indicators:

- Roscommon, Sligo and Kerry are in the top left quadrant of Figure 4.14a-4.14c following each separate adjustment for age (65+ and $85+)$ and mortality.

- Leitrim is in the top left quadrant of Figure $4.14 \mathrm{~b}$ following adjustment for older age $85+$. 
FIGURE 4.14 SCATTER PLOT OF LOCATION QUOTIENTS OF THE NUMBER OF WTE PUBLIC AND PRIVATE NON-ACUTE PHYSIOTHERAPISTS PER 10,000 TOTAL POPULATION AND PER 10,000 NEEDS-ADJUSTED POPULATIONS BY GEOGRAPHIC AREA, IRELAND 2014

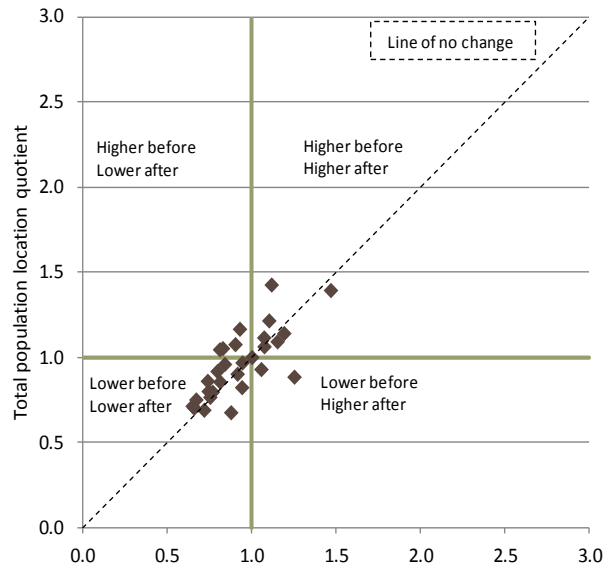

Olderpop

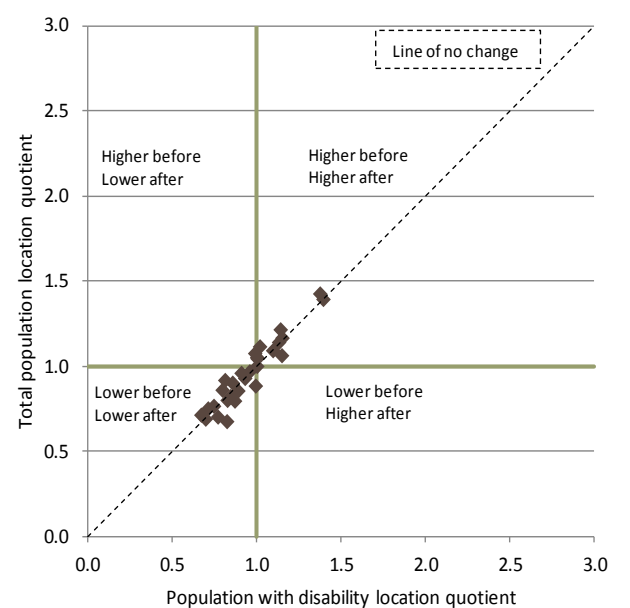

b

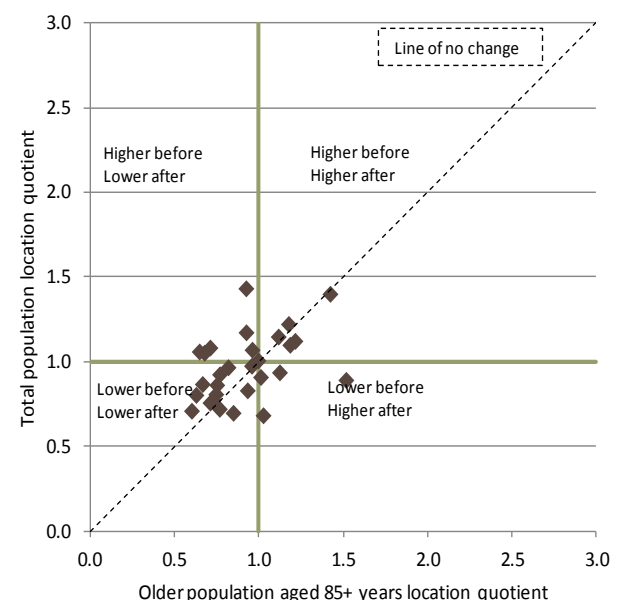

e

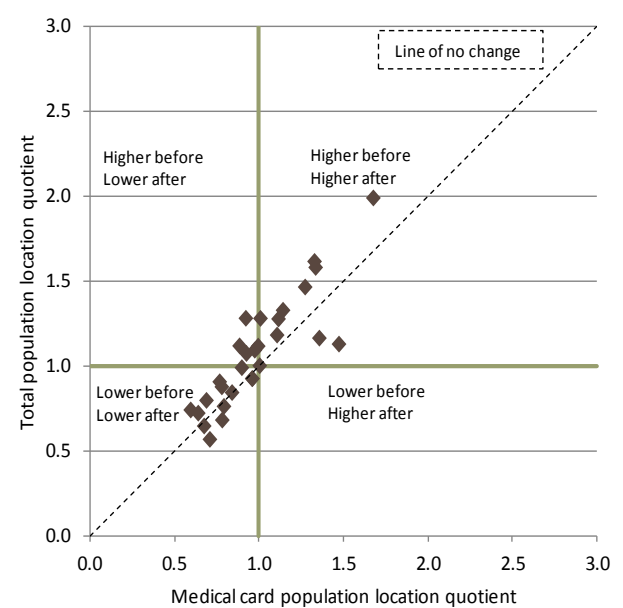

C

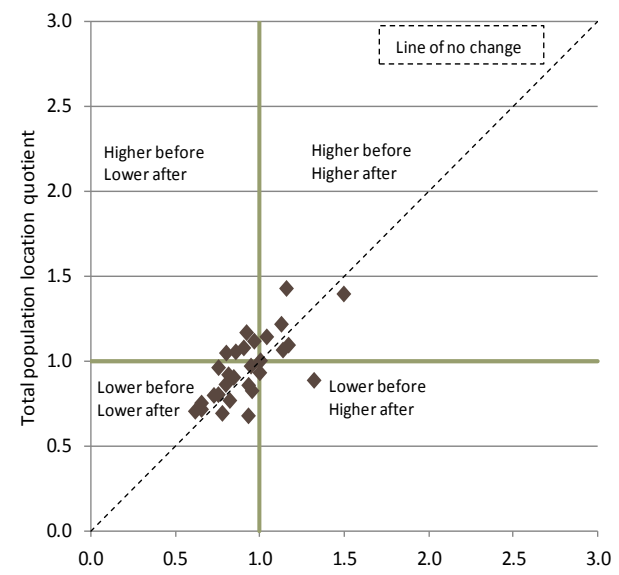

Mortality-adjusted population location quotient

f

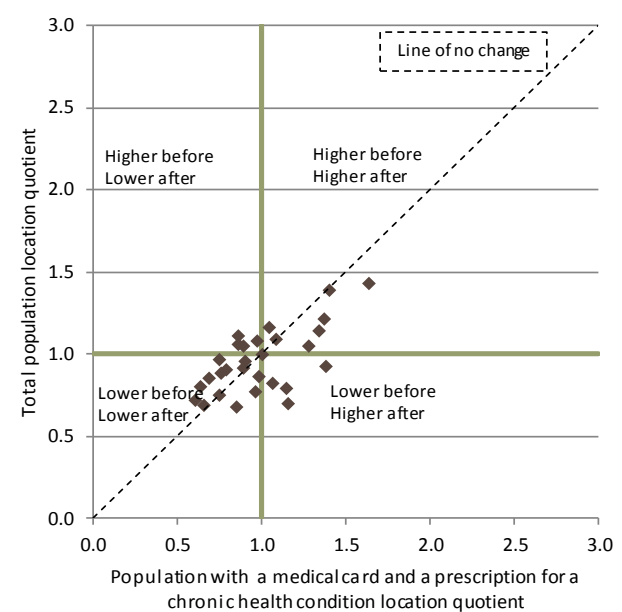

Notes: An area's location quotient is the area value divided by the national value. 'Higher before' means higher than the national value before adjustment. 'Lower before' means lower than the national value before adjustment. 'Higher after' means higher than the national value after adjustment. 'Lower after' means lower than the national value after adjustment. See Box 3.1 for help on interpreting the scatter plots. (g) Adjustment for Medical Card coverage and adjustment for the population with a Medical Card and a prescription for a chronic health condition are made for publicly employed PTs only. 


\subsubsection{Supply of occupational therapists}

Table 4.12 and Figure 4.15 illustrate the geographic distribution of the number of publicly employed non-acute OTs in Ireland in 2014, with areas ranked by WTEs per 10,000 population from highest to lowest.

The Gini coefficient for the distribution of OTs is 0.175 , indicating an unequal distribution, and area values range from 1.2 OTs per 10,000 population in Wicklow to 5.3 OTs per 10,000 in Leitrim (national average $2.2 / 10,000$ ).

A more detailed examination of the geographic patterns shows that:

- Compared with the national value, there are more OTs per 10,000 population in a selection of counties in the border region (Donegal is within $5 \%$ of the national value) and in Dublin relative to the rest of the country.

- As observed for PTs, the numbers of WTE OTs in the commuter areas around Dublin are among the lowest in the country - Wicklow $(1.2 / 10,000)$, Meath $(1.3 / 10,000)$ and Kildare $(1.4 / 10,000)$.

- These commuter areas would require 14-19 additional WTE publicly employed non-acute OTs to increase supply in those areas to the national level - Kildare (-18.9 WTE OTs), Meath (-17.7 WTE OTs) and Wicklow (-14.0 WTE OTs). In contrast, Dublin South has more than 29 WTE OTs in excess of the national level of supply. ${ }^{59}$

59 The number for Dublin South excludes 34.1 WTE OTs in the NRH in Dún Laoghaire, which is a national service rather than a local community service. 
TABLE 4.12 NUMBER OF WTE PUBLICLY EMPLOYED NON-ACUTE OCCUPATIONAL THERAPISTS BY GEOGRAPHIC AREA, IRELAND 2014

\begin{tabular}{|c|c|c|c|c|c|}
\hline Geographic area & $\begin{array}{l}\text { WTE publicly } \\
\text { employed OTs }\end{array}$ & Population & $\begin{array}{l}\text { WTE publicly } \\
\text { employed OTs per } \\
10,000 \text { population }\end{array}$ & $\begin{array}{l}\text { Ratio of area } \\
\text { value to } \\
\text { national } \\
\text { value }\end{array}$ & $\begin{array}{l}\text { Excess or deficit of } \\
\text { WTEs compared } \\
\text { with national value }\end{array}$ \\
\hline Leitrim & 16.4 & 30,925 & 5.3 & 2.37 & 9.5 \\
\hline Sligo & 28.0 & 65,104 & 4.3 & 1.91 & 13.3 \\
\hline Dublin South & 187.7 & 704,937 & 2.7 & 1.18 & 29.2 \\
\hline Westmeath & 25.0 & 86,854 & 2.9 & 1.28 & 5.5 \\
\hline Monaghan & 16.9 & 59,822 & 2.8 & 1.25 & 3.4 \\
\hline Laois & 22.4 & 80,166 & 2.8 & 1.24 & 4.4 \\
\hline Louth & 33.8 & 123,082 & 2.7 & 1.22 & 6.1 \\
\hline Carlow & 14.2 & 53,957 & 2.6 & 1.17 & 2.1 \\
\hline Dublin North & 147.8 & 594,002 & 2.5 & 1.11 & 14.3 \\
\hline Cavan & 17.6 & 72,750 & 2.4 & 1.07 & 1.2 \\
\hline Longford & 9.1 & 37,559 & 2.4 & 1.07 & 0.6 \\
\hline Mayo & 29.8 & 129,395 & 2.3 & 1.02 & 0.7 \\
\hline Roscommon & 14.0 & 63,296 & 2.2 & 0.99 & -0.2 \\
\hline Donegal & 35.1 & 159,358 & 2.2 & 0.98 & -0.7 \\
\hline Cork & 113.7 & 524,199 & 2.2 & 0.96 & -4.2 \\
\hline Kilkenny & 20.5 & 96,050 & 2.1 & 0.95 & -1.1 \\
\hline Kerry & 30.7 & 144,259 & 2.1 & 0.95 & -1.7 \\
\hline Limerick & 40.8 & 192,681 & 2.1 & 0.94 & -2.5 \\
\hline Galway & 53.3 & 254,959 & 2.1 & 0.93 & -4.1 \\
\hline Tipperary South & 18.2 & 87,672 & 2.1 & 0.92 & -1.5 \\
\hline Offaly & 15.2 & 75,561 & 2.0 & 0.89 & -1.8 \\
\hline Clare & 23.1 & 119,027 & 1.9 & 0.86 & -3.7 \\
\hline Waterford & 21.6 & 113,792 & 1.9 & 0.85 & -3.9 \\
\hline Wexford & 24.5 & 144,373 & 1.7 & 0.76 & -7.9 \\
\hline Kildare & 30.5 & 219,570 & 1.4 & 0.62 & -18.9 \\
\hline Meath & 25.5 & 191,931 & 1.3 & 0.59 & -17.7 \\
\hline Tipperary North & 9.2 & 69,861 & 1.3 & 0.58 & -6.5 \\
\hline Wicklow & 17.1 & 138,421 & 1.2 & 0.55 & -14.0 \\
\hline Ireland & $1,041.5$ & $4,633,563$ & 2.2 & 1.00 & 0.0 \\
\hline Gini coefficient & & & 0.171 & & \\
\hline
\end{tabular}

Source: Data on the number of WTE publicly employed non-acute occupational therapists are from the HSE's HSPC December 2014.

Notes: (a) Excess or deficit of WTEs compared with national value is calculated as: area WTEs - (area WTEs/ratio of area value to national value). (b) The Gini coefficient summarises inequality in the distribution of publicly employed nonacute OTs across areas, with 0 representing complete equality across areas and 1 representing complete inequality across areas. (c) The numbers for Dublin South exclude 34.1 WTE OTs in the NRH in Dún Laoghaire, which is a national service rather than a local community service. 


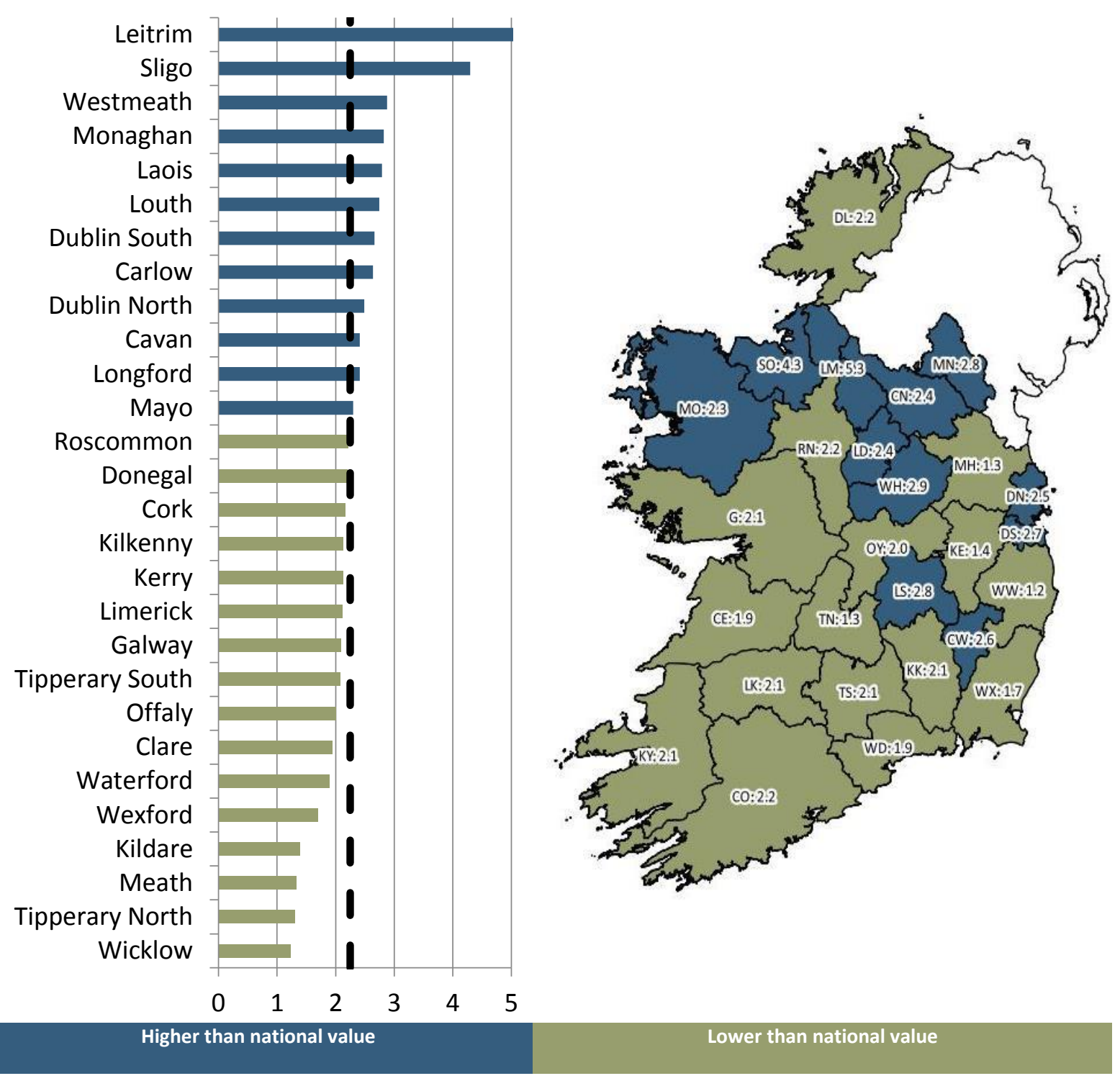

\section{Needs-adjusted occupational therapist supply}

Figure 4.16 illustrates the impact on the geographic pattern of OT supply following adjustment of the population for a range of need indicators. ${ }^{60}$ Further details can be found in Appendices 4 and 5 .

As with PT supply, for each need indicator (i.e. older age groups, mortality, disability, Medical Card coverage and morbidity), the majority of the areas are positioned close to the 'line of no change', and fall in the top right or bottom left quadrants. The adjustment of OT supply for disability (Figure 4.16d) shows the least change in the position of areas relative to the national value; the data points 
in the scatter plot lie very close to the 'line of no change'.

\section{Ratio of area supply relative to national supply before and after}

\section{adjustment}

Some notable area-specific patterns are:

- With the exception of Kildare, all areas that have a lower level of WTE OTs per capita relative to the national value before adjustment continue to have a lower level relative to the national value following adjustment, for all need indicators (i.e. bottom left quadrant in Figure 4.16a-4.16f).

- Kildare lies in the bottom right quadrant of Figure $4.16 \mathrm{~b}$ (i.e. lower before, higher after) following adjustment of the population for age $85+$.

- Cavan and Longford are in the top left quadrant (i.e. higher before, lower after) following adjustment of OT supply for Medical Card coverage and for age 85+ (Cavan) and morbidity (Longford). 
FIGURE 4.16 SCATTER PLOT OF LOCATION QUOTIENTS OF THE NUMBER OF WTE PUBLICLY EMPLOYED NON-ACUTE OCCUPATIONAL THERAPISTS PER 10,000 TOTAL POPULATION AND PER 10,000 NEEDS-ADJUSTED POPULATIONS BY GEOGRAPHIC AREA, IRELAND 2014
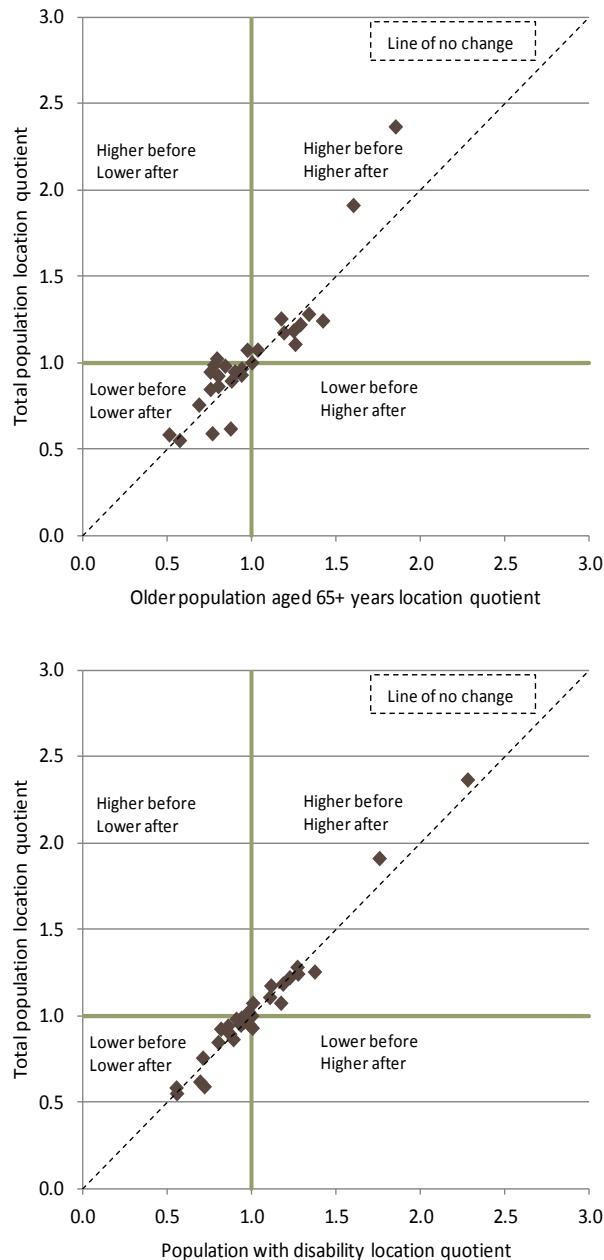

b

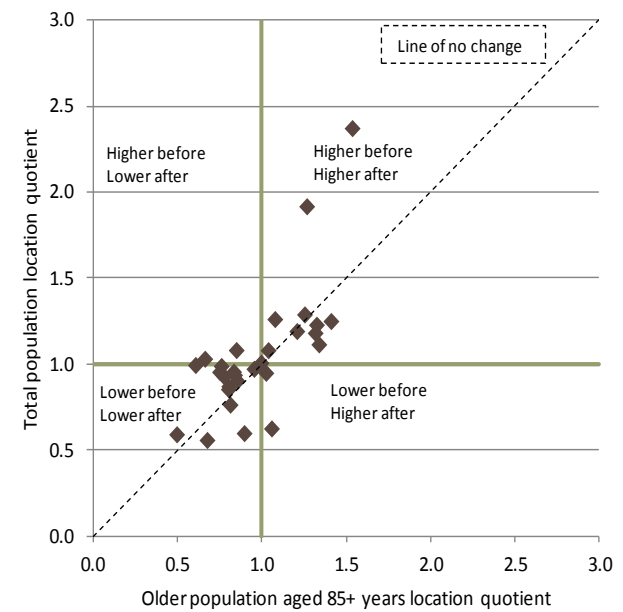

e

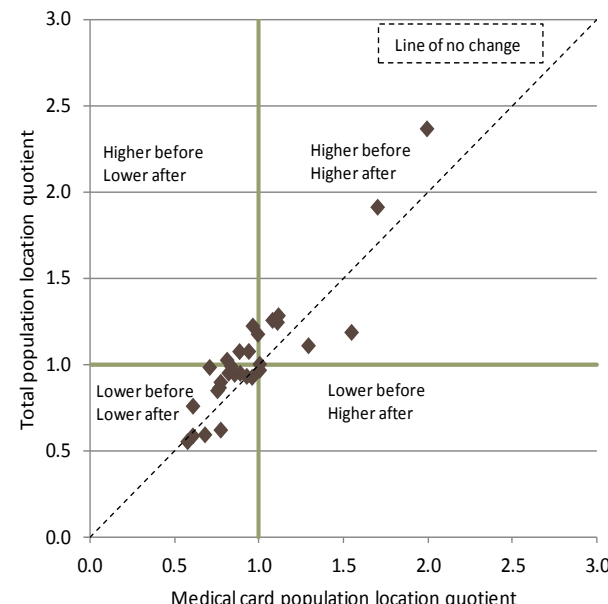

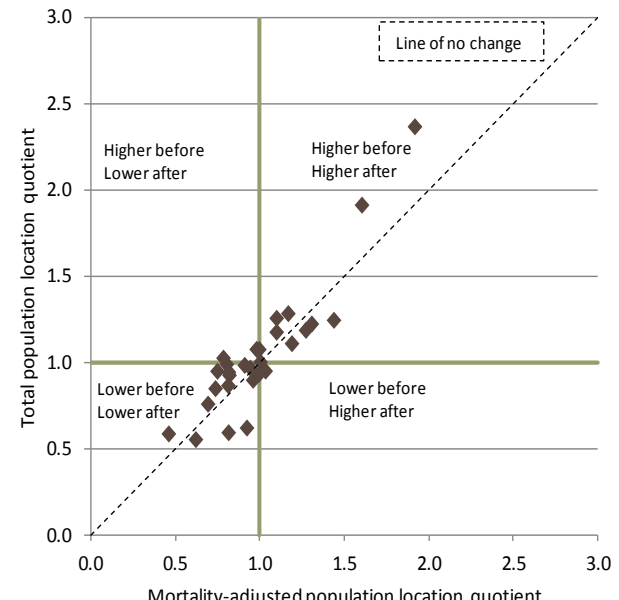

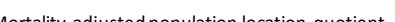

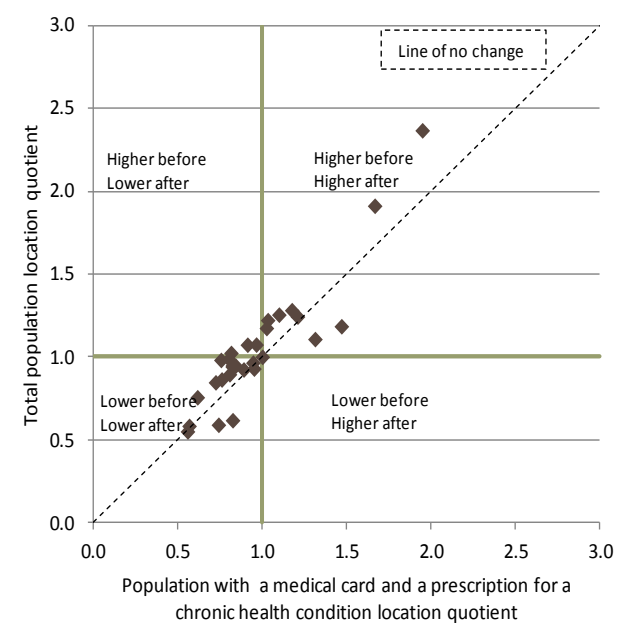

Notes: $\quad$ An area's location quotient is the area value divided by the national value. 'Higher before' means higher than the national value before adjustment. 'Lower before' means lower than the national value before adjustment. 'Higher after' means higher than the national value after adjustment. 'Lower after' means lower than the national value after adjustment. See Box 3.1 for help on interpreting the scatter plots. 


\subsubsection{Supply of speech and language therapists}

The geographic distribution of the number of publicly employed non-acute SLTs in Ireland in 2014 is presented in Table 4.13 and Figure 4.17, with areas ranked by WTEs per 10,000 population from highest to lowest.

The Gini coefficient for the distribution of SLTs is 0.120 , indicating an unequal distribution. Area values range from 1.1 SLTs per 10,000 population in Carlow to 2.3 SLTs per 10,000 in Sligo (national average 1.5/10,000).

Looking in more detail at the geographic patterns:

- Compared with the national value, there are more SLTs per 10,000 population in a cluster of counties in the northwest of the country including Sligo, Roscommon, Leitrim, Westmeath, Longford, Mayo (and Galway is within $5 \%$ of the national value). The ratio of SLTs in an area to the national value is also high in Tipperary South, Dublin (North and South) and Cork.

- Similar to PTs and OTs, the numbers of WTE SLTs in the commuter areas around Dublin are among the lowest in the country - Kildare, Wicklow and Meath (1.1-1.2/10,000).

- Also similar to PTs and OTs, the highest deficits in SLT supply (measured by the number of WTE publicly employed non-acute SLTs required to bring supply to the national level) are observed in the commuter areas but the absolute numbers are much smaller. Relative to the national level of supply the deficit in the commuter belt ranges from -9.5 WTE SLTs in Kildare to -7.0 WTE SLTs in Meath and -5.6 in Wicklow. In contrast, Dublin North has a relative excess of 8.5 WTE SLTs.

Analysis of the supply of publicly employed SLTs needs to be supplemented with analysis of supply of private SLT services. There is limited information on the extent to which SLTs are working in private practice in Ireland and further investigation is required into this area. 
TABLE 4.13

NUMBER OF WTE PUBLICLY EMPLOYED NON-ACUTE SPEECH AND LANGUAGE THERAPISTS BY GEOGRAPHIC AREA, IRELAND 2014

\begin{tabular}{|c|c|c|c|c|c|}
\hline Geographic area & $\begin{array}{l}\text { WTE publicly } \\
\text { employed SLTs }\end{array}$ & Population & $\begin{array}{c}\text { WTE publicly } \\
\text { employed SLTs per } \\
10,000 \text { population }\end{array}$ & $\begin{array}{c}\text { Ratio of area } \\
\text { value to } \\
\text { national } \\
\text { value }\end{array}$ & $\begin{array}{l}\text { Excess or deficit of } \\
\text { WTEs compared } \\
\text { with national value }\end{array}$ \\
\hline Sligo & 14.8 & 65,104 & 2.3 & 1.47 & 4.7 \\
\hline Roscommon & 13.7 & 63,296 & 2.2 & 1.40 & 3.9 \\
\hline Leitrim & 6.5 & 30,925 & 2.1 & 1.37 & 1.8 \\
\hline Westmeath & 18.2 & 86,854 & 2.1 & 1.36 & 4.8 \\
\hline Longford & 7.3 & 37,559 & 1.9 & 1.25 & 1.5 \\
\hline Mayo & 23.7 & 129,395 & 1.8 & 1.18 & 3.7 \\
\hline Tipperary South & 15.4 & 87,672 & 1.8 & 1.14 & 1.9 \\
\hline Dublin North & 100.4 & 594,002 & 1.7 & 1.09 & 8.5 \\
\hline Cork & 88.4 & 524,199 & 1.7 & 1.09 & 7.3 \\
\hline Dublin South ${ }^{c}$ & 116.3 & 704,937 & 1.6 & 1.07 & 7.2 \\
\hline Galway & 41.3 & 254,959 & 1.6 & 1.05 & 1.8 \\
\hline Laois & 12.6 & 80,166 & 1.6 & 1.01 & 0.2 \\
\hline Kerry & 22.6 & 144,259 & 1.6 & 1.01 & 0.2 \\
\hline Tipperary North & 10.8 & 69,861 & 1.5 & 1.00 & 0.0 \\
\hline Donegal & 24.1 & 159,358 & 1.5 & 0.98 & -0.5 \\
\hline Monaghan & 9.0 & 59,822 & 1.5 & 0.97 & -0.3 \\
\hline Cavan & 10.8 & 72,750 & 1.5 & 0.96 & -0.5 \\
\hline Limerick & 26.5 & 192,681 & 1.4 & 0.89 & -3.3 \\
\hline Waterford & 15.2 & 113,792 & 1.3 & 0.87 & -2.4 \\
\hline Offaly & 10.1 & 75,561 & 1.3 & 0.86 & -1.6 \\
\hline Louth & 16.0 & 123,082 & 1.3 & 0.84 & -3.1 \\
\hline Wexford & 18.4 & 144,373 & 1.3 & 0.83 & -3.9 \\
\hline Clare & 15.2 & 119,027 & 1.3 & 0.82 & -3.3 \\
\hline Meath & 22.7 & 191,931 & 1.2 & 0.76 & -7.0 \\
\hline Kilkenny & 11.2 & 96,050 & 1.2 & 0.75 & -3.7 \\
\hline Wicklow & 15.8 & 138,421 & 1.1 & 0.74 & -5.6 \\
\hline Kildare & 24.1 & 219,570 & 1.1 & 0.71 & -9.9 \\
\hline Carlow & 5.8 & 53,957 & 1.1 & 0.69 & -2.6 \\
\hline Ireland & 716.9 & $4,633,563$ & 1.5 & 1.00 & 0.0 \\
\hline Gini coefficient & & & 0.120 & & \\
\hline
\end{tabular}

Source: Data on the number of WTE publicly employed non-acute SLTS are from the HSE's HSPC December 2014.

Notes: (a) Excess or deficit of WTEs compared with national value is calculated as: area WTEs - (area WTEs/ratio of area value to national value). (b) The Gini coefficient summarises inequality in the distribution of publicly employed nonacute SLTs across areas, with 0 representing complete equality across areas and 1 representing complete inequality across areas. (c) The numbers for Dublin South exclude 13.5 WTE SLTs in the NRH in Dún Laoghaire, which is a national service rather than a local community service. 


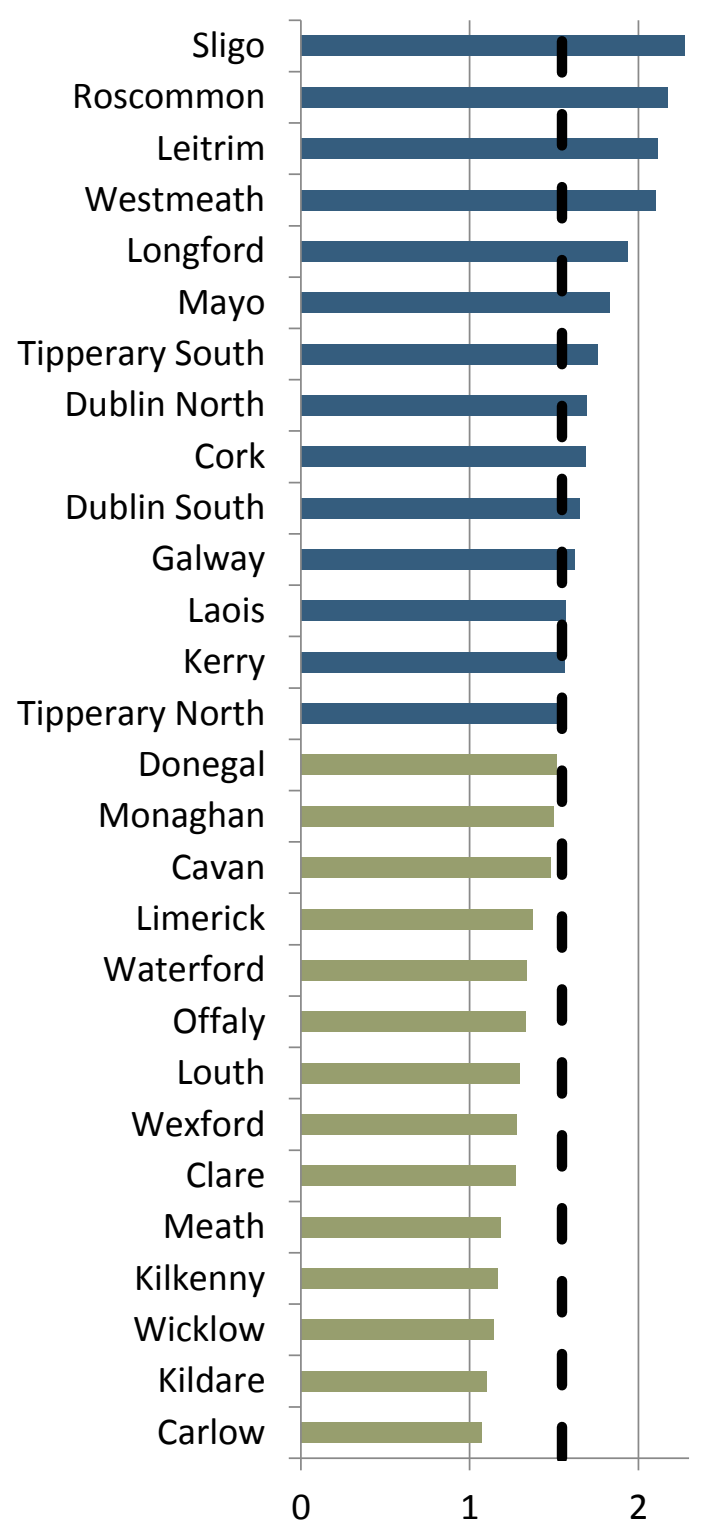

Higher than national value

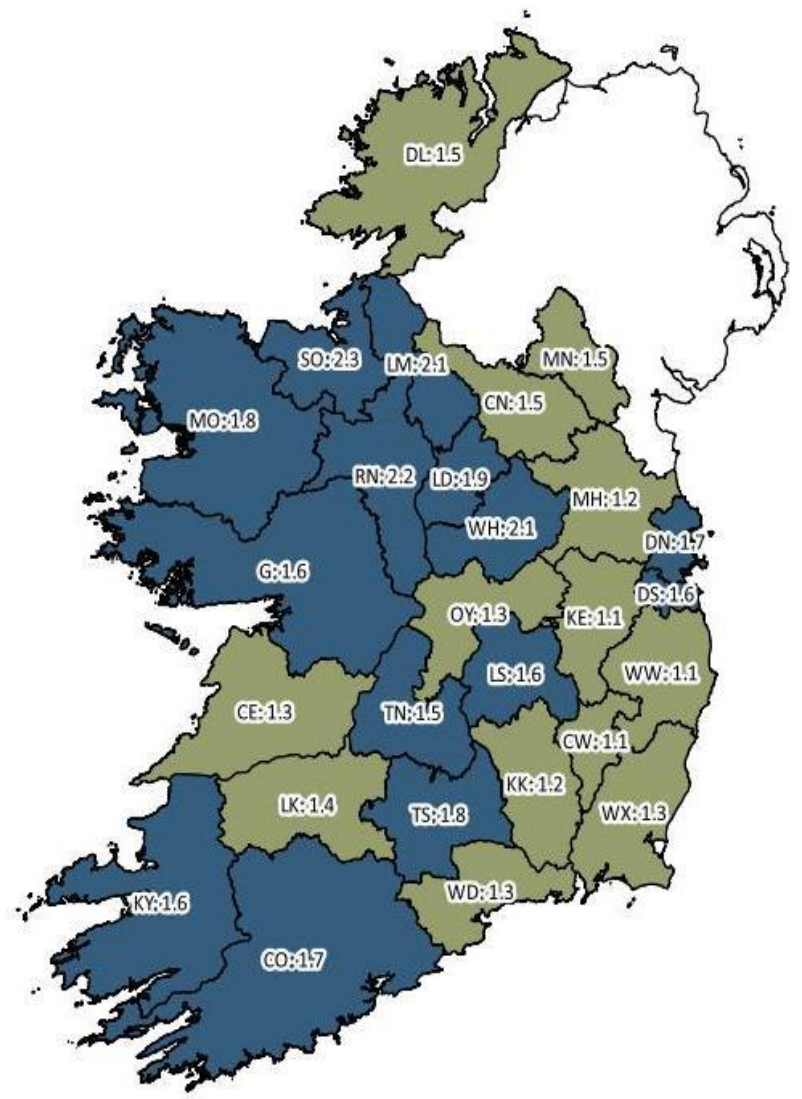

Lower than national value

\section{Needs-adjusted speech and language therapist supply}

Figure 4.18 illustrates the impact on the geographic pattern of SLT supply following adjustment of the population for a range of need indicators. ${ }^{61}$ Further details can be found in Appendices 4 and 5 .

For each need indicator, the majority of areas are positioned close to the 'line of no change' and fall in the top right or bottom left quadrant of Figure 4.18.

61 See Section 3.4.2 for the definitions of the need indicators and how they were used to adjust supply. 
As with PT and OT supply, the adjustment of SLT supply for disability (Figure 4.18d) shows the least change in the position of areas relative to the national value; the data points in the scatter plot lie very close to the 'line of no change' ${ }^{62}$

\section{Ratio of area supply relative to national supply before and after adjustment}

Some notable area-specific patterns are as follows.

- With the exception of Kildare and Meath, all areas that have a lower level of WTE SLTS per capita relative to the national value before adjustment continue to have a lower level relative to the national value following adjustment, for all need indicators (i.e. bottom left quadrant in Figure 4.18a-4.18f).

- Kildare and Meath lie in the bottom right quadrant of Figure $4.18 \mathrm{~b}$ and $4.18 \mathrm{c}$ (i.e. lower before, higher after) following adjustment of the population for age (85+) and for mortality.

- Mayo lies inside the top left quadrant of Figure 4.18a-4.18c (i.e. higher before, lower after) and 4.18e and 4.18f following each separate adjustment for age (65+ and 85+), mortality, Medical Card coverage and morbidity. Roscommon and Leitrim lie inside the top left quadrant of Figure $4.18 \mathrm{~b}$ following adjustment for age (85+).

62 Adjustment is made for older age groups given that SLT services are important for rehabilitation following stroke and other conditions that affect mainly older age groups. Another dominant use group is the 0-4 age group for early speech development (Wren et al., 2017). Adjustment for the 0-4 age group, and for both age 85+ and 0-4 together, shows very little change in the distribution of supply across counties. 
FIGURE 4.18 SCATTER PLOT OF LOCATION QUOTIENTS OF THE NUMBER OF WTE PUBLICLY EMPLOYED NON-ACUTE SPEECH AND LANGUAGE THERAPISTS PER 10,000 TOTAL POPULATION AND PER 10,000 NEEDS-ADJUSTED POPULATIONS BY GEOGRAPHIC AREA, IRELAND 2014

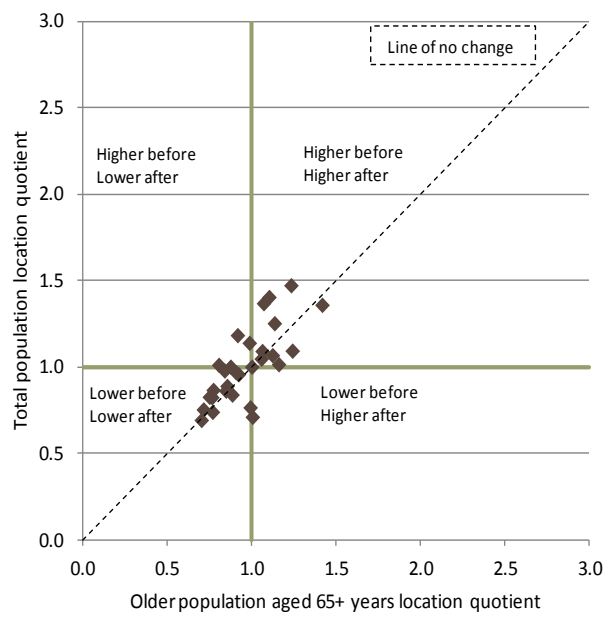

d

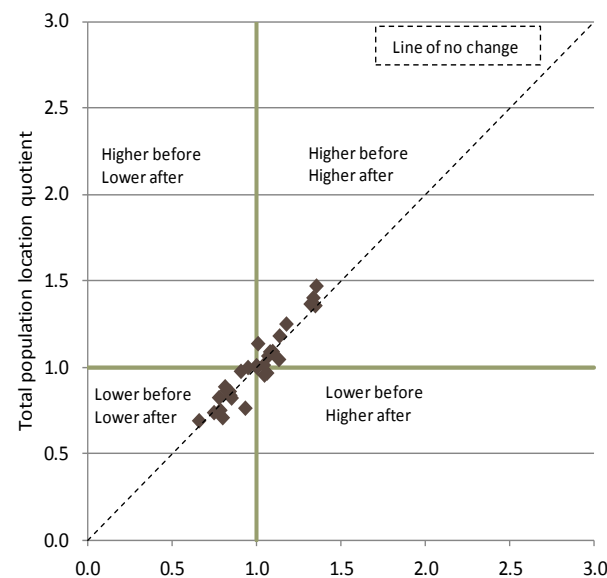

b

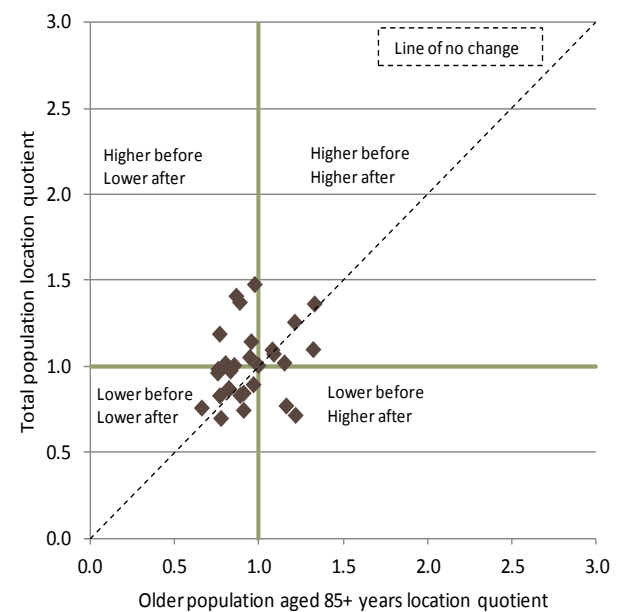

e

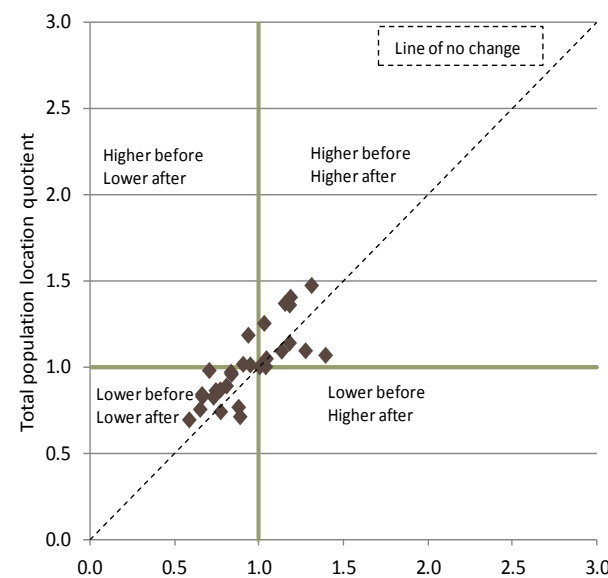

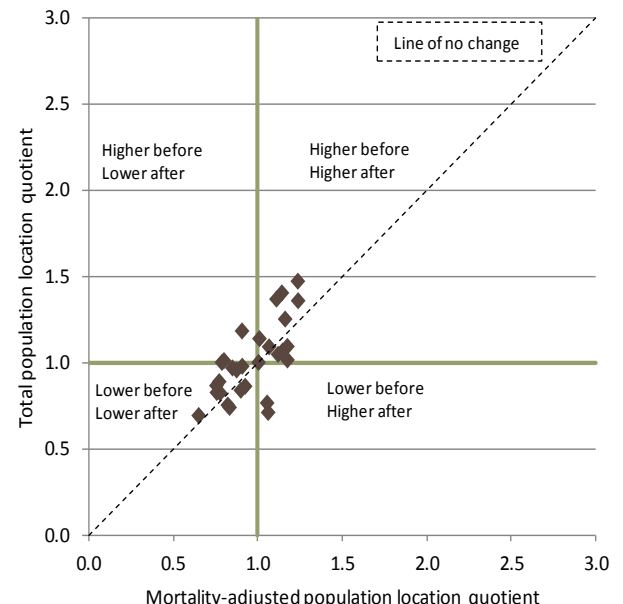

(05)

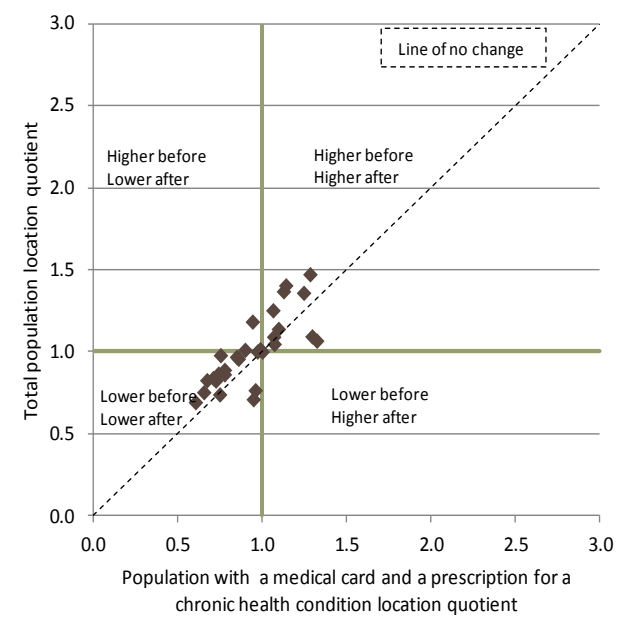

An area's location quotient is the area value divided by the national value. 'Higher before' means higher than the national value before adjustment. 'Lower before' means lower than the national value before adjustment. 'Higher after' means higher than the national value after adjustment. 'Lower after' means lower than the national value after adjustment. See Box 3.1 for help on interpreting the scatter plots. 


\subsubsection{Supply of podiatrists and chiropodists ${ }^{63}$}

The geographic distribution of the number of publicly employed non-acute P\&Cs in Ireland in 2014 is presented in Table 4.14 and Figure 4.19, with areas ranked by WTEs per 10,000 population from highest to lowest.

The Gini coefficient for the distribution of P\&Cs is by far the highest (0.615) estimated in this report, indicating a very unequal distribution. Area values range from no P\&Cs in a number of areas (e.g. Dublin North) to 0.37 P\&Cs per 10,000 in Sligo (national average $0.07 / 10,000$ ).

Looking in more detail at the geographic patterns:

- There are no publicly employed P\&Cs in any of the following areas: Dublin North, Kerry, Laois, Limerick, Roscommon, Tipperary South and Wexford.

- Other areas with fewer P\&Cs per 10,000 population than the national value are concentrated in eastern areas including Louth, Waterford, Wicklow, Kilkenny, Kildare, Carlow, Dublin South and Meath. The ratio of P\&Cs in an area to the national value is also low in Mayo and Longford.

- Given the low national average number of publicly employed P\&Cs, the deficits in P\&C supply (as measured by the number of WTE publicly employed non-acute P\&Cs required to bring supply in an area to the national level) are very small. Dublin North would require 4.3 additional P\&Cs to bring supply in that area up to the national value, and in other areas the size of the deficit ranges from -1.9 to -0.1 .

The extent to which podiatry and chiropody services are undertaken by the private sector needs to be examined given the low level of public supply relative to other non-acute services analysed in this report.

63 We include all public employees using the title of 'chiropodist' or 'podiatrist', though the title 'podiatrist' has replaced the title 'chiropodist' (Citizens Information, 2018). While the HSE is not legally obliged to provide chiropody or podiatry services, where available these services can be provided by LHOs or voluntary organisations on behalf of the HSE (Citizens Information, 2018). 
TABLE 4.14 NUMBER OF WTE PUBLICLY EMPLOYED NON-ACUTE PODIATRISTS AND CHIROPODISTS BY GEOGRAPHIC AREA, IRELAND 2014

\begin{tabular}{|c|c|c|c|c|c|}
\hline Geographic area & $\begin{array}{l}\text { WTE publicly } \\
\text { employed P\&Cs }\end{array}$ & Population & $\begin{array}{l}\text { WTE publicly employed } \\
\text { P\&Cs per } 10,000 \\
\text { population }\end{array}$ & $\begin{array}{l}\text { Ratio of area } \\
\text { value to } \\
\text { national } \\
\text { value }\end{array}$ & $\begin{array}{c}\text { Excess or deficit of } \\
\text { WTEs compared } \\
\text { with national } \\
\text { value }\end{array}$ \\
\hline Sligo & 2.4 & 65,104 & 0.37 & 5.04 & 1.9 \\
\hline Leitrim & 1.1 & 30,925 & 0.36 & 4.92 & 0.9 \\
\hline Galway & 6.4 & 254,959 & 0.25 & 3.46 & 4.6 \\
\hline Clare & 2.8 & 119,027 & 0.23 & 3.22 & 1.9 \\
\hline Monaghan & 1.2 & 59,822 & 0.20 & 2.76 & 0.8 \\
\hline Donegal & 2.9 & 159,358 & 0.18 & 2.55 & 1.8 \\
\hline Westmeath & 1.2 & 86,854 & 0.14 & 1.87 & 0.5 \\
\hline Cork & 7.1 & 524,199 & 0.13 & 1.85 & 3.2 \\
\hline Offaly & 0.9 & 75,561 & 0.12 & 1.59 & 0.3 \\
\hline Tipperary North & 0.7 & 69,861 & 0.10 & 1.36 & 0.2 \\
\hline Cavan & 0.6 & 72,750 & 0.08 & 1.12 & 0.1 \\
\hline Longford & 0.2 & 37,559 & 0.06 & 0.81 & -0.1 \\
\hline Meath & 1.0 & 191,931 & 0.05 & 0.68 & -0.4 \\
\hline Dublin South & 3.2 & 704,937 & 0.04 & 0.62 & -1.9 \\
\hline Carlow & 0.2 & 53,957 & 0.04 & 0.54 & -0.2 \\
\hline Mayo & 0.5 & 129,395 & 0.04 & 0.53 & -0.4 \\
\hline Kildare & 0.8 & 219,570 & 0.04 & 0.50 & -0.8 \\
\hline Kilkenny & 0.3 & 96,050 & 0.03 & 0.42 & -0.4 \\
\hline Wicklow & 0.2 & 138,421 & 0.01 & 0.19 & -0.8 \\
\hline Waterford & 0.1 & 113,792 & 0.01 & 0.12 & -0.7 \\
\hline Louth & 0.0 & 123,082 & 0.00 & 0.01 & -0.9 \\
\hline Dublin North & 0.0 & 594,002 & 0.00 & 0.00 & -4.3 \\
\hline Kerry & 0.0 & 144,259 & 0.00 & 0.00 & -1.0 \\
\hline Laois & 0.0 & 80,166 & 0.00 & 0.00 & -0.6 \\
\hline Limerick & 0.0 & 192,681 & 0.00 & 0.00 & -1.4 \\
\hline Roscommon & 0.0 & 63,296 & 0.00 & 0.00 & -0.5 \\
\hline Tipperary South & 0.0 & 87,672 & 0.00 & 0.00 & -0.6 \\
\hline Wexford & 0.0 & 144,373 & 0.00 & 0.00 & -1.0 \\
\hline Ireland & 33.6 & $4,633,563$ & 0.07 & 1.00 & 0.0 \\
\hline Gini coefficient & & & 0.615 & & \\
\hline
\end{tabular}

Source: Data on the number of WTE publicly employed non-acute P\&Cs are from the HSE's HSPC December 2014

Notes: (a) Excess or deficit of WTEs compared with national value is calculated as: area WTEs - (area WTEs/ratio of area value to national value). (b) The Gini coefficient summarises inequality in the distribution of publicly employed nonacute podiatrists and chiropodists across areas, with 0 representing complete equality across areas and 1 representing complete inequality across areas. 


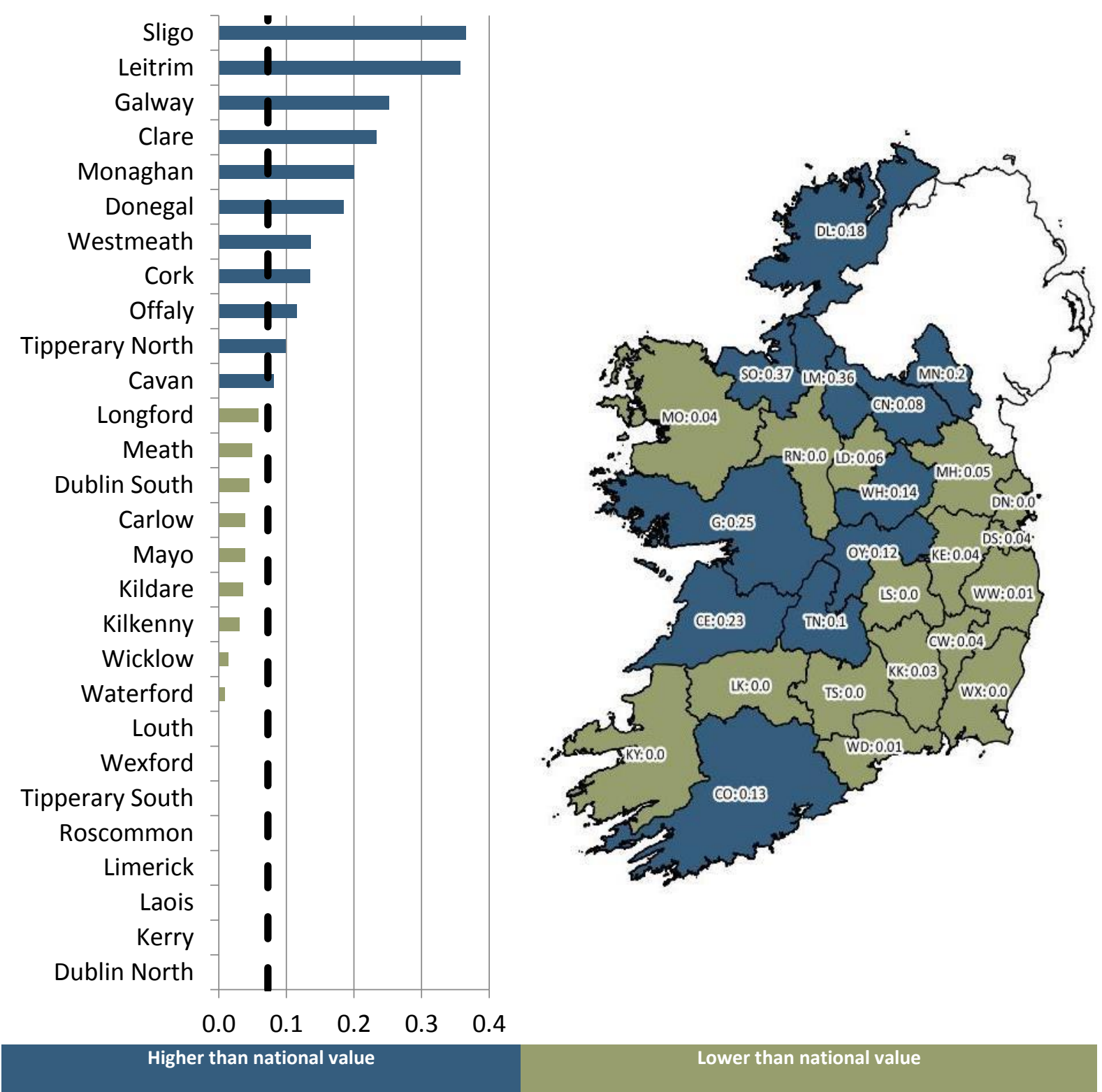

\section{Needs-adjusted podiatrist and chiropodist supply}

Figure 4.20 illustrates the impact on the geographic pattern of P\&C supply following adjustment of the population for a range of need indicators. ${ }^{64}$ Further details can be found in Appendices 4 and 5 .

\section{Ratio of area supply relative to national supply before and after adjustment}

Compared with PT, OT and SLT supply, only one area changes its position relative

64 See Section 3.4.2 for the definitions of the need indicators and how they were used to adjust supply. 
106 | Geographic Profile of Healthcare Needs and Non-Acute Healthcare Supply in Ireland

to national supply levels following adjustment for need indicators:

- Cavan lies inside the top left quadrant (i.e. higher before, lower after) of Figure $4.20 \mathrm{~b}$ following adjustment of P\&C supply for age (85+). 
FIGURE 4.20 SCATTER PLOT OF LOCATION QUOTIENTS OF THE NUMBER OF WTE PUBLICLY EMPLOYED NON-ACUTE PODIATRISTS AND CHIROPODISTS PER 10,000 TOTAL POPULATION AND PER 10,000 NEEDS-ADJUSTED POPULATIONS BY GEOGRAPHIC AREA, IRELAND 2014

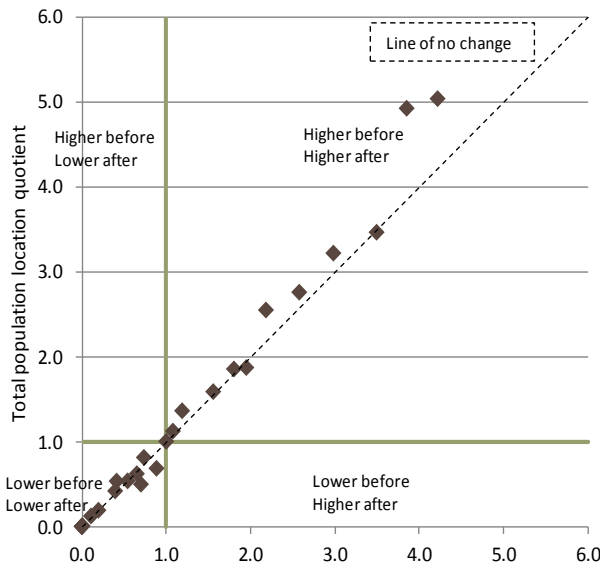

Olderpopulation aged $65+$ years location quotient

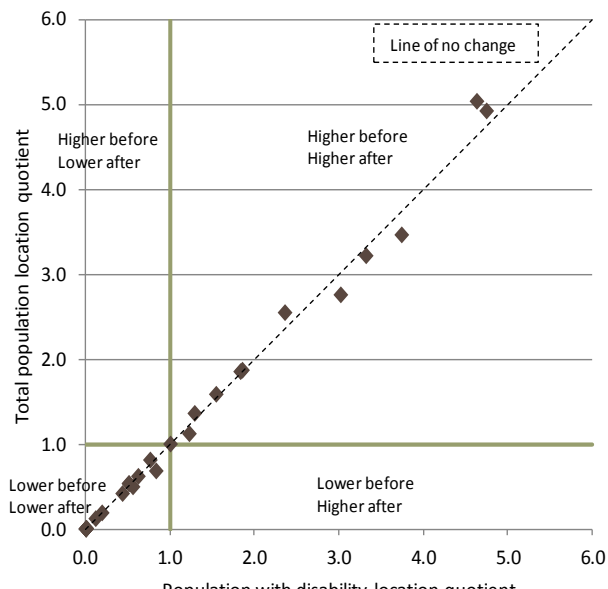

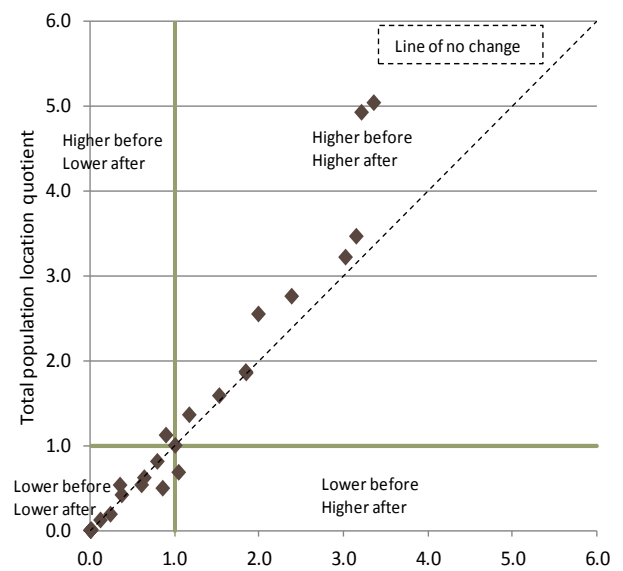

Older population aged $85+$ years location quotient

e

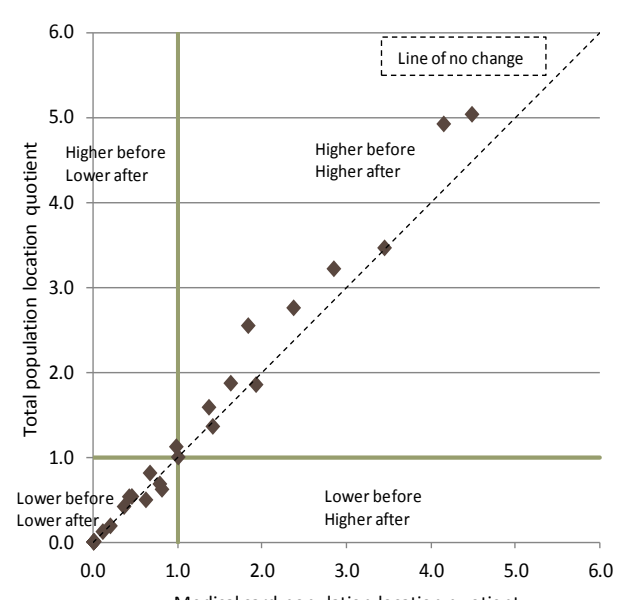

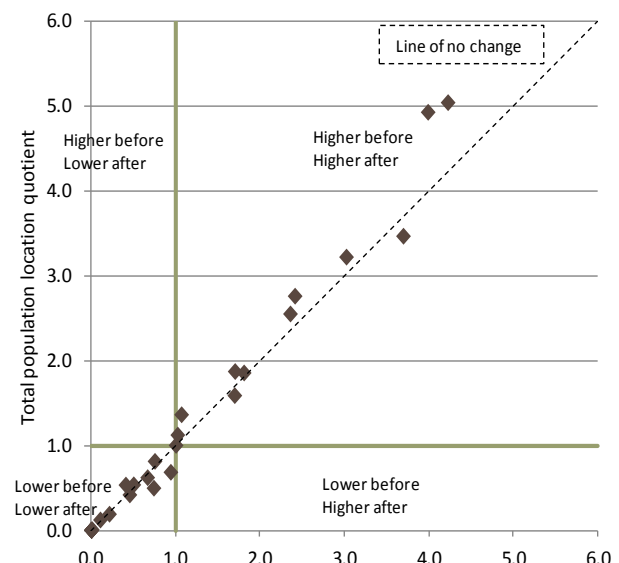

Mortality-adjusted population location quotien

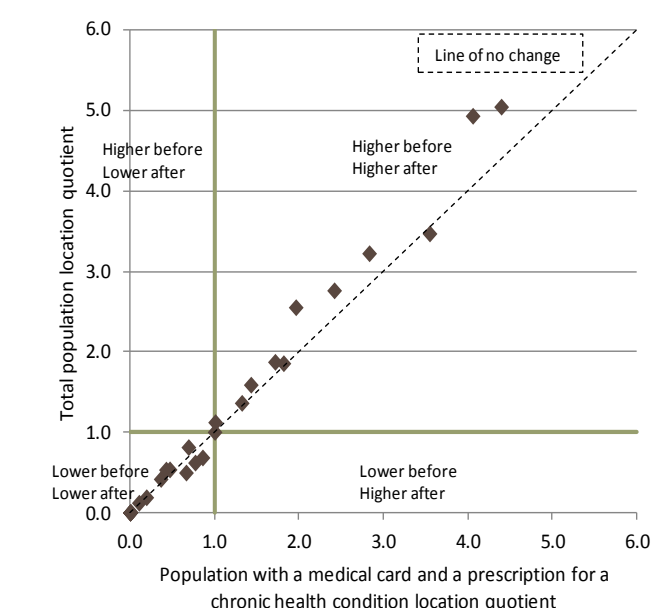

Notes: $\quad$ An area's location quotient is the area value divided by the national value. 'Higher before' means higher than the national value before adjustment. 'Lower before' means lower than the national value before adjustment. 'Higher after' means higher than the national value after adjustment. 'Lower after' means lower than the national value after adjustment. See Box 3.1 for help on value before adjustment. 'Higher after' means higher than the national value after adjustment. 'Lower after' means lower than the national value after adjustment. See Box 3.1 for help on
interpreting the scatter plots. (g) Fewer areas are plotted in these scatter plots compared with other services as nine areas have no publicly employed non-acute P\&Cs and all these areas are plotted at $(0.0,0.0)$. 


\subsubsection{Supply of counsellors and psychologists}

The geographic distribution of the number of publicly employed non-acute CO\&PSYs in Ireland in 2014 is presented in Table 4.15 and Figure 4.21, where areas are ranked by WTEs per 10,000 population from highest to lowest.

The Gini coefficient for the distribution of CO\&PSYs at 0.168 is similar to that for PTs and OTs and indicates an unequal distribution. Area values range from 0.9 CO\&PSYs per 10,000 population in Cavan to 2.5 CO\&PSYs per 10,000 in Leitrim (national average 1.8/10,000).

A more detailed examination of the geographic patterns shows that:

- Compared with the national value, there are more CO\&PSYs per 10,000 population in a cluster of counties in the northwest of the country (e.g. Leitrim, Sligo, Westmeath, Longford, Galway and Donegal), and in parts of the east (Louth and Dublin) and south (Limerick and Cork) relative to the rest of the country.

- As observed for other allied health professionals, the numbers of WTE CO\&PSYs in the commuter areas around Dublin are among the lowest in the country: Kildare $(1.0 / 10,000)$, Wicklow $(1.1 / 10,000)$ and Meath $(1.2 / 10,000)$.

- Relative to the national level of supply, the deficit in the commuter belt (measured by the number of WTE publicly employed non-acute CO\&PSYs required to bring the supply to the national level) ranges from -17.1 WTE CO\&PSYs in Kildare to -10.4 in Meath and -9.4 in Wicklow. In contrast, Dublin North has 17.7 WTE CO\&PSYs in excess of the national level of supply. 
TABLE 4.15 NUMBER OF WTE PUBLICLY EMPLOYED NON-ACUTE COUNSELLORS AND PSYCHOLOGISTS BY GEOGRAPHIC AREA, IRELAND 2014

\begin{tabular}{|c|c|c|c|c|c|}
\hline Geographic area & $\begin{array}{l}\text { WTE publicly } \\
\text { employed } \\
\text { CO\&PSYs }\end{array}$ & Population & $\begin{array}{l}\text { WTE publicly } \\
\text { employed } \\
\text { CO\&PSYs per } \\
10,000 \text { population }\end{array}$ & $\begin{array}{c}\text { Ratio of area } \\
\text { value to } \\
\text { national } \\
\text { value }\end{array}$ & $\begin{array}{l}\text { Excess or deficit of } \\
\text { WTEs compared } \\
\text { with national value }\end{array}$ \\
\hline Leitrim & 7.6 & 30,925 & 2.5 & 1.40 & 2.2 \\
\hline Sligo & 15.9 & 65,104 & 2.4 & 1.39 & 4.5 \\
\hline Westmeath & 21.0 & 86,854 & 2.4 & 1.38 & 5.8 \\
\hline Laois & 19.4 & 80,166 & 2.4 & 1.38 & 5.3 \\
\hline Louth & 28.8 & 123,082 & 2.3 & 1.34 & 7.2 \\
\hline Limerick & 41.2 & 192,681 & 2.1 & 1.22 & 7.4 \\
\hline Dublin North & 121.9 & 594,002 & 2.1 & 1.17 & 17.7 \\
\hline Longford & 7.7 & 37,559 & 2.0 & 1.17 & 1.1 \\
\hline Cork & 105.8 & 524,199 & 2.0 & 1.15 & 13.8 \\
\hline Galway & 49.6 & 254,959 & 1.9 & 1.11 & 4.8 \\
\hline Donegal & 30.8 & 159,358 & 1.9 & 1.10 & 2.9 \\
\hline Dublin South & 130.2 & 704,937 & 1.8 & 1.05 & 6.5 \\
\hline Wexford & 26.0 & 144,373 & 1.8 & 1.03 & 0.7 \\
\hline Mayo & 21.9 & 129,395 & 1.7 & 0.96 & -0.8 \\
\hline Tipperary South & 14.7 & 87,672 & 1.7 & 0.96 & -0.7 \\
\hline Offaly & 12.1 & 75,561 & 1.6 & 0.91 & -1.1 \\
\hline Kilkenny & 15.2 & 96,050 & 1.6 & 0.90 & -1.7 \\
\hline Waterford & 17.2 & 113,792 & 1.5 & 0.86 & -2.8 \\
\hline Tipperary North & 9.5 & 69,861 & 1.4 & 0.77 & -2.8 \\
\hline Roscommon & 8.5 & 63,296 & 1.3 & 0.77 & -2.6 \\
\hline Clare & 15.9 & 119,027 & 1.3 & 0.76 & -4.9 \\
\hline Meath & 23.3 & 191,931 & 1.2 & 0.69 & -10.4 \\
\hline Carlow & 6.5 & 53,957 & 1.2 & 0.69 & -3.0 \\
\hline Wicklow & 14.9 & 138,421 & 1.1 & 0.61 & -9.4 \\
\hline Monaghan & 6.3 & 59,822 & 1.1 & 0.60 & -4.2 \\
\hline Kildare & 21.4 & 219,570 & 1.0 & 0.56 & -17.1 \\
\hline Kerry & 13.1 & 144,259 & 0.9 & 0.52 & -12.2 \\
\hline Cavan & 6.5 & 72,750 & 0.9 & 0.51 & -6.2 \\
\hline Ireland & 812.9 & $4,633,563$ & 1.8 & 1.00 & 0.0 \\
\hline
\end{tabular}

Source: Data on the number of WTE publicly employed non-acute CO\&PSYs are from the HSE's HSPC December 2014.

Notes: (a) Excess or deficit of WTEs compared with national value is calculated as: area WTEs - (area WTEs/ratio of area value to national value). (b) The Gini coefficient summarises inequality in the distribution of publicly employed nonacute CO\&PSYs across areas, with 0 representing complete equality across areas and 1 representing complete inequality across areas. (c) These numbers exclude student clinical psychologists. If student clinical psychologists are included, the total number of WTE CO\&PSY in Ireland increases to 945 (2/10,000 population). 


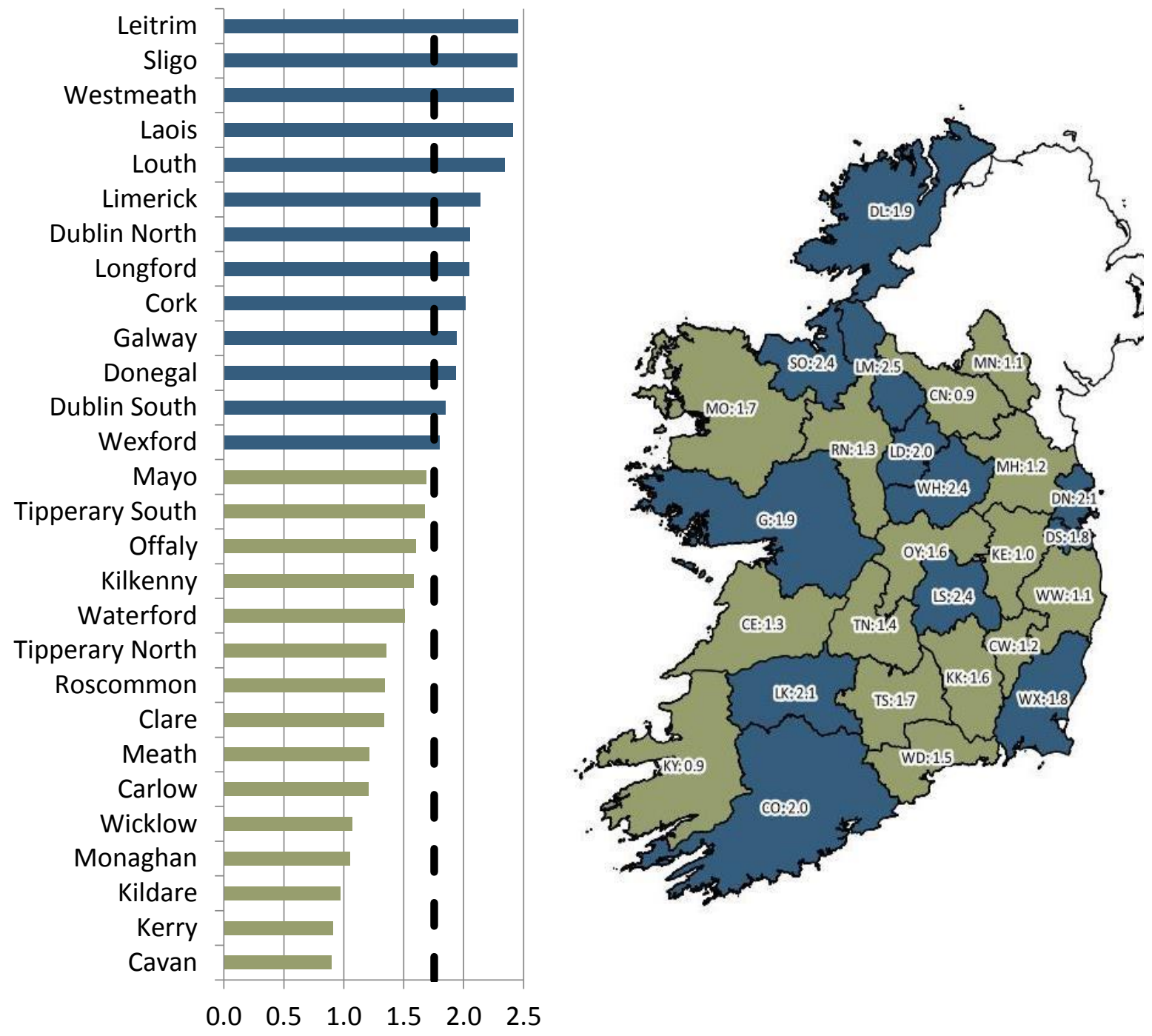

\section{Needs-adjusted counsellor and psychologist supply}

Figure 4.22 illustrates the impact on the geographic pattern of CO\&PSY supply following adjustment of the population for a range of need indicators. ${ }^{65}$ Further details can be found in Appendices 4 and 5 .

As with PT supply, for each need indicator (i.e. older age groups, mortality, disability, Medical Card coverage and morbidity), the majority of the areas are positioned close to the 'line of no change', and fall in the top right or bottom left quadrant. The adjustment of CO\&PSY supply for disability (Figure 4.22d) shows the least change in the position of areas relative to the national value; the data points

65 See Section 3.4.2 for the definitions of the need indicators and how they were used to adjust supply. 
in the scatter plot lie very close to the 'line of no change'. The adjustment of CO\&PSY supply for the $85+$ population (Figure 4.22b) shows the largest amount of change, as the data points are more dispersed about the 'line of no change' than in the other graphs.

\section{Ratio of area supply relative to national supply before and after adjustment}

Some notable area-specific patterns are:

- With the exception of Meath, all areas that have a lower level of WTE CO\&PSYs per capita relative to the national value before adjustment continue to have a lower level relative to the national value following adjustment, for all need indicators (i.e. bottom left quadrant in Figure 4.22a-4.22f).

- Donegal lies in the top left quadrant of Figure 4.22a, 4.22b, 4.22e and 4.22f (i.e. higher before, lower after) following adjustment of the population for age $(65+$ and $85+)$, Medical Card coverage and morbidity.

- Leitrim and Sligo lie in the top left quadrant of Figure 4.22c following adjustment for age (85+).

- All other areas that have a higher level of WTE CO\&PSYs per capita relative to the national value before adjustment continue to have a higher level relative to the national value following adjustment, for all need indicators (i.e. top right quadrant in Figure 4.22a$4.22 \mathrm{e})$. 
FIGURE 4.22 SCATTER PLOT OF LOCATION QUOTIENTS OF THE NUMBER OF WTE PUBLICLY EMPLOYED NON-ACUTE COUNSELLORS AND PSYCHOLOGISTS PER 10,000 TOTAL POPULATION AND PER 10,000 NEEDS-ADJUSTED POPULATIONS BY GEOGRAPHIC AREA, IRELAND 2014

a

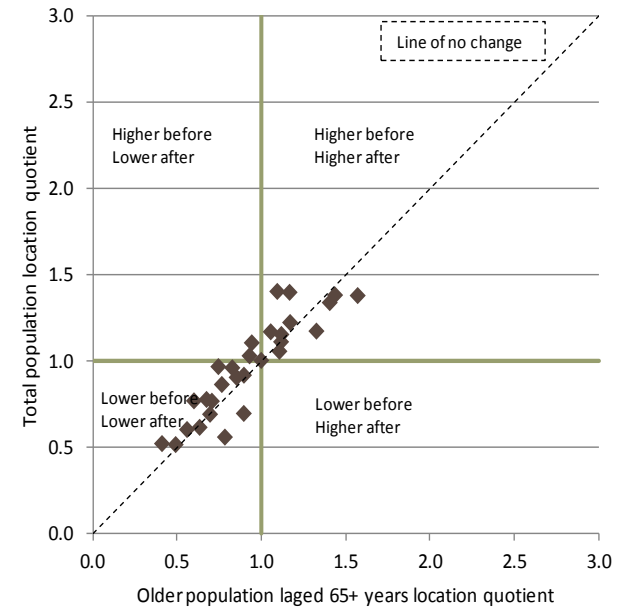

d

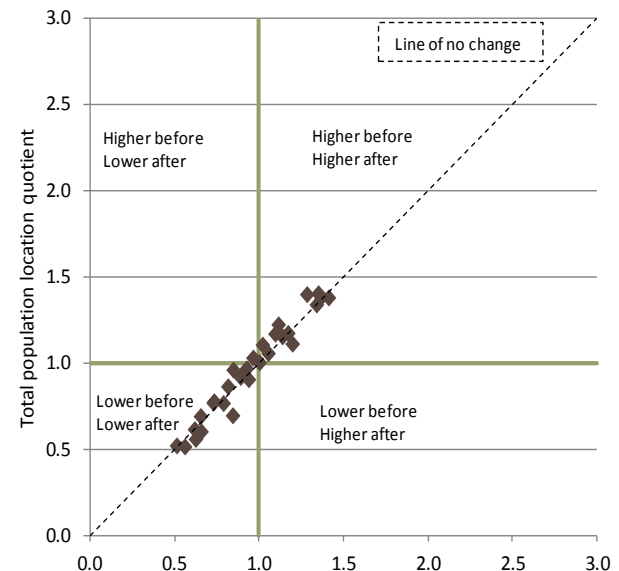

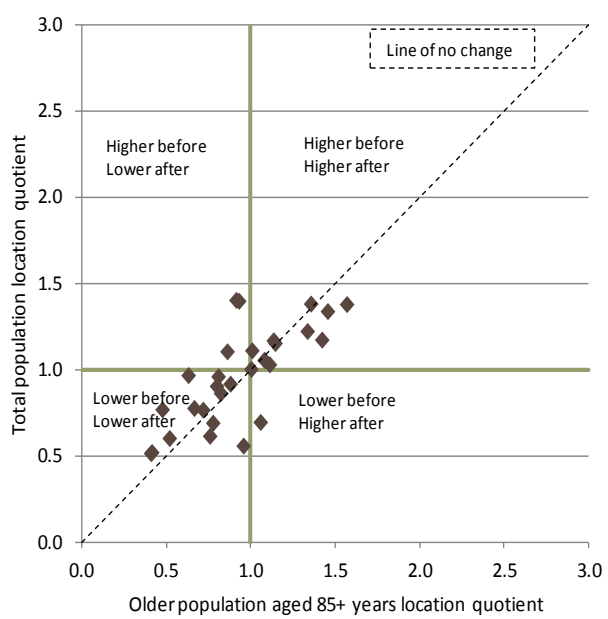

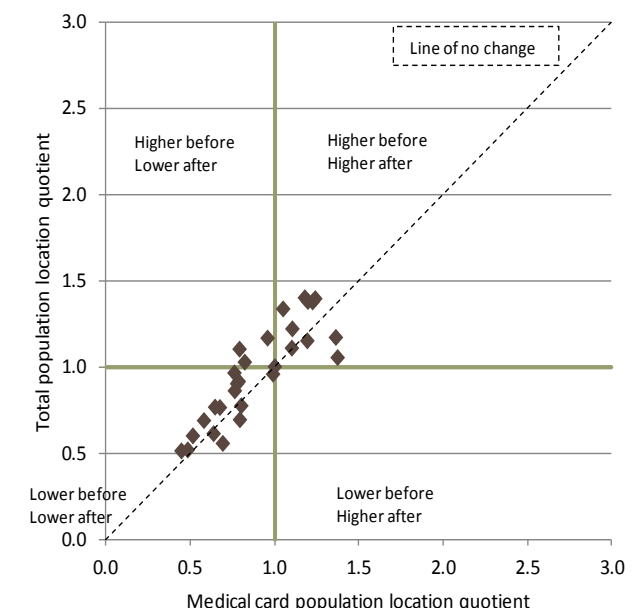

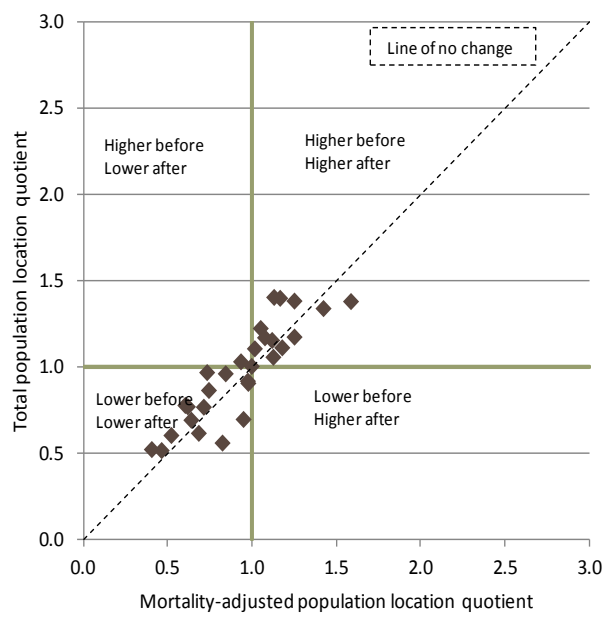

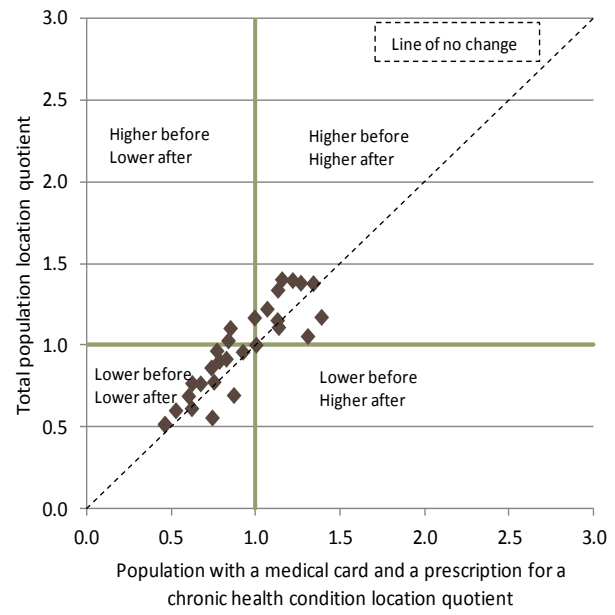




\subsubsection{Supply of social workers}

The geographic distribution of the number of publicly employed non-acute SWs in Ireland in 2014 is presented in Table 4.16 and Figure 4.23, with areas ranked by WTEs per 10,000 population from highest to lowest.

The Gini coefficient for the distribution of SWs is 0.214 , indicating an unequal distribution, and area values range from 0.6 SWs per 10,000 population in Carlow to $2.5 \mathrm{SWs}$ per 10,000 in Sligo (national average $1.5 / 10,000$ ).

A more detailed examination of the geographic patterns suggests:

- Compared with the national value, there are more SWs per 10,000 population in the border counties in the north and in the northwest (e.g. Sligo, Louth, Leitrim, Donegal, Galway, Roscommon and Monaghan), in Dublin and in other selected areas (Laois and Tipperary South).

- As observed for other allied health professionals, the numbers of WTE SWs in the commuter areas around Dublin are among the lowest in the country: Meath $(0.7 / 10,000)$, Wicklow $(0.8 / 10,000)$ and Kildare $(0.9 / 10,000)$.

- The commuter areas would require 9.5-14.5 additional WTE publicly employed nonacute SWs to increase supply in those areas to the national level - Meath (-14.5 WTE SWs), Kildare (-12.7 WTE SWs) and Wicklow (-9.5 WTE SWs). In contrast, Dublin South has more than 29 WTE SWs in excess of the national level of supply. 
TABLE 4.23 NUMBER OF WTE PUBLICLY EMPLOYED NON-ACUTE SOCIAL WORKERS BY GEOGRAPHIC AREA, IRELAND 2014

\begin{tabular}{|c|c|c|c|c|c|}
\hline Geographic area & $\begin{array}{l}\text { WTE publicly } \\
\text { employed SWs }\end{array}$ & Population & $\begin{array}{c}\text { WTE publicly } \\
\text { employed SWs per } \\
10,000 \text { population }\end{array}$ & $\begin{array}{l}\text { Ratio of area } \\
\text { value to } \\
\text { national } \\
\text { value }\end{array}$ & $\begin{array}{l}\text { Excess or deficit of } \\
\text { WTEs compared } \\
\text { with national value }\end{array}$ \\
\hline Sligo & 16.3 & 65,104 & 2.5 & 1.68 & 6.6 \\
\hline Louth & 29.3 & 123,082 & 2.4 & 1.59 & 10.9 \\
\hline Leitrim & 6.9 & 30,925 & 2.2 & 1.50 & 2.3 \\
\hline Laois & 16.5 & 80,166 & 2.1 & 1.38 & 4.5 \\
\hline Donegal & 31.6 & 159,358 & 2.0 & 1.33 & 7.8 \\
\hline Dublin South & 134.8 & 704,937 & 1.9 & 1.28 & 29.3 \\
\hline Galway & 46.1 & 254,959 & 1.8 & 1.21 & 7.9 \\
\hline Roscommon & 11.0 & 63,296 & 1.7 & 1.16 & 1.5 \\
\hline Tipperary South & 14.8 & 87,672 & 1.7 & 1.13 & 1.6 \\
\hline Dublin North & 99.6 & 594,002 & 1.7 & 1.12 & 10.6 \\
\hline Monaghan & 9.8 & 59,822 & 1.6 & 1.09 & 0.8 \\
\hline Westmeath & 13.2 & 86,854 & 1.5 & 1.02 & 0.2 \\
\hline Limerick & 29.2 & 192,681 & 1.5 & 1.01 & 0.3 \\
\hline Kerry & 21.8 & 144,259 & 1.5 & 1.01 & 0.2 \\
\hline Waterford & 16.6 & 113,792 & 1.5 & 0.98 & -0.4 \\
\hline Cavan & 10.5 & 72,750 & 1.4 & 0.96 & -0.4 \\
\hline Cork & 75.0 & 524,199 & 1.4 & 0.96 & -3.5 \\
\hline Clare & 13.5 & 119,027 & 1.1 & 0.76 & -4.3 \\
\hline Mayo & 12.5 & 129,395 & 1.0 & 0.64 & -6.9 \\
\hline Kildare & 20.1 & 219,570 & 0.9 & 0.61 & -12.7 \\
\hline Kilkenny & 8.7 & 96,050 & 0.9 & 0.61 & -5.6 \\
\hline Tipperary North & 6.3 & 69,861 & 0.9 & 0.60 & -4.2 \\
\hline Wexford & 12.4 & 144,373 & 0.9 & 0.57 & -9.2 \\
\hline Wicklow & 11.3 & 138,421 & 0.8 & 0.54 & -9.5 \\
\hline Offaly & 6.0 & 75,561 & 0.8 & 0.53 & -5.4 \\
\hline Meath & 14.2 & 191,931 & 0.7 & 0.49 & -14.5 \\
\hline Longford & 2.8 & 37,559 & 0.7 & 0.49 & -2.9 \\
\hline Carlow & 3.0 & 53,957 & 0.6 & 0.37 & -5.1 \\
\hline Ireland & 693.8 & $4,633,563$ & 1.5 & 1.00 & 0.0 \\
\hline Gini coefficient & & & 0.214 & & \\
\hline
\end{tabular}

Source: Data on the number of WTE publicly employed non-acute social workers are from the HSE'S HSPC December 2014.

Notes: (a) Excess or deficit of WTEs compared with national value is calculated as: area WTEs - (area WTEs/ratio of area value to national value). (b) The Gini coefficient summarises inequality in the distribution of SWs across areas, with 0 representing complete equality across areas and 1 representing complete inequality across areas. 


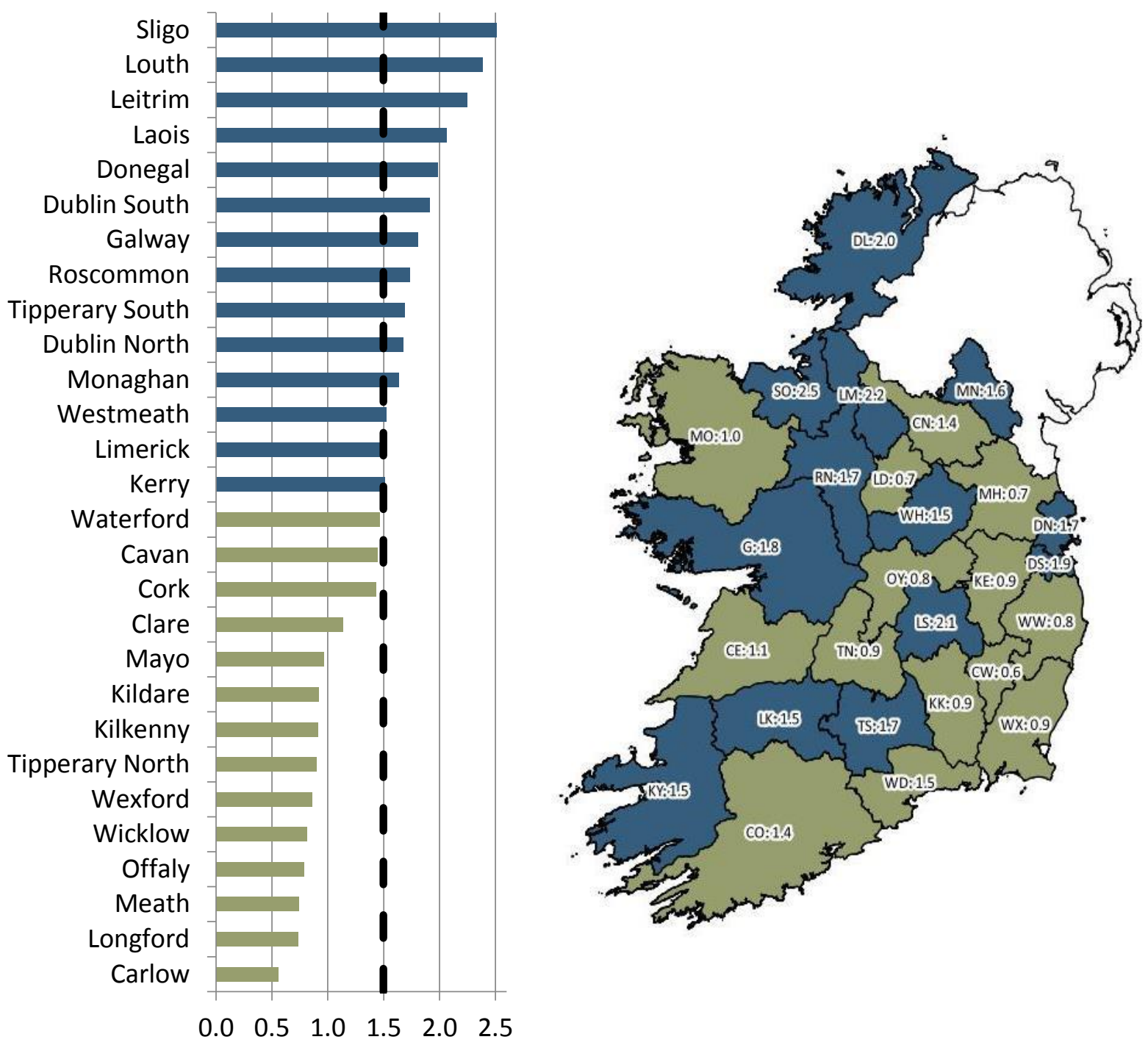

\section{Needs-adjusted social worker supply}

Figure 4.24 illustrates the impact on the geographic pattern of SW supply following adjustment of the population for a range of need indicators. ${ }^{66}$ Further details can be found in Appendices 4 and 5 .

\section{Ratio of area supply relative to national supply before and after adjustment}

As with other allied health professional supply, for each need indicator (i.e. older age groups, mortality, disability, Medical Card coverage and morbidity), the

66 See Section 3.4.2 for the definitions of the need indicators and how they were used to adjust supply. 
majority of the areas are positioned close to the 'line of no change' and fall in the top right or bottom left quadrant.

Some notable area-specific patterns are as follows.

- With the exception of Kildare, all areas that have a lower level of WTE SWs per capita relative to the national value before adjustment continue to have a lower level relative to the national value following adjustment, for all need indicators (i.e. bottom left quadrant in Figure 4.24a-4.24f).

- Roscommon lies in the top left quadrant of Figure 4.34a-c and 4.34e (i.e. higher before, lower after) following adjustment of the population for mortality, age $(65+$ and $85+)$ and morbidity.

- Monaghan lies in the top left quadrant of Figure $4.24 \mathrm{~b}$ and $4.24 \mathrm{e}$ following adjustment of the population for age $(85+)$ and Medical Card coverage.

- Tipperary South lies in the top left quadrant of Figure $4.24 \mathrm{~b}$ following adjustment of the population for age $(85+)$. 
Findings | 117

FIGURE 4.24 SCATTER PLOT OF LOCATION QUOTIENTS OF THE NUMBER OF WTE PUBLICLY EMPLOYED NON-ACUTE SOCIAL WORKERS PER 10,000 TOTAL POPULATION AND PER 10,000 NEEDS-ADJUSTED POPULATIONS BY GEOGRAPHIC AREA, IRELAND 2014

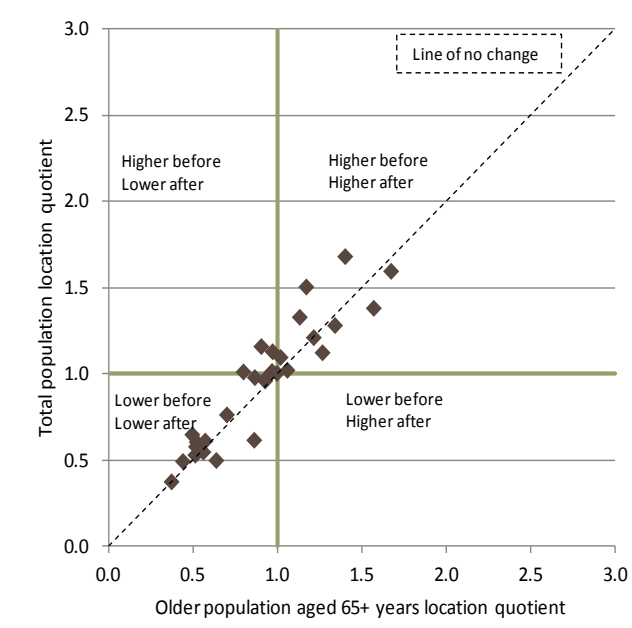

d

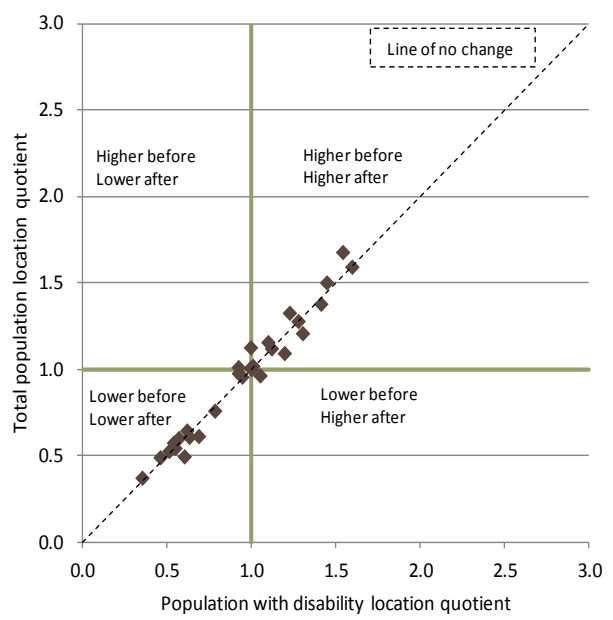

b

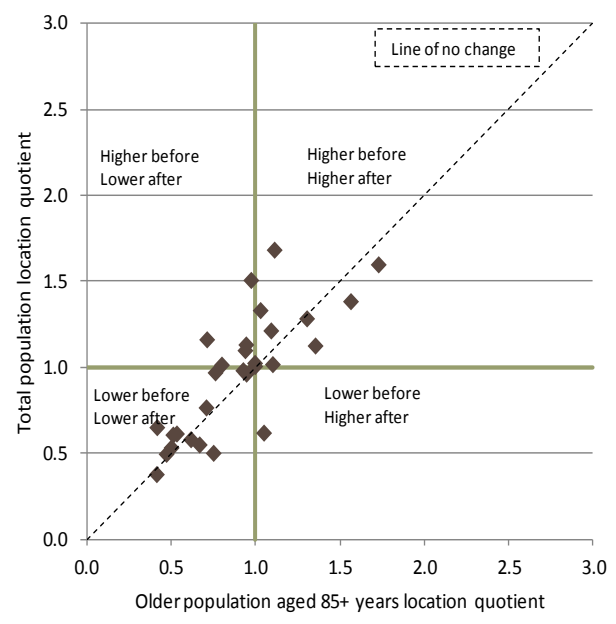

e

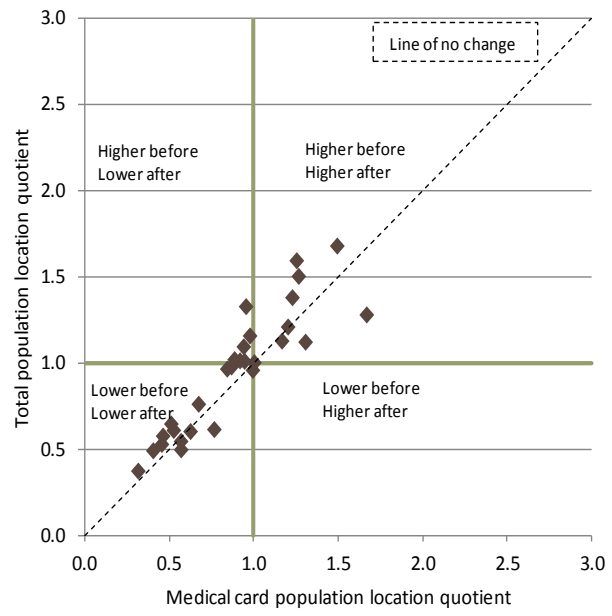

C
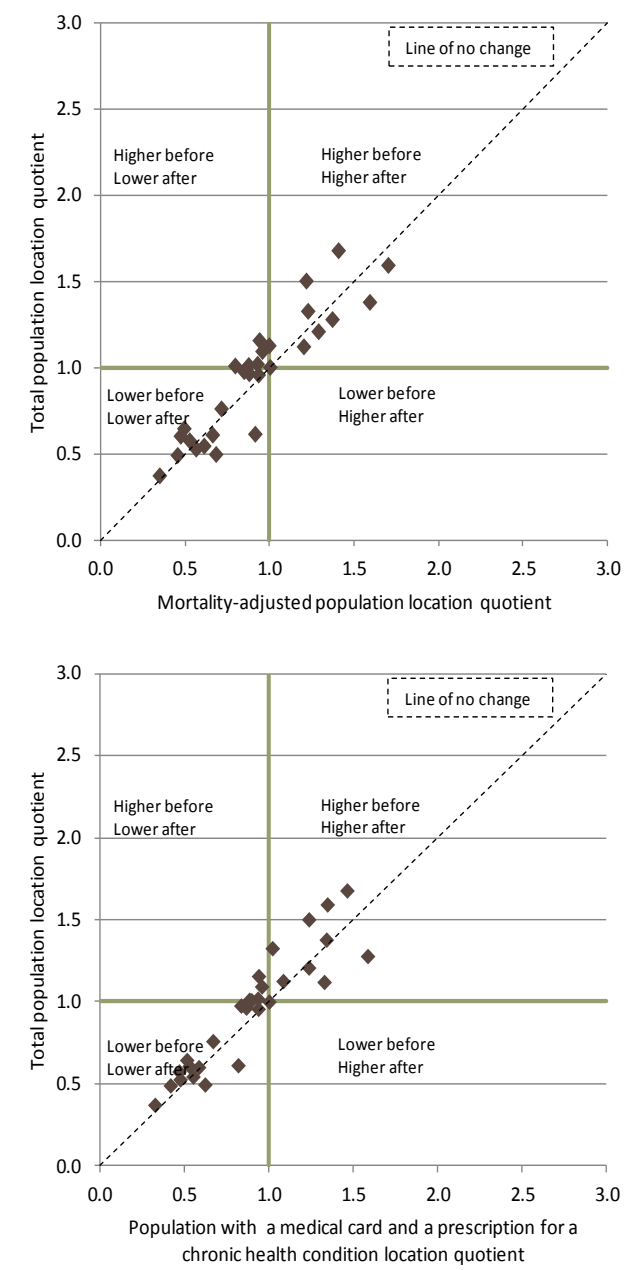

Notes:

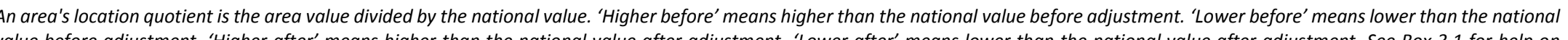

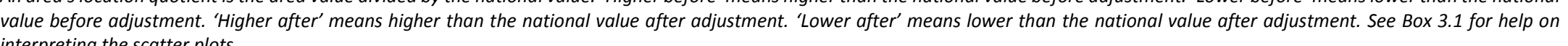
interpreting the scatter plots. 


\subsection{PROFILE OF NON-ACUTE HEALTHCARE SUPPLY BY GEOGRAPHIC AREA - LONG-TERM CARE}

\subsubsection{Overview of long-term residential care supply in Ireland 2015}

Table 4.17 and Figure 4.25 show the number of long-term residential care (LTRC) homes and LTRC beds in Ireland in 2015. Areas are ranked by number of beds per 1,000 population aged $65+$ years from highest to lowest. Supply is presented by population aged $65+$ years, rather than by total population, because long-term care services are almost exclusively used by older people (DOH, 2015a; Nursing Homes Ireland, 2015; Wren et al., 2017).

The distribution of LTRC beds is not uniform across the country, illustrated by the Gini coefficient of 0.091 .

\subsubsection{Geographic patterns of long-term care supply in Ireland in $\mathbf{2} 015$}

Table 4.17 and Figure 4.25 show substantial geographic variation in the number of LTRC beds per 1,000 population aged 65+ years: area values range from 33 in Laois to 75.5 in Kildare.

A more detailed examination of the geographic patterns of bed supply shows that:

- The number of beds per 1,000 population aged $65+$ years is generally lower in areas along the north-west, east and south-east coasts than in the midlands.

- Table 4.17 also shows the excess or deficit of LTRC beds in each area when compared with the national value. Substantial numbers of beds would be required in some areas to increase supply to the national level. These deficits are highest in Dublin North (509 beds), Dublin South (290 beds), Donegal (231 beds), Kerry (163 beds), Laois (150 beds) and Wexford (106 beds). 
TABLE 4.17 NUMBER OF LONG-TERM RESIDENTIAL CARE CENTRES AND LONG-TERM RESIDENTIAL CARE BEDS BY GEOGRAPHIC AREA, IRELAND 2014

\begin{tabular}{|c|c|c|c|c|c|c|}
\hline Geographic area & $\begin{array}{l}\text { Number of } \\
\text { LTRC } \\
\text { centres }\end{array}$ & $\begin{array}{l}\text { Number of } \\
\text { beds }\end{array}$ & $\begin{array}{l}\text { Population } \\
\text { aged } 65+ \\
\text { years }\end{array}$ & $\begin{array}{c}\text { Beds per } \\
1,000 \\
\text { population } \\
\text { aged } 65+ \\
\text { years }\end{array}$ & $\begin{array}{l}\text { Ratio of area } \\
\text { value to } \\
\text { national } \\
\text { value }\end{array}$ & $\begin{array}{l}\text { Excess or deficit } \\
\text { of beds compared } \\
\text { with national } \\
\text { value }\end{array}$ \\
\hline Kildare & 22 & 1,496 & 19,814 & 75.5 & 1.52 & 510.1 \\
\hline Roscommon & 14 & 674 & 10,281 & 65.6 & 1.32 & 162.4 \\
\hline Tipperary North & 18 & 637 & 10,200 & 62.5 & 1.26 & 129.5 \\
\hline Galway & 44 & 1,840 & 32,231 & 57.1 & 1.15 & 236.3 \\
\hline Wicklow & 20 & 970 & 17,015 & 57.0 & 1.15 & 123.4 \\
\hline Westmeath & 15 & 605 & 10,623 & 57.0 & 1.14 & 76.4 \\
\hline Kilkenny & 18 & 723 & 12,931 & 55.9 & 1.12 & 79.6 \\
\hline Cavan & 11 & 527 & 9,639 & 54.7 & 1.10 & 47.4 \\
\hline Longford & 4 & 289 & 5,288 & 54.7 & 1.10 & 25.9 \\
\hline Carlow & 8 & 369 & 6,794 & 54.3 & 1.09 & 31.0 \\
\hline Offaly & 11 & 528 & 9,817 & 53.8 & 1.08 & 39.5 \\
\hline Limerick & 27 & 1,365 & 25,591 & 53.3 & 1.07 & 91.7 \\
\hline Clare & 15 & 864 & 16,379 & 52.8 & 1.06 & 49.0 \\
\hline Cork & 71 & 3,607 & 68,704 & 52.5 & 1.06 & 188.5 \\
\hline Leitrim & 6 & 257 & 5,043 & 51.0 & 1.02 & 6.1 \\
\hline Meath & 20 & 954 & 18,900 & 50.5 & 1.01 & 13.6 \\
\hline Louth & 14 & 700 & 14,907 & 47.0 & 0.94 & -41.7 \\
\hline Mayo & 26 & 1,000 & 21,330 & 46.9 & 0.94 & -61.3 \\
\hline Dublin South & 63 & 3,962 & 85,457 & 46.4 & 0.93 & -290.1 \\
\hline Tipperary South & 16 & 586 & 12,916 & 45.4 & 0.91 & -56.7 \\
\hline Monaghan & 7 & 369 & 8,161 & 45.2 & 0.91 & -37.1 \\
\hline Waterford & 12 & 734 & 16,291 & 45.1 & 0.91 & -76.6 \\
\hline Wexford & 16 & 905 & 20,311 & 44.6 & 0.90 & -105.6 \\
\hline Kerry & 23 & 988 & 23,135 & 42.7 & 0.86 & -163.1 \\
\hline Dublin North & 44 & 2,814 & 66,781 & 42.1 & 0.85 & -508.8 \\
\hline Sligo & 7 & 405 & 9,916 & 40.8 & 0.82 & -88.4 \\
\hline Donegal & 23 & 950 & 23,728 & 40.0 & 0.80 & -230.6 \\
\hline Laois & 6 & 295 & 8,951 & 33.0 & 0.66 & -150.4 \\
\hline Ireland & 581 & 29,413 & 591,134 & 49.8 & 1.00 & 0.0 \\
\hline \multicolumn{4}{|l|}{ Gini coefficient } & 0.091 & & \\
\hline
\end{tabular}

Sources: $\quad$ Data on the number of LTRC centres and LTRC beds are from the Health Information and Quality Authority's (HIQA) list of designated residential centres for older people (February 2015) and the DOH's list of long-stay units (February 2015).

Notes: (a) Excess or deficit of beds compared with national value is calculated as: area beds - (area beds/ratio of area value to national value). (b) The Gini coefficient summarises inequality in the distribution of beds across areas, with 0 representing complete equality across areas and 1 representing complete inequality across areas. 


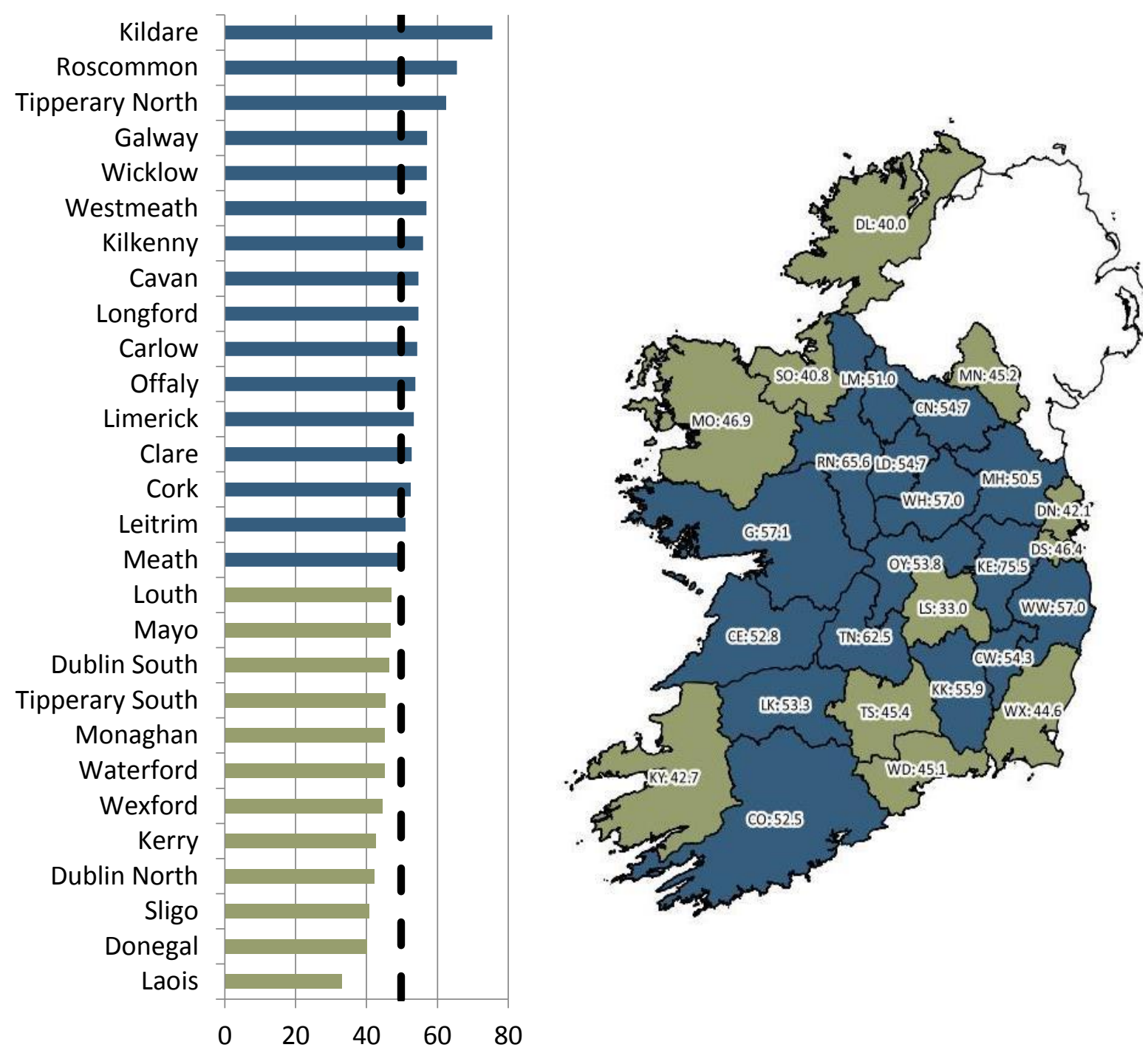

\subsubsection{Geographic patterns of long-term residential care supply within Dublin 2015}

This section presents the geographic profile of LTRC beds within Dublin, highlighting the variations that occur across smaller areas (Table 4.18 and Figure 4.26).

The number of LTRC beds per 1,000 population aged $65+$ years for the Dublin region $(44.5 / 1,000)$ is lower than the national value $(49.8 / 1,000)$ and the range of values is larger in the Dublin region, from 0.0/1,000 in Dublin 2 to 287.3/1,000 in Dublin 20. The Gini coefficient for the distribution of LTRC beds across areas is 
higher for the Dublin region (0.502) than for the national profile (0.091), indicating greater inequality in the geographic distribution of LTRC beds within Dublin than across the country.

There are some notable findings in specific areas:

- The relatively high number of beds per 1,000 population aged 65+ years in Dublin 20 and Dublin 15 is partly due to two long-term care centres in these areas with a relatively large number of beds. ${ }^{67}$ Dublin 15 also has a relatively low proportion of population age 65+ years.

- Table 4.18 also shows the excess or deficit of beds in each Dublin area when compared with the national value. Overall the Dublin region has a deficit of 799 beds compared with the national value. The largest deficits are observed in south Dublin: Dublin 12 (429 beds), Dublin 14 (278 beds), Dublin 24 (256 beds) and Dublin 22 (242 beds).

It is important to note that the patterns of LTRC bed supply at this level of disaggregation need to be interpreted with caution given the overlapping catchment areas for long-term care centres located within small geographic distances.

67 Phoenix Park Community Nursing Units, St Mary's Hospital, Phoenix Park in Dublin 20 (186 beds for residential care of older adults) and Elm Green Nursing Home, Castleknock in Dublin 15 (96 beds). 
TABLE 4.18 NUMBER OF LONG-TERM RESIDENTIAL CARE CENTRES AND LONG-TERM RESIDENTIAL CARE BEDS BY DUBLIN AREA, IRELAND 2014

\begin{tabular}{|c|c|c|c|c|c|c|}
\hline Geographic area & $\begin{array}{l}\text { Number of } \\
\text { LTRC centres }\end{array}$ & $\begin{array}{l}\text { Number of } \\
\text { beds }\end{array}$ & $\begin{array}{l}\text { Population } \\
\text { aged } 65+ \\
\text { years }\end{array}$ & $\begin{array}{c}\text { Beds per } \\
1,000 \\
\text { population } \\
\text { aged } 65+ \\
\text { years }\end{array}$ & $\begin{array}{l}\text { Ratio of area } \\
\text { value to } \\
\text { national } \\
\text { value }\end{array}$ & $\begin{array}{l}\text { Excess or deficit } \\
\text { of beds compared } \\
\text { with national } \\
\text { value }\end{array}$ \\
\hline Dublin 20 & 4 & 358 & 1,246 & 287.3 & 5.77 & 296.0 \\
\hline Dublin 15 & 3 & 210 & 1,200 & 175.0 & 3.52 & 150.3 \\
\hline Dublin 4 & 8 & 408 & 5,054 & 80.7 & 1.62 & 156.5 \\
\hline Dublin 6 & 7 & 332 & 4,307 & 77.1 & 1.55 & 117.7 \\
\hline Dublin 18 & 4 & 284 & 3,834 & 74.1 & 1.49 & 93.2 \\
\hline Dublin Other South & 22 & 1,507 & 20,699 & 72.8 & 1.46 & 477.1 \\
\hline Dublin Other North & 13 & 915 & 15,274 & 59.9 & 1.20 & 155.0 \\
\hline Dublin 9 & 7 & 563 & 9,945 & 56.6 & 1.14 & 68.2 \\
\hline Dublin 6w & 3 & 199 & 3,858 & 51.6 & 1.04 & 7.0 \\
\hline Dublin 10 & 1 & 168 & 3,356 & 50.1 & 1.01 & 1.0 \\
\hline Dublin 16 & 3 & 208 & 4,641 & 44.8 & 0.90 & -22.9 \\
\hline Dublin 11 & 6 & 326 & 8,402 & 38.8 & 0.78 & -92.1 \\
\hline Dublin 3 & 4 & 193 & 5,896 & 32.7 & 0.66 & -100.4 \\
\hline Dublin 5 & 4 & 295 & 10,111 & 29.2 & 0.59 & -208.1 \\
\hline Dublin 17 & 1 & 72 & 2,505 & 28.7 & 0.58 & -52.6 \\
\hline Dublin 8 & 4 & 183 & 7,010 & 26.1 & 0.52 & -165.8 \\
\hline Dublin 1 & 1 & 45 & 2,114 & 21.3 & 0.43 & -60.2 \\
\hline Dublin 24 & 3 & 188 & 8,923 & 21.1 & 0.42 & -256.0 \\
\hline Dublin 7 & 3 & 119 & 6,260 & 19.0 & 0.38 & -192.5 \\
\hline Dublin 14 & 2 & 84 & 7,280 & 11.5 & 0.23 & -278.2 \\
\hline Dublin 13 & 1 & 43 & 3,822 & 11.3 & 0.23 & -147.2 \\
\hline Dublin 22 & 2 & 49 & 5,846 & 8.4 & 0.17 & -241.9 \\
\hline Dublin 12 & 1 & 27 & 9,174 & 2.9 & 0.06 & -429.5 \\
\hline Dublin 2 & 0 & 0 & 1,481 & 0.0 & 0.00 & -73.7 \\
\hline Total & 107 & 6,776 & 152,238 & 44.5 & 0.89 & -798.9 \\
\hline Gini coefficient & & & & 0.502 & & \\
\hline
\end{tabular}

Sources: Data on the number of LTRC centres and LTRC beds are from the Health Information and Quality Authority's (HIQA) list of designated residential centres for older people (February 2015) and the DOH's list of long-stay units (February 2015).

Notes: (a) Excess or deficit of beds compared with national value is calculated as: area beds - (area beds/ratio of area value to national value). (b) The Gini coefficient summarises inequality in the distribution of beds across areas, with 0 representing complete equality across areas and 1 representing complete inequality across areas. 

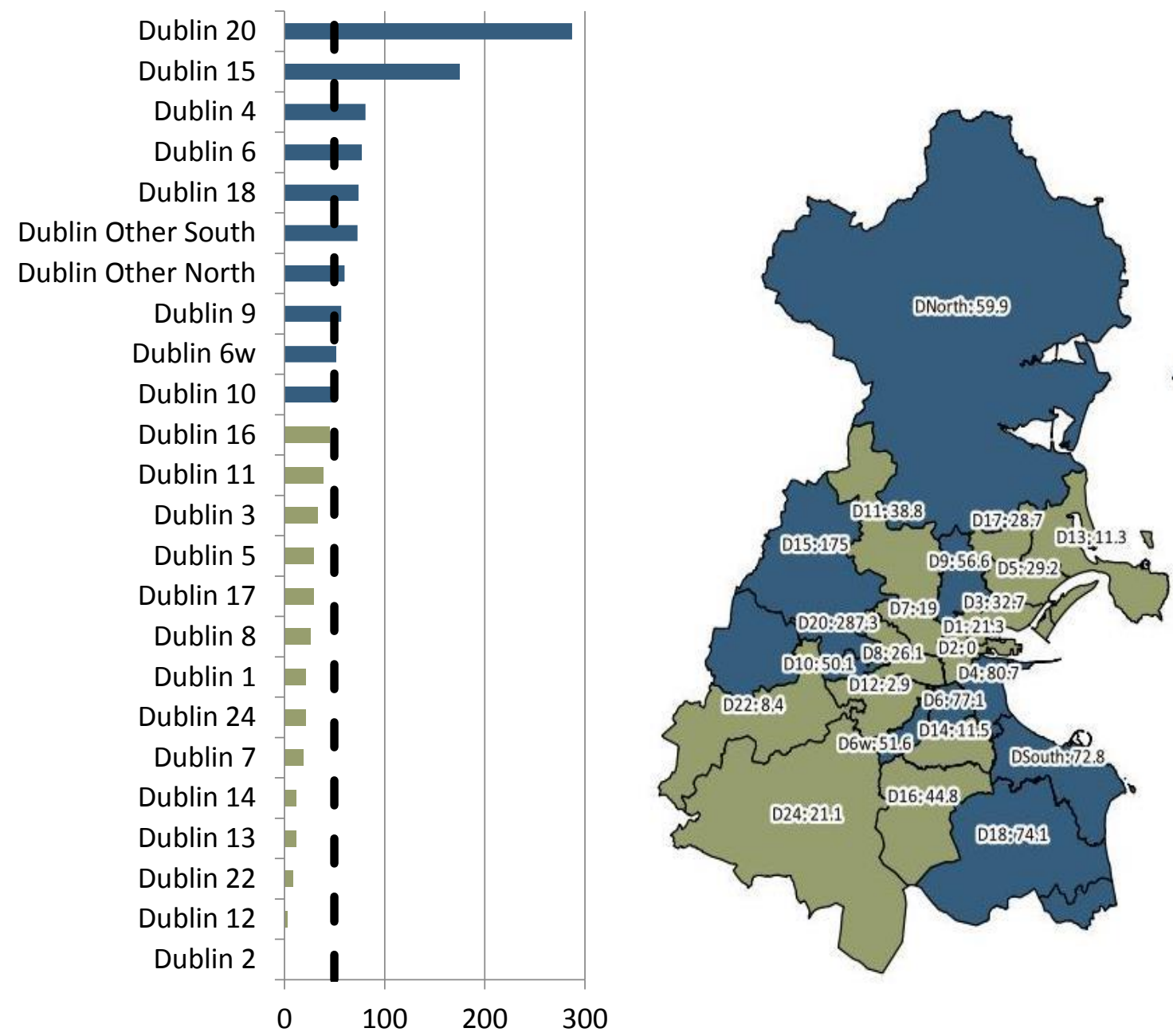

\section{Needs-adjusted long-term residential care supply}

Figure 4.27 illustrates the impact on the geographic pattern of LTRC supply following adjustment of the population aged $65+$ for four separate need indicators (further details can be found in Appendices 4 and 5): $:^{68}$

- age - population aged $85+$ years

- mortality - population aged $65+$ years adjusted for area mortality

- disability - population aged $65+$ years with a disability.

Comparing Gini coefficients for the equality of the distribution of LTRC beds across

68 See Section 3.4.2 for the definitions of the need indicators and how they were used to adjust supply. 
areas suggests that the distribution is less equal once the population is adjusted for need (except for disability). The Gini coefficient ranges from 0.091 for the unadjusted population aged $65+$ to 0.146 following adjustment for the mortality (see Table 4.20).

\section{Ratio of area supply relative to national supply before and after adjustment}

Overall, for each need indicator, most areas do not change their position relative to national LTRC bed supply levels after adjusting the population for need:

- With the exception of two areas (Dublin South and Wexford), all areas that have a lower level of LTRC beds per capita relative to the national value before adjustment continue to have a lower level relative to the national value following adjustment, for all need indicators (i.e. bottom left quadrant in Figure 4.27a-4.27c).

- Wexford lies in the bottom right quadrant of Figure 4.27a (i.e. lower before, higher after) following adjustment of the population for age (85+).

- One area falls in the top left quadrant (i.e. higher before, lower after) following adjustment of LTRC bed supply for need indicators:

- Cavan lies in the top left quadrant of Figure 4.27a following adjustment for age (85+). 
FIGURE 4.27 SCATTER PLOT OF LOCATION QUOTIENTS OF THE NUMBER OF LONG-TERM RESIDENTIAL CARE BEDS PER 1,000 POPULATION AGED 65+ YEARS AND PER 1,000 NEEDS-ADJUSTED POPULATIONS AGED 65+ YEARS BY GEOGRAPHIC AREA, IRELAND 2014

a
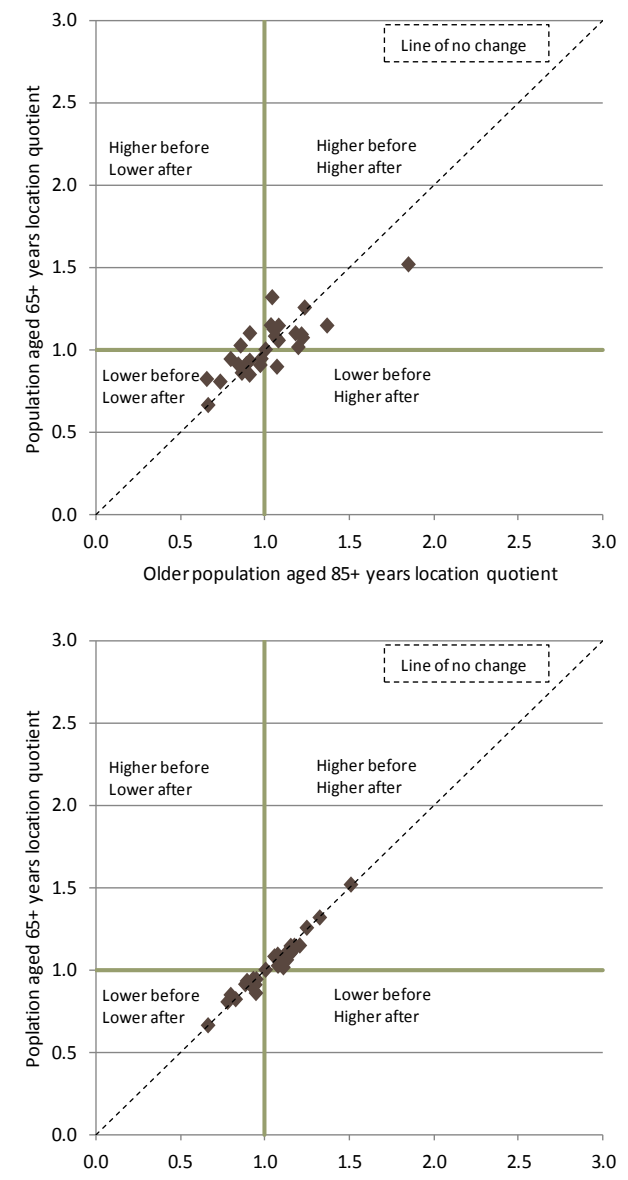

Population aged $65+$ rears with disabilty location quotient

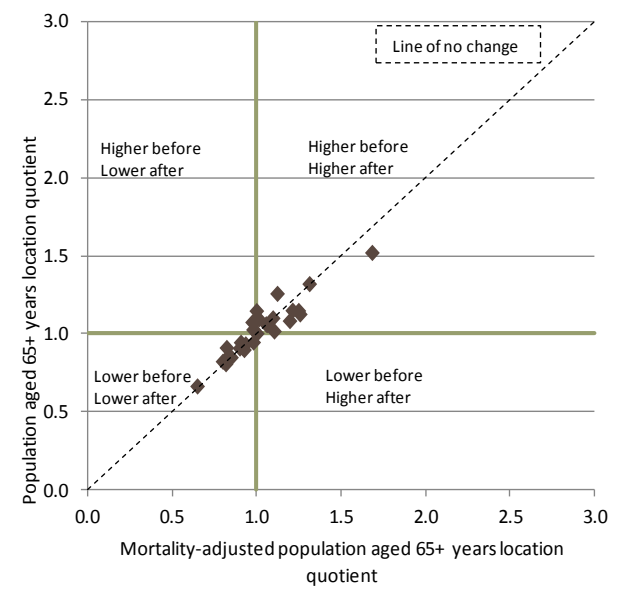

Notes: $\quad$ An area's location quotient is the area value divided by the national value. 'Higher before' means higher than the national value before adjustment 'Lower before' means lower than the national value before adjustment. 'Higher after' means higher than the national value after adjustment. 'Lower after' means lower than the national value after adjustment. See Box 3.1 for help on interpreting the scatter plots. 


\subsubsection{GEOGRAPHIC SUPPLY OF HOME CARE}

The geographic distribution of the annual average number of home care hours (HCHs) per person aged 65+ in Ireland in 2014 is presented in Table 4.19 and Figure 4.28. This combines HCHs provided as part of the Home Help scheme and the HCP scheme. In Table 4.19 and Figure 4.28, areas are ranked by hours per person aged $65+$ from highest to lowest.

The Gini coefficient for the distribution of $\mathrm{HCHs}$ is 0.101 , indicating an unequal distribution, and area values range from 15.4 $\mathrm{HCHs}$ per person aged 65+ in Dublin South to $34.5 \mathrm{HCHs}$ in Sligo (national average 24.1 per person aged 65+).

A more detailed examination of the geographic patterns shows that:

- Compared with the national value, there are more $\mathrm{HCH}$ ser person aged $65+$ in the border counties in the north and in the northwest (e.g. Sligo, Leitrim, Louth, Donegal, Roscommon, Cavan and Monaghan), Kerry, Dublin North, Meath and Cork.

- The numbers of average annual $\mathrm{HCH}$ in two of the three main commuter areas around Dublin are among the lowest in the country - Kildare (17.2) and Wicklow (20.3). However, unlike for other services, the supply of $\mathrm{HCHs}$ in the third main commuter county, Meath, is among the highest in the country (30) and the supply in Dublin South is the lowest in the country (15.4).

- Dublin South would require more than 748,000 additional publicly financed $\mathrm{HCH}$ to increase supply in that area to the national level. 
TABLE 4.19 ANNUAL AVERAGE NUMBER OF PUBLICLY FINANCED HOME CARE HOURS PER PERSON AGED 65+ BY GEOGRAPHIC AREA, IRELAND 2014

\begin{tabular}{|c|c|c|c|c|c|c|c|}
\hline Geographic area & $\begin{array}{c}\text { Number } \\
\text { of home } \\
\text { care } \\
\text { packages }\end{array}$ & $\begin{array}{l}\text { Number of } \\
\text { home help } \\
\text { hours }\end{array}$ & $\begin{array}{c}\text { Annual } \\
\text { average } \\
\text { number of } \\
\text { HCHs }\end{array}$ & $\begin{array}{c}\text { Population } \\
\text { aged } 65+ \\
\text { years }\end{array}$ & $\begin{array}{c}\text { Annual } \\
\text { average } \\
\text { hours per } \\
\text { pop aged } \\
65+\text { years }\end{array}$ & $\begin{array}{c}\text { Ratio of area } \\
\text { value to } \\
\text { national value }\end{array}$ & $\begin{array}{l}\text { Excess or } \\
\text { deficit of hours } \\
\text { compared with } \\
\text { national value }\end{array}$ \\
\hline Sligo & 220 & 275,617 & 341,828 & 9,916 & 34.5 & 1.43 & 102,521 \\
\hline Leitrim & 104 & 132,587 & 163,796 & 5,043 & 32.5 & 1.35 & 42,091 \\
\hline Kerry & 500 & 567,300 & 717,600 & 23,135 & 31.0 & 1.29 & 159,273 \\
\hline Dublin North & 3,299 & $1,045,075$ & $2,036,754$ & 66,781 & 30.5 & 1.26 & 425,110 \\
\hline Louth & 763 & 218,310 & 447,690 & 14,907 & 30.0 & 1.24 & 87,933 \\
\hline Meath & 387 & 450,514 & 566,762 & 18,900 & 30.0 & 1.24 & 110,640 \\
\hline Donegal & 360 & 599,054 & 707,138 & 23,728 & 29.8 & 1.23 & 134,499 \\
\hline Cork & 924 & $1,670,522$ & $1,948,276$ & 68,704 & 28.4 & 1.18 & 290,212 \\
\hline Roscommon & 193 & 231,948 & 289,964 & 10,281 & 28.2 & 1.17 & 41,848 \\
\hline Cavan & 274 & 188,961 & 271,276 & 9,639 & 28.1 & 1.17 & 38,654 \\
\hline Monaghan & 233 & 154,778 & 224,735 & 8,161 & 27.5 & 1.14 & 27,782 \\
\hline Tipperary North & 131 & 214,501 & 253,881 & 10,200 & 24.9 & 1.03 & 7,719 \\
\hline Galway & 533 & 639,502 & 799,722 & 32,231 & 24.8 & 1.03 & 21,877 \\
\hline Tipperary South & 164 & 269,187 & 318,607 & 12,916 & 24.7 & 1.02 & 6,900 \\
\hline Limerick & 440 & 459,620 & 591,734 & 25,591 & 23.1 & 0.96 & $-25,865$ \\
\hline Carlow & 93 & 128,217 & 156,309 & 6,794 & 23.0 & 0.95 & $-7,654$ \\
\hline Laois & 224 & 135,065 & 202,364 & 8,951 & 22.6 & 0.94 & $-13,655$ \\
\hline Wexford & 264 & 368,464 & 447,822 & 20,311 & 22.0 & 0.91 & $-42,352$ \\
\hline Mayo & 334 & 360,175 & 460,575 & 21,330 & 21.6 & 0.89 & $-54,191$ \\
\hline Kilkenny & 149 & 218,343 & 263,173 & 12,931 & 20.4 & 0.84 & $-48,896$ \\
\hline Wicklow & 357 & 238,085 & 345,500 & 17,015 & 20.3 & 0.84 & $-65,131$ \\
\hline Westmeath & 158 & 166,888 & 214,276 & 10,623 & 20.2 & 0.84 & $-42,093$ \\
\hline Offaly & 213 & 128,574 & 192,637 & 9,817 & 19.6 & 0.81 & $-44,281$ \\
\hline Longford & 71 & 75,538 & 96,987 & 5,288 & 18.3 & 0.76 & $-30,631$ \\
\hline Kildare & 318 & 245,068 & 340,558 & 19,814 & 17.2 & 0.71 & $-137,622$ \\
\hline Waterford & 118 & 240,489 & 276,054 & 16,291 & 16.9 & 0.70 & $-117,104$ \\
\hline Clare & 157 & 228,990 & 276,238 & 16,379 & 16.9 & 0.70 & $-119,044$ \\
\hline Dublin South & 2,218 & 647,112 & $1,313,843$ & 85,457 & 15.4 & 0.64 & $-748,541$ \\
\hline Ireland & 13,199 & $10,298,482$ & $14,266,101$ & 591,134 & 24.1 & 1.00 & 0 \\
\hline Gini coefficient & & & & 0.101 & & & \\
\hline
\end{tabular}

Sources: Data on the supply of publicly financed home care were provided by the Social Care Division of the HSE.

Notes: (a) Excess or deficit of HCHs compared with national value is calculated as: area hours - (area hours/ratio of area value to national value). (b) The Gini coefficient summarises inequality in the distribution of HCHs across areas, with 0 representing complete equality across areas and 1 representing complete inequality across areas. 


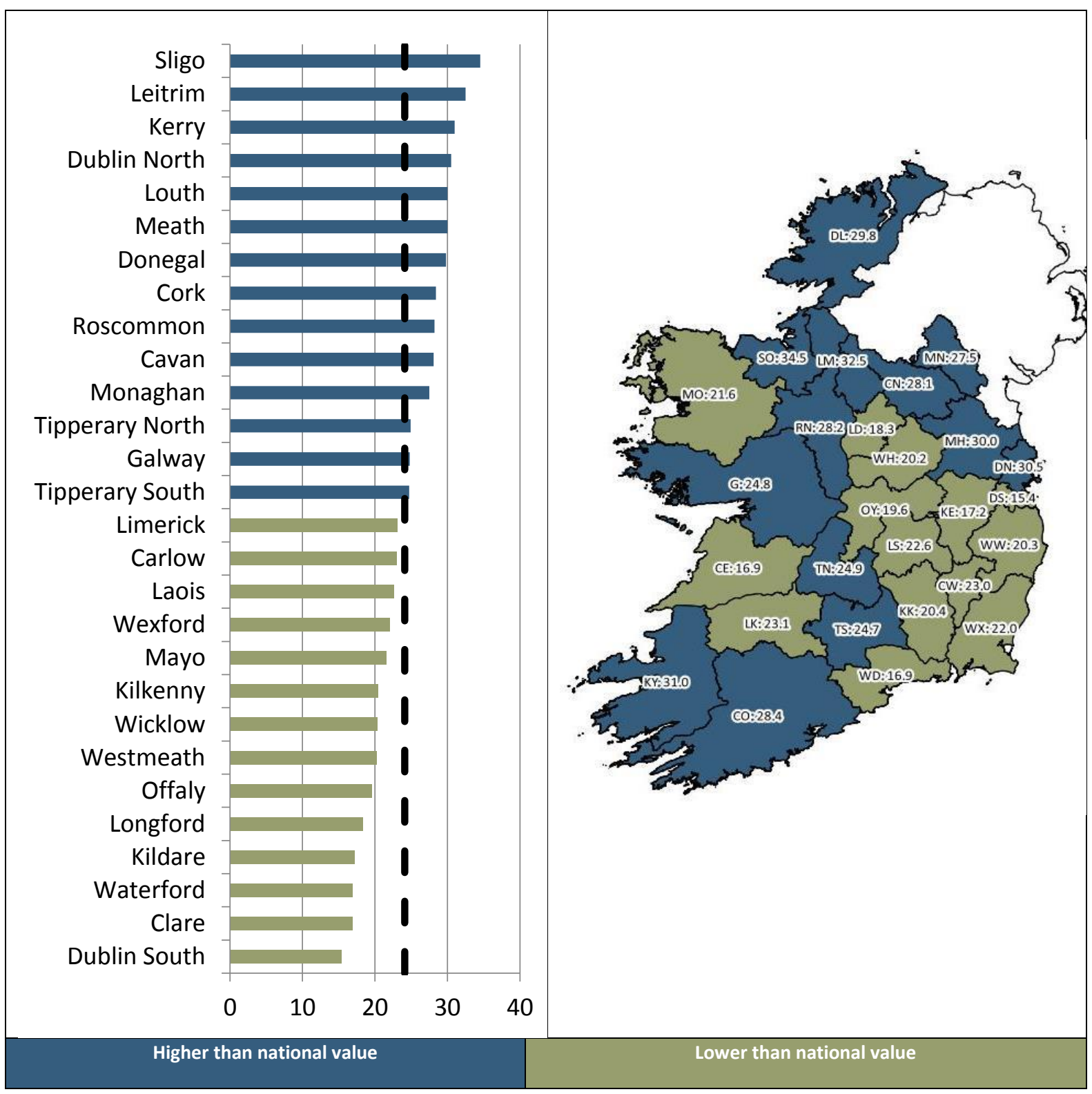

\section{Needs-adjusted home care supply}

Figure 4.29 illustrates the impact on the geographic pattern of home care supply following adjustment of the population for a range of need indicators. ${ }^{69}$ Further details can be found in Appendices 4 and 5 .

As with other non-acute supply, for each need indicator (i.e. older age groups, mortality and disability), the majority of the areas are positioned close to the 'line of no change', and fall in the top right or bottom left quadrant. The adjustment of home care supply for disability (Figure 4.29c) shows the least change in the position 
of areas relative to the national value; the data points in the scatter plot lie very close to the 'line of no change'. The adjustment of home care supply for the 85+ population (Figure 4.29a) shows the largest amount of change, as the data points are more dispersed about the 'line of no change' than in the other graphs.

\section{Ratio of area supply relative to national supply before and after adjustment}

Some notable area-specific patterns are:

- With the exception of Wexford, all areas that have a lower level of $\mathrm{HCHs}$ per person aged $65+$ relative to the national value before adjustment continue to have a lower level relative to the national value following adjustment, for all need indicators (i.e. bottom left quadrant in Figures 4.29a-4.29c).

- Wexford lies in the bottom right quadrant of Figure 4.29a following adjustment for age $85+$.

- With the exception of Roscommon, all areas that have a higher level of HCHs per person aged $65+$ relative to the national value before adjustment continue to have a higher level relative to the national value following adjustment, for all need indicators (i.e. top right quadrant in Figures 4.29a-4.29c).

- Roscommon lies in the top left quadrant of Figure 4.29a following adjustment for age $85+$. 
FIGURE 4.29 SCATTER PLOT OF LOCATION QUOTIENTS OF THE MEAN NUMBER OF PUBLICLY FINANCED HOME CARE HOURS PER PERSON AGED 65+ AND NEEDS-ADJUSTED POPULATIONS AGED 65+ BY GEOGRAPHIC AREA, IRELAND 2014

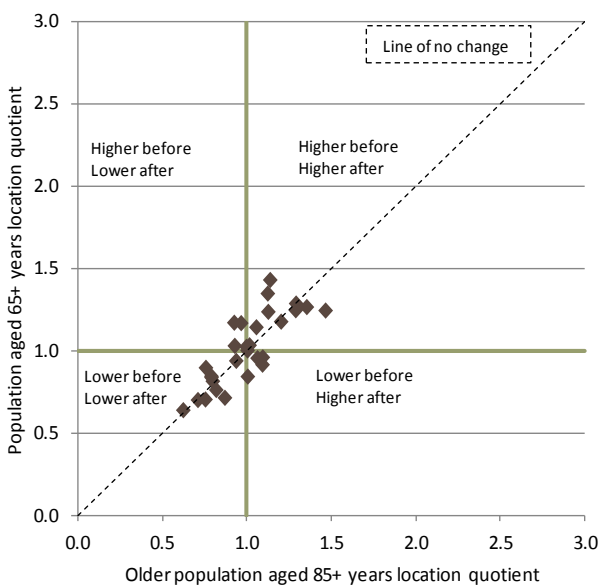

C

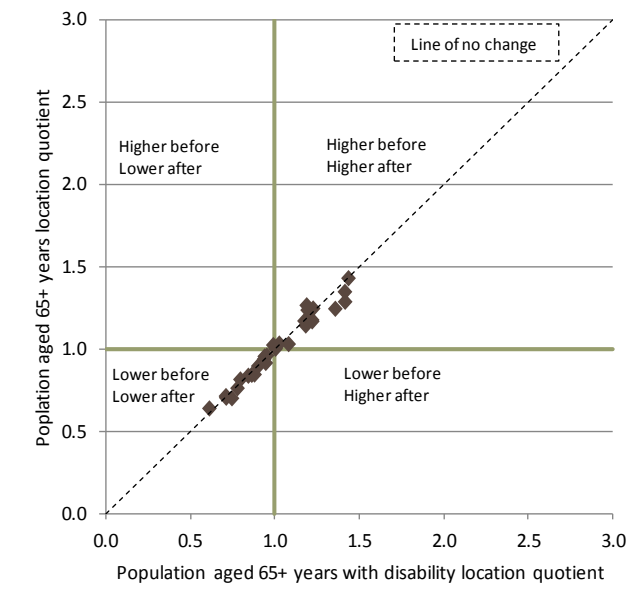

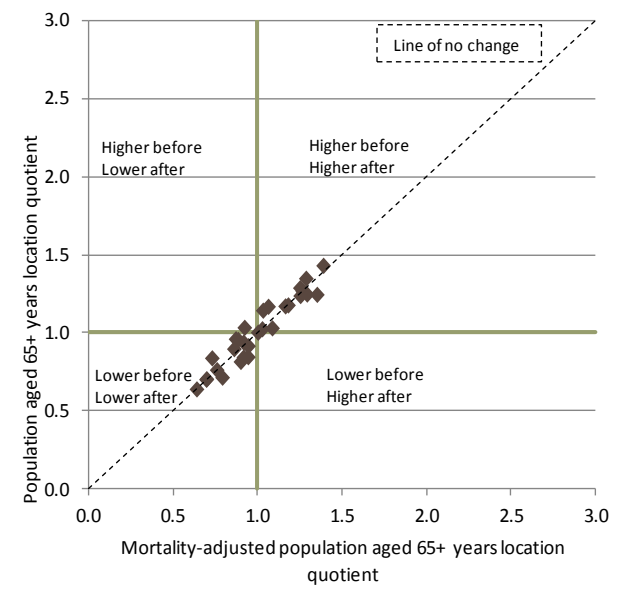




\subsection{Non-acute services - comparison of Gini coefficients}

Table 4.20 summarises the Gini coefficients for each of the non-acute supply variables outlined in Sections 4.4-4.6. It is important to note that this is just a summary index that hides some of the detail on how each of the services is distributed around the country. Nevertheless there is value in comparing the indices to give some indication of the scale within which the geographic distribution of these services vary.

\section{Comparison across services}

A priori, the location of publicly employed services would be expected to be more evenly distributed across areas, particularly once adjusted for need, given that decisions on location are made by the public employer (in the Irish case, the HSE) and are expected to be governed by plans for delivering co-ordinated services in line with local needs.

The Gini coefficients based on the unadjusted total population in Table 4.20 do not follow expected patterns. The Gini coefficients for GP and LTRC beds would be expected, a priori, to be higher than those for publicly employed services. GPs are private practitioners with more flexibility to choose where to locate in accordance with a number of factors (desirability of location, potential GMS contract, potential for private income stream, etc.), and over 75 per cent of LTRC beds are in privately run nursing homes (DOH, 2015b). The Gini coefficient for GPs (0.096) and for LTRC beds (0.091) based on the unadjusted population, while large, is lower (more equal) than that for the publicly employed services included in Table 4.20.

Interestingly after controlling for need, the Gini coefficients for LTRC increase, indicating a more uneven distribution after adjustment for each of the need indicators. Similarly, the Gini coefficient for PTs, which includes both public and private practitioners, increases following adjustment for need (e.g. from 0.116 to 0.142 after adjustment for age $85+$ ). The Gini coefficient for GPs shows a more mixed response to need adjustment.

In contrast, the Gini coefficients for the publicly employed CNs, OTs, SLTs and P\&Cs generally fall following adjustment for each of the needs, indicating a more equal distribution once needs have been taken into account. Nevertheless, the Gini coefficients for these services are still higher than those for GPs and LTRC for most of the need adjustments. The effect of needs adjustment on the Gini coefficients for SWs and CO/PSYs is mixed.

It is also important to note that for some of these services, the distributional profile is incomplete and private supply needs to be examined where feasible (e.g. P\&Cs, SLTs, HCHs). 


\section{Comparison across adjustment indicators}

Adjustment for disability reduces the Gini coefficient for each non-acute service presented in this report except for long-term and home care. Adjustment for mortality, age 65+ and 85+ reduces the Gini coefficient for most of the services (the main exceptions are PTs and CO/PSYs, and LTRC and home care).

Adjustments for Medical Card holders and for Medical Card holders with a prescription for a chronic condition have similar impacts on the Gini coefficient, and this is not surprising given that the latter 'morbidity' adjustment is based on a subset of the Medical Card population.

TABLE 4.20 GINI COEFFICIENTS FOR THE GEOGRAPHIC DISTRIBUTION OF SELECTED NON-ACUTE HEALTHCARE SERVICES, IRELAND 2014

\begin{tabular}{|c|c|c|c|c|c|c|c|}
\hline Supply variable & $\begin{array}{c}\text { Total } \\
\text { population }\end{array}$ & $\begin{array}{l}\text { Age } \\
65+ \\
\text { years }\end{array}$ & $\begin{array}{l}\text { Age } \\
85+ \\
\text { years }\end{array}$ & Mortality & Disability & $\begin{array}{l}\text { Medical } \\
\text { Card }\end{array}$ & $\begin{array}{c}\text { Medical Card } \\
\text { plus prescription }\end{array}$ \\
\hline $\begin{array}{l}\text { General } \\
\text { practitioners }^{a}\end{array}$ & 0.096 & 0.093 & 0.122 & 0.093 & 0.082 & 0.115 & 0.103 \\
\hline Community nursing ${ }^{a}$ & 0.125 & 0.105 & 0.117 & 0.106 & 0.115 & 0.114 & 0.110 \\
\hline Physiotherapists $^{a}$ & 0.116 & 0.119 & 0.142 & 0.119 & 0.107 & N/A & $\mathrm{N} / \mathrm{A}$ \\
\hline $\begin{array}{l}\text { Occupational } \\
\text { therapists }^{\mathrm{a}}\end{array}$ & 0.171 & 0.166 & 0.153 & 0.162 & 0.169 & 0.169 & 0.167 \\
\hline $\begin{array}{l}\text { Speech and language } \\
\text { therapists }^{\mathrm{a}}\end{array}$ & 0.120 & 0.104 & 0.104 & 0.101 & 0.109 & 0.134 & 0.125 \\
\hline $\begin{array}{l}\text { Podiatrists and } \\
\text { chiropodists }^{\mathrm{a}}\end{array}$ & 0.615 & 0.594 & 0.571 & 0.596 & 0.610 & 0.605 & 0.601 \\
\hline $\begin{array}{l}\text { Counsellors and } \\
\text { psychologists }^{\mathrm{a}}\end{array}$ & 0.168 & 0.178 & 0.189 & 0.175 & 0.159 & 0.170 & 0.172 \\
\hline Social workers ${ }^{a}$ & 0.214 & 0.215 & 0.205 & 0.215 & 0.211 & 0.220 & 0.218 \\
\hline $\begin{array}{l}\text { Long-term } \\
\text { residential care } \\
\text { beds }^{\mathbf{b}}\end{array}$ & N/A & 0.091 & 0.119 & 0.146 & 0.095 & N/A & N/A \\
\hline Home care hours $^{b}$ & N/A & 0.101 & 0.116 & 0.122 & 0.129 & $\mathrm{~N} / \mathrm{A}$ & $\mathrm{N} / \mathrm{A}$ \\
\hline
\end{tabular}

\footnotetext{
Legend:

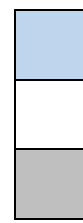

Decrease in Gini coefficient relative to the baseline Gini (i.e. based on total population) across adjustment indicators (suggests decreased inequality).

No change in Gini coefficient relative to the baseline Gini (i.e. based on total population) across adjustment indicators.

Increase in Gini coefficient relative to the baseline Gini (i.e. based on total population) across adjustment indicators (suggests increased inequality).
}

Notes: (a) The Gini coefficient for the total population is the base to which the other Gini coefficients are compared. (b) The Gini coefficient for the population aged 65+ years is the base to which the other Gini coefficients are compared. 


\section{Discussion and conclusions}

\subsection{INTRODUCTION}

The previous chapter presents findings on the geographic profile of ten key nonacute services in Ireland in $\mathbf{2 0 1 4}$ with and without adjustment for healthcare need indicators. These findings are discussed in this chapter, where we draw out key conclusions and highlight areas that require further consideration in the current policy context of improving resource allocation and expanding non-acute primary, community and long-term care services in Ireland.

This analysis was undertaken using data from 2014 (and 2015 in the case of longterm residential care (LTRC)). Due to the lack of a comprehensive database on care supply in Ireland, the identification and collation of the data supply included, specifically surveying private physiotherapists (PTs), was in itself a major contribution of the report. Changes in regional supply and population since 2014 may have altered some of the supply rankings summarised in the findings. However, due to the absence of a systematic resource allocation system in Ireland that relates supply to population need, it is likely that inequalities persist and the counties ranked as having low relative supply of care remain insufficiently served. This report does not therefore propose which areas require greater supply of which services, or which services may require particular attention to increase supply. Instead, it shows that considerable regional inequality in the supply of non-acute services exists and, importantly, this cannot be explained on the basis of need. In the context of a national policy objective of moving care from acute hospitals into the community and the establishment of Regional Integrated Care Organisations (RICOs) such under-supply in certain regions may present hospitals and healthcare administrators in these regions with greater challenges than in other areas which are better resourced.

Section 5.2 draws on the findings from Chapter 4 on supply of non-acute primary, community and long-term care across counties in Ireland to provide a high-level synthesis of the results across counties and services. Section 5.3 discusses the sensitivity of these results to adjustments for needs. Section 5.4 considers how our results relate to optimum supply. Section 5.5 situates the findings in the context of the Irish health and social care system, and examines the implications for policy, future planning and resource allocation decision making. Section 5.6 discusses limitations of the report and data challenges encountered. Section 5.7 concludes. 


\subsection{BROADER GEOGRAPHICAL PATTERNS IN EQUITY OF SUPPLY}

Table 5.1 provides a high-level synthesis of the report's findings on the geographic variation in the supply of non-acute services in Ireland in 2014. A simple ranking system is employed. The per capita supply of each service compared to the national average ('Ratio of area value to national value' in Chapter 4) is presented for each county. Counties with supply of a service 10 per cent lower than the national average are denoted as a red circle. Counties with supply of a service 10 per cent higher than the national average are denoted as a green circle. Where per capita supply of a service is within 10 per cent of the national average, this is denoted as an amber circle. Counties are sorted by the number of services where supply is lower than the national average.

While results in Chapter 4 show geographic variations in the supply of individual non-acute services, Table 5.1 reveals broader patterns. Using this metric, the Greater Dublin commuter belt and South East counties have lower relative supply of many non-acute primary and community care services than the national average. Kildare and Meath have lower relative supply (at least 10 per cent lower than the national value) for all non-acute community and primary care services. Wexford and Wicklow have lower relative supply (at least 10 per cent lower than the national value) for seven of the eight non-acute community and primary care services examined.

In contrast to the low relative supply on the East coast, three counties on the West coast - Galway, Sligo and Leitrim - as well as Cork, Westmeath and Tipperary South have higher relative supply for many services, and do not have lower relative supply for more than one of the services examined. Interestingly, no apparent relationship was seen between supply of home care and LTRC, i.e. low (high) relative supply of LTRC one does not imply low (high) relative supply of home care. No county also has low relative supply of both LTRC and home care. There also appears to be no relationship between non-acute primary/community care supply and long-term care supply. 


\begin{tabular}{|c|c|c|c|c|c|c|c|c|c|c|c|}
\hline & \multicolumn{8}{|c|}{ Non-Acute Primary and Community Care } & \multicolumn{2}{|c|}{ Long-Term Care } & \multirow{2}{*}{$\begin{array}{l}\text { Number of services } \\
>10 \text { per cent below } \\
\text { national average }\end{array}$} \\
\hline & $G P^{1}$ & $\mathrm{PHN} / \mathrm{CN}^{2}$ & $\mathbf{P T}^{3}$ & $\mathrm{OT}^{2}$ & $S L T^{2}$ & $P \& C^{2}$ & CO\&PSY ${ }^{2}$ & $s w^{2}$ & LTRC $^{4}$ & $\mathrm{HCH}^{5}$ & \\
\hline Kildare & 0 & O & 0 & 0 & 0 & 0 & O & O & O & O & 9 \\
\hline Meath & 0 & 0 & 0 & 0 & 0 & 0 & 0 & 0 & 0 & 0 & 8 \\
\hline Wexford & 0 & 0 & 0 & 0 & 0 & O & 0 & O & 0 & 0 & 8 \\
\hline Wicklow & 0 & 0 & O & 0 & 0 & O & O & O & 0 & O & 8 \\
\hline Clare & O & 0 & O & 0 & O & O & 0 & 0 & O & 0 & 7 \\
\hline Kilkenny & 0 & 0 & O & 0 & 0 & 0 & O & O & 0 & 0 & 7 \\
\hline Waterford & 0 & 0 & O & 0 & 0 & 0 & 0 & 0 & 0 & 0 & 7 \\
\hline Offaly & 0 & 0 & O & 0 & 0 & 0 & 0 & O & 0 & 0 & 5 \\
\hline Carlow & 0 & 0 & 0 & 0 & 0 & 0 & 0 & 0 & 0 & 0 & 5 \\
\hline Laois & 0 & 0 & 0 & 0 & 0 & C & 0 & 0 & 0 & 0 & 4 \\
\hline Limerick & 0 & 0 & 0 & 0 & 0 & 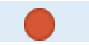 & 0 & 0 & 0 & 0 & 3 \\
\hline Mayo & 0 & 0 & 0 & 0 & 0 & 0 & 0 & O & O & 0 & 3 \\
\hline Tipperary North & 0 & 0 & 0 & 0 & 0 & 0 & 0 & 0 & 0 & 0 & 3 \\
\hline Dublin North & 0 & 0 & 0 & 0 & 0 & 0 & 0 & 0 & 0 & 0 & 3 \\
\hline Kerry & 0 & 0 & 0 & 0 & 0 & 0 & 0 & 0 & 0 & 0 & 3 \\
\hline Monaghan & 0 & 0 & 0 & 0 & 0 & $\mathrm{C}$ & 0 & 0 & 0 & 0 & 3 \\
\hline Longford & 0 & 0 & 0 & 0 & 0 & 0 & 0 & O & 0 & 0 & 3 \\
\hline Roscommon & 0 & 0 & 0 & 0 & 0 & 0 & 0 & 0 & 0 & 0 & 3 \\
\hline Dublin South & 0 & 0 & 0 & 0 & 0 & 0 & O & 0 & 0 & 0 & 2 \\
\hline Cavan & 0 & 0 & O & 0 & 0 & 0 & 0 & 0 & 0 & 0 & 2 \\
\hline Louth & 0 & 0 & 0 & 0 & 0 & 0 & 0 & 0 & 0 & 0 & 2 \\
\hline Donegal & 0 & 0 & 0 & 0 & 0 & O & 0 & O & 0 & 0 & 2 \\
\hline Tipperary South & 0 & 0 & 0 & 0 & 0 & 0 & 0 & 0 & 0 & 0 & 1 \\
\hline Westmeath & 0 & O & O & 0 & 0 & 0 & 0 & 0 & O & 0 & 1 \\
\hline Leitrim & 0 & 0 & 0 & 0 & 0 & 0 & 0 & 0 & 0 & 0 & 1 \\
\hline Sligo & 0 & 0 & 0 & 0 & 0 & 0 & 0 & 0 & 0 & 0 & 1 \\
\hline Cork & 0 & 0 & 0 & 0 & 0 & 0 & 0 & 0 & 0 & 0 & 0 \\
\hline Galway & 0 & 0 & 0 & 0 & 0 & 0 & 0 & 0 & 0 & 0 & 0 \\
\hline
\end{tabular}

County has supply at least 10 per cent higher than national average.

County has supply at least 10 per cent lower than national average.

County has supply approximately equal to the national average.

Notes: $\quad 1$. The number of GPs is converted to estimated WTEs based on survey evidence on full- and part-time working practices of GPs in Ireland. See Chapter 3 for more details. 2. Publicly employed WTEs. See Chapter 3 for more details. 3. Publicly employed and privately employed WTE PTs. See Chapter 3 for more details. 4. Long-term residential care beds in public and private long-term residential care centres. See Chapter 3 for more details. 5. Publicly funded home care hours from the Home Help and Home Care Package schemes. See Chapter 3 for more details.

\subsection{SENSITIVITY OF RESULTS}

The assumptions behind Table 5.1 are intended to provide a high-level illustration of how areas fare across services. It does not attempt to assign levels of relative importance to each of the services examined or consider the extent to which lower relative supply of one service could be traded off with higher relative supply of another service. Furthermore, it is important to consider the factors that contribute to variations in supply and test whether results are consistent across different adjustment factors.

As discussed for each individual service in Chapter 4, the analysis adjusts supply for need factors (age, mortality, disability rates, Medical Card rates, chronic illness 
rates). The needs-adjustment approach adopted in this analysis adjusts for each need indicator separately and it is important to note that these are highly correlated measures (e.g. mortality adjustment incorporates age and morbidity effects). However, despite these complications the results consistently show that needs adjustment does not remove, and in some cases reveals a higher level of, inequality in the geographic distributions of supply.

Therefore, many of the high-level features indicated by Table 5.1 remain regardless of the adjustments made for need factors. In particular, the finding that counties in the greater Dublin commuter belt and in the South East have non-acute primary and community service supply lower than the national value is robust to changes of this kind. One exception is Kildare: following adjustment, the level of supply in Kildare is higher than the national average for community nurses (CNs), PTs, GPs and speech and language therapist (SLTs) for some need indicators. There is a small number of areas where the supply falls from above the national average to below the national average after adjustment. In particular, in Mayo the supply of CNs, GPs and SLTs lies above the national average prior to adjustment but below the national average following adjustment for most adjustment indicators. In Roscommon, the supply of PTs, social workers (SWs) and CNs changes from above to below the national average following adjustment, and in Sligo and Kerry, the supply of PTs changes from above to below the national average following adjustment for most indicators.

When comparing across the different adjustment factors, for each type of supply, the factor most likely to influence rankings is the population age 85+. Interestingly, while disability is a key driver of non-acute care use, little change in supply rankings is observed after adjusting for disability rates.

\subsection{RELATIONSHIP OF THESE FINDINGS TO OPTIMUM LEVELS OF SUPPLY}

As outlined in Chapter 2, in addition to assessing equity in the geographic supply of non-acute services in Ireland, policymakers are concerned with determining overall adequacy of supply. As a starting point, this report assesses supply in each area against the benchmark of the national average. This is a useful baseline against which to assess supply in each county, and the analysis has highlighted some potentially important signs of under-supply of non-acute services in specific areas in the country relative to the national average. However, to determine adequacy, it is important to assess the national average against a more robust benchmark of the level of supply that is deemed optimal to meet a given level of need. International levels of supply are often used as benchmarks but these are typically subject to caveats about international variations in definitions of roles and responsibilities of healthcare personnel, qualifications, etc. 
The results in Table 5.1 summarise the geographic variation in supply across counties in Ireland in 2014. Within Chapter 4, the relative and absolute increases in supply (i.e. WTE GPs, WTE therapists, home care hours) that would be required for low-supply counties to reach the national average value are provided. However, the national average does not necessarily represent adequate coverage, so it is not necessarily the appropriate value to strive for when increasing supply.

There are reasons to think that optimal supply may be higher than the national average for some services. For example, Figure 4.7 shows that that in GP care Ireland ranks just above the middle of the distribution of OECD countries, with 7.8 GPs per 10,000 (see Figure 4.7), though this ranking would be much lower if GPs in training were removed from the OECD estimate. This illustrates the difficulty in situating overall supply in Ireland within an international context. International comparisons were not practicable for the other services examined, but there is clear evidence from Ireland of unmet need and long waiting times for public community therapy services and home care in particular (Wren et al., 2017). Alternative benchmarks could include clinical standards outlining optimum care levels (e.g. Wren et al. (2014) examined the quality of rehabilitation care for stroke survivors against international best practice protocols). Assessing adequacy in this manner for the wide range of services examined was beyond the scope of the analysis in this report. Nevertheless, even where the national average does not equate to the optimal level of supply, the counties with lower relative supply identified in Figure 5.1 will require the largest adjustments in supply to reach the future target values if equity is to be achieved.

\subsection{DISCUSSION OF FINDINGS ON DRIVERS OF GEOGRAPHIC VARIATIONS IN HEALTH AND SOCIAL CARE SUPPLY}

The focus of this report has been to compile and present data on the supply of nonacute services in Ireland in 2014 and to examine the extent to which the supply varies across the country. In the subsequent report from this project (Walsh et al., 2019b), we will discuss in greater details the factors that require greater consideration when designing resource allocation decisions and planning for the health system in the future. However, it is important to consider the drivers of current geographic supply patterns so that policymakers can introduce appropriate measures if they wish to address apparent over- or under-supply in specific areas and RICOs. Furthermore, the findings from this report need to be interpreted in the context of how the Irish health and social care system has evolved.

As discussed earlier, geographic variations in supply remain after adjustment for many indicators of need. This suggests that the geographic variations in supply are more likely to be driven by other, non-needs factors. These factors could include the influence of historic rather than population-based budgeting practices for non- 
acute services as discussed in Chapter 2, location decision factors in the case of privately employed services (GPs, private nursing homes, etc.) and the lack of defined resources allocation formulas for non-acute care and population-based budgeting practices.

Another factor that may have contributed to observed variations in supply is the inability of service planning to keep up with demographic changes in Ireland over time. There have been sizeable changes in the distribution of the population by county over the past 30 years, in particular the increase in populations in Dublin and the greater Dublin commuter counties. The populations of Kildare and Meath increased, as a proportion of national population, by more than 40 per cent between 1986 and 2016. ${ }^{70}$ If non-acute supply distribution has not kept pace with changing population distributions, this would help to explain the low levels of per capita supply relative to the national average in these counties. Other counties that have seen large increases in population (as a proportion of the national population) include Wicklow (12 per cent) and Wexford (9 per cent), also in the east of the country. Conversely, Sligo and Leitrim have seen some of the largest declines in population (12-13 per cent), as a proportion of national population, over the same time period, which may account for why per capita non-acute supply is consistently higher than in other counties. However, there are exceptions to these general patterns: Galway experienced a similar increase in population to Wicklow and Wexford, as a proportion of national population, over the same time period but levels of per capita non-acute supply are high relative to the national value.

The above examples highlight the importance of planning and resource allocation decisions to take account of changing demographics. Future migration within and into Ireland may exacerbate the regional disparities in needs-adjusted supply found in this report, especially if the largest population increases occur in the areas already seeing low supply of health and social care services: the greater Dublin commuter belt counties and the South East. Between 2016 and 2040, much of the projected growth of population is expected to occur in cities and surrounding areas including Dublin, Kildare, Meath and Louth (Morgenroth, 2018). Population growth in general is projected to be faster in the Eastern region (Dublin and Leinster counties) as compared to other regions (Morgenroth, 2018). This means that medium- and long-term resource allocation and capacity planning policies such as the National Planning Framework - 'Project Ireland 2040' (Government of Ireland, 2018) - should take account of the implications of projected demographic change for service demand in the regions currently with lower relative supply and where population increases are projected to be greatest. 
In addition to population size, population structure is a key driver of health and social care demand and therefore the required supply of services. Age is key, especially for services used predominantly by older populations (e.g. long-term care). This report considered the effects of adjusting for the percentage of the population aged $65+$ and $85+.{ }^{71}$ The results suggest that changes in the age profiles of counties over time may help explain some of the inequality in supply. This factor will likely continue to affect the distribution of service needs in future. Between 2016 and 2040, the average age of the population is projected to increase significantly, from 36.9 to 42.8 years (Morgenroth, 2018). Therefore, both increases in the population and changes in the age structure of the population will need to be accounted for in future planning of health and social care services. As evidence shows that the services predominantly used by older people will face larger increases in demand in the future (Wren et al., 2017), and population ageing is occurring at different rates across regions, this will also need to be taken into account when planning allocation of resources in these regions. In particular, the supply of LTRC requires more substantial investment in infrastructure than for the other non-acute services examined here, and factors such as land suitability and affordability are assumed to influence location decisions. With most LTRC beds now being provided by private care centres, the supply is also likely to be influenced by market factors such as land prices. In future work we plan to examine this sector more closely.

As outlined in Chapter 2, while a number of significant structural changes have occurred in the Irish health and social care system in recent years, there remains an institutional legacy with regard to regional-based Health Boards that were in place until the establishment of the HSE in 2005. Therefore, in addition to the lack of national resource allocation formulas, some of the differences in supply identified in this report may be a consequence of the historical regional health board structure of the Irish health and social care system. In this context, local autonomy for some aspects of service planning has resulted in a divergence in the development of non-acute care supply in the past, with some of this divergence remaining and underpinning the large inequalities in supply across Ireland. The contribution of historical persistence is difficult to quantify, though others have made similar arguments previously, and some examples do exist to support this hypothesis. For example, the first home care scheme was established as part of the 1970 Health Act. But at the outset of this scheme, home care service provision at was at the discretion of the local health authorities (Timonen and Doyle, 2008). Similarly in recent years, as shown in Table 4.19, in many regions the Home Help scheme was the by far the most prominent provider of home care hours, while in other regions the Home Care Package scheme, which originally was targeted

71 In the case of SLTs, adjustment for the 0-4 age group, and for age 85+ and 0-4 together was also examined. 
towards more complex patients, had a larger role. As part of Sláintecare, the establishment of RICOs means that aspects of localised decision-making will remain. While this will facilitate better matching by health managers of care supply with local patient demand, providing appropriate data, information and guidance at the national level could also help address imbalances in the non-acute care supply. Furthermore, while greater autonomy may exist at the RICO level, it is important that elements such as data infrastructure, data gathering, and resource allocation mechanisms remain systematic and consistent across RICOs.

In this report, due to the influence of eligibility rules on the access to and demand for healthcare services in Ireland, non-acute supply estimates were adjusted for the Medical Card (GP Visit Card) population in each county. Medical Card status is a key enabling factor for receiving publicly funded healthcare, and to some degree public health service provision is based around the Medical Card population. Medical Cards are also used in the report to adjust for socioeconomic conditions as eligibility is largely based on income means-testing, and holding a Medical Card is frequently used as an indicator of lower socioeconomic status (Coughlan et al., 2013; Morrissey, 2019). Within primary care, much of GP income comes from the General Medical Services (GMS) scheme. While GPs are private practitioners, it is difficult for policymakers to allocate or incentivise increased supply in underserved areas. The GMS scheme does offer a potential mechanism to reallocate primary care supply. At the moment capitation payments with the GMS scheme are based primarily on age and sex. As we discuss in this report, a range of other need factors influence demand for health care. In the UK, where GPs are also private undertakings, capitated reimbursement is based on the Carr-Hill formula, which uses a broader list of factors when assessing the drivers of workload for GP practices. As well as patient age and sex, reimbursement is determined by the number of patients from LTRC centres, patient list turnover and rurality of the practice. The NHS formulas also adjust for staff market forces, reflecting the geographical variation in labour costs. A similar system here, perhaps taking account of other factors such as deprivation, might allow for a better alignment of need with supply. A similar resource allocation process could be considered for publicly provided therapy care (e.g. PTs, occupational therapists (OTs), SLTs), especially as access to these services is often dependent on Medical Card status. If free primary and community care are to be expanded in line with Sláintecare proposals, this will further increase demand for GP care (Nolan and Smith, 2012; O'Callaghan et al., 2018) and likely other community care services, placing additional demands on the workforce at the national and regional levels.

We have given primary, community and long-term care considerable attention in this report due to the large proportion of total care provided by these sectors. New policy proposals including Sláintecare have identified a need to move some care away from the acute hospital sector to the primary, community and long-term care 
sectors (Houses of the Oireachtas Committee on the Future of Healthcare, 2017). To what extent care can be easily substituted away from hospitals is less well understood. The second report from the project will provide analyses of the substitutability between acute and long-term care, building on the data collected for this report (Walsh et al., 2019b). Where care can be substituted towards the community sector, planning and provision of services will be required to meet this demand. Sláintecare and others do emphasise the requirement to invest in primary, community and long-term care; our research emphasises that there will be an important regional planning dimension in these investment requirements.

\subsection{LIMITATIONS}

\subsubsection{Data gaps}

It is worth emphasising the challenges in obtaining accurate assessments of the supply of non-acute services in the Irish health and social care system. The analyses in this report were based on capturing data from a range of different sources, which accounted for a considerable amount of time in the project. However, a number of gaps in data remain, in particular the supply of private health professionals (SLTs, podiatrists and chiropodists, etc.), GP practice nurses, disability and mental health services, as well as non-acute care utilisation. These data gaps affect not just the scope of this report but also the ability to allocate health resources in an equitable manner and the scope for health research in Ireland more generally to inform the policy debate.

New data sources are coming on stream that could be useful for future analysis. For example, CORU, the new multi-profession regulator responsible for the registration of health and social care professionals, now has registration open for PTs, OTs, SLTs, SWs and others (CORU, 2017). It may be possible to learn more about local variations in the delivery of non-acute services that are not apparent in data on WTE numbers. For example, in some areas private providers have been contracted to deliver selected non-acute services and these arrangements are not captured in available data. Also, there may be role substitution/overlapping (e.g. overlapping roles of CNs, PTs and OTs; type of services provided in the home support scheme) that varies across areas, and this again requires further information on how services are organised at local level.

\subsubsection{Needs adjustment}

The needs adjustment methods do not control for correlations among the need indicators. In particular, as noted in Chapter 4, the Medical Card can be considered an indicator of healthcare need and socioeconomic status as well as being an indicator of healthcare accessibility. Controlling for correlations in the eligibility 
and needs adjustment indicators would require multivariate analysis that is beyond the scope of available data (i.e. data on supply would be required for areas at lower levels of disaggregation than are currently available).

Sensitivity analysis around which needs indicators are most applicable to which services is also needed. For example, for needs adjustment of long-term care supply, the 65+ age adjustment may be too low and the 85+ age adjustment may be too high given the expected age profile of long-term care residents (Wren et al. 2012). Examination of long-term care supply controlling for the population at different age groupings above 65 could be instructive.

This analysis used the Medical Card to capture enabling factors in healthcare use and also to proxy socioeconomic and healthcare needs, but additional analysis could consider other ways of capturing the effects of poverty and deprivation.

The analysis has also shown how the patterns of supply vary in relation to eligibility and different indicators of needs. This information could in turn help inform decisions on what factors to include in a resource allocation model. For example, using the Census indicator of disability has relatively little effect when it is used to need-adjust supply estimates. This may indicate that disability is relatively evenly spread across regions or it could imply that the questions on disability included in the Census are too broad to capture relevant variations in needs. By contrast, there is much more change in the estimated distributions when one controls for the population aged $85+$.

\subsection{CONCLUSIONS}

This project was motivated by the need to inform the current reform programme that is aiming to achieve greater integration in the Irish health and social care system via shifting care, where appropriate, from acute hospitals to non-acute settings, building capacity in primary and social care, and other measures (Houses of the Oireachtas Committee on the Future of Healthcare, 2017; Government of Ireland, 2018). The analysis in this report contributes to the evidence base on the supply of non-acute services around the country, while the second report from this project will examine the ways in which acute and non-acute sectors interact in the system (Walsh et al., 2019b).

This report sets out the geographic distribution, by county, of the ten most commonly used non-acute healthcare services in Ireland in 2014. Adjustments are made for a range of different need indicators, and supply in each area is compared with national average supply. The data show that there is an unequal distribution of non-acute services across the country. The finding that the distribution of supply is unequal even after controlling for healthcare need factors is consistent with 
anecdotal evidence of inequity in access to non-acute care cited in many policy documents, and it underlines the importance of moving towards population-based resource allocations if equity is to be improved. The analysis has also examined how the patterns of supply vary in relation to different indicators of needs. This information can help inform policymakers as to what factors could be included in a resource allocation model. Assessment of supply in each area relative to national average supply highlights areas with consistent under-supply of services relative to the national average. While the adequacy of national average supply of each service itself needs to be assessed, this evidence supports the goals of the reform programme to build capacity in primary, community and long-term care in a way that supports equitable care provision.

Changes in regional health and social care supply and population in the five years since our data were collected may have altered the actual situation away from some of the estimates in this report. However, in the absence of a national resource allocation system relating supply to population needs, it is likely that significant inequalities persist. This report thus stops short of trying to identify which areas require greater supply of particular services to achieve an equitable allocation. Instead, it demonstrates that without a resource allocation system there has been considerable regional inequality in the supply of non-acute services, and this cannot be explained on any needs basis we could identify. The analysis from the report also highlights the desirability of collecting better data to extend these analyses over time and to allow for consistent and systematic assessment of health and social care supply.

The second report from this project will extend this analysis to consider the substitutability of acute and long-term care services for older people and its implications for resource allocation planning in the Irish health and social care system in the future (Walsh et al., 2019b). 
144 | Geographic Profile of Healthcare Needs and Non-Acute Healthcare Supply in Ireland 


\section{REFERENCES}

Allin, S., M. Grignon, and J. Le Grand (2010). 'Subjective unmet need and utilization of health care services in Canada: what are the equity implications?', Social Science \& Medicine, Vol. 70 , No. 3, pp. 465-472.

An Bord Altranais (2005). Requirements and standards for public health nurse registration education programmes, Dublin: An Bord Altranais, available at: http://www.nursingboard.ie/en/publications_current.aspx?page $=3$

Andersen, R.M. (1995). 'Revisiting the behavioral model and access to medical care: does it matter?', Journal of Health and Social Behavior, Vol. 36, No. 1, pp. 1-10.

Andersen, R.M., P. L. Davidson, and S.E. Baumeister (2013). 'Improving access to care', in G.F. Kominski (ed.) Changing the U.S. health care system: key issues in health services policy and management (4th ed.), San Francisco: Jossey-Bass.

Asaria, M., T. Doran, and R. Cookson (2016). 'The costs of inequality: whole-population modelling study of lifetime inpatient hospital costs in the English National Health Service by level of neighbourhood deprivation', Journal of Epidemiology and Community Health, Vol. 70, No. 10, pp. 990-996.

Asthana, S., A. Gibson, G. Moon, J. Dicker, and P. Brigham (2004). 'The pursuit of equity in NHS resource allocation: should morbidity replace utilisation as the basis for setting health care capitations?', Social Science \& Medicine, Vol. 58, No. 3, pp. 539-551.

Birch, S., T. Mason, M. Sutton, and W. Whittaker (2013). 'Not enough doctors or not enough needs? Refocusing health workforce planning from providers and services to populations and needs', Journal of Health Services Research and Policy, Vol. 18, No. 2, pp. 107-113.

Brick, A., A. Nolan, J. O'Reilly, and S. Smith (2010). Resource allocation, financing and sustainability in health care. Evidence for the Expert Group on Resource Allocation and Financing in the Health Sector, Vol. I, Dublin: Department of Health and Economic and Social Research Institute, available at: http://www.esri.ie/publications/resource-allocation-financing-and-sustainabilityin-health-care-evidence-for-the-expert-group-on-resource-allocation-andfinancing-in-the-health-sector-vols-1-and-2/

Brick, A., A. Nolan, J. O'Reilly, and S. Smith (2012). 'Conflicting financial incentives in the Irish health-care system', The Economic and Social Review, Vol. 43, No. 2, pp. 273-301.

Cardoso, T., M.D. Oliveira, A. Barbosa-Povoa, and S. Nickel (2012). 'Modeling the demand for long-term care services under uncertain information', Health Care Management Science, Vol. 15, No. 4, pp. 385-412.

Care Alliance Ireland (2018). Public provision of home care in Ireland - update, Briefing Paper 2, Dublin: Care Alliance Ireland.

Carr-Hill, R., G. Hardman, S. Martin, S. Peacock, T. Sheldon, and P. Smith (1994). A formula for distributing NHS revenues based on small area use of hospital beds, York: 
Centre for Health Economics, University of York, available at: http://www.york.ac.uk/che/pdf/op22.pdf

Carrillo, J.E., V.A. Carrillo, H.R. Perez, D. Salas-Lopez, A. Natale-Pereira, and A.T. Byron (2011). 'Defining and targeting health care access barriers', Journal of Health Care for the Poor and Underserved, Vol. 22, No. 2, pp. 562-575.

Chen, Y.M. and E.A. Thompson (2010). 'Understanding factors that influence success of home- and community-based services in keeping older adults in community settings', Journal of Aging and Health, Vol. 22, No. 3, pp. 267-291.

Citizens Information (2015). Community care services, available at: http://www.citizensinformation.ie/en/health/care_in_your_community/commun ity_care_services.html

Citizens Information (2019). Entitlement to health services, available at: http://www.citizensinformation.ie/en/health/entitlement_to_health_services/en titlement_to_public_health_services.html

Citizens Information (2018). Chiropody and podiatry services, available at: https://www.citizensinformation.ie/en/health/health_services/care_in_your_co mmunity/chiropody_services.html

Collins, C. and M. O'Riordan (2015). The future of Irish general practice: ICGP member survey 2015, Dublin: Irish College of General Practitioners, available at: http://www.icgp.ie/go/library/catalogue/item/E21F0871-DDC4-1AD420024CFC3C37FE68

Connolly, S., A. Nolan, B. Walsh, and M.-A.Wren (2018). Universal GP care in Ireland: potential cost implications, The Economic and Social Review, Vol. 49, No. 1, pp. 93-109.

Connolly, S. and M.-A. Wren (2019). Universal health care in Ireland - what are the prospects for reform? Health Systems and Reform, Vol. 5, No. 2, pp. 94-99.

CORU (2017). Health and Social Care Professionals Council. Annual report 2017, available at: http://coru.ie/uploads/documents/CORU_Annual_Report_2017_FV.pdf

Coughlan, D., B. Turner, and A. Trujillo (2013). 'Motivation for a health-literate health care system-does socioeconomic status play a substantial role? Implications for an Irish health policymaker', Journal of Health Communication, Vol. 18, Suppl. 1, pp. 158-171.

CSO (2010). Mortality differentials in Ireland, Dublin: Central Statistics Office, available at: http://www.cso.ie/en/media/csoie/census/documents/Mortality_Differentials_in _Ireland.pdf

CSO (2012a). Census 2011: Population classified by area. Dublin: Central Statistics Office, available at:

http://www.cso.ie/en/census/census2011reports/census2011populationclassifie dbyareaformerlyvolumeone/

CSO (2012b). Census 2011 small area population statistics (SAPS), Dublin: Central Statistics Office, available at: http://www.cso.ie/en/census/census2011smallareapopulationstatisticssaps/ 
CSO (2012c). Census 2011 Profile 8: Our Bill of Health. Health, Disability and Carers in Ireland, Dublin: Central Statistics Office, available at:

http://www.cso.ie/en/census/census2011reports/census2011profile8ourbillofhe alth-healthdisabilityandcarersinireland/

CSO (2013). Regional population projections 2016-2031, Dublin: Central Statistics Office, available at:

http://www.cso.ie/en/releasesandpublications/er/rpp/regionalpopulationproject ions2016-2031/

CSO (2015a). Vital statistics yearly summary 2014, Dublin: Central Statistics Office, available at: http://www.cso.ie/en/releasesandpublications/ep/pvsys/vitalstatisticsyearlysummary2014/ [last accessed 15/12/2015].

CSO (2015b). Population and Migration Estimates. Dublin: Central Statistics Office, available at: http://www.cso.ie/en/statistics/population/

CSO (2016). Census of Population 2016, available at: https://www.cso.ie/en/census/census2016reports/

Department of the Taoiseach (2016). A Programme for a Partnership Government. Dublin, Ireland: Department of theTaoiseach, available at: https://www.taoiseach.gov.ie/eng/Work_Of_The_Department/Programme_for_ Government/Programme_for_Government.html

DOH (2012). Future health. A strategic framework for reform of the health service 20122015, Dublin: Department of Health, available at: http://health.gov.ie/blog/publications/future-health-a-strategic-framework-forreform-of-the-health-service-2012-2015/

DOH (2013). Healthy Ireland. A framework for improved health and wellbeing 2013-2025, Dublin: Department of Health, available at: http://health.gov.ie/healthy-ireland/

DOH (2014). The path to universal healthcare. White Paper on universal health insurance, Dublin: Department of Health, available at: http://health.gov.ie/futurehealth/universal-health-insurance/the-white-paper-on-uhi/

DOH (2015a). Long-stay activity statistics 2013, Dublin: Department of Health, available at: http://health.gov.ie/wp-content/uploads/2014/03/Long-Stay-ActivityStatistics-2012.pdf

DOH (2015b). Potential measures to encourage provision of nursing home and community nursing unit facilities. Final report to Department of Health, Dublin: DKM Economic Consultants, available at: https://health.gov.ie/wpcontent/uploads/2015/12/2015-07-30-DoH-Nursing-Homes-Study-FinalReport.pdf

DOH (2019). Sláintecare action plan 2019, Dublin: Department of Health, available at: https://health.gov.ie/wp-content/uploads/2019/03/SI\%C3\%A1intecare-ActionPlan-2019.pdf

DOHC (2001). Primary care - a new direction, Dublin: Department of Health and Children. 
Eighan, J., B. Walsh, S. Smith, M.-A. Wren, S. Barron, and E. Morgenroth (2019). 'A profile of physiotherapy supply in Ireland', Irish Journal of Medical Science, Vol. 188, No. 1, pp. 19-27.

Expert Panel on Medical Need for Medical Card Eligibility (2014). Report of the Expert Panel on Medical Need for Medical Card Eligibility, Dublin: Health Service Executive, available at: http://www.hse.ie/eng/services/publications/corporate/expertpanelmedicalneed .pdf

Fishman, P.A. and D.K. Shay (1999). 'Development and estimation of a pediatric chronic disease score using automated pharmacy data', Medical Care, Vol. 37, No. 9, pp. 874-883.

Fishman, P.A., M.J. Goodman, M.C. Hornbrook, R.T. Meenan, D.J. Bachman, and M.C. O'Keeffe Rosetti (2003). 'Risk adjustment using automated ambulatory pharmacy data: the RxRisk model', Medical Care, Vol. 41, No. 1, pp. 84-99.

Foley, R. (2008). 'Geographies of informal care in Ireland, 2002-2006', Irish Geography, Vol. 41, No. 3, pp. 261-278.

Girasek, E., E. Kovacs, Z. Aszalos, E. Eke, K. Ragany, R. Kovacs, Z. Cserhati, and M. Szocska (2016). 'Headcount and FTE data in the European health workforce monitoring and planning process', Human Resources for Health, Vol. 14, Suppl. 1, p. 42.

Goddard, M., H. Gravelle, A. Hole, and G. Marini, (2010). 'Where did all the GPs go? Increasing supply and geographical equity in England and Scotland', Journal of Health Services Research and Policy, Vol. 15, No. 1, pp. 28-35.

Government of Ireland (2018a). Sláintecare implementation strategy, Dublin: Government of Ireland, available at: https://health.gov.ie/blog/publications/Sláintecare-implementation-strategy/

Government of Ireland (2018b). Project Ireland 2040. National Planning Framework, Dublin: Government of Ireland, available at: http://npf.ie/wpcontent/uploads/Project-Ireland-2040-NPF.pdf

Gravelle, H. and M. Sutton (2001). 'Inequality in the geographical distribution of general practitioners in England and Wales 1974-1995', Journal of Health Services Research and Policy, Vol. 6, No. 1, pp. 6-13.

Grossman, M. (1972). 'On the concept of health capital and the demand for health', Journal of Political Economy, Vol. 80, No. 2, pp. 223-255.

Guagliardo, M.F. (2004). 'Spatial accessibility of primary care: concepts, methods and challenges', International Journal of Health Geographics, Vol. 3, No. 1, p. 3.

Gulliford, M. (2009). 'Modernizing concepts of access and equity', Health Economics, Policy and Law, Vol. 4, Part 2, pp. 223-230.

Hann, M. and H. Gravelle, (2004). 'The maldistribution of general practitioners in England and Wales: 1974-2003', British Journal of General Practice, Vol. 54, No. 509, pp. 894-898. 
Health Information and Quality Authority (2014). Annual overview report on the regulation of designated centres for older people -2013, Dublin: Health Information and Quality Authority, available at:

http://www.hiqa.ie/publications/annual-overview-report-regulation-designatedcentres-older-people-\%E2\%80\%93-2013-0

Houses of the Oireachtas Committee on the Future of Healthcare (2017). Sláintecare report, Dublin: Houses of the Oireachtas, available at:

https://webarchive.oireachtas.ie/parliament/media/committees/futureofhealthc are/oireachtas-committee-on-the-future-of-healthcare-Sláintecare-report300517.pdf

HSE (2014). Primary Care Reimbursement Service. Statistical analysis of claims and payments 2014, Dublin: Health Service Executive, available at: https://www.hse.ie/eng/staff/pcrs/pcrs-publications/pcrs-statanalyis14.pdf

HSE (2015a). Medical workforce planning. Future demand for general practitioners 20152025, Dublin: National Doctor Training and Planning, HR Directorate, Health Service Executive, available at: http://www.hse.ie/portal/eng/staff/Leadership_Education_Development/MET/pl an/reports/Medical_Workforce_Planning_Future_Demand_for_General_Practitio ners_2015-2025.pdf

HSE (2015b). Public hospitals in Ireland, Dublin: Health Service Executive, available at: http://www.hse.ie/eng/services/list/3/hospitals/

HSE (2019). Medical Card and GP Visit Card national assessment guidelines, Dublin: Health Service Executive, available at: https://www2.hse.ie/file-library/medicalcards/medical-cards-national-assessment-guidelines.pdf

Hudson, E. and A. Nolan (2015). 'Public healthcare eligibility and the utilisation of GP services by the older population in Ireland', Journal of the Economics of Ageing, Vol. 6, pp. 24-43.

Irish College of General Practitioners (2015). GP training: the training path, Dublin: Irish College of General Practitioners, available at: http://www.icgp.ie/go/become_a_gp/the_training_path

ISA Review Project Team (2014). Community healthcare organisations. Report and Recommendations of the Integrated Service Area Review Group, Dublin: Health Service Executive, available at:

http://www.hse.ie/eng/services/publications/corporate/CHOReport.html

Ishikawa, T., K. Fujiwara, H. Ohba, T. Suzuki, and K. Ogasawara. (2017). 'Forecasting the regional distribution and sufficiency of physicians in Japan with a coupled system dynamics-geographic information system model', Human Resources for Health, Vol. 15, No. 1, p. 64.

Iyer, P.M., P.H. McNamara, M. Fitzgerald, L. Smyth, C. Dardis, T. Jawad, P.K. Plunkett, and C.P. Doherty (2012). 'A seizure care pathway in the emergency department: preliminary quality and safety improvements', Epilepsy Research and Treatment, Vol. 2012, No. 273175. 
Jahangir, E., V. Irazola, and A. Rubinstein (2012). 'Need, enabling, predisposing, and behavioral determinants of access to preventative care in Argentina: analysis of the national survey of risk factors', PLOS One, Vol. 7, No. 9, e45053.

Keegan, C., A. Brick, B. Walsh, A. Bergin, J. Eighan, and M.-A. Wren (2019). 'How many beds? Capacity implications of hospital care demand projections in the Irish hospital system, 2015-2030', International Journal of Health Planning and Management, Vol. 34, No. 1, pp. e569-e582.

Keegan, C. and S. Smith (2013). 'The length of stay of in-patient stroke discharges in Irish acute hospitals', The Economic and Social Review, Vol. 44, No. 3, pp. 351-370.

Keegan, C., C. Teljeur, B. Turner, and S. Thomas, (2016). 'Switching insurer in the Irish voluntary health insurance market: determinants, incentives, and risk equalization', European Journal of Health Economics, Vol. 17, No. 7, pp. 823-831.

Koolman, X. and E. van Doorslaer (2004). 'On the interpretation of a concentration index of inequality', Health Economics, Vol. 13, pp. 649-656.

Layte, R. (2007). 'Equity in the utilisation of hospital inpatient services in Ireland? An improved approach to the measurement of health need', The Economic and Social Review, Vol. 38, No. 2, pp. 191-210.

Layte, R., J. Banks, C. Walsh, and G. McKnight (2015). 'Trends in socio-economic inequalities in mortality by sex in Ireland from the 1980s to the 2000s', Irish Journal of Medical Science, Vol. 184, No. 3, pp. 613-621.

Layte, R., M. Barry, K. Bennett, A. Brick, E. Morgenroth, C. Normand, et al. (2009). Projecting the impact of demographic change on the demand for and delivery of health care in Ireland, Research Series No. 13, Dublin: The Economic and Social Research Institute.

Layte, R. and B. Nolan (2004). 'Equity in the utilisation of health care in Ireland', The Economic and Social Review, Vol. 35, No. 32, pp. 111-134.

Lindamer, L. A., L. Liu, D.H. Sommerfeld, D.P. Folsom, W. Hawthorne, P. Garcia, G.A. Aarons, and D.V. Jeste (2012). 'Predisposing, enabling, and need factors associated with high service use in a public mental health system', Administration and Policy in Mental Health, Vol. 39, No. 3, pp. 200-209.

Mansfield, G., C. Collins, M. O'Riordan, and K. Ryan (2015). Bridging the gap - how GP trainees and recent graduates identify themselves as the future Irish general practice workforce, Dublin: Irish College of General Practitioners, available at: http://www.icgp.ie/go/library/catalogue/item/5B609C9A-E91A-F6B8EC65E85D61DE7729

Marmot, M. (2010). Fair society, healthy lives: the Marmot Review: strategic review of health inequalities in England post-2010, available at: http://www.instituteofhealthequity.org/resources-reports/fair-society-healthylives-the-marmot-review

Martins, C., L.F. Azevedo, O. Ribeiro, L. Sa, P. Santos, L. Couto, A. Costa-Pereira, and A.P. Hespanhol (2013). 'A population-based nationwide cross-sectional study on preventive health services utilization in Portugal-what services (and 
frequencies) are deemed necessary by patients?', PLOS One, Vol. 8, No. 11, e81256.

McDonald, A., K. Frazer, C. Duignan, M. Healy, A. Irving, P. Marteinsson, B. Molloy, and E. McNicholas (2015). "Validating the "intervention wheel" in the context of Irish public health nursing', British Journal of Community Nursing, Vol. 20, No. 3, pp. 140-146.

McIntyre, D., M. Thiede, and S. Birch (2009). 'Access as a policy-relevant concept in lowand middle-income countries', Health Economics, Policy and Law, Vol. 4, Part 2, pp. 179-193.

Merikangas, K.R., J.P. He, M. Burstein, J. Swendsen, S. Avenevoli, B. Case, K., et al. (2011). 'Service utilization for lifetime mental disorders in U.S. adolescents: results of the National Comorbidity Survey-Adolescent Supplement (NCS-A)', Journal of the American Academy of Child and Adolescent Psychiatry, Vol. 50, No. 1, pp. 32-45.

Mohan, G., A. Nolan, and S. Lyons, (2019). 'An investigation of the effect of accessibility to General Practitioner services on healthcare utilisation among older people', Social Science and Medicine, Vol. 220, pp. 254-263.

Morgenroth, E. (2008). The impact of demographic change on demand for and delivery of health services in Ireland 2006-2021. Report 2: Demographic projections for the period until 2021, available at: https://www.esri.ie/pubs/BKMNEXT166.pdf

Morgenroth, E. (2014). 'Projected population change and housing demand: a county level analysis', ESRI Research Note, Dublin: The Economic and Social Research Institute, available at: https://www.esri.ie/system/files/media/file-uploads/2015-

07/RN20140203.pdf

Morgenroth, E. (2018). Prospects for Irish regions and counties: scenarios and implications, Research Series No. 70, Dublin: The Economic and Social Research Institute.

Morris, S., R. Carr-Hill, P. Dixon, M. Law, N. Rice, M. Sutton, and L. Vallejo-Torres (2007). Combining age related and additional needs (CARAN) report: 2007 review of the needs formulae for hospital services and prescribing activity in England, available at:

http://webarchive.nationalarchives.gov.uk/20120503034600/http:/www.dh.gov. uk/prod_consum_dh/groups/dh_digitalassets/documents/digitalasset/dh_09316 9.pdf

Morris, S., M. Sutton, and H. Gravelle (2005). 'Inequity and inequality in the use of health care in England: an empirical investigation', Social Science and Medicine, Vol. 60, No. 6, pp. 1251-1266.

Morrissey, K. (2019). 'Comorbidity and healthcare use for individuals with CVD in the [sic] Ireland: a cross-sectional, population-based study', BMJ Open, Vol. 9, No. 1, e025305.

Morrissey, K., G. Clarke, D. Ballas, S. Hynes, and C. O'Donoghue (2008). Examining access to GP services in rural Ireland using microsimulation analysis, Area, Vol. 40, No. 3, pp. 354-364. 
National Health Service (2016). Technical guide to allocation formulae and pace of change for 2016-17 to 2020-21 revenue allocations to Clinical Commissioning Groups and commissioning areas, available at:

https://www.england.nhs.uk/publication/technical-guide-to-allocation-formulaeand-pace-of-change-for-2016-17-to-2020-21-revenue-allocations-to-clinicalcommissioning-groups-and-commissioning-areas/

NHS England. (2017). NHS England research plan, available at: https://www.england.nhs.uk/wp-content/uploads/2017/04/nhse-researchplan.pdf

Nolan, A. and R. Layte (2017). 'The impact of transitions in insurance coverage on GP visiting among children in Ireland', Social Science and Medicine, Vol. 180, 94-100.

Nolan, A. and S. Smith (2012). 'The effect of differential eligibility for free GP services on GP utilisation in Ireland', Social Science and Medicine, Vol. 74, No. 10, pp. 16441651.

Nursing Homes Ireland (2015). Annual private nursing home survey 2014/2015, Dublin: Nursing Homes Ireland, available at: http://www.nhi.ie/index.php?p=news179

O'Callaghan, M.E., L. Zgaga, D. O'Ciardha, and T. O'Dowd (2018). 'Free children's visits and general practice attendance', Annals of Family Medicine, Vol. 16, pp. 246249.

O'Donnell, O., S. O'Neill, T. Van Ourti, and B. Walsh (2016). 'Conindex: estimation of concentration indices', Stata Journal, Vol. 16, pp. 112-138.

O'Kelly, M., C. Teljeur, F. O'Kelly, A. Ni Shuilleabhain, and T. O'Dowd (2016b). Structure of general practice in Ireland 1982-2015, Dublin: Department of Public Health and Primary Care, Trinity College Centre for Health Sciences, available at: http://www.tcd.ie/academicunits/schools/medicine/public_health_primary_care /assets/pdf/structure-of-general-practice-2016.pdf

Okumura, M.J., A.O. Hersh, J.F. Hilton, and D.S. Lotstein (2013). 'Change in health status and access to care in young adults with special health care needs: results from the 2007 national survey of adult transition and health', Journal of Adolescent Health, Vol. 52, No. 4, pp. 413-418.

PA Consulting (2018). Health service capacity review 2018. Review of health demand and capacity requirements in Ireland to 2031, Dublin: Department of Health, available at: https://health.gov.ie/wp-content/uploads/2018/02/71580-DoH-DublinReport-v6.pdf

Penchansky, R. and J.W. Thomas (1981). 'The concept of access: definition and relationship to consumer satisfaction', Medical Care, Vol. 19, No. 2, pp. 127-140.

Penno, E., R. Gauld, and R. Audas (2013). 'How are population-based funding formulae for healthcare composed? A comparative analysis of seven models', BMC Health Services Research, Vol. 13, p. 470.

Pohlmeier, W. and V. Ulrich, (1995). 'An econometric model of the two-part decisionmaking process in the demand for health care', Journal of Human Resources, Vol. 30, No. 2, pp. 339-361. 
Primary Care Reimbursement Service (2017). Statistical analysis of claims and payments 2017, Dublin: Health Service Executive, available at: https://www.hse.ie/eng/staff/pcrs/pcrs-publications/annual-report-2017.pdf

Rice, N. and P.C. Smith (2001). 'Ethics and geographical equity in health care', Journal of Medical Ethics, Vol. 27, No. 4, pp. 256-261.

Robinson, G. (1998). Methods and techniques in human geography, Toronto: Wiley.

Ruane, F. (2010). Report of the Expert Group on Resource Allocation and Financing in the Health Sector, Dublin: Department of Health and Children, available at: http://health.gov.ie/blog/publications/report-of-the-expert-group-on-resourceallocation-and-financing-in-the-health-sector/

Ryvicker, M., W.T. Gallo, and M.C. Fahs (2012). 'Environmental factors associated with primary care access among urban older adults', Social Science and Medicine, Vol. 75, No. 5, pp. 914-921.

Shi, L., B. Starfield, R. Politzer, and J. Regan (2002). 'Primary care, self-rated health, and reductions in social disparities in health', Health Services Research, Vol. 37, No. 3, pp. 529-550.

Siegel, M., D. Koller, V. Vogt, and L. Sundmacher (2016). 'Developing a composite index of spatial accessibility across different health care sectors: a German example', Health Policy, Vol. 120, No. 2, pp. 205-212.

Sloan, K.L., A.E. Sales, C.F. Liu, P. Fishman, P. Nichol, N.T. Suzuki, and N.D. Sharp (2003). 'Construction and characteristics of the RxRisk-V: a VA-adapted pharmacy-based case-mix instrument', Medical Care, Vol. 41, No. 6, pp. 761-774.

Smith, S. (2010). 'Equity in Irish health care financing: measurement issues', Health Economics, Policy, and Law, Vol. 5, No. 2, pp. 149-169.

Smith, S. and C. Normand (2009). 'Analysing equity in health care financing: a flow of funds approach', Social Science and Medicine, Vol. 69, No. 3, pp. 379-386.

Teljeur, C., T. O'Dowd, S. Thomas, and A. Kelly (2010). 'The distribution of GPs in Ireland in relation to deprivation', Health and Place, Vol. 16, No. 6, pp. 1077-1083.

Teljeur, C., E. Tyrrell, A. Kelly, T. O'Dowd, and S. Thomas (2014). 'Getting a handle on the general practice workforce in Ireland', Irish Journal of Medical Science, Vol. 183, No. 2, pp. 207-213.

Thomas, S., E. Tyrrell, R. Layte, C. Normand, and T. O'Dowd (2012). Handbook on the development of a model to forecast the demand for and supply of GP and practice nurse services, Dublin: Department of Health and Children.

Timonen, V. and M. Doyle (2008). 'From the workhouse to the home: evolution of care policy for older people in Ireland', International Journal of Sociology and Social Policy, Vol. 28, No. 3/4, pp. 76-89.

Timonen, V., M. Doyle, and C. O'Dwyer (2012). 'Expanded, but not regulated: ambiguity in home-care policy in Ireland', Health and Social Care in the Community, Vol. 20, No. 3, pp. 310-318. 
Tudor Hart, J. (1971). 'The inverse care law', The Lancet, Vol. 297, No. 7696, pp. 405-412.

van Doorslaer, E. and C. Masseria (2004). Income-related inequality in the use of medical care in 21 OECD countries, OECD Health Working Papers 14, Paris: OECD.

van Doorslaer, E., O. O'Donnell, R.P. Rannan-Eliya, A. Somanathan, S.R. Adhikari, C.C. Garg, et al. (2007). 'Catastrophic payments for health care in Asia', Health Economics, Vol. 16, No. 11, pp. 1159-1184.

Vega, A., S. O'Shea, C. Murrin, and A. Staines (2010). Towards the development of a resource allocation model for primary, continuing and community care in the health services, Dublin: Dublin City University, available at: http://doras.dcu.ie/15040/

Walsh, B., M. Silles, and C. O'Neill (2012). 'The role of private medical insurance in socioeconomic inequalities in cancer screening uptake in the Republic of Ireland', Health Economics, Vol. 12, pp. 1250-1256.

Walsh, B., A. Nolan, A. Brick, and C. Keegan (2019a). 'Did the expansion of free GP care impact demand for emergency department attendances? A difference-indifferences analysis', Social Science and Medicine, Vol. 222, pp. 101-111.

Walsh, B., M.-A. Wren, S. Smith, S. Lyons, J. Eighan, and E. Morgenroth (2019b). An analysis of the effects on irish hospital care of the supply of care inside, and outside, the hospital. The Economic and Social Research Institute (forthcoming).

WHO, EQUINET, REACH Trust, and TARSC (2010). Monitoring equity in access to AIDS treatment programmes: a review of concepts, models, methods and indicators, Geneva: World Health Organisation, available at:

http://www.who.int/sdhconference/resources/who_monitoring_equity_aids.pdf

Wren, M.-A. (2003). Unhealthy state: anatomy of a sick society, Dublin: New Island Books.

Wren, M.-A. and S. Connolly (2016). 'Challenges in achieving universal healthcare in Ireland', ESRI Budget Perspectives, Dublin: The Economic and Social Research Institute.

Wren, M.-A., P. Gillespie, S. Smith, and K. Kearns (2014). Towards earlier discharge, better outcomes, lower costs: stroke rehabilitation in Ireland, report prepared for the Irish Heart Foundation, Dublin: The Economic and Social Research Institute and the Royal College of Surgeons in Ireland, available at: http://5.159.40.83/UserFiles/publications/BKMNEXT277.pdf

Wren, M.-A., C. Keegan, B. Walsh, A. Bergin, J. Eighan, A. Brick, et al. (2017). Projections of demand for healthcare in Ireland, 2015-2030, first report from the HIPPOCRATES Model, Research Series No. 67, Dublin: The Economic and Social Research Institute.

Wren, M.-A., C. Normand, D. O'Reilly, S.M. Cruise, S. Connolly, and C. Murphy (2012). Towards the development of a predictive model of long-term care demand for Northern Ireland and the Republic of Ireland, Dublin: Centre for Health Policy and Management, Trinity College Dublin, available at: www.medicine.tcd.ie/health_policy_management]. 


\section{APPENDIX 1}

\section{Census 2011 disability questions}

Census 2011 data were used to estimate the proportion of people with disability in each study area in 2014. Census 2011 defines a person with disability as someone who responded 'yes' to any of the seven categories on long-lasting conditions (question 16) or 'yes' to any of the four categories on difficulties (question 17). The two questions, and their descriptions, are reproduced from www.census.ie.

\section{Question 16 - Do you have any of the following long-lasting conditions or difficulties?}

'The results of questions 16 and 17 coupled with other questions will provide important data on the number of people whose activities are reduced because of a disability and the effect of the disability on their lives. The questions are slightly different to those asked in 2006. In question 16, vision and hearing impairments have been separated and there is a separate category for intellectual disabilities. The questions were chosen after pre-census consultation with experts from the various disability umbrella bodies and government departments.'
16 Do you have any of the following long-lasting conditions or difficulties?

(a) Blindness or a serious Yes No vision impairment

(b) Deafness or a serious Yes No hearing impairment

(c) A difficulty with basic physical Yes No activities such as walking, climbing stairs, reaching, lifting or carrying

(d) An intellectual disability Yes No

(e) A difficulty with learning, Yes No remembering or concentrating

(f) A psychological or Yes No emotional condition

(g) A difficulty with pain, Yes No breathing, or any other chronic illness or condition 
Question 17 - If you answered 'Yes' to question 16, do you have any difficulty in doing any of the following?

'The results of questions 16 and 17 coupled with other questions will provide important data on the number of people whose activities are reduced because of a disability and the effect of the disability on their lives. The questions are slightly different to those asked in 2006. The questions were chosen after pre-census consultation with experts from the various disability umbrella bodies and government departments.'
17 If 'Yes' to any of the categories specified in Question 16, do you have any difficulty in doing any of the following?

(a) Dressing, bathing or getting Yes No around inside the home

(b) Going outside the home alone to shop or visit a doctor's surgery

(c) Working at a job or business Yes No or attending school or college

(d) Participating in other Yes No activities, for example leisure or using transport 


\section{APPENDIX 2}

\section{Population proportions used to redistribute need and supply from Local Health Offices to study areas}

\section{TABLE A2.1 GEOGRAPHIC AREAS USED IN THE STUDY BY THE SHARES OF LOCAL HEALTH OFFICE POPULATIONS THAT COMPRISE THE STUDY AREAS}

\begin{tabular}{|c|c|c|c|c|c|c|c|c|c|c|c|c|c|c|c|c|c|c|c|c|}
\hline \multirow{2}{*}{$\begin{array}{l}\text { Geographic } \\
\text { areas used in the } \\
\text { study }\end{array}$} & \multirow{2}{*}{$\begin{array}{l}\text { Local Health Office(s) (LHOs) } \\
\text { that comprise the study area }\end{array}$} & \multicolumn{19}{|c|}{ Age-specific proportions of Local Health Office population(s) that comprise the study area, Census 2011} \\
\hline & & $0-4$ & $5-9$ & $10-14$ & $15-19$ & $20-24$ & $25-29$ & $30-34$ & $35-39$ & $40-44$ & $45-49$ & $50-54$ & $55-59$ & $60-64$ & $65-69$ & 70-74 & 75-79 & $80-84$ & $85+$ & Total \\
\hline Carlow & Carlow/Kilkenny LHO & 0.428 & 0.434 & 0.408 & 0.409 & 0.465 & 0.450 & 0.440 & 0.421 & 0.420 & 0.404 & 0.396 & 0.400 & 0.404 & 0.397 & 0.416 & 0.385 & 0.393 & 0.366 & 0.419 \\
\hline \multirow[t]{3}{*}{ Cavan } & Cavan/Monaghan LHO & 0.531 & 0.536 & 0.543 & 0.515 & 0.511 & 0.512 & 0.523 & 0.526 & 0.533 & 0.521 & 0.521 & 0.519 & 0.516 & 0.516 & 0.512 & 0.528 & 0.534 & 0.534 & 0.524 \\
\hline & Meath LHO & 0.024 & 0.021 & 0.023 & 0.020 & 0.024 & 0.026 & 0.022 & 0.017 & 0.020 & 0.021 & 0.020 & 0.023 & 0.019 & 0.020 & 0.023 & 0.024 & 0.026 & 0.023 & 0.022 \\
\hline & Sligo/Leitrim/West Cavan LHO & 0.008 & 0.012 & 0.014 & 0.013 & 0.017 & 0.014 & 0.011 & 0.010 & 0.012 & 0.017 & 0.016 & 0.014 & 0.015 & 0.015 & 0.012 & 0.015 & 0.020 & 0.023 & 0.014 \\
\hline \multirow[t]{3}{*}{ Clare } & Clare LHO & 1.000 & 1.000 & 1.000 & 1.000 & 1.000 & 1.000 & 1.000 & 1.000 & 1.000 & 1.000 & 1.000 & 1.000 & 1.000 & 1.000 & 1.000 & 1.000 & 1.000 & 1.000 & 1.000 \\
\hline & Limerick LHO & 0.066 & 0.071 & 0.071 & 0.085 & 0.082 & 0.053 & 0.057 & 0.061 & 0.068 & 0.064 & 0.062 & 0.060 & 0.056 & 0.047 & 0.041 & 0.035 & 0.031 & 0.028 & 0.063 \\
\hline & $\begin{array}{l}\text { Tipperary North/East Limerick } \\
\text { LHO }\end{array}$ & 0.029 & 0.031 & 0.031 & 0.027 & 0.022 & 0.030 & 0.028 & 0.031 & 0.027 & 0.035 & 0.033 & 0.034 & 0.038 & 0.029 & 0.035 & 0.030 & 0.029 & 0.033 & 0.030 \\
\hline \multirow[t]{4}{*}{ Cork } & Cork North LHO & 1.000 & 1.000 & 1.000 & 1.000 & 1.000 & 1.000 & 1.000 & 1.000 & 1.000 & 1.000 & 1.000 & 1.000 & 1.000 & 1.000 & 1.000 & 1.000 & 1.000 & 1.000 & 1.000 \\
\hline & Cork North Lee LHO & 1.000 & 1.000 & 1.000 & 1.000 & 1.000 & 1.000 & 1.000 & 1.000 & 1.000 & 1.000 & 1.000 & 1.000 & 1.000 & 1.000 & 1.000 & 1.000 & 1.000 & 1.000 & 1.000 \\
\hline & Cork South Lee LHO & 1.000 & 1.000 & 1.000 & 1.000 & 1.000 & 1.000 & 1.000 & 1.000 & 1.000 & 1.000 & 1.000 & 1.000 & 1.000 & 1.000 & 1.000 & 1.000 & 1.000 & 1.000 & 1.000 \\
\hline & Cork West LHO & 1.000 & 1.000 & 1.000 & 1.000 & 1.000 & 1.000 & 1.000 & 1.000 & 1.000 & 1.000 & 1.000 & 1.000 & 1.000 & 1.000 & 1.000 & 1.000 & 1.000 & 1.000 & 1.000 \\
\hline Donegal & Donegal LHO & 0.980 & 0.980 & 0.983 & 0.986 & 0.987 & 0.984 & 0.979 & 0.981 & 0.981 & 0.983 & 0.982 & 0.983 & 0.983 & 0.981 & 0.982 & 0.982 & 0.983 & 0.987 & 0.982 \\
\hline \multirow[t]{3}{*}{ Dublin North } & Dublin North LHO & 1.000 & 1.000 & 1.000 & 1.000 & 1.000 & 1.000 & 1.000 & 1.000 & 1.000 & 1.000 & 1.000 & 1.000 & 1.000 & 1.000 & 1.000 & 1.000 & 1.000 & 1.000 & 1.000 \\
\hline & Dublin North West LHO & 1.000 & 1.000 & 1.000 & 1.000 & 1.000 & 1.000 & 1.000 & 1.000 & 1.000 & 1.000 & 1.000 & 1.000 & 1.000 & 1.000 & 1.000 & 1.000 & 1.000 & 1.000 & 1.000 \\
\hline & Dublin North Central LHO & 1.000 & 1.000 & 1.000 & 1.000 & 1.000 & 1.000 & 1.000 & 1.000 & 1.000 & 1.000 & 1.000 & 1.000 & 1.000 & 1.000 & 1.000 & 1.000 & 1.000 & 1.000 & 1.000 \\
\hline \multirow[t]{5}{*}{ Dublin South } & Dublin South City LHO & 1.000 & 1.000 & 1.000 & 1.000 & 1.000 & 1.000 & 1.000 & 1.000 & 1.000 & 1.000 & 1.000 & 1.000 & 1.000 & 1.000 & 1.000 & 1.000 & 1.000 & 1.000 & 1.000 \\
\hline & Dún Laoghaire LHO & 1.000 & 1.000 & 1.000 & 1.000 & 1.000 & 1.000 & 1.000 & 1.000 & 1.000 & 1.000 & 1.000 & 1.000 & 1.000 & 1.000 & 1.000 & 1.000 & 1.000 & 1.000 & 1.000 \\
\hline & Dublin South East LHO & 1.000 & 1.000 & 1.000 & 1.000 & 1.000 & 1.000 & 1.000 & 1.000 & 1.000 & 1.000 & 1.000 & 1.000 & 1.000 & 1.000 & 1.000 & 1.000 & 1.000 & 1.000 & 1.000 \\
\hline & Dublin South West LHO & 1.000 & 1.000 & 1.000 & 1.000 & 1.000 & 1.000 & 1.000 & 1.000 & 1.000 & 1.000 & 1.000 & 1.000 & 1.000 & 1.000 & 1.000 & 1.000 & 1.000 & 1.000 & 1.000 \\
\hline & Dublin West LHO & 1.000 & 1.000 & 1.000 & 1.000 & 1.000 & 1.000 & 1.000 & 1.000 & 1.000 & 1.000 & 1.000 & 1.000 & 1.000 & 1.000 & 1.000 & 1.000 & 1.000 & 1.000 & 1.000 \\
\hline Galway & Galway LHO & 1.000 & 1.000 & 1.000 & 1.000 & 1.000 & 1.000 & 1.000 & 1.000 & 1.000 & 1.000 & 1.000 & 1.000 & 1.000 & 1.000 & 1.000 & 1.000 & 1.000 & 1.000 & 1.000 \\
\hline Kerry & Kerry LHO & 1.000 & 1.000 & 1.000 & 1.000 & 1.000 & 1.000 & 1.000 & 1.000 & 1.000 & 1.000 & 1.000 & 1.000 & 1.000 & 1.000 & 1.000 & 1.000 & 1.000 & 1.000 & 1.000 \\
\hline Kildare & Kildare/West Wicklow LHO & 0.921 & 0.923 & 0.921 & 0.921 & 0.931 & 0.936 & 0.931 & 0.926 & 0.922 & 0.915 & 0.912 & 0.921 & 0.911 & 0.901 & 0.895 & 0.890 & 0.890 & 0.898 & 0.921 \\
\hline \multirow[t]{2}{*}{ Kilkenny } & Carlow/Kilkenny LHO & 0.572 & 0.566 & 0.592 & 0.591 & 0.535 & 0.550 & 0.560 & 0.579 & 0.580 & 0.596 & 0.604 & 0.600 & 0.596 & 0.603 & 0.584 & 0.615 & 0.607 & 0.634 & 0.581 \\
\hline & Waterf & 0.171 & 0.170 & 0.159 & 0.150 & 0.135 & 0.156 & 0.169 & 0.175 & 0.156 & 0.143 & 0.148 & 0.148 & 0.144 & 0.142 & 0.137 & 0.125 & 0.128 & 0.137 & 0.154 \\
\hline Laois & Laois/Offaly LHO & 0.547 & 0.527 & 0.499 & 0.485 & 0.513 & 0.540 & 0.546 & 0.527 & 0.522 & 0.498 & 0.496 & 0.493 & 0.476 & 0.481 & 0.473 & 0.474 & 0.484 & 0.461 & 0.512 \\
\hline \multirow[t]{2}{*}{ Leitrim } & Donegal LHO & 0.020 & 0.020 & 0.017 & 0.014 & 0.013 & 0.016 & 0.021 & 0.019 & 0.019 & 0.017 & 0.018 & 0.017 & 0.017 & 0.019 & 0.018 & 0.018 & 0.017 & 0.013 & 0.018 \\
\hline & Sligo/Leitrim/West Cavan LHO & 0.321 & 0.324 & 0.303 & 0.268 & 0.235 & 0.287 & 0.302 & 0.312 & 0.308 & 0.302 & 0.308 & 0.318 & 0.300 & 0.307 & 0.319 & 0.329 & 0.334 & 0.312 & 0.302 \\
\hline \multirow[t]{2}{*}{ Limerick } & Limerick LHO & 0.934 & 0.929 & 0.928 & 0.915 & 0.918 & 0.947 & 0.942 & 0.939 & 0.932 & 0.936 & 0.938 & 0.94 & 0.944 & 0.953 & 0.959 & 0.965 & 0.97 & 0.972 & 0.937 \\
\hline & $\begin{array}{l}\text { Tipperary North/East Limerick } \\
\text { LHO }\end{array}$ & 0.309 & 0.286 & 0.279 & 0.381 & 0.477 & 0.356 & 0.351 & 0.306 & 0.28 & 0.263 & 0.27 & 0.268 & 0.271 & 0.263 & 0.253 & 0.217 & 0.207 & 0.227 & 0.308 \\
\hline Longford & Longford/Westmeath LHO & 0.320 & 0.325 & 0.307 & 0.293 & 0.286 & 0.296 & 0.301 & 0.303 & 0.308 & 0.297 & 0.311 & 0.335 & 0.346 & 0.345 & 0.323 & 0.339 & 0.324 & 0.317 & 0.312 \\
\hline
\end{tabular}




\begin{tabular}{|c|c|c|c|c|c|c|c|c|c|c|c|c|c|c|c|c|c|c|c|c|}
\hline \multirow{2}{*}{$\begin{array}{l}\text { Geographic } \\
\text { areas used in the } \\
\text { study }\end{array}$} & \multirow{2}{*}{$\begin{array}{l}\text { Local Health Office(s) (LHOs) } \\
\text { that comprise the study area }\end{array}$} & \multicolumn{19}{|c|}{ Age-specific proportions of Local Health Office population(s) that comprise the study area, Census 2011} \\
\hline & & $0-4$ & 5-9 & 10-14 & $15-19$ & 20-24 & 25-29 & 30-34 & 35-39 & 40-44 & 45-49 & $50-54$ & 55-59 & 60-64 & 65-69 & 70-74 & 75-79 & 80-84 & $85+$ & Total \\
\hline \multirow[t]{2}{*}{ Louth } & Cavan/Monaghan LHO & 0.008 & .008 & .006 & 0.006 & 0.004 & 0.004 & 0.006 & 0.009 & 0.006 & 0.007 & 0.005 & 0.007 & 0.006 & 0.005 & 0.004 & 0.005 & 0.004 & 0.004 & 0.006 \\
\hline & Louth LHO & 1.000 & 1.000 & 1.000 & 1.000 & 1.000 & 1.000 & 1.000 & 1.000 & 1.000 & 1.000 & 1.000 & 1.000 & 1.000 & 1.000 & 1.000 & 1.000 & 1.000 & 1.000 & 1.000 \\
\hline Mayo & Mayo LHO & 1.000 & 1.000 & 1.000 & 1.000 & 1.000 & 1.000 & 1.000 & 1.000 & 1.000 & 1.000 & 1.000 & 1.000 & 1.000 & 1.000 & 1.000 & 1.000 & 1.000 & 1.000 & 1.000 \\
\hline \multirow[t]{2}{*}{ Meath } & Cavan/Monaghan LHO & 0.002 & 0.002 & 0.003 & 0.002 & 0.002 & 0.002 & 0.002 & 0.002 & 0.003 & 0.003 & 0.004 & 0.003 & 0.003 & 0.004 & 0.003 & 0.002 & 0.002 & 0.003 & 0.003 \\
\hline & Meath LHO & 0.976 & 0.979 & 0.977 & 0.980 & 0.976 & 0.974 & 0.978 & 0.983 & 0.980 & 0.979 & 0.980 & 0.977 & 0.981 & 0.980 & 0.977 & 0.976 & 0.974 & 0.977 & 0.978 \\
\hline Monaghan & Cavan/Monaghan LHO & 0.459 & 0.454 & 0.448 & 0.477 & 0.483 & 0.481 & 0.469 & 0.463 & 0.458 & 0.469 & 0.470 & 0.472 & 0.475 & 0.475 & 0.481 & 0.466 & 0.460 & 0.461 & 0.467 \\
\hline Offaly & Laois/Offaly LHO & 0.453 & 0.473 & 0.501 & 0.515 & 0.487 & 0.460 & 0.454 & 0.473 & 0.478 & 0.502 & 0.504 & 0.507 & 0.524 & 0.519 & 0.527 & 0.526 & 0.516 & 0.539 & 0.488 \\
\hline Roscommon & Roscommon LHO & 1.000 & 1.000 & 1.000 & 1.000 & 1.000 & 1.000 & 1.000 & 1.000 & 1.000 & 1.000 & 1.000 & 1.000 & 1.000 & 1.000 & 1.000 & 1.000 & 1.000 & 1.000 & 1.000 \\
\hline Sligo & Sligo/Leitrim/West Cava & 0.671 & 0.664 & 0.683 & 0.720 & 0.747 & 0.699 & 0.686 & 0.678 & 0.680 & 0.681 & 0.676 & 0.669 & 0.685 & 0.679 & 0.669 & 0.656 & 0.646 & 0.665 & 0.684 \\
\hline \multirow[t]{2}{*}{ Tipperary North } & $\begin{array}{l}\text { Tipperary North/East Limerick } \\
\text { LHO }\end{array}$ & 0.305 & 0.308 & 0.316 & 0.259 & 0.2 & 0.25 & 0.26 & 0.2 & 0 & 0.3 & 0.303 & 0.308 & 0.3 & 0 & 0.313 & 0.3 & 0.348 & 0.325 & 0.293 \\
\hline & Tipperary South LHO & 0.431 & 0.421 & 0.429 & .411 & 0.408 & 0.397 & 0.410 & 0.421 & .429 & 0.415 & 0.406 & 0.413 & 0.416 & 0.409 & 0.412 & 0.414 & 0.429 & 0.414 & 0.417 \\
\hline \multirow[t]{2}{*}{ Tipperary South } & $\begin{array}{l}\text { Tipperary North/East Limerick } \\
\text { LHO }\end{array}$ & 0.358 & 0.375 & 0.374 & 0.332 & 0.282 & 0.358 & 0.354 & 0.367 & 0.378 & 0.391 & 0.393 & 0.389 & 0.385 & 0.397 & 0.399 & 0.422 & 0.416 & 0.415 & 0.368 \\
\hline & Tipperary South LHO & 0.506 & 514 & 0.508 & 528 & 0.527 & 0.552 & 0.543 & 0.521 & 0.513 & 0.521 & 0.526 & 0.521 & 0.523 & 0.523 & 0.526 & 0.529 & 0.513 & 0.529 & 0.523 \\
\hline \multirow[t]{2}{*}{ Waterford } & Tipper & 0.063 & .065 & 0.063 & 0.061 & 0.064 & 0.05 & 0.047 & 0.058 & 0.058 & 0.064 & 0.068 & 0.067 & 0.06 & 0.068 & 0.062 & 0.058 & 0.058 & 0.056 & 0.061 \\
\hline & Waterf & 0.83 & 0.83 & 0.841 & 0.85 & 0.865 & 0.844 & 0.831 & 0.826 & 0.844 & 0.857 & 0.852 & 0.852 & 0.855 & 0.857 & 0.863 & 0.875 & 0.872 & 0.863 & 0.846 \\
\hline Westmeath & stmeath LHO & 0.680 & 0.675 & 0.693 & 0.707 & 0.714 & 0.704 & 0.699 & 0.697 & 0.692 & 0.703 & 0.689 & 0.665 & 0.654 & 0.655 & 0.677 & 0.661 & 0.676 & 0.683 & 0.688 \\
\hline Wexford & Wexford LHO & 1.000 & 1.000 & 1.000 & 1.000 & 1.000 & 1.000 & 1.000 & 1.000 & 1.000 & 1.000 & 1.000 & 1.000 & 1.000 & 1.000 & 1.000 & 1.000 & 1.000 & 1.000 & 1.000 \\
\hline \multirow[t]{2}{*}{ Wicklow } & Kildare/West Wicklow LHO & 0.079 & 0.077 & 0.079 & 0.079 & 0.069 & 0.064 & 0.069 & 0.074 & 0.078 & 0.085 & 0.088 & 0.079 & 0.089 & 0.099 & 0.105 & 0.110 & 0.110 & 0.102 & 0.079 \\
\hline & Wicklow LHO & 1.000 & 1.000 & 1.000 & 1.000 & 1.000 & 1.000 & 1.000 & 1.000 & 1.000 & 1.000 & 1.000 & 1.000 & 1.000 & 1.000 & 1.000 & 1.000 & 1.000 & 1.000 & 1.000 \\
\hline
\end{tabular}

Source: Cross-classification of Census 2011 population counts by county, LHO and age provided by Heath Intelligence of the Health Service Executive (HSE).

Notes: (a) Some need and supply data were collected for LHO area rather than the study areas. The proportions above were used to redistribute data from LHOs to study areas based on share of population. Age-specific proportions were used to redistribute age-specific need characteristics (i.e. age-specific number of people with Medical Cards, age-specific number of people with Medical Cards and a prescription for a chronic health condition). The total proportions were used to redistribute supply that is not specific to particular age groups (i.e. community nurses and allied health professionals). 


\section{APPENDIX 3}

\section{Methods for calculating the Gini coefficient}

The Gini coefficient is a summary measure of relative inequality and is calculated from a Lorenz curve.

For the geographic supply of healthcare, the Lorenz curve plots the cumulative proportion of supply; for example, the number of GPs ( $y$-axis) against the cumulative proportion of the total population ( $x$-axis).

If all areas had the same proportion of GPs to population, the Lorenz curve would coincide with the $45^{\circ}$ line. If the distribution of GPs is unequal across areas, the Lorenz curve lies below the $45^{\circ}$ line. The Gini coefficient is calculated as twice the area between the $45^{\circ}$ line and the Lorenz curve.

The Gini lies between 0 or complete equality and 1 or complete inequality. For example, for the supply of GPs, a Gini coefficient of 0 indicates that all areas have the same GP per capita while a Gini coefficient of 1 indicates that one area has all the GPs.

The Gini is a measure of relative inequality, so that, for example, in the case of GP supply, the size of the coefficient is unaffected by a doubling of GP supply in every area (Gravelle and Sutton, 2001).

The Gini can also be estimated in many pieces of statistical software, including using the conindex command in Stata (O'Donnell et al., 2016). 


\section{APPENDIX 4}

\section{Needs-adjusted geographic supply of non-acute healthcare services: supplementary tables}

TABLE A4.1 ESTIMATED NUMBER OF WTE GPS PER 10,000 TOTAL POPULATION AND NEEDS-ADJUSTED POPULATIONS BY GEOGRAPHIC AREA, IRELAND 2014

\begin{tabular}{|c|c|c|c|c|c|c|c|c|c|c|c|c|c|c|}
\hline \multirow[t]{2}{*}{ Geographic area } & \multicolumn{2}{|c|}{ Total population } & \multicolumn{2}{|c|}{$\begin{array}{l}\text { Population aged } 65+ \\
\text { years }\end{array}$} & \multicolumn{2}{|c|}{$\begin{array}{l}\text { Population aged } 85+ \\
\text { years }\end{array}$} & \multicolumn{2}{|c|}{$\begin{array}{l}\text { Mortality-adjusted } \\
\text { population }\end{array}$} & \multicolumn{2}{|c|}{$\begin{array}{l}\text { Population with } \\
\text { disability }\end{array}$} & \multicolumn{2}{|c|}{$\begin{array}{l}\text { Population with Medical } \\
\text { Card or GP Visit Card }\end{array}$} & \multicolumn{2}{|c|}{$\begin{array}{l}\text { Population with Medical } \\
\text { Card and prescription } \\
\text { for chronic condition }\end{array}$} \\
\hline & $\begin{array}{c}\text { Estimated } \\
\text { WTE GPs } \\
\text { per } 10,000\end{array}$ & $\begin{array}{c}\text { Ratio of } \\
\text { area value } \\
\text { to } \\
\text { national } \\
\text { value }\end{array}$ & $\begin{array}{c}\text { Estimated } \\
\text { WTE GPs } \\
\text { per } 10,000\end{array}$ & $\begin{array}{c}\text { Ratio of } \\
\text { area value } \\
\text { to } \\
\text { national } \\
\text { value }\end{array}$ & $\begin{array}{c}\text { Estimated } \\
\text { WTE GPs } \\
\text { per } 10,000\end{array}$ & $\begin{array}{c}\text { Ratio of } \\
\text { area value } \\
\text { to } \\
\text { national } \\
\text { value }\end{array}$ & $\begin{array}{c}\text { Estimated } \\
\text { WTE GPs } \\
\text { per } 10,000\end{array}$ & $\begin{array}{c}\text { Ratio of } \\
\text { area value } \\
\text { to } \\
\text { national } \\
\text { value }\end{array}$ & $\begin{array}{c}\text { Estimated } \\
\text { WTE GPs } \\
\text { per } 10,000\end{array}$ & $\begin{array}{c}\text { Ratio of } \\
\text { area value } \\
\text { to } \\
\text { national } \\
\text { value }\end{array}$ & $\begin{array}{l}\text { Estimated } \\
\text { WTE GPs } \\
\text { per 10,000 }\end{array}$ & $\begin{array}{l}\text { Ratio of } \\
\text { area value } \\
\text { to national } \\
\text { value }\end{array}$ & $\begin{array}{c}\text { Estimated } \\
\text { WTE GPs } \\
\text { per } 10,000\end{array}$ & $\begin{array}{c}\text { Ratio of } \\
\text { area value } \\
\text { to } \\
\text { national } \\
\text { value }\end{array}$ \\
\hline Sligo & 7.7 & 1.36 & 50.5 & 1.14 & 367.5 & 0.90 & 6.4 & 1.14 & 54.4 & 1.2 & 16.4 & 1.21 & 35.2 & 1.18 \\
\hline Cork & 7.0 & 1.23 & 53.3 & 1.20 & 498.9 & 1.23 & 6.8 & 1.20 & 53.1 & 1.2 & 17.2 & 1.26 & 35.9 & 1.21 \\
\hline Galway & 6.8 & 1.20 & 53.7 & 1.21 & 442.8 & 1.09 & 7.2 & 1.28 & 56.4 & 1.3 & 16.2 & 1.19 & 36.4 & 1.23 \\
\hline Waterford & 6.5 & 1.15 & 45.7 & 1.03 & 448.0 & 1.10 & 5.7 & 1.00 & 47.6 & 1.1 & 14.0 & 1.03 & 29.3 & 0.99 \\
\hline Kerry & 6.5 & 1.15 & 40.5 & 0.91 & 372.4 & 0.91 & 5.1 & 0.90 & 49.4 & 1.1 & 14.6 & 1.07 & 30.3 & 1.02 \\
\hline Mayo & 6.4 & 1.13 & 38.7 & 0.87 & 298.9 & 0.73 & 4.9 & 0.86 & 47.1 & 1.1 & 12.3 & 0.90 & 26.7 & 0.90 \\
\hline Carlow & 6.3 & 1.11 & 49.9 & 1.12 & 508.4 & 1.25 & 5.9 & 1.04 & 45.9 & 1.1 & 12.7 & 0.93 & 28.8 & 0.97 \\
\hline Westmeath & 6.2 & 1.09 & 50.4 & 1.14 & 435.3 & 1.07 & 5.6 & 0.99 & 47.0 & 1.1 & 12.9 & 0.95 & 29.7 & 1.00 \\
\hline Limerick & 6.0 & 1.06 & 45.2 & 1.02 & 472.0 & 1.16 & 5.2 & 0.92 & 42.2 & 1.0 & 13.1 & 0.96 & 27.5 & 0.93 \\
\hline Dublin South & 6.0 & 1.06 & 49.3 & 1.11 & 439.8 & 1.08 & 6.4 & 1.13 & 46.0 & 1.1 & 18.6 & 1.37 & 38.9 & 1.31 \\
\hline Louth & 5.9 & 1.05 & 49.0 & 1.10 & 463.6 & 1.14 & 6.3 & 1.12 & 45.7 & 1.0 & 11.3 & 0.83 & 26.3 & 0.88 \\
\hline Donegal & 5.9 & 1.04 & 39.7 & 0.89 & 330.9 & 0.81 & 5.5 & 0.96 & 42.1 & 1.0 & 10.4 & 0.76 & 23.9 & 0.80 \\
\hline Tipperary South & 5.7 & 1.01 & 38.8 & 0.87 & 345.4 & 0.85 & 5.0 & 0.89 & 38.8 & 0.9 & 14.2 & 1.05 & 28.8 & 0.97 \\
\hline Wicklow & 5.6 & 0.99 & 45.8 & 1.03 & 499.4 & 1.23 & 6.3 & 1.11 & 43.6 & 1.0 & 14.1 & 1.03 & 29.9 & 1.00 \\
\hline Tipperary North & 5.5 & 0.97 & 37.6 & 0.85 & 338.6 & 0.83 & 4.3 & 0.76 & 40.0 & 0.9 & 13.7 & 1.01 & 28.0 & 0.94 \\
\hline Longford & 5.5 & 0.97 & 39.0 & 0.88 & 383.5 & 0.94 & 5.1 & 0.90 & 39.6 & 0.9 & 10.8 & 0.80 & 24.5 & 0.82 \\
\hline Offaly & 5.2 & 0.92 & 40.1 & 0.90 & 359.1 & 0.88 & 5.6 & 0.98 & 39.0 & 0.9 & 10.8 & 0.79 & 24.6 & 0.83 \\
\hline Cavan & 5.1 & 0.91 & 38.7 & 0.87 & 293.2 & 0.72 & 4.7 & 0.82 & 43.1 & 1.0 & 10.7 & 0.79 & 24.2 & 0.81 \\
\hline Roscommon & 5.0 & 0.88 & 30.7 & 0.69 & 222.1 & 0.55 & 4.0 & 0.71 & 36.5 & 0.8 & 10.2 & 0.75 & 21.3 & 0.72 \\
\hline Wexford & 4.9 & 0.87 & 34.9 & 0.79 & 381.3 & 0.94 & 4.5 & 0.79 & 35.4 & 0.8 & 9.5 & 0.70 & 21.0 & 0.71 \\
\hline Dublin North & 4.9 & 0.86 & 43.2 & 0.97 & 423.2 & 1.04 & 5.2 & 0.92 & 37.3 & 0.9 & 13.6 & 1.00 & 30.2 & 1.02 \\
\hline Clare & 4.8 & 0.84 & 34.8 & 0.78 & 322.2 & 0.79 & 4.5 & 0.79 & 37.9 & 0.9 & 10.2 & 0.75 & 22.1 & 0.74 \\
\hline Leitrim & 4.7 & 0.83 & 29.0 & 0.65 & 221.1 & 0.54 & 3.8 & 0.68 & 35.0 & 0.8 & 9.6 & 0.70 & 20.4 & 0.69 \\
\hline Laois & 4.7 & 0.83 & 41.9 & 0.94 & 383.1 & 0.94 & 5.4 & 0.95 & 36.9 & 0.8 & 10.0 & 0.74 & 23.9 & 0.80 \\
\hline Kilkenny & 4.6 & 0.82 & 34.5 & 0.78 & 294.8 & 0.72 & 5.0 & 0.89 & 37.1 & 0.9 & 9.6 & 0.70 & 21.2 & 0.71 \\
\hline
\end{tabular}




\begin{tabular}{|c|c|c|c|c|c|c|c|c|c|c|c|c|c|c|}
\hline \multirow[t]{2}{*}{ Geographic area } & \multicolumn{2}{|c|}{ Total population } & \multicolumn{2}{|c|}{$\begin{array}{l}\text { Population aged } 65+ \\
\text { years }\end{array}$} & \multicolumn{2}{|c|}{$\begin{array}{l}\text { Population aged } 85+ \\
\text { years }\end{array}$} & \multicolumn{2}{|c|}{$\begin{array}{l}\text { Mortality-adjusted } \\
\text { population }\end{array}$} & \multicolumn{2}{|c|}{$\begin{array}{l}\text { Population with } \\
\text { disability }\end{array}$} & \multicolumn{2}{|c|}{$\begin{array}{l}\text { Population with Medical } \\
\text { Card or GP Visit Card }\end{array}$} & \multicolumn{2}{|c|}{$\begin{array}{l}\text { Population with Medical } \\
\text { Card and prescription } \\
\text { for chronic condition }\end{array}$} \\
\hline & $\begin{array}{c}\text { Estimated } \\
\text { WTE GPs } \\
\text { per } 10,000\end{array}$ & $\begin{array}{c}\text { Ratio of } \\
\text { area value } \\
\text { to } \\
\text { national } \\
\text { value }\end{array}$ & $\begin{array}{c}\text { Estimated } \\
\text { WTE GPs } \\
\text { per } 10,000\end{array}$ & $\begin{array}{c}\text { Ratio of } \\
\text { area value } \\
\text { to } \\
\text { national } \\
\text { value }\end{array}$ & $\begin{array}{c}\text { Estimated } \\
\text { WTE GPs } \\
\text { per } 10,000\end{array}$ & $\begin{array}{c}\text { Ratio of } \\
\text { area value } \\
\text { to } \\
\text { national } \\
\text { value }\end{array}$ & $\begin{array}{c}\text { Estimated } \\
\text { WTE GPs } \\
\text { per } 10,000\end{array}$ & $\begin{array}{c}\text { Ratio of } \\
\text { area value } \\
\text { to } \\
\text { national } \\
\text { value }\end{array}$ & $\begin{array}{c}\text { Estimated } \\
\text { WTE GPs } \\
\text { per } 10,000\end{array}$ & $\begin{array}{c}\text { Ratio of } \\
\text { area value } \\
\text { to } \\
\text { national } \\
\text { value }\end{array}$ & $\begin{array}{l}\text { Estimated } \\
\text { WTE GPs } \\
\text { per } 10,000\end{array}$ & $\begin{array}{l}\text { Ratio of } \\
\text { area value } \\
\text { to national } \\
\text { value }\end{array}$ & $\begin{array}{c}\text { Estimated } \\
\text { WTE GPs } \\
\text { per } 10,000\end{array}$ & $\begin{array}{c}\text { Ratio of } \\
\text { area value } \\
\text { to } \\
\text { national } \\
\text { value }\end{array}$ \\
\hline Monaghan & 4.2 & 0.73 & 30.4 & 0.69 & 257.4 & 0.63 & 3.6 & 0.64 & 35.0 & 0.8 & 8.5 & 0.63 & 19.1 & 0.64 \\
\hline Kildare & 4.0 & 0.71 & 44.7 & 1.01 & 498.6 & 1.22 & 6.0 & 1.06 & 34.8 & 0.8 & 12.0 & 0.88 & 28.2 & 0.95 \\
\hline Meath & 3.7 & 0.65 & 37.3 & 0.84 & 402.1 & 0.99 & 5.0 & 0.89 & 34.4 & 0.8 & 10.1 & 0.74 & 24.1 & 0.81 \\
\hline Ireland & 5.7 & 1.00 & 44.4 & 1.00 & 407.1 & 1.00 & 5.7 & 1.00 & 43.6 & 1.0 & 13.6 & 1.00 & 29.7 & 1.00 \\
\hline Gini coefficient & 0.096 & & 0.093 & & 0.122 & & 0.093 & & 0.082 & & 0.115 & & 0.103 & \\
\hline
\end{tabular}

Sources: Data on the number and location of GPs are from the Irish College of General Practitioners and the Irish Medical Directory at September 2014 and were made available by Department of Public Health and Primary Care, Trinity College Dublin.

Notes: (a) A GP practising in more than one area is assigned in equal proportions to each area. The number of GPs is converted to estimated WTEs based on survey evidence on full- and part-time working practices of GPs in Ireland. See Chapter 3 for more details. (b) Mortality-adjusted area populations are calculated by multiplying the area's 2014 population estimate by: area crude mortality rate 2014/national crude mortality rate 2014. (c) Area populations with disability are calculated by applying area disability rates from Census 2011 to area population estimates 2014. (d) Area populations with morbidity are the proportion of people with a full Medical Card who are receiving a prescription for a chronic health condition in 2014 applied to the number of people with a full Medical Card at December 2014. (e) The Gini coefficient summarises inequality in the distribution of GPs across areas, with 0 representing complete equality across areas and 1 representing complete inequality across areas. 
TABLE A4.2 NUMBER OF WTE COMMUNITY NURSES PER 10,000 TOTAL POPULATION AND NEEDS-ADJUSTED POPULATIONS BY GEOGRAPHIC AREA, IRELAND 2014

\begin{tabular}{|c|c|c|c|c|c|c|c|c|c|c|c|c|c|c|}
\hline \multirow[t]{2}{*}{$\begin{array}{l}\text { Geographic } \\
\text { area }\end{array}$} & \multicolumn{2}{|c|}{ Total population } & \multicolumn{2}{|c|}{$\begin{array}{c}\text { Population aged } 65+ \\
\text { years }\end{array}$} & \multicolumn{2}{|c|}{$\begin{array}{c}\text { Population aged } 85+ \\
\text { years }\end{array}$} & \multicolumn{2}{|c|}{$\begin{array}{l}\text { Mortality-adjusted } \\
\text { population }\end{array}$} & \multicolumn{2}{|c|}{$\begin{array}{l}\text { Population with } \\
\text { disability }\end{array}$} & \multicolumn{2}{|c|}{$\begin{array}{l}\text { Population with } \\
\text { Medical Card }\end{array}$} & \multicolumn{2}{|c|}{$\begin{array}{l}\text { Population with } \\
\text { Medical Card and } \\
\text { prescription for chronic } \\
\text { condition }\end{array}$} \\
\hline & $\begin{array}{l}\text { WTEs per } \\
10,000\end{array}$ & $\begin{array}{l}\text { Ratio of } \\
\text { area } \\
\text { value to } \\
\text { national } \\
\text { value }\end{array}$ & $\begin{array}{c}\text { WTEs per } \\
10,000\end{array}$ & $\begin{array}{l}\text { Ratio of } \\
\text { area } \\
\text { value to } \\
\text { national } \\
\text { value }\end{array}$ & $\begin{array}{c}\text { WTEs per } \\
10,000\end{array}$ & $\begin{array}{c}\text { Ratio of } \\
\text { area } \\
\text { value to } \\
\text { national } \\
\text { value }\end{array}$ & $\begin{array}{c}\text { WTEs per } \\
10,000\end{array}$ & $\begin{array}{l}\text { Ratio of } \\
\text { area } \\
\text { value to } \\
\text { national } \\
\text { value }\end{array}$ & $\begin{array}{c}\text { WTEs per } \\
10,000\end{array}$ & $\begin{array}{l}\text { Ratio of } \\
\text { area } \\
\text { value to } \\
\text { national } \\
\text { value }\end{array}$ & $\begin{array}{c}\text { WTEs per } \\
10,000\end{array}$ & $\begin{array}{l}\text { Ratio of } \\
\text { area } \\
\text { value to } \\
\text { national } \\
\text { value }\end{array}$ & $\begin{array}{c}\text { WTEs per } \\
10,000\end{array}$ & $\begin{array}{l}\text { Ratio of } \\
\text { area } \\
\text { value to } \\
\text { national } \\
\text { value }\end{array}$ \\
\hline Longford & 10.0 & 1.87 & 70.9 & 1.7 & 697.0 & 1.8 & 9.2 & 1.7 & 72.1 & 1.7 & 21.4 & 1.53 & 44.5 & 1.6 \\
\hline Westmeath & 9.5 & 1.78 & 78.0 & 1.9 & 673.0 & 1.7 & 8.7 & 1.6 & 72.7 & 1.8 & 21.6 & 1.55 & 45.9 & 1.6 \\
\hline Donegal & 7.5 & 1.39 & 50.1 & 1.2 & 417.5 & 1.1 & 6.9 & 1.3 & 53.0 & 1.3 & 14.0 & 1.00 & 30.1 & 1.1 \\
\hline Kerry & 7.0 & 1.31 & 43.7 & 1.0 & 401.3 & 1.0 & 5.5 & 1.0 & 53.2 & 1.3 & 17.1 & 1.22 & 32.6 & 1.2 \\
\hline Leitrim & 7.0 & 1.31 & 43.0 & 1.0 & 327.7 & 0.9 & 5.7 & 1.1 & 51.9 & 1.3 & 15.4 & 1.10 & 30.3 & 1.1 \\
\hline Sligo & 6.8 & 1.27 & 44.6 & 1.1 & 324.7 & 0.8 & 5.7 & 1.1 & 48.0 & 1.2 & 15.8 & 1.13 & 31.1 & 1.1 \\
\hline Roscommon & 6.5 & 1.21 & 39.8 & 0.9 & 287.5 & 0.7 & 5.2 & 1.0 & 47.2 & 1.1 & 14.2 & 1.02 & 27.5 & 1.0 \\
\hline $\begin{array}{l}\text { Tipperary } \\
\text { North }\end{array}$ & 6.3 & 1.17 & 42.9 & 1.0 & 385.9 & 1.0 & 4.9 & 0.9 & 45.6 & 1.1 & 17.0 & 1.21 & 31.9 & 1.1 \\
\hline $\begin{array}{l}\text { Tipperary } \\
\text { South }\end{array}$ & 6.3 & 1.17 & 42.5 & 1.0 & 379.0 & 1.0 & 5.5 & 1.0 & 42.6 & 1.0 & 16.9 & 1.21 & 31.6 & 1.1 \\
\hline Monaghan & 6.1 & 1.14 & 44.6 & 1.1 & 377.5 & 1.0 & 5.3 & 1.0 & 51.3 & 1.2 & 13.7 & 0.98 & 28.0 & 1.0 \\
\hline Cavan & 5.9 & 1.11 & 44.9 & 1.1 & 339.3 & 0.9 & 5.4 & 1.0 & 49.9 & 1.2 & 13.5 & 0.97 & 28.0 & 1.0 \\
\hline Mayo & 5.8 & 1.07 & 34.9 & 0.8 & 269.5 & 0.7 & 4.4 & 0.8 & 42.4 & 1.0 & 11.9 & 0.85 & 24.0 & 0.9 \\
\hline Galway & 5.7 & 1.07 & 45.3 & 1.1 & 373.6 & 1.0 & 6.1 & 1.1 & 47.6 & 1.2 & 14.9 & 1.06 & 30.7 & 1.1 \\
\hline Offaly & 5.6 & 1.04 & 42.8 & 1.0 & 383.8 & 1.0 & 5.9 & 1.1 & 41.6 & 1.0 & 12.5 & 0.89 & 26.3 & 0.9 \\
\hline Laois & 5.5 & 1.03 & 49.4 & 1.2 & 450.9 & 1.2 & 6.4 & 1.2 & 43.5 & 1.1 & 12.8 & 0.92 & 28.1 & 1.0 \\
\hline Carlow & 5.5 & 1.02 & 43.4 & 1.0 & 442.5 & 1.2 & 5.1 & 1.0 & 39.9 & 1.0 & 12.1 & 0.86 & 25.1 & 0.9 \\
\hline Louth & 5.4 & 1.00 & 44.3 & 1.1 & 419.4 & 1.1 & 5.7 & 1.1 & 41.4 & 1.0 & 11.0 & 0.79 & 23.8 & 0.8 \\
\hline Kilkenny & 5.2 & 0.97 & 38.7 & 0.9 & 330.5 & 0.9 & 5.7 & 1.1 & 41.6 & 1.0 & 11.7 & 0.84 & 23.7 & 0.8 \\
\hline Clare & 5.2 & 0.97 & 37.7 & 0.9 & 349.2 & 0.9 & 4.9 & 0.9 & 41.1 & 1.0 & 12.0 & 0.86 & 23.9 & 0.9 \\
\hline Dublin South & 5.0 & 0.93 & 41.1 & 1.0 & 367.0 & 1.0 & 5.3 & 1.0 & 38.4 & 0.9 & 17.0 & 1.21 & 32.5 & 1.2 \\
\hline Dublin North & 5.0 & 0.93 & 44.1 & 1.1 & 432.6 & 1.1 & 5.3 & 1.0 & 38.2 & 0.9 & 15.1 & 1.08 & 30.9 & 1.1 \\
\hline Cork & 4.9 & 0.92 & 37.5 & 0.9 & 350.7 & 0.9 & 4.8 & 0.9 & 37.3 & 0.9 & 13.3 & 0.95 & 25.2 & 0.9 \\
\hline Limerick & 4.7 & 0.89 & 35.7 & 0.9 & 372.2 & 1.0 & 4.1 & 0.8 & 33.3 & 0.8 & 11.2 & 0.80 & 21.7 & 0.8 \\
\hline Waterford & 4.7 & 0.88 & 33.0 & 0.8 & 323.2 & 0.8 & 4.1 & 0.8 & 34.4 & 0.8 & 10.9 & 0.78 & 21.1 & 0.8 \\
\hline
\end{tabular}




\begin{tabular}{|c|c|c|c|c|c|c|c|c|c|c|c|c|c|c|}
\hline \multirow[t]{2}{*}{$\begin{array}{l}\text { Geographic } \\
\text { area }\end{array}$} & \multicolumn{2}{|c|}{ Total population } & \multicolumn{2}{|c|}{$\begin{array}{c}\text { Population aged } 65+ \\
\text { years }\end{array}$} & \multicolumn{2}{|c|}{$\begin{array}{l}\text { Population aged } 85+ \\
\text { years }\end{array}$} & \multicolumn{2}{|c|}{$\begin{array}{l}\text { Mortality-adjusted } \\
\text { population }\end{array}$} & \multicolumn{2}{|c|}{$\begin{array}{l}\text { Population with } \\
\text { disability }\end{array}$} & \multicolumn{2}{|c|}{$\begin{array}{l}\text { Population with } \\
\text { Medical Card }\end{array}$} & \multicolumn{2}{|c|}{$\begin{array}{l}\text { Population with } \\
\text { Medical Card and } \\
\text { prescription for chronic } \\
\text { condition }\end{array}$} \\
\hline & $\begin{array}{c}\text { WTEs per } \\
10,000\end{array}$ & $\begin{array}{l}\text { Ratio of } \\
\text { area } \\
\text { value to } \\
\text { national } \\
\text { value }\end{array}$ & $\begin{array}{l}\text { WTEs per } \\
10,000\end{array}$ & $\begin{array}{l}\text { Ratio of } \\
\text { area } \\
\text { value to } \\
\text { national } \\
\text { value }\end{array}$ & $\begin{array}{c}\text { WTEs per } \\
10,000\end{array}$ & $\begin{array}{l}\text { Ratio of } \\
\text { area } \\
\text { value to } \\
\text { national } \\
\text { value }\end{array}$ & $\begin{array}{l}\text { WTEs per } \\
10,000\end{array}$ & $\begin{array}{l}\text { Ratio of } \\
\text { area } \\
\text { value to } \\
\text { national } \\
\text { value }\end{array}$ & $\begin{array}{l}\text { WTEs per } \\
10,000\end{array}$ & $\begin{array}{l}\text { Ratio of } \\
\text { area } \\
\text { value to } \\
\text { national } \\
\text { value }\end{array}$ & $\begin{array}{c}\text { WTEs per } \\
10,000\end{array}$ & $\begin{array}{l}\text { Ratio of } \\
\text { area } \\
\text { value to } \\
\text { national } \\
\text { value }\end{array}$ & $\begin{array}{c}\text { WTEs per } \\
10,000\end{array}$ & $\begin{array}{c}\text { Ratio of } \\
\text { area } \\
\text { value to } \\
\text { national } \\
\text { value }\end{array}$ \\
\hline Wicklow & 4.6 & 0.86 & 37.2 & 0.9 & 406.3 & 1.1 & 5.1 & 1.0 & 35.5 & 0.9 & 12.5 & 0.89 & 24.3 & 0.9 \\
\hline Kildare & 4.5 & 0.83 & 49.5 & 1.2 & 551.5 & 1.4 & 6.6 & 1.2 & 38.5 & 0.9 & 14.5 & 1.04 & 31.2 & 1.1 \\
\hline Wexford & 4.3 & 0.80 & 30.3 & 0.7 & 331.3 & 0.9 & 3.9 & 0.7 & 30.8 & 0.7 & 8.9 & 0.64 & 18.2 & 0.6 \\
\hline Meath & 3.6 & 0.67 & 36.2 & 0.9 & 390.8 & 1.0 & 4.9 & 0.9 & 33.4 & 0.8 & 10.7 & 0.76 & 23.5 & 0.8 \\
\hline Ireland & 5.4 & 1.00 & 41.9 & 1.0 & 384.6 & 1.0 & 5.4 & 1.0 & 41.2 & 1.0 & 14.0 & 1.00 & 28.1 & 1.0 \\
\hline Gini coefficient & 0.125 & & 0.105 & & 0.117 & & 0.106 & & 0.115 & & 0.114 & & 0.110 & \\
\hline
\end{tabular}

Source: Data on the number of community nurses are from the Health Service Executive's (HSE) Health Services Personnel Census (HSPC) December 2014.

Notes: (a) Mortality-adjusted area populations are calculated by multiplying the area's 2014 population estimate by: area crude mortality rate 2014/national crude mortality rate 2014. (b) Area populations with disability are calculated by applying area disability rates from Census 2011 to area population estimates 2014. (c) Area populations with morbidity are the proportion of people with a full Medical Card who are receiving a prescription for a chronic health condition in 2014 applied to the number of people with a full Medical Card at December 2014. (d) The Gini coefficient summarises inequality in the distribution of community nurses across areas, with O representing complete equality across areas and 1 representing complete inequality across areas. (e) Tipperary North and Tipperary South have the same WTE per population value because data were not available separately. 
TABLE A4.3 NUMBER OF WTE PUBLIC AND PRIVATE NON-ACUTE PHYSIOTHERAPISTS (PTS) PER 10,000 TOTAL POPULATION AND NEEDS-ADJUSTED POPULATIONS BY GEOGRAPHIC AREA, IRELAND 2014

\begin{tabular}{|c|c|c|c|c|c|c|c|c|c|c|c|c|c|c|}
\hline \multirow[t]{2}{*}{$\begin{array}{l}\text { Geographic } \\
\text { area }\end{array}$} & \multicolumn{2}{|c|}{ Total population } & \multicolumn{2}{|c|}{$\begin{array}{l}\text { Population aged } 65+ \\
\text { years }\end{array}$} & \multicolumn{2}{|c|}{$\begin{array}{l}\text { Population aged } 85+ \\
\text { years }\end{array}$} & \multicolumn{2}{|c|}{$\begin{array}{l}\text { Mortality-adjusted } \\
\text { population }\end{array}$} & \multicolumn{2}{|c|}{$\begin{array}{l}\text { Population with } \\
\text { disability }\end{array}$} & \multicolumn{2}{|c|}{$\begin{array}{l}\text { Population with a } \\
\text { Medical Card }\end{array}$} & \multicolumn{2}{|c|}{$\begin{array}{l}\text { Population with } \\
\text { Medical Card and } \\
\text { prescription for } \\
\text { chronic condition }\end{array}$} \\
\hline & $\begin{array}{c}\text { WTE PTs } \\
\text { per } \\
10,000\end{array}$ & $\begin{array}{c}\text { Ratio of } \\
\text { area } \\
\text { value to } \\
\text { national } \\
\text { value }\end{array}$ & $\begin{array}{c}\text { WTE PTs } \\
\text { per } \\
10,000\end{array}$ & $\begin{array}{l}\text { Ratio of } \\
\text { area } \\
\text { value to } \\
\text { national } \\
\text { value }\end{array}$ & $\begin{array}{c}\text { WTE PTs } \\
\text { per } \\
10,000\end{array}$ & $\begin{array}{c}\text { Ratio of } \\
\text { area } \\
\text { value to } \\
\text { national } \\
\text { value }\end{array}$ & $\begin{array}{c}\text { WTE PTs } \\
\text { per } \\
10,000\end{array}$ & $\begin{array}{l}\text { Ratio of } \\
\text { area } \\
\text { value to } \\
\text { national } \\
\text { value }\end{array}$ & $\begin{array}{c}\text { WTE PTs } \\
\text { per } \\
10,000\end{array}$ & $\begin{array}{l}\text { Ratio of } \\
\text { area } \\
\text { value to } \\
\text { national } \\
\text { value }\end{array}$ & $\begin{array}{c}\text { WTE public } \\
\text { PTs per } \\
10,000\end{array}$ & $\begin{array}{c}\text { Ratio of } \\
\text { area } \\
\text { value to } \\
\text { national } \\
\text { value }\end{array}$ & $\begin{array}{c}\text { WTE } \\
\text { public } \\
\text { PTs per } \\
10,000\end{array}$ & $\begin{array}{c}\text { Ratio of } \\
\text { area } \\
\text { value to } \\
\text { national } \\
\text { value }\end{array}$ \\
\hline Leitrim & 5.1 & 1.43 & 31.4 & 1.12 & 239.2 & 0.93 & 4.1 & 1.15 & 37.9 & 1.37 & 7.5 & 1.67 & 14.7 & 1.64 \\
\hline Dublin South & 5.0 & 1.39 & 41.2 & 1.47 & 367.7 & 1.43 & 5.4 & 1.49 & 38.4 & 1.39 & 6.6 & 1.47 & 12.5 & 1.40 \\
\hline Longford & 4.4 & 1.22 & 31.0 & 1.10 & 304.2 & 1.18 & 4.0 & 1.12 & 31.4 & 1.14 & 5.9 & 1.32 & 12.3 & 1.37 \\
\hline Kerry & 4.2 & 1.17 & 26.1 & 0.93 & 239.5 & 0.93 & 3.3 & 0.92 & 31.7 & 1.15 & 4.9 & 1.10 & 9.4 & 1.05 \\
\hline Westmeath & 4.1 & 1.14 & 33.5 & 1.19 & 288.7 & 1.12 & 3.7 & 1.04 & 31.2 & 1.13 & 5.7 & 1.27 & 12.0 & 1.34 \\
\hline Limerick & 4.0 & 1.12 & 30.1 & 1.07 & 314.2 & 1.22 & 3.5 & 0.96 & 28.1 & 1.02 & 4.0 & 1.89 & 7.7 & 0.86 \\
\hline Louth & 3.9 & 1.09 & 32.3 & 1.15 & 306.3 & 1.19 & 4.2 & 1.17 & 30.2 & 1.09 & 4.5 & 1.00 & 9.7 & 1.08 \\
\hline Sligo & 3.9 & 1.08 & 25.3 & 0.90 & 184.4 & 0.72 & 3.2 & 0.90 & 27.3 & 0.99 & 4.4 & 0.99 & 8.7 & 0.97 \\
\hline Galway & 3.8 & 1.06 & 30.2 & 1.07 & 248.7 & 0.96 & 4.1 & 1.13 & 31.7 & 1.15 & 3.7 & 0.84 & 7.7 & 0.86 \\
\hline Roscommon & 3.8 & 1.05 & 23.2 & 0.83 & 168.0 & 0.65 & 3.1 & 0.85 & 27.6 & 1.00 & 6.0 & 1.33 & 11.5 & 1.28 \\
\hline Mayo & 3.7 & 1.05 & 22.7 & 0.81 & 175.6 & 0.68 & 2.9 & 0.80 & 27.7 & 1.00 & 3.9 & 0.88 & 8.0 & 0.89 \\
\hline Cork & 3.5 & 0.97 & 26.5 & 0.94 & 247.9 & 0.96 & 3.4 & 0.94 & 26.4 & 0.96 & 3.5 & 0.79 & 6.7 & 0.74 \\
\hline $\begin{array}{l}\text { Tipperary } \\
\text { North }\end{array}$ & 3.4 & 0.96 & 23.6 & 0.84 & 212.0 & 0.82 & 2.7 & 0.75 & 25.1 & 0.91 & 4.3 & 0.96 & 8.0 & 0.90 \\
\hline Dublin North & 3.3 & 0.93 & 29.6 & 1.05 & 290.5 & 1.13 & 3.6 & 1.00 & 25.6 & 0.93 & 6.1 & 1.35 & 12.4 & 1.38 \\
\hline $\begin{array}{l}\text { Tipperary } \\
\text { South }\end{array}$ & 3.3 & 0.92 & 22.3 & 0.79 & 199.1 & 0.77 & 2.9 & 0.81 & 22.4 & 0.81 & 4.3 & 0.96 & 8.0 & 0.89 \\
\hline Carlow & 3.2 & 0.90 & 25.7 & 0.91 & 261.6 & 1.02 & 3.0 & 0.84 & 23.6 & 0.86 & 3.4 & 0.76 & 7.1 & 0.79 \\
\hline Kildare & 3.2 & 0.88 & 35.2 & 1.25 & 392.0 & 1.52 & 4.7 & 1.32 & 27.4 & 0.99 & 3.2 & 0.71 & 6.8 & 0.75 \\
\hline Donegal & 3.1 & 0.86 & 20.7 & 0.74 & 172.8 & 0.67 & 2.9 & 0.79 & 22.0 & 0.80 & 4.1 & 0.92 & 8.8 & 0.98 \\
\hline Kilkenny & 3.1 & 0.86 & 22.8 & 0.81 & 194.8 & 0.76 & 3.3 & 0.93 & 24.5 & 0.89 & 3.1 & 0.68 & 6.2 & 0.69 \\
\hline Laois & 3.0 & 0.82 & 26.4 & 0.94 & 241.4 & 0.94 & 3.4 & 0.95 & 23.3 & 0.84 & 4.3 & 0.97 & 9.5 & 1.06 \\
\hline Clare & 2.9 & 0.80 & 20.9 & 0.74 & 193.3 & 0.75 & 2.7 & 0.75 & 22.8 & 0.82 & 2.8 & 0.64 & 5.7 & 0.63 \\
\hline Cavan & 2.9 & 0.80 & 21.5 & 0.77 & 163.0 & 0.63 & 2.6 & 0.72 & 24.0 & 0.87 & 5.0 & 1.11 & 10.3 & 1.14 \\
\hline Offaly & 2.7 & 0.77 & 21.1 & 0.75 & 189.3 & 0.73 & 2.9 & 0.82 & 20.5 & 0.74 & 4.1 & 0.92 & 8.7 & 0.97 \\
\hline Waterford & 2.7 & 0.75 & 18.8 & 0.67 & 184.4 & 0.72 & 2.3 & 0.65 & 19.6 & 0.71 & 3.5 & 0.78 & 6.7 & 0.75 \\
\hline Wexford & 2.6 & 0.71 & 18.2 & 0.65 & 198.8 & 0.77 & 2.3 & 0.65 & 18.5 & 0.67 & 2.6 & 0.59 & 5.4 & 0.60 \\
\hline Monaghan & 2.5 & 0.70 & 18.5 & 0.66 & 156.2 & 0.61 & 2.2 & 0.61 & 21.2 & 0.77 & 5.1 & 1.14 & 10.4 & 1.16 \\
\hline
\end{tabular}




\begin{tabular}{|c|c|c|c|c|c|c|c|c|c|c|c|c|c|c|}
\hline \multirow[t]{2}{*}{$\begin{array}{l}\text { Geographic } \\
\text { area }\end{array}$} & \multicolumn{2}{|c|}{ Total population } & \multicolumn{2}{|c|}{$\begin{array}{l}\text { Population aged } 65+ \\
\text { years }\end{array}$} & \multicolumn{2}{|c|}{$\begin{array}{l}\text { Population aged } 85+ \\
\text { years }\end{array}$} & \multicolumn{2}{|c|}{$\begin{array}{l}\text { Mortality-adjusted } \\
\text { population }\end{array}$} & \multicolumn{2}{|c|}{$\begin{array}{l}\text { Population with } \\
\text { disability }\end{array}$} & \multicolumn{2}{|c|}{$\begin{array}{l}\text { Population with a } \\
\text { Medical Card }\end{array}$} & \multicolumn{2}{|c|}{$\begin{array}{l}\text { Population with } \\
\text { Medical Card and } \\
\text { prescription for } \\
\text { chronic condition }\end{array}$} \\
\hline & $\begin{array}{c}\text { WTE PTs } \\
\text { per } \\
10,000\end{array}$ & $\begin{array}{l}\text { Ratio of } \\
\text { area } \\
\text { value to } \\
\text { national } \\
\text { value }\end{array}$ & $\begin{array}{c}\text { WTE PTs } \\
\text { per } \\
10,000\end{array}$ & $\begin{array}{c}\text { Ratio of } \\
\text { area } \\
\text { value to } \\
\text { national } \\
\text { value }\end{array}$ & $\begin{array}{c}\text { WTE PTs } \\
\text { per } \\
10,000\end{array}$ & $\begin{array}{l}\text { Ratio of } \\
\text { area } \\
\text { value to } \\
\text { national } \\
\text { value }\end{array}$ & $\begin{array}{c}\text { WTE PTs } \\
\text { per } \\
10,000\end{array}$ & $\begin{array}{l}\text { Ratio of } \\
\text { area } \\
\text { value to } \\
\text { national } \\
\text { value }\end{array}$ & $\begin{array}{c}\text { WTE PTs } \\
\text { per } \\
10,000\end{array}$ & $\begin{array}{l}\text { Ratio of } \\
\text { area } \\
\text { value to } \\
\text { national } \\
\text { value }\end{array}$ & $\begin{array}{c}\text { WTE public } \\
\text { PTs per } \\
10,000\end{array}$ & $\begin{array}{c}\text { Ratio of } \\
\text { area } \\
\text { value to } \\
\text { national } \\
\text { value }\end{array}$ & $\begin{array}{c}\text { WTE } \\
\text { public } \\
\text { PTs per } \\
10,000\end{array}$ & $\begin{array}{l}\text { Ratio of } \\
\text { area } \\
\text { value to } \\
\text { national } \\
\text { value }\end{array}$ \\
\hline Wicklow & 2.5 & 0.69 & 20.1 & 0.72 & 219.8 & 0.85 & 2.8 & 0.77 & 19.2 & 0.70 & 3.0 & 0.67 & 5.9 & 0.65 \\
\hline Meath & 2.4 & 0.68 & 24.6 & 0.88 & 265.5 & 1.03 & 3.3 & 0.93 & 22.7 & 0.82 & 3.5 & 0.78 & 7.6 & 0.85 \\
\hline Ireland & 3.6 & 1.00 & 28.1 & 1.00 & 257.8 & 1.00 & 3.6 & 1.00 & 27.6 & 1.00 & 4.5 & 1.00 & 9.0 & 1.00 \\
\hline Gini coefficient & 0.116 & & 0.119 & & 0.142 & & 0.119 & & 0.107 & & 0.150 & & 0.149 & \\
\hline
\end{tabular}

Source: Data on the number of WTE publicly employed non-acute physiotherapists are from the HSE's HSPC December 2014. Data on the number of WTE privately employed non-acute physiotherapists are from the register of the Irish Society of Chartered Physiotherapists (ISCP).

Notes: (a) Mortality-adjusted area populations are calculated by multiplying the area's 2014 population estimate by: area crude mortality rate 2014/national crude mortality rate 2014. (b) Area populations with disability are calculated by applying area disability rates from Census 2011 to area population estimates 2014. (c) Area populations with morbidity are the proportion of people with a full Medical Card who are receiving a prescription for a chronic health condition in 2014 applied to the number of people with a full Medical Card at December 2014. (d) The Gini coefficient summarises inequality in the distribution of PTs across areas, with 0 representing complete equality across areas and 1 representing complete inequality across areas. (e) The number of private PTs is converted to WTEs using information from a survey of ISCP members, namely that $60 \%$ of PTs work full-time (1 WTE - over and above 1,500 hours per year) and $40 \%$ work part-time (0.5 WTE), giving an adjustment factor of $0.8=(0.6 \times 1+0.4 \times 0.5)$. The survey was conducted by the ESRI in November 2015. 
TABLE A4.4 NUMBER OF WTE PUBLICLY EMPLOYED NON-ACUTE OCCUPATIONAL THERAPISTS (OTS) PER 10,000 TOTAL POPULATION AND NEEDSADJUSTED POPULATIONS BY GEOGRAPHIC AREA, IRELAND 2014

\begin{tabular}{|c|c|c|c|c|c|c|c|c|c|c|c|c|c|c|}
\hline \multirow[t]{2}{*}{$\begin{array}{l}\text { Geographic } \\
\text { area }\end{array}$} & \multicolumn{2}{|c|}{ Total population } & \multicolumn{2}{|c|}{$\begin{array}{l}\text { Population aged } 65+ \\
\text { years }\end{array}$} & \multicolumn{2}{|c|}{$\begin{array}{l}\text { Population aged } 85+ \\
\text { years }\end{array}$} & \multicolumn{2}{|c|}{$\begin{array}{l}\text { Mortality-adjusted } \\
\text { population }\end{array}$} & \multicolumn{2}{|c|}{$\begin{array}{l}\text { Population with } \\
\text { disability }\end{array}$} & \multicolumn{2}{|c|}{$\begin{array}{l}\text { Population with a } \\
\text { Medical Card }\end{array}$} & \multicolumn{2}{|c|}{$\begin{array}{l}\text { Population with } \\
\text { Medical Card and } \\
\text { prescription for chronic } \\
\text { condition }\end{array}$} \\
\hline & $\begin{array}{c}\text { WTE OTs } \\
\text { per } \\
10,000\end{array}$ & $\begin{array}{l}\text { Ratio of } \\
\text { area } \\
\text { value to } \\
\text { national } \\
\text { value }\end{array}$ & $\begin{array}{c}\text { WTE OTS } \\
\text { per10,00 } \\
0\end{array}$ & $\begin{array}{l}\text { Ratio of } \\
\text { area } \\
\text { value to } \\
\text { national } \\
\text { value }\end{array}$ & $\begin{array}{l}\text { WTE OTs } \\
\text { per } \\
10,000\end{array}$ & $\begin{array}{l}\text { Ratio of } \\
\text { area } \\
\text { value to } \\
\text { national } \\
\text { value }\end{array}$ & $\begin{array}{c}\text { WTE OTs } \\
\text { per } \\
10,000\end{array}$ & $\begin{array}{l}\text { Ratio of } \\
\text { area } \\
\text { value to } \\
\text { national } \\
\text { value }\end{array}$ & $\begin{array}{c}\text { WTE OTs } \\
\text { per } \\
10,000\end{array}$ & $\begin{array}{c}\text { Ratio of } \\
\text { area } \\
\text { value to } \\
\text { national } \\
\text { value }\end{array}$ & $\begin{array}{c}\text { WTE OTs } \\
\text { per } \\
10,000 \\
\text { populatio } \\
n\end{array}$ & $\begin{array}{l}\text { Ratio of } \\
\text { area } \\
\text { value to } \\
\text { national } \\
\text { value }\end{array}$ & $\begin{array}{c}\text { WTE OTs } \\
\text { per } \\
10,000\end{array}$ & $\begin{array}{l}\text { Ratio of } \\
\text { area } \\
\text { value to } \\
\text { national } \\
\text { value } \\
\end{array}$ \\
\hline Leitrim & 5.3 & 2.37 & 32.6 & 1.85 & 248.8 & 1.54 & 4.3 & 1.91 & 39.4 & 2.28 & 11.7 & 1.99 & 23.0 & 1.95 \\
\hline Sligo & 4.3 & 1.91 & 28.2 & 1.60 & 205.3 & 1.27 & 3.6 & 1.60 & 30.4 & 1.75 & 10.0 & 1.70 & 19.6 & 1.67 \\
\hline Dublin South & 2.7 & 1.18 & 22.0 & 1.25 & 195.9 & 1.21 & 2.9 & 1.27 & 20.5 & 1.18 & 9.1 & 1.54 & 17.3 & 1.47 \\
\hline Westmeath & 2.9 & 1.28 & 23.5 & 1.34 & 203.2 & 1.26 & 2.6 & 1.16 & 22.0 & 1.27 & 6.5 & 1.11 & 13.9 & 1.17 \\
\hline Monaghan & 2.8 & 1.25 & 20.7 & 1.17 & 174.8 & 1.08 & 2.5 & 1.10 & 23.7 & 1.37 & 6.3 & 1.08 & 13.0 & 1.10 \\
\hline Laois & 2.8 & 1.24 & 25.0 & 1.42 & 228.5 & 1.41 & 3.2 & 1.43 & 22.0 & 1.27 & 6.5 & 1.11 & 14.3 & 1.21 \\
\hline Louth & 2.7 & 1.22 & 22.7 & 1.29 & 214.7 & 1.33 & 2.9 & 1.30 & 21.2 & 1.22 & 5.6 & 0.96 & 12.2 & 1.03 \\
\hline Carlow & 2.6 & 1.17 & 21.0 & 1.19 & 213.4 & 1.32 & 2.5 & 1.10 & 19.3 & 1.11 & 5.8 & 0.99 & 12.1 & 1.02 \\
\hline Dublin North & 2.5 & 1.11 & 22.1 & 1.26 & 216.9 & 1.34 & 2.7 & 1.19 & 19.1 & 1.11 & 7.6 & 1.29 & 15.5 & 1.31 \\
\hline Cavan & 2.4 & 1.07 & 18.2 & 1.03 & 137.8 & 0.85 & 2.2 & 0.98 & 20.3 & 1.17 & 5.5 & 0.94 & 11.4 & 0.96 \\
\hline Longford & 2.4 & 1.07 & 17.1 & 0.97 & 168.4 & 1.04 & 2.2 & 0.99 & 17.4 & 1.01 & 5.2 & 0.88 & 10.8 & 0.91 \\
\hline Mayo & 2.3 & 1.02 & 14.0 & 0.79 & 107.7 & 0.67 & 1.8 & 0.78 & 17.0 & 0.98 & 4.7 & 0.81 & 9.6 & 0.81 \\
\hline Roscommon & 2.2 & 0.99 & 13.7 & 0.78 & 98.7 & 0.61 & 1.8 & 0.80 & 16.2 & 0.94 & 4.9 & 0.83 & 9.4 & 0.80 \\
\hline Donegal & 2.2 & 0.98 & 14.8 & 0.84 & 123.5 & 0.76 & 2.0 & 0.91 & 15.7 & 0.91 & 4.1 & 0.70 & 8.9 & 0.75 \\
\hline Cork & 2.2 & 0.96 & 16.5 & 0.94 & 154.8 & 0.96 & 2.1 & 0.94 & 16.5 & 0.95 & 5.9 & 1.00 & 11.1 & 0.94 \\
\hline Kilkenny & 2.1 & 0.95 & 15.8 & 0.90 & 135.3 & 0.84 & 2.3 & 1.03 & 17.0 & 0.98 & 4.8 & 0.82 & 9.7 & 0.82 \\
\hline Kerry & 2.1 & 0.95 & 13.3 & 0.75 & 121.9 & 0.75 & 1.7 & 0.75 & 16.2 & 0.93 & 5.2 & 0.88 & 9.9 & 0.84 \\
\hline Limerick & 2.1 & 0.94 & 15.9 & 0.90 & 166.2 & 1.03 & 1.8 & 0.81 & 14.9 & 0.86 & 5.0 & 0.85 & 9.7 & 0.82 \\
\hline Galway & 2.1 & 0.93 & 16.5 & 0.94 & 136.2 & 0.84 & 2.2 & 0.99 & 17.3 & 1.00 & 5.4 & 0.92 & 11.2 & 0.95 \\
\hline $\begin{array}{l}\text { Tipperary } \\
\text { South }\end{array}$ & 2.1 & 0.92 & 14.1 & 0.80 & 125.6 & 0.78 & 1.8 & 0.82 & 14.1 & 0.82 & 5.6 & 0.96 & 10.5 & 0.89 \\
\hline Offaly & 2.0 & 0.89 & 15.5 & 0.88 & 138.7 & 0.86 & 2.1 & 0.96 & 15.0 & 0.87 & 4.5 & 0.77 & 9.5 & 0.81 \\
\hline Clare & 1.9 & 0.86 & 14.1 & 0.80 & 130.7 & 0.81 & 1.8 & 0.81 & 15.4 & 0.89 & 4.5 & 0.76 & 9.0 & 0.76 \\
\hline Waterford & 1.9 & 0.85 & 13.3 & 0.75 & 130.3 & 0.81 & 1.6 & 0.73 & 13.9 & 0.80 & 4.4 & 0.75 & 8.5 & 0.72 \\
\hline Wexford & 1.7 & 0.76 & 12.1 & 0.69 & 132.0 & 0.82 & 1.6 & 0.69 & 12.3 & 0.71 & 3.6 & 0.61 & 7.3 & 0.62 \\
\hline Kildare & 1.4 & 0.62 & 15.4 & 0.87 & 171.6 & 1.06 & 2.1 & 0.92 & 12.0 & 0.69 & 4.5 & 0.77 & 9.7 & 0.82 \\
\hline
\end{tabular}



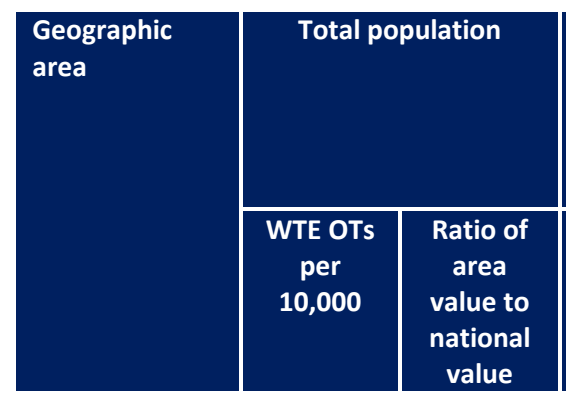

Meath

Tipperary

North

Wicklow

Ireland

Gini coefficient
0.55
1.00

0.171 1.3

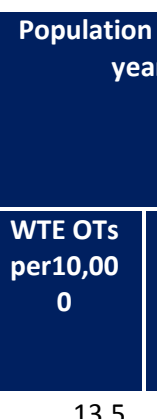

years

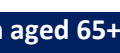

years

s

Ratio of
area
value to
nation
value

value
0.59

\begin{tabular}{l|l|l|}
1.3 & 0.58
\end{tabular}

$1.2 \quad 0.55$

$\begin{array}{ll}9.0 & 0.51\end{array}$

$10.1 \quad 0.57$

\begin{tabular}{|l|l|}
\hline .58 \\
\hline .55 \\
\hline .00
\end{tabular}

\begin{tabular}{|l|l|}
\hline 10.1 & 0.57 \\
\hline 17.6 & 1.00 \\
\hline
\end{tabular}

0.166

\begin{tabular}{|l|l|l|}
\hline 0.57 & 109.9 & 0.68 \\
\hline 1.00 & 161.6 & 1.00 \\
\hline
\end{tabular}

\begin{tabular}{|c|c|}
\hline \multicolumn{2}{|c|}{$\begin{array}{c}\text { Population aged } 85+ \\
\text { years }\end{array}$} \\
\hline $\begin{array}{c}\text { WTE OTs } \\
\text { per } \\
10,000\end{array}$ & $\begin{array}{c}\text { Ratio of } \\
\text { area } \\
\text { value to } \\
\text { national } \\
\text { value }\end{array}$ \\
\hline
\end{tabular}

\begin{tabular}{|c|c|}
\multicolumn{2}{|c|}{$\begin{array}{c}\text { Mortality-adjusted } \\
\text { population }\end{array}$} \\
\hline $\begin{array}{c}\text { WTE OTs } \\
\text { per } \\
10,000\end{array}$ & $\begin{array}{c}\text { Ratio of } \\
\text { area } \\
\text { value to } \\
\text { national } \\
\text { value }\end{array}$ \\
\hline
\end{tabular}

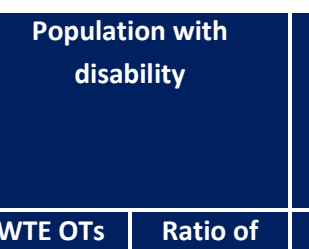

\section{Population with a \\ Medical Card}

Population with

prescription for chronic

condition

\begin{tabular}{c|c} 
per & area \\
10,000 & value to \\
& national \\
value
\end{tabular}

\begin{tabular}{|c|c|}
\hline WTE OTs & Ratio of \\
per & area \\
10,000 & value to \\
populatio & national
\end{tabular}

WTE OTs $\quad$ Ratio of

per

10,000

n value

value

value 0.72

n

\begin{tabular}{|r|r|r|r|r|r|r|}
\hline 0.81 & 12.4 & 0.72 & 4.0 & 0.68 & 8.7 & 0.74 \\
\hline 0.46 & 9.6 & 0.55 & 3.6 & 0.60 & 6.7 & 0.57 \\
\hline
\end{tabular}

8.7

value to

national

8.7 value

$\begin{array}{lll}0.62 & 9.6 & 0.55\end{array}$

\begin{tabular}{l|l}
3.4 & 0.57 \\
5.9 & 1.00
\end{tabular}

$6.6 \quad 0.56$

0.153

\begin{tabular}{l|l}
1.4 & 0.62 \\
2.2 & 1.00
\end{tabular}

$\begin{array}{rr}9.6 & 0.55 \\ 17.3 & 1.00\end{array}$

6.6
11.8

1.00

Source: Data on the number of WTE publicly employed non-acute occupational therapists are from the HSE's HSPC December 2014.

Notes: (a) Mortality-adjusted area populations are calculated by multiplying the area's 2014 population estimate by: Area crude mortality rate 2014 / National crude mortality rate 2014. (b) Area populations with disability are calculated by applying area disability rates from Census 2011 to area population estimates 2014. (c) Area populations with morbidity are the proportion of people with a full Medical Card who are receiving a prescription for a chronic health condition in 2014 applied to the number of people with a full Medical Card at December 2014. (d) The Gini coefficient summarises inequality in the distribution of OTs across areas with 0 representing complete equality across areas and 1 representing complete inequality across areas. 
TABLE A4.5 NUMBER OF WTE PUBLICLY EMPLOYED NON-ACUTE SPEECH AND LANGUAGE THERAPISTS (SLTS) PER 10,000 TOTAL POPULATION AND NEEDSADJUSTED POPULATIONS BY GEOGRAPHIC AREA, IRELAND 2014

\begin{tabular}{|c|c|c|c|c|c|c|c|c|c|c|c|c|c|c|}
\hline \multirow[t]{2}{*}{$\begin{array}{l}\text { Geographic } \\
\text { area }\end{array}$} & \multicolumn{2}{|c|}{ Total population } & \multicolumn{2}{|c|}{$\begin{array}{l}\text { Population aged } 65+ \\
\text { years }\end{array}$} & \multicolumn{2}{|c|}{$\begin{array}{l}\text { Population aged } 85+ \\
\text { years }\end{array}$} & \multicolumn{2}{|c|}{$\begin{array}{l}\text { Mortality-adjusted } \\
\text { population }\end{array}$} & \multicolumn{2}{|c|}{$\begin{array}{l}\text { Population with } \\
\text { disability }\end{array}$} & \multicolumn{2}{|c|}{$\begin{array}{l}\text { Population with a } \\
\text { Medical Card }\end{array}$} & \multicolumn{2}{|c|}{$\begin{array}{l}\text { Population with } \\
\text { Medical Card and } \\
\text { prescription for } \\
\text { chronic condition }\end{array}$} \\
\hline & $\begin{array}{c}\text { WTE SLTS } \\
\text { per } \\
10,000\end{array}$ & $\begin{array}{c}\text { Ratio } \\
\text { area } \\
\text { value to } \\
\text { national } \\
\text { value }\end{array}$ & $\begin{array}{c}\text { WTE SLTS } \\
\text { per } \\
10,000\end{array}$ & $\begin{array}{c}\text { Ratio of } \\
\text { area } \\
\text { value to } \\
\text { national } \\
\text { value }\end{array}$ & $\begin{array}{c}\text { WTE SLTS } \\
\text { per } \\
10,000\end{array}$ & $\begin{array}{c}\text { Ratio } \\
\text { area } \\
\text { value to } \\
\text { national } \\
\text { value }\end{array}$ & $\begin{array}{c}\text { WTE SLTS } \\
\text { per } \\
10,000\end{array}$ & $\begin{array}{c}\text { Ratio } \\
\text { area } \\
\text { value to } \\
\text { national } \\
\text { value }\end{array}$ & $\begin{array}{c}\text { WTE SLTS } \\
\text { per } \\
10,000\end{array}$ & $\begin{array}{c}\text { Ratio } \\
\text { area } \\
\text { value to } \\
\text { national } \\
\text { value }\end{array}$ & $\begin{array}{c}\text { WTE SLTS } \\
\text { per } \\
10,000\end{array}$ & $\begin{array}{c}\text { Ratio } \\
\text { area } \\
\text { value to } \\
\text { national } \\
\text { value }\end{array}$ & $\begin{array}{c}\text { WTE SLTS } \\
\text { per } \\
10,000\end{array}$ & $\begin{array}{c}\text { Ratio } \\
\text { area } \\
\text { value to } \\
\text { national } \\
\text { value }\end{array}$ \\
\hline Sligo & 2.3 & 1.47 & 14.9 & 1.23 & 108.8 & 0.98 & 1.9 & 1.23 & 16.1 & 1.35 & 5.3 & 1.31 & 10.4 & 1.28 \\
\hline Roscommon & 2.2 & 1.40 & 13.4 & 1.10 & 96.6 & 0.87 & 1.8 & 1.14 & 15.9 & 1.33 & 4.8 & 1.18 & 9.2 & 1.14 \\
\hline Leitrim & 2.1 & 1.37 & 13.0 & 1.07 & 99.0 & 0.89 & 1.7 & 1.11 & 15.7 & 1.32 & 4.7 & 1.15 & 9.1 & 1.13 \\
\hline Westmeath & 2.1 & 1.36 & 17.2 & 1.42 & 148.2 & 1.33 & 1.9 & 1.23 & 16.0 & 1.34 & 4.8 & 1.18 & 10.1 & 1.24 \\
\hline Longford & 1.9 & 1.25 & 13.8 & 1.13 & 135.2 & 1.22 & 1.8 & 1.16 & 14.0 & 1.17 & 4.2 & 1.03 & 8.6 & 1.06 \\
\hline Mayo & 1.8 & 1.18 & 11.1 & 0.92 & 85.7 & 0.77 & 1.4 & 0.90 & 13.5 & 1.13 & 3.8 & 0.93 & 7.6 & 0.94 \\
\hline $\begin{array}{l}\text { Tipperary } \\
\text { South }\end{array}$ & 1.8 & 1.14 & 11.9 & 0.99 & 106.5 & 0.96 & 1.6 & 1.01 & 12.0 & 1.01 & 4.8 & 1.18 & 8.9 & 1.10 \\
\hline Dublin North & 1.7 & 1.09 & 15.0 & 1.24 & 147.3 & 1.33 & 1.8 & 1.17 & 13.0 & 1.09 & 5.1 & 1.27 & 10.5 & 1.29 \\
\hline Cork & 1.7 & 1.09 & 12.9 & 1.06 & 120.4 & 1.08 & 1.6 & 1.06 & 12.8 & 1.08 & 4.6 & 1.13 & 8.7 & 1.07 \\
\hline Dublin South & 1.6 & 1.07 & 13.6 & 1.12 & 121.4 & 1.09 & 1.8 & 1.14 & 12.7 & 1.07 & 5.6 & 1.39 & 10.7 & 1.32 \\
\hline Galway & 1.6 & 1.05 & 12.8 & 1.06 & 105.6 & 0.95 & 1.7 & 1.12 & 13.4 & 1.13 & 4.2 & 1.04 & 8.7 & 1.07 \\
\hline Laois & 1.6 & 1.01 & 14.1 & 1.16 & 128.4 & 1.15 & 1.8 & 1.17 & 12.4 & 1.04 & 3.7 & 0.90 & 8.0 & 0.99 \\
\hline Kerry & 1.6 & 1.01 & 9.7 & 0.80 & 89.5 & 0.81 & 1.2 & 0.80 & 11.9 & 1.00 & 3.8 & 0.94 & 7.3 & 0.90 \\
\hline $\begin{array}{l}\text { Tipperary } \\
\text { North }\end{array}$ & 1.5 & 1.00 & 10.6 & 0.87 & 95.3 & 0.86 & 1.2 & 0.78 & 11.3 & 0.95 & 4.2 & 1.04 & 7.9 & 0.97 \\
\hline Donegal & 1.5 & 0.98 & 10.2 & 0.84 & 84.7 & 0.76 & 1.4 & 0.90 & 10.8 & 0.90 & 2.8 & 0.70 & 6.1 & 0.75 \\
\hline Monaghan & 1.5 & 0.97 & 11.0 & 0.91 & 92.8 & 0.83 & 1.3 & 0.85 & 12.6 & 1.06 & 3.4 & 0.83 & 6.9 & 0.85 \\
\hline Cavan & 1.5 & 0.96 & 11.2 & 0.92 & 84.5 & 0.76 & 1.3 & 0.87 & 12.4 & 1.04 & 3.4 & 0.83 & 7.0 & 0.86 \\
\hline Limerick & 1.4 & 0.89 & 10.3 & 0.85 & 108.0 & 0.97 & 1.2 & 0.77 & 9.6 & 0.81 & 3.3 & 0.80 & 6.3 & 0.78 \\
\hline Waterford & 1.3 & 0.87 & 9.4 & 0.77 & 91.7 & 0.83 & 1.2 & 0.75 & 9.8 & 0.82 & 3.1 & 0.77 & 6.0 & 0.74 \\
\hline Offaly & 1.3 & 0.86 & 10.3 & 0.85 & 91.9 & 0.83 & 1.4 & 0.92 & 10.0 & 0.84 & 3.0 & 0.74 & 6.3 & 0.78 \\
\hline Louth & 1.3 & 0.84 & 10.7 & 0.88 & 101.5 & 0.91 & 1.4 & 0.90 & 10.0 & 0.84 & 2.7 & 0.66 & 5.8 & 0.71 \\
\hline Wexford & 1.3 & 0.83 & 9.1 & 0.75 & 99.2 & 0.89 & 1.2 & 0.75 & 9.2 & 0.77 & 2.7 & 0.66 & 5.5 & 0.67 \\
\hline Clare & 1.3 & 0.82 & 9.3 & 0.76 & 85.8 & 0.77 & 1.2 & 0.77 & 10.1 & 0.85 & 2.9 & 0.73 & 5.9 & 0.72 \\
\hline Meath & 1.2 & 0.76 & 12.0 & 0.99 & 129.6 & 1.17 & 1.6 & 1.05 & 11.1 & 0.93 & 3.5 & 0.88 & 7.8 & 0.96 \\
\hline Kilkenny & 1.2 & 0.75 & 8.6 & 0.71 & 73.9 & 0.66 & 1.3 & 0.82 & 9.3 & 0.78 & 2.6 & 0.65 & 5.3 & 0.65 \\
\hline Wicklow & 1.1 & 0.74 & 9.3 & 0.77 & 101.5 & 0.91 & 1.3 & 0.83 & 8.9 & 0.74 & 3.1 & 0.77 & 6.1 & 0.75 \\
\hline
\end{tabular}




\begin{tabular}{|c|c|c|c|c|c|c|c|c|c|c|c|c|c|c|}
\hline Kildare & 1.1 & 0.71 & 12.2 & 1.00 & 135.7 & 1.22 & 1.6 & 1.06 & 9.5 & 0.80 & 3.6 & 0.88 & 7.7 & 0.95 \\
\hline Carlow & 1.1 & 0.69 & 8.5 & 0.70 & 86.6 & 0.78 & 1.0 & 0.65 & 7.8 & 0.66 & 2.4 & 0.58 & 4.9 & 0.60 \\
\hline Ireland & 1.5 & 1.00 & 12.1 & 1.00 & 111.2 & 1.00 & 1.5 & 1.00 & 11.9 & 1.00 & 4.0 & 1.00 & 8.1 & 1.00 \\
\hline Gini coefficient & 0.120 & & 0.104 & & 0.104 & & 0.101 & & 0.109 & & 0.134 & & 0.125 & \\
\hline
\end{tabular}

Source: Data on the number of WTE publicly employed non-acute speech and language therapists are from the HSE's HSPC December 2014.

Notes: (a) Mortality-adjusted area populations are calculated by multiplying the area's 2014 population estimate by: area crude mortality rate 2014/national crude mortality rate 2014. (b) Area populations with disability are calculated by applying area disability rates from Census 2011 to area population estimates 2014. (c) Area populations with morbidity are the proportion of people with a full Medical Card who are receiving a prescription for a chronic health condition in 2014 applied to the number of people with a full Medical Card at December 2014. (d) The Gini coefficient summarises inequality in the distribution of SLTs across areas, with 0 representing complete equality across areas and 1 representing complete inequality across areas. 
TABLE A4-6 NUMBER OF WTE PUBLICLY EMPLOYED NON-ACUTE PODIATRISTS AND CHIROPODISTS (P\&CS) PER 10,000 TOTAL POPULATION AND NEEDSADJUSTED POPULATIONS BY GEOGRAPHIC AREA, IRELAND 2014

\begin{tabular}{|c|c|c|c|c|c|c|c|c|c|c|c|c|c|c|}
\hline \multirow[t]{2}{*}{$\begin{array}{l}\text { Geographic } \\
\text { area }\end{array}$} & \multicolumn{2}{|c|}{ Total population } & \multicolumn{2}{|c|}{$\begin{array}{c}\text { Population aged } 65+ \\
\text { years }\end{array}$} & \multicolumn{2}{|c|}{$\begin{array}{l}\text { Population aged } 85+ \\
\text { years }\end{array}$} & \multicolumn{2}{|c|}{$\begin{array}{l}\text { Mortality-adjusted } \\
\text { population }\end{array}$} & \multicolumn{2}{|c|}{$\begin{array}{l}\text { Population with } \\
\text { disability }\end{array}$} & \multicolumn{2}{|c|}{$\begin{array}{l}\text { Population with a } \\
\text { Medical Card }\end{array}$} & \multicolumn{2}{|c|}{$\begin{array}{c}\text { Population with } \\
\text { Medical Card and } \\
\text { prescription for chronic } \\
\text { condition }\end{array}$} \\
\hline & $\begin{array}{c}\text { WTE } \\
\text { P\&Cs per } \\
10,000\end{array}$ & $\begin{array}{l}\text { Ratio of } \\
\text { area } \\
\text { value to } \\
\text { national } \\
\text { value }\end{array}$ & $\begin{array}{c}\text { WTE } \\
\text { P\&Cs per } \\
10,000\end{array}$ & $\begin{array}{l}\text { Ratio of } \\
\text { area } \\
\text { value to } \\
\text { national } \\
\text { value }\end{array}$ & $\begin{array}{c}\text { WTE } \\
\text { P\&Cs per } \\
10,000\end{array}$ & $\begin{array}{l}\text { Ratio of } \\
\text { area } \\
\text { value to } \\
\text { national } \\
\text { value }\end{array}$ & $\begin{array}{c}\text { WTE } \\
\text { P\&CS per } \\
10,000\end{array}$ & $\begin{array}{l}\text { Ratio of } \\
\text { area } \\
\text { value to } \\
\text { national } \\
\text { value }\end{array}$ & $\begin{array}{c}\text { WTE } \\
\text { P\&Cs per } \\
10,000\end{array}$ & $\begin{array}{l}\text { Ratio of } \\
\text { area } \\
\text { value to } \\
\text { national } \\
\text { value }\end{array}$ & $\begin{array}{c}\text { WTE } \\
\text { P\&Cs per } \\
10,000\end{array}$ & $\begin{array}{c}\text { Ratio of } \\
\text { area } \\
\text { value to } \\
\text { national } \\
\text { value }\end{array}$ & $\begin{array}{c}\text { WTE } \\
\text { P\&Cs per } \\
10,000\end{array}$ & $\begin{array}{l}\text { Ratio of } \\
\text { area } \\
\text { value to } \\
\text { national } \\
\text { value }\end{array}$ \\
\hline Sligo & 0.37 & 5.04 & 2.40 & 4.22 & 17.48 & 3.35 & 0.31 & 4.22 & 5.04 & 4.63 & 0.85 & 4.48 & 1.67 & 4.39 \\
\hline Leitrim & 0.36 & 4.92 & 2.19 & 3.85 & 16.72 & 3.21 & 0.29 & 3.98 & 4.92 & 4.74 & 0.79 & 4.14 & 1.54 & 4.05 \\
\hline Galway & 0.25 & 3.46 & 1.99 & 3.50 & 16.40 & 3.14 & 0.27 & 3.69 & 3.46 & 3.74 & 0.65 & 3.44 & 1.35 & 3.54 \\
\hline Clare & 0.23 & 3.22 & 1.70 & 2.98 & 15.73 & 3.02 & 0.22 & 3.02 & 3.22 & 3.32 & 0.54 & 2.84 & 1.08 & 2.83 \\
\hline Monaghan & 0.20 & 2.76 & 1.47 & 2.58 & 12.41 & 2.38 & 0.17 & 2.41 & 2.76 & 3.02 & 0.45 & 2.37 & 0.92 & 2.42 \\
\hline Donegal & 0.18 & 2.55 & 1.24 & 2.18 & 10.36 & 1.99 & 0.17 & 2.35 & 2.55 & 2.36 & 0.35 & 1.83 & 0.75 & 1.96 \\
\hline Westmeath & 0.14 & 1.87 & 1.11 & 1.95 & 9.58 & 1.84 & 0.12 & 1.70 & 1.87 & 1.85 & 0.31 & 1.62 & 0.65 & 1.71 \\
\hline Cork & 0.13 & 1.85 & 1.03 & 1.80 & 9.60 & 1.84 & 0.13 & 1.81 & 1.85 & 1.83 & 0.36 & 1.92 & 0.69 & 1.81 \\
\hline Offaly & 0.12 & 1.59 & 0.89 & 1.56 & 7.94 & 1.52 & 0.12 & 1.70 & 1.59 & 1.54 & 0.26 & 1.36 & 0.54 & 1.43 \\
\hline $\begin{array}{l}\text { Tipperary } \\
\text { North }\end{array}$ & 0.10 & 1.36 & 0.68 & 1.19 & 6.08 & 1.17 & 0.08 & 1.07 & 1.36 & 1.29 & 0.27 & 1.41 & 0.50 & 1.32 \\
\hline Cavan & 0.08 & 1.12 & 0.61 & 1.08 & 4.65 & 0.89 & 0.07 & 1.02 & 1.12 & 1.22 & 0.19 & 0.98 & 0.38 & 1.01 \\
\hline Longford & 0.06 & 0.81 & 0.42 & 0.74 & 4.11 & 0.79 & 0.05 & 0.75 & 0.81 & 0.76 & 0.13 & 0.67 & 0.26 & 0.69 \\
\hline Meath & 0.05 & 0.68 & 0.50 & 0.88 & 5.43 & 1.04 & 0.07 & 0.94 & 0.68 & 0.83 & 0.15 & 0.78 & 0.33 & 0.86 \\
\hline Dublin South & 0.04 & 0.62 & 0.37 & 0.65 & 3.31 & 0.63 & 0.05 & 0.66 & 0.62 & 0.62 & 0.15 & 0.81 & 0.29 & 0.77 \\
\hline Carlow & 0.04 & 0.54 & 0.31 & 0.54 & 3.14 & 0.60 & 0.04 & 0.50 & 0.54 & 0.51 & 0.09 & 0.45 & 0.18 & 0.47 \\
\hline Mayo & 0.04 & 0.53 & 0.23 & 0.41 & 1.81 & 0.35 & 0.03 & 0.41 & 0.53 & 0.51 & 0.08 & 0.42 & 0.16 & 0.42 \\
\hline Kildare & 0.04 & 0.50 & 0.40 & 0.70 & 4.45 & 0.85 & 0.05 & 0.74 & 0.50 & 0.56 & 0.12 & 0.62 & 0.25 & 0.66 \\
\hline Kilkenny & 0.03 & 0.42 & 0.22 & 0.39 & 1.92 & 0.37 & 0.03 & 0.45 & 0.42 & 0.43 & 0.07 & 0.36 & 0.14 & 0.36 \\
\hline Wicklow & 0.01 & 0.19 & 0.11 & 0.20 & 1.22 & 0.23 & 0.02 & 0.21 & 0.19 & 0.19 & 0.04 & 0.20 & 0.07 & 0.19 \\
\hline Waterford & 0.01 & 0.12 & 0.06 & 0.11 & 0.60 & 0.12 & 0.01 & 0.10 & 0.12 & 0.11 & 0.02 & 0.11 & 0.04 & 0.10 \\
\hline Louth & 0.00 & 0.01 & 0.00 & 0.01 & 0.04 & 0.01 & 0.00 & 0.01 & 0.01 & 0.01 & 0.00 & 0.01 & 0.00 & 0.01 \\
\hline Dublin North & 0.00 & 0.00 & 0.00 & 0.00 & 0.00 & 0.00 & 0.00 & 0.00 & 0.00 & 0.00 & 0.00 & 0.00 & 0.00 & 0.00 \\
\hline Kerry & 0.00 & 0.00 & 0.00 & 0.00 & 0.00 & 0.00 & 0.00 & 0.00 & 0.00 & 0.00 & 0.00 & 0.00 & 0.00 & 0.00 \\
\hline Laois & 0.00 & 0.00 & 0.00 & 0.00 & 0.00 & 0.00 & 0.00 & 0.00 & 0.00 & 0.00 & 0.00 & 0.00 & 0.00 & 0.00 \\
\hline Limerick & 0.00 & 0.00 & 0.00 & 0.00 & 0.00 & 0.00 & 0.00 & 0.00 & 0.00 & 0.00 & 0.00 & 0.00 & 0.00 & 0.00 \\
\hline Roscommon & 0.00 & 0.00 & 0.00 & 0.00 & 0.00 & 0.00 & 0.00 & 0.00 & 0.00 & 0.00 & 0.00 & 0.00 & 0.00 & 0.00 \\
\hline
\end{tabular}




\begin{tabular}{|c|c|c|c|c|c|c|c|c|c|c|c|c|c|c|}
\hline \multirow[t]{2}{*}{$\begin{array}{l}\text { Geographic } \\
\text { area }\end{array}$} & \multicolumn{2}{|c|}{ Total population } & \multicolumn{2}{|c|}{$\begin{array}{c}\text { Population aged } 65+ \\
\text { years }\end{array}$} & \multicolumn{2}{|c|}{$\begin{array}{l}\text { Population aged } 85+ \\
\text { years }\end{array}$} & \multicolumn{2}{|c|}{$\begin{array}{l}\text { Mortality-adjusted } \\
\text { population }\end{array}$} & \multicolumn{2}{|c|}{$\begin{array}{l}\text { Population with } \\
\text { disability }\end{array}$} & \multicolumn{2}{|c|}{$\begin{array}{l}\text { Population with a } \\
\text { Medical Card }\end{array}$} & \multicolumn{2}{|c|}{$\begin{array}{l}\text { Population with } \\
\text { Medical Card and } \\
\text { prescription for chronic } \\
\text { condition }\end{array}$} \\
\hline & $\begin{array}{c}\text { WTE } \\
\text { P\&Cs per } \\
10,000\end{array}$ & $\begin{array}{l}\text { Ratio of } \\
\text { area } \\
\text { value to } \\
\text { national } \\
\text { value }\end{array}$ & $\begin{array}{c}\text { WTE } \\
\text { P\&Cs per } \\
10,000\end{array}$ & $\begin{array}{l}\text { Ratio of } \\
\text { area } \\
\text { value to } \\
\text { national } \\
\text { value }\end{array}$ & $\begin{array}{c}\text { WTE } \\
\text { P\&Cs per } \\
10,000\end{array}$ & $\begin{array}{l}\text { Ratio of } \\
\text { area } \\
\text { value to } \\
\text { national } \\
\text { value }\end{array}$ & $\begin{array}{c}\text { WTE } \\
\text { P\&Cs per } \\
10,000\end{array}$ & $\begin{array}{l}\text { Ratio of } \\
\text { area } \\
\text { value to } \\
\text { national } \\
\text { value }\end{array}$ & $\begin{array}{c}\text { WTE } \\
\text { P\&Cs per } \\
10,000\end{array}$ & $\begin{array}{l}\text { Ratio of } \\
\text { area } \\
\text { value to } \\
\text { national } \\
\text { value }\end{array}$ & $\begin{array}{c}\text { WTE } \\
\text { P\&CS per } \\
10,000\end{array}$ & $\begin{array}{l}\text { Ratio of } \\
\text { area } \\
\text { value to } \\
\text { national } \\
\text { value }\end{array}$ & $\begin{array}{c}\text { WTE } \\
\text { P\&Cs per } \\
10,000\end{array}$ & $\begin{array}{l}\text { Ratio of } \\
\text { area } \\
\text { value to } \\
\text { national } \\
\text { value }\end{array}$ \\
\hline $\begin{array}{l}\text { Tipperary } \\
\text { South }\end{array}$ & 0.00 & 0.00 & 0.00 & 0.00 & 0.00 & 0.00 & 0.00 & 0.00 & 0.00 & 0.00 & 0.00 & 0.00 & 0.00 & 0.00 \\
\hline Wexford & 0.00 & 0.00 & 0.00 & 0.00 & 0.00 & 0.00 & 0.00 & 0.00 & 0.00 & 0.00 & 0.00 & 0.00 & 0.00 & 0.00 \\
\hline Ireland & 0.07 & 1.00 & 0.57 & 1.00 & 5.22 & 1.00 & 0.07 & 1.00 & 1.00 & 1.00 & 0.19 & 1.00 & 0.38 & 1.00 \\
\hline Gini coefficient & 0.615 & & 0.594 & & 0.571 & & 0.596 & & 0.610 & & 0.605 & & 0.601 & \\
\hline
\end{tabular}

Source: Data on the number of WTE publicly employed non-acute podiatrists and chiropodists are from the HSE's HSPC December 2014.

Notes: (a) Mortality-adjusted area populations are calculated by multiplying the area's 2014 population estimate by: area crude mortality rate 2014/national crude mortality rate 2014. (b) Area populations with disability are calculated by applying area disability rates from Census 2011 to area population estimates 2014 . (c) Area populations with morbidity are the proportion of people populations with disability are calculated by applying area disability rates from Census 2011 to area population estimates 2014. (c) Area populations with morbidity are the proportion of people
with a full Medical Card who are receiving a prescription for a chronic health condition in 2014 applied to the number of people with a full Medical Card at December 2014 . (d) The Gini coefficient summarises inequality in the distribution of $P \& C s$ across areas, with 0 representing complete equality across areas and 1 representing complete inequality across areas. 
TABLE A4-7 NUMBER OF WTE PUBLICLY EMPLOYED NON-ACUTE COUNSELLORS AND PSYCHOLOGISTS (CO\&PSYS) PER 10,000 TOTAL POPULATION AND NEEDS-ADJUSTED POPULATIONS BY GEOGRAPHIC AREA, IRELAND 2014

\begin{tabular}{|c|c|c|c|c|c|c|c|c|c|c|c|c|c|c|}
\hline \multirow[t]{2}{*}{$\begin{array}{l}\text { Geographic } \\
\text { area }\end{array}$} & \multicolumn{2}{|c|}{ Total population } & \multicolumn{2}{|c|}{$\begin{array}{c}\text { Population aged } 65+ \\
\text { years }\end{array}$} & \multicolumn{2}{|c|}{$\begin{array}{c}\text { Population aged } 85+ \\
\text { years }\end{array}$} & \multicolumn{2}{|c|}{$\begin{array}{l}\text { Mortality-adjusted } \\
\text { population }\end{array}$} & \multicolumn{2}{|c|}{$\begin{array}{l}\text { Population with } \\
\text { disability }\end{array}$} & \multicolumn{2}{|c|}{$\begin{array}{l}\text { Population with a } \\
\text { Medical Card }\end{array}$} & \multicolumn{2}{|c|}{$\begin{array}{l}\text { Population with } \\
\text { Medical Card and } \\
\text { prescription for chronic } \\
\text { condition }\end{array}$} \\
\hline & $\begin{array}{c}\text { WTE } \\
\text { CO\&PSYs } \\
\text { per } \\
10,000\end{array}$ & $\begin{array}{l}\text { Ratio of } \\
\text { area } \\
\text { value to } \\
\text { national } \\
\text { value }\end{array}$ & $\begin{array}{c}\text { WTE } \\
\text { cO\&PSYs } \\
\text { per } \\
10,000\end{array}$ & $\begin{array}{l}\text { Ratio of } \\
\text { area } \\
\text { value to } \\
\text { national } \\
\text { value }\end{array}$ & $\begin{array}{c}\text { WTE } \\
\text { CO\&PSYs } \\
\text { per } \\
10,000\end{array}$ & $\begin{array}{l}\text { Ratio of } \\
\text { area } \\
\text { value to } \\
\text { national } \\
\text { value }\end{array}$ & $\begin{array}{c}\text { WTE } \\
\text { CO\&PSYs } \\
\text { per } \\
10,000\end{array}$ & $\begin{array}{l}\text { Ratio of } \\
\text { area } \\
\text { value to } \\
\text { national } \\
\text { value }\end{array}$ & $\begin{array}{c}\text { WTE } \\
\text { CO\&PSYs } \\
\text { per } \\
10,000\end{array}$ & $\begin{array}{l}\text { Ratio of } \\
\text { area } \\
\text { value to } \\
\text { national } \\
\text { value }\end{array}$ & $\begin{array}{c}\text { WTE } \\
\text { CO\&PSYs } \\
\text { per } \\
10,000\end{array}$ & $\begin{array}{l}\text { Ratio of } \\
\text { area } \\
\text { value to } \\
\text { national } \\
\text { value }\end{array}$ & $\begin{array}{c}\text { WTE } \\
\text { CO\&PSYs } \\
\text { per } \\
10,000\end{array}$ & $\begin{array}{c}\text { Ratio of } \\
\text { area } \\
\text { value to } \\
\text { national } \\
\text { value }\end{array}$ \\
\hline Leitrim & 2.5 & 1.40 & 15.1 & 1.10 & 114.9 & 0.91 & 2.0 & 1.13 & 18.2 & 1.35 & 5.4 & 1.18 & 10.6 & 1.15 \\
\hline Sligo & 2.4 & 1.39 & 16.1 & 1.17 & 117.0 & 0.93 & 2.0 & 1.17 & 17.3 & 1.28 & 5.7 & 1.24 & 11.2 & 1.22 \\
\hline Westmeath & 2.4 & 1.38 & 19.8 & 1.44 & 170.7 & 1.35 & 2.2 & 1.25 & 18.4 & 1.37 & 5.5 & 1.20 & 11.6 & 1.26 \\
\hline Laois & 2.4 & 1.38 & 21.6 & 1.57 & 197.5 & 1.57 & 2.8 & 1.59 & 19.0 & 1.41 & 5.6 & 1.22 & 12.3 & 1.34 \\
\hline Louth & 2.3 & 1.34 & 19.3 & 1.41 & 183.2 & 1.45 & 2.5 & 1.43 & 18.1 & 1.34 & 4.8 & 1.05 & 10.4 & 1.13 \\
\hline Limerick & 2.1 & 1.22 & 16.1 & 1.17 & 168.1 & 1.33 & 1.8 & 1.05 & 15.0 & 1.11 & 5.1 & 1.10 & 9.8 & 1.07 \\
\hline Dublin North & 2.1 & 1.17 & 18.3 & 1.33 & 178.9 & 1.42 & 2.2 & 1.25 & 15.8 & 1.17 & 6.2 & 1.36 & 12.8 & 1.39 \\
\hline Longford & 2.0 & 1.17 & 14.5 & 1.06 & 142.8 & 1.13 & 1.9 & 1.08 & 14.8 & 1.09 & 4.4 & 0.96 & 9.1 & 0.99 \\
\hline Cork & 2.0 & 1.15 & 15.4 & 1.12 & 144.0 & 1.14 & 2.0 & 1.12 & 15.3 & 1.14 & 5.5 & 1.19 & 10.4 & 1.13 \\
\hline Galway & 1.9 & 1.11 & 15.4 & 1.12 & 126.8 & 1.01 & 2.1 & 1.18 & 16.1 & 1.20 & 5.1 & 1.10 & 10.4 & 1.13 \\
\hline Donegal & 1.9 & 1.10 & 13.0 & 0.94 & 108.3 & 0.86 & 1.8 & 1.02 & 13.8 & 1.02 & 3.6 & 0.79 & 7.8 & 0.85 \\
\hline Dublin South & 1.8 & 1.05 & 15.2 & 1.11 & 135.9 & 1.08 & 2.0 & 1.13 & 14.2 & 1.05 & 6.3 & 1.37 & 12.0 & 1.31 \\
\hline Wexford & 1.8 & 1.03 & 12.8 & 0.93 & 139.9 & 1.11 & 1.6 & 0.94 & 13.0 & 0.96 & 3.8 & 0.82 & 7.7 & 0.84 \\
\hline Mayo & 1.7 & 0.96 & 10.3 & 0.75 & 79.2 & 0.63 & 1.3 & 0.74 & 12.5 & 0.92 & 3.5 & 0.76 & 7.1 & 0.77 \\
\hline $\begin{array}{l}\text { Tipperary } \\
\text { South }\end{array}$ & 1.7 & 0.96 & 11.4 & 0.83 & 101.6 & 0.81 & 1.5 & 0.85 & 11.4 & 0.85 & 4.5 & 0.99 & 8.5 & 0.92 \\
\hline Offaly & 1.6 & 0.91 & 12.3 & 0.90 & 110.6 & 0.88 & 1.7 & 0.98 & 12.0 & 0.89 & 3.6 & 0.79 & 7.6 & 0.82 \\
\hline Kilkenny & 1.6 & 0.90 & 11.7 & 0.85 & 100.4 & 0.80 & 1.7 & 0.98 & 12.6 & 0.94 & 3.6 & 0.78 & 7.2 & 0.78 \\
\hline Waterford & 1.5 & 0.86 & 10.5 & 0.77 & 103.4 & 0.82 & 1.3 & 0.75 & 11.0 & 0.81 & 3.5 & 0.76 & 6.8 & 0.73 \\
\hline $\begin{array}{l}\text { Tipperary } \\
\text { North }\end{array}$ & 1.4 & 0.77 & 9.3 & 0.68 & 83.6 & 0.66 & 1.1 & 0.61 & 9.9 & 0.73 & 3.7 & 0.80 & 6.9 & 0.75 \\
\hline Roscommon & 1.3 & 0.77 & 8.3 & 0.60 & 59.8 & 0.47 & 1.1 & 0.62 & 9.8 & 0.73 & 3.0 & 0.65 & 5.7 & 0.62 \\
\hline Clare & 1.3 & 0.76 & 9.7 & 0.71 & 90.2 & 0.72 & 1.3 & 0.72 & 10.6 & 0.79 & 3.1 & 0.67 & 6.2 & 0.67 \\
\hline Meath & 1.2 & 0.69 & 12.3 & 0.90 & 133.0 & 1.06 & 1.7 & 0.95 & 11.4 & 0.84 & 3.6 & 0.79 & 8.0 & 0.87 \\
\hline Carlow & 1.2 & 0.69 & 9.6 & 0.70 & 97.6 & 0.77 & 1.1 & 0.64 & 8.8 & 0.65 & 2.7 & 0.58 & 5.5 & 0.60 \\
\hline Wicklow & 1.1 & 0.61 & 8.7 & 0.63 & 95.3 & 0.76 & 1.2 & 0.69 & 8.3 & 0.62 & 2.9 & 0.64 & 5.7 & 0.62 \\
\hline Monaghan & 1.1 & 0.60 & 7.7 & 0.56 & 65.1 & 0.52 & 0.9 & 0.52 & 8.8 & 0.66 & 2.4 & 0.51 & 4.8 & 0.52 \\
\hline Kildare & 1.0 & 0.56 & 10.8 & 0.78 & 120.3 & 0.95 & 1.4 & 0.83 & 8.4 & 0.62 & 3.2 & 0.69 & 6.8 & 0.74 \\
\hline
\end{tabular}




\begin{tabular}{|c|c|c|c|c|c|c|c|c|c|c|c|c|c|c|}
\hline \multirow[t]{2}{*}{$\begin{array}{l}\text { Geographic } \\
\text { area }\end{array}$} & \multicolumn{2}{|c|}{ Total population } & \multicolumn{2}{|c|}{$\begin{array}{l}\text { Population aged } 65+ \\
\text { years }\end{array}$} & \multicolumn{2}{|c|}{$\begin{array}{l}\text { Population aged } 85+ \\
\text { years }\end{array}$} & \multicolumn{2}{|c|}{$\begin{array}{l}\text { Mortality-adjusted } \\
\text { population }\end{array}$} & \multicolumn{2}{|c|}{$\begin{array}{l}\text { Population with } \\
\text { disability }\end{array}$} & \multicolumn{2}{|c|}{$\begin{array}{l}\text { Population with a } \\
\text { Medical Card }\end{array}$} & \multicolumn{2}{|c|}{$\begin{array}{c}\text { Population with } \\
\text { Medical Card and } \\
\text { prescription for chronic } \\
\text { condition }\end{array}$} \\
\hline & $\begin{array}{c}\text { WTE } \\
\text { CO\&PSYs } \\
\text { per } \\
10,000\end{array}$ & $\begin{array}{c}\text { Ratio of } \\
\text { area } \\
\text { value to } \\
\text { national } \\
\text { value }\end{array}$ & $\begin{array}{c}\text { WTE } \\
\text { CO\&PSYs } \\
\text { per } \\
10,000\end{array}$ & $\begin{array}{l}\text { Ratio of } \\
\text { area } \\
\text { value to } \\
\text { national } \\
\text { value }\end{array}$ & $\begin{array}{c}\text { WTE } \\
\text { CO\&PSYs } \\
\text { per } \\
10,000\end{array}$ & $\begin{array}{l}\text { Ratio of } \\
\text { area } \\
\text { value to } \\
\text { national } \\
\text { value }\end{array}$ & $\begin{array}{c}\text { WTE } \\
\text { CO\&PSYs } \\
\text { per } \\
10,000\end{array}$ & $\begin{array}{l}\text { Ratio of } \\
\text { area } \\
\text { value to } \\
\text { national } \\
\text { value }\end{array}$ & $\begin{array}{c}\text { WTE } \\
\text { CO\&PSYs } \\
\text { per } \\
10,000\end{array}$ & $\begin{array}{l}\text { Ratio of } \\
\text { area } \\
\text { value to } \\
\text { national } \\
\text { value }\end{array}$ & $\begin{array}{c}\text { WTE } \\
\text { CO\&PSYs } \\
\text { per } \\
10,000\end{array}$ & $\begin{array}{l}\text { Ratio of } \\
\text { area } \\
\text { value to } \\
\text { national } \\
\text { value }\end{array}$ & $\begin{array}{c}\text { WTE } \\
\text { CO\&PSYs } \\
\text { per } \\
10,000\end{array}$ & $\begin{array}{l}\text { Ratio of } \\
\text { area } \\
\text { value to } \\
\text { national } \\
\text { value }\end{array}$ \\
\hline Kerry & 0.9 & 0.52 & 5.7 & 0.41 & 52.0 & 0.41 & 0.7 & 0.41 & 6.9 & 0.51 & 2.2 & 0.48 & 4.2 & 0.46 \\
\hline Cavan & 0.9 & 0.51 & 6.8 & 0.49 & 51.3 & 0.41 & 0.8 & 0.47 & 7.5 & 0.56 & 2.0 & 0.45 & 4.2 & 0.46 \\
\hline Ireland & 1.8 & 1.00 & 13.8 & 1.00 & 126.1 & 1.00 & 1.8 & 1.00 & 13.5 & 1.00 & 4.6 & 1.0 & 9.2 & 1.00 \\
\hline Gini coefficient & 0.168 & & 0.178 & & 0.189 & & 0.175 & & 0.159 & & 0.170 & & 0.172 & \\
\hline
\end{tabular}

Source: Data on the number of WTE publicly employed non-acute counsellors and psychologists are from the HSE's HSPC December 2014

Notes: (a) Mortality-adjusted area populations are calculated by multiplying the area's 2014 population estimate by: area crude mortality rate 2014/national crude mortality rate 2014. (b) Area populations with disability are calculated by applying area disability rates from Census 2011 to area population estimates 2014. (c) Area populations with morbidity are the proportion of people with a full Medical Card who are receiving a prescription for a chronic health condition in 2014 applied to the number of people with a full Medical Card at December 2014. (d) The Gini coefficient summarises inequality in the distribution of CO\&PSYs across areas, with 0 representing complete equality across areas and 1 representing complete inequality across areas. 
TABLE A4-8 NUMBER OF WTE PUBLICLY EMPLOYED NON-ACUTE SOCIAL WORKERS (SWS) PER 10,000 TOTAL POPULATION AND NEEDS-ADJUSTED POPULATIONS BY GEOGRAPHIC AREA, IRELAND 2014

\begin{tabular}{|c|c|c|c|c|c|c|c|c|c|c|c|c|c|c|}
\hline \multirow[t]{2}{*}{$\begin{array}{l}\text { Geographic } \\
\text { area }\end{array}$} & \multicolumn{2}{|c|}{ Total population } & \multicolumn{2}{|c|}{$\begin{array}{c}\text { Population aged } 65+ \\
\text { years }\end{array}$} & \multicolumn{2}{|c|}{$\begin{array}{c}\text { Population aged } 85+ \\
\text { years }\end{array}$} & \multicolumn{2}{|c|}{$\begin{array}{l}\text { Mortality-adjusted } \\
\text { population }\end{array}$} & \multicolumn{2}{|c|}{$\begin{array}{l}\text { Population with } \\
\text { disability }\end{array}$} & \multicolumn{2}{|c|}{$\begin{array}{l}\text { Population with a } \\
\text { Medical Card }\end{array}$} & \multicolumn{2}{|c|}{$\begin{array}{l}\text { Population with } \\
\text { Medical Card and } \\
\text { prescription for } \\
\text { chronic condition }\end{array}$} \\
\hline & $\begin{array}{c}\text { WTE SWs } \\
\text { per } \\
10,000\end{array}$ & $\begin{array}{c}\text { Ratio of } \\
\text { area } \\
\text { value to } \\
\text { national } \\
\text { value }\end{array}$ & $\begin{array}{c}\text { WTE SWs } \\
\text { per } \\
10,000\end{array}$ & $\begin{array}{c}\text { Ratio of } \\
\text { area } \\
\text { value to } \\
\text { national } \\
\text { value }\end{array}$ & $\begin{array}{c}\text { WTE SWs } \\
\text { per } \\
10,000\end{array}$ & $\begin{array}{c}\text { Ratio of } \\
\text { area } \\
\text { value to } \\
\text { national } \\
\text { value }\end{array}$ & $\begin{array}{c}\text { WTE SWs } \\
\text { per } \\
10,000\end{array}$ & $\begin{array}{c}\text { Ratio of } \\
\text { area } \\
\text { value to } \\
\text { national } \\
\text { value }\end{array}$ & $\begin{array}{c}\text { WTE SWs } \\
\text { per } \\
10,000\end{array}$ & $\begin{array}{c}\text { Ratio of } \\
\text { area } \\
\text { value to } \\
\text { national } \\
\text { value }\end{array}$ & $\begin{array}{c}\text { WTE SWs } \\
\text { per } \\
10,000\end{array}$ & $\begin{array}{l}\text { Ratio of } \\
\text { area } \\
\text { value to } \\
\text { national } \\
\text { value }\end{array}$ & $\begin{array}{c}\text { WTE SWs } \\
\text { per } \\
10,000\end{array}$ & $\begin{array}{c}\text { Ratio of } \\
\text { area } \\
\text { value to } \\
\text { national } \\
\text { value }\end{array}$ \\
\hline Sligo & 2.5 & 1.68 & 16.5 & 1.40 & 120.0 & 1.12 & 2.1 & 1.40 & 17.8 & 1.54 & 5.8 & 1.49 & 11.5 & 1.46 \\
\hline Louth & 2.4 & 1.59 & 19.7 & 1.68 & 186.4 & 1.73 & 2.5 & 1.70 & 18.4 & 1.59 & 4.9 & 1.25 & 10.6 & 1.35 \\
\hline Leitrim & 2.2 & 1.50 & 13.8 & 1.17 & 105.1 & 0.98 & 1.8 & 1.21 & 16.7 & 1.45 & 4.9 & 1.26 & 9.7 & 1.24 \\
\hline Laois & 2.1 & 1.38 & 18.5 & 1.57 & 168.7 & 1.57 & 2.4 & 1.59 & 16.3 & 1.41 & 4.8 & 1.23 & 10.5 & 1.34 \\
\hline Donegal & 2.0 & 1.33 & 13.3 & 1.14 & 111.1 & 1.03 & 1.8 & 1.22 & 14.1 & 1.22 & 3.7 & 0.95 & 8.0 & 1.02 \\
\hline Dublin South & 1.9 & 1.28 & 15.8 & 1.34 & 140.7 & 1.31 & 2.0 & 1.37 & 14.7 & 1.28 & 6.5 & 1.66 & 12.4 & 1.58 \\
\hline Galway & 1.8 & 1.21 & 14.3 & 1.22 & 117.9 & 1.10 & 1.9 & 1.29 & 15.0 & 1.30 & 4.7 & 1.20 & 9.7 & 1.23 \\
\hline Roscommon & 1.7 & 1.16 & 10.7 & 0.91 & 77.0 & 0.72 & 1.4 & 0.94 & 12.7 & 1.10 & 3.8 & 0.97 & 7.4 & 0.94 \\
\hline $\begin{array}{l}\text { Tipperary } \\
\text { South }\end{array}$ & 1.7 & 1.13 & 11.4 & 0.97 & 101.9 & 0.95 & 1.5 & 0.99 & 11.5 & 0.99 & 4.6 & 1.16 & 8.5 & 1.08 \\
\hline Dublin North & 1.7 & 1.12 & 14.9 & 1.27 & 146.1 & 1.36 & 1.8 & 1.20 & 12.9 & 1.12 & 5.1 & 1.30 & 10.4 & 1.33 \\
\hline Monaghan & 1.6 & 1.09 & 12.0 & 1.02 & 101.4 & 0.94 & 1.4 & 0.95 & 13.8 & 1.19 & 3.7 & 0.94 & 7.5 & 0.96 \\
\hline Westmeath & 1.5 & 1.02 & 12.5 & 1.06 & 107.5 & 1.00 & 1.4 & 0.93 & 11.6 & 1.01 & 3.5 & 0.88 & 7.3 & 0.93 \\
\hline Limerick & 1.5 & 1.01 & 11.4 & 0.97 & 118.9 & 1.10 & 1.3 & 0.87 & 10.6 & 0.92 & 3.6 & 0.92 & 6.9 & 0.88 \\
\hline Kerry & 1.5 & 1.01 & 9.4 & 0.80 & 86.4 & 0.80 & 1.2 & 0.79 & 11.5 & 0.99 & 3.7 & 0.94 & 7.0 & 0.90 \\
\hline Waterford & 1.5 & 0.98 & 10.2 & 0.87 & 100.1 & 0.93 & 1.3 & 0.85 & 10.6 & 0.92 & 3.4 & 0.86 & 6.5 & 0.83 \\
\hline Cavan & 1.4 & 0.96 & 10.9 & 0.93 & 82.3 & 0.77 & 1.3 & 0.88 & 12.1 & 1.05 & 3.3 & 0.84 & 6.8 & 0.86 \\
\hline Cork & 1.4 & 0.96 & 10.9 & 0.93 & 102.1 & 0.95 & 1.4 & 0.93 & 10.9 & 0.94 & 3.9 & 0.99 & 7.4 & 0.94 \\
\hline Clare & 1.1 & 0.76 & 8.3 & 0.70 & 76.6 & 0.71 & 1.1 & 0.71 & 9.0 & 0.78 & 2.6 & 0.67 & 5.2 & 0.67 \\
\hline Mayo & 1.0 & 0.64 & 5.9 & 0.50 & 45.2 & 0.42 & 0.7 & 0.49 & 7.1 & 0.62 & 2.0 & 0.51 & 4.0 & 0.51 \\
\hline Kildare & 0.9 & 0.61 & 10.2 & 0.87 & 113.3 & 1.05 & 1.4 & 0.91 & 7.9 & 0.69 & 3.0 & 0.76 & 6.4 & 0.82 \\
\hline Kilkenny & 0.9 & 0.61 & 6.8 & 0.58 & 57.7 & 0.54 & 1.0 & 0.66 & 7.3 & 0.63 & 2.0 & 0.52 & 4.1 & 0.53 \\
\hline $\begin{array}{l}\text { Tipperary } \\
\text { North }\end{array}$ & 0.9 & 0.60 & 6.2 & 0.52 & 55.4 & 0.51 & 0.7 & 0.47 & 6.5 & 0.57 & 2.4 & 0.62 & 4.6 & 0.58 \\
\hline Wexford & 0.9 & 0.57 & 6.1 & 0.52 & 66.8 & 0.62 & 0.8 & 0.52 & 6.2 & 0.54 & 1.8 & 0.46 & 3.7 & 0.47 \\
\hline Wicklow & 0.8 & 0.54 & 6.6 & 0.56 & 72.2 & 0.67 & 0.9 & 0.61 & 6.3 & 0.55 & 2.2 & 0.57 & 4.3 & 0.55 \\
\hline
\end{tabular}




\begin{tabular}{|c|c|c|c|c|c|c|c|c|c|c|c|c|c|c|}
\hline \multirow[t]{2}{*}{$\begin{array}{l}\text { Geographic } \\
\text { area }\end{array}$} & \multicolumn{2}{|c|}{ Total population } & \multicolumn{2}{|c|}{$\begin{array}{l}\text { Population aged 65+ } \\
\text { years }\end{array}$} & \multicolumn{2}{|c|}{$\begin{array}{l}\text { Population aged } 85+ \\
\text { years }\end{array}$} & \multicolumn{2}{|c|}{$\begin{array}{l}\text { Mortality-adjusted } \\
\text { population }\end{array}$} & \multicolumn{2}{|c|}{$\begin{array}{l}\text { Population with } \\
\text { disability }\end{array}$} & \multicolumn{2}{|c|}{$\begin{array}{l}\text { Population with a } \\
\text { Medical Card }\end{array}$} & \multicolumn{2}{|c|}{$\begin{array}{l}\text { Population with } \\
\text { Medical Card and } \\
\text { prescription for } \\
\text { chronic condition }\end{array}$} \\
\hline & $\begin{array}{c}\text { WTE SWs } \\
\text { per } \\
10,000\end{array}$ & $\begin{array}{l}\text { Ratio of } \\
\text { area } \\
\text { value to } \\
\text { national } \\
\text { value }\end{array}$ & $\begin{array}{c}\text { WTE SWs } \\
\text { per } \\
10,000\end{array}$ & $\begin{array}{c}\text { Ratio of } \\
\text { area } \\
\text { value to } \\
\text { national } \\
\text { value }\end{array}$ & $\begin{array}{c}\text { WTE SWs } \\
\text { per } \\
10,000\end{array}$ & $\begin{array}{c}\text { Ratio of } \\
\text { area } \\
\text { value to } \\
\text { national } \\
\text { value }\end{array}$ & $\begin{array}{c}\text { WTE SWs } \\
\text { per } \\
10,000\end{array}$ & $\begin{array}{l}\text { Ratio of } \\
\text { area } \\
\text { value to } \\
\text { national } \\
\text { value }\end{array}$ & $\begin{array}{c}\text { WTE SWs } \\
\text { per } \\
10,000\end{array}$ & $\begin{array}{c}\text { Ratio of } \\
\text { area } \\
\text { value to } \\
\text { national } \\
\text { value }\end{array}$ & $\begin{array}{c}\text { WTE SWs } \\
\text { per } \\
10,000\end{array}$ & $\begin{array}{c}\text { Ratio of } \\
\text { area } \\
\text { value to } \\
\text { national } \\
\text { value }\end{array}$ & $\begin{array}{c}\text { WTE SWs } \\
\text { per } \\
10,000\end{array}$ & $\begin{array}{c}\text { Ratio of } \\
\text { area } \\
\text { value to } \\
\text { national } \\
\text { value }\end{array}$ \\
\hline Offaly & 0.8 & 0.53 & 6.1 & 0.52 & 54.3 & 0.50 & 0.8 & 0.56 & 5.9 & 0.51 & 1.8 & 0.45 & 3.7 & 0.47 \\
\hline Meath & 0.7 & 0.49 & 7.5 & 0.64 & 81.2 & 0.75 & 1.0 & 0.68 & 6.9 & 0.60 & 2.2 & 0.57 & 4.9 & 0.62 \\
\hline Longford & 0.7 & 0.49 & 5.2 & 0.44 & 51.1 & 0.48 & 0.7 & 0.45 & 5.3 & 0.46 & 1.6 & 0.40 & 3.3 & 0.42 \\
\hline Carlow & 0.6 & 0.37 & 4.4 & 0.38 & 44.9 & 0.42 & 0.5 & 0.35 & 4.1 & 0.35 & 1.2 & 0.31 & 2.5 & 0.32 \\
\hline Ireland & 1.5 & 1.00 & 11.7 & 1.00 & 107.6 & 1.00 & 1.5 & 1.00 & 11.5 & 1.00 & 3.9 & 1.00 & 7.9 & 1.00 \\
\hline Gini coefficient & 0.214 & & 0.215 & & 0.205 & & 0.215 & & 0.211 & & 0.220 & & 0.218 & \\
\hline
\end{tabular}

Source: Data on the number of WTE publicly employed non-acute social workers are from the HSE's HSPC December 2014.

Notes: (a) Mortality-adjusted area populations are calculated by multiplying the area's 2014 population estimate by: area crude mortality rate 2014/national crude mortality rate 2014. (b) Area populations with disability are calculated by applying area disability rates from Census 2011 to area population estimates 2014. (c) Area populations with morbidity are the proportion of people populations with disability are calculated by applying area disability rates from Census 2011 to area population estimates 2014. (c) Area populations with morbidity are the proportion of people
with a full Medical Card who are receiving a prescription for a chronic health condition in 2014 applied to the number of people with a full Medical Card at December 2014. (d) The Gini coefficient summarises inequality in the distribution of SWs across areas with 0 representing complete equality across areas and 1 representing complete inequality across areas. 
TABLE A4.9 NUMBER OF LONG-TERM RESIDENTIAL CARE BEDS PER 1,000 POPULATION AGED 65+ YEARS AND NEEDS-ADJUSTED POPULATIONS AGED 65+ YEARS BY GEOGRAPHIC AREA, IRELAND 2014

\begin{tabular}{|c|c|c|c|c|c|c|c|c|}
\hline \multirow[t]{2}{*}{ Geographic area } & \multicolumn{2}{|c|}{$\begin{array}{c}\text { Population aged } 65+ \\
\text { years }\end{array}$} & \multicolumn{2}{|c|}{$\begin{array}{c}\text { Mortality-adjusted } \\
\text { population aged } 65+ \\
\text { years }\end{array}$} & \multicolumn{2}{|c|}{$\begin{array}{c}\text { Population aged } 85+ \\
\text { years }\end{array}$} & \multicolumn{2}{|c|}{$\begin{array}{c}\text { Population with } \\
\text { disability aged } 65+\text { years }\end{array}$} \\
\hline & $\begin{array}{c}\text { Number } \\
\text { of beds } \\
\text { per } 1,000\end{array}$ & $\begin{array}{c}\text { Ratio of } \\
\text { area value } \\
\text { to national } \\
\text { value }\end{array}$ & $\begin{array}{c}\text { Number of } \\
\text { beds per } \\
1,000\end{array}$ & $\begin{array}{c}\text { Ratio of } \\
\text { area value } \\
\text { to national } \\
\text { value }\end{array}$ & $\begin{array}{l}\text { Number of } \\
\text { beds per } \\
1,000\end{array}$ & $\begin{array}{c}\text { Ratio of } \\
\text { area value } \\
\text { to national } \\
\text { value }\end{array}$ & $\begin{array}{c}\text { Number of } \\
\text { beds per } \\
1,000\end{array}$ & $\begin{array}{c}\text { Ratio of } \\
\text { area value } \\
\text { to national } \\
\text { value }\end{array}$ \\
\hline Kildare & 75.5 & 1.52 & 836.5 & 1.68 & 841.9 & 1.85 & $1,983.0$ & 1.51 \\
\hline Roscommon & 65.6 & 1.32 & 651.9 & 1.31 & 474.0 & 1.04 & $1,739.6$ & 1.32 \\
\hline Tipperary North & 62.5 & 1.26 & 557.2 & 1.12 & 561.7 & 1.23 & $1,638.7$ & 1.24 \\
\hline Galway & 57.1 & 1.15 & 602.1 & 1.21 & 470.7 & 1.03 & $1,583.9$ & 1.20 \\
\hline Wicklow & 57.0 & 1.15 & 619.8 & 1.25 & 622.2 & 1.36 & $1,541.9$ & 1.17 \\
\hline Westmeath & 57.0 & 1.14 & 496.1 & 1.00 & 491.5 & 1.08 & $1,513.6$ & 1.15 \\
\hline Kilkenny & 55.9 & 1.12 & 624.1 & 1.25 & 477.9 & 1.05 & $1,537.1$ & 1.17 \\
\hline Cavan & 54.7 & 1.10 & 497.5 & 1.00 & 413.7 & 0.91 & $1,510.8$ & 1.15 \\
\hline Longford & 54.7 & 1.10 & 544.3 & 1.09 & 537.2 & 1.18 & $1,475.2$ & 1.12 \\
\hline Carlow & 54.3 & 1.09 & 502.6 & 1.01 & 553.2 & 1.21 & $1,411.8$ & 1.07 \\
\hline Offaly & 53.8 & 1.08 & 593.8 & 1.19 & 481.8 & 1.06 & $1,386.9$ & 1.05 \\
\hline Limerick & 53.3 & 1.07 & 483.6 & 0.97 & 556.5 & 1.22 & $1,398.4$ & 1.06 \\
\hline Clare & 52.8 & 1.06 & 524.0 & 1.05 & 489.0 & 1.07 & $1,482.8$ & 1.13 \\
\hline Cork & 52.5 & 1.06 & 526.6 & 1.06 & 491.1 & 1.08 & $1,438.7$ & 1.09 \\
\hline Leitrim & 51.0 & 1.02 & 486.4 & 0.98 & 388.8 & 0.85 & $1,414.2$ & 1.07 \\
\hline Meath & 50.5 & 1.01 & 548.2 & 1.10 & 544.5 & 1.19 & $1,456.0$ & 1.11 \\
\hline Louth & 47.0 & 0.94 & 486.8 & 0.98 & 444.7 & 0.97 & $1,221.4$ & 0.93 \\
\hline Mayo & 46.9 & 0.94 & 449.9 & 0.90 & 362.1 & 0.79 & $1,245.3$ & 0.95 \\
\hline Dublin South & 46.4 & 0.93 & 463.7 & 0.93 & 413.5 & 0.91 & $1,172.4$ & 0.89 \\
\hline Tipperary South & 45.4 & 0.91 & 455.0 & 0.91 & 404.4 & 0.89 & $1,159.5$ & 0.88 \\
\hline Monaghan & 45.2 & 0.91 & 408.0 & 0.82 & 382.4 & 0.84 & $1,236.8$ & 0.94 \\
\hline Waterford & 45.1 & 0.91 & 446.6 & 0.90 & 441.9 & 0.97 & $1,202.9$ & 0.91 \\
\hline Wexford & 44.6 & 0.90 & 459.7 & 0.92 & 486.8 & 1.07 & $1,216.7$ & 0.92 \\
\hline Kerry & 42.7 & 0.86 & 415.1 & 0.83 & 392.2 & 0.86 & $1,242.1$ & 0.94 \\
\hline Dublin North & 42.1 & 0.85 & 421.5 & 0.85 & 413.0 & 0.91 & $1,045.7$ & 0.79 \\
\hline Sligo & 40.8 & 0.82 & 396.6 & 0.80 & 297.4 & 0.65 & $1,083.9$ & 0.82 \\
\hline Donegal & 40.0 & 0.80 & 405.6 & 0.82 & 333.8 & 0.73 & $1,021.4$ & 0.78 \\
\hline Laois & 33.0 & 0.66 & 321.7 & 0.65 & 301.0 & 0.66 & 868.5 & 0.66 \\
\hline Ireland & 49.8 & 1.00 & 497.6 & 1.00 & 456.2 & 1.00 & $1,317.5$ & 1.00 \\
\hline Gini coefficient & 0.091 & & 0.146 & & 0.119 & & 0.095 & \\
\hline
\end{tabular}

Sources: Data on the number of LTRC beds are from the Health Information and Quality Authority's list of designated residential centres for older people (February 2015) and the Department of Health's list of long-stay units (February 2015).

Notes: (a) Mortality-adjusted area populations are calculated by multiplying the area's 2014 population estimate by: area crude mortality rate 2014/national crude mortality rate 2014. (b) Area populations with disability are calculated by applying area disability rates from Census 2011 to area population estimates 2014. (c) Area populations with morbidity are the proportion of people with a full Medical Card who are receiving a prescription for a chronic health condition in 2014 applied to the number of people with a full Medical Card at December 2014. (d) The Gini coefficient summarises inequality in the distribution of long-term beds across areas, with 0 representing complete equality across areas and 1 representing complete inequality across areas. 
TABLE A4.10 ANNUAL AVERAGE NUMBER OF PUBLICLY FINANCED HOME CARE HOURS PER PERSON AGED 65+ YEARS AND NEEDS-ADJUSTED POPULATIONS AGED 65+ YEARS BY GEOGRAPHIC AREA, IRELAND 2014

\begin{tabular}{|c|c|c|c|c|c|c|c|c|}
\hline \multirow[t]{2}{*}{ Geographic area } & \multicolumn{2}{|c|}{$\begin{array}{c}\text { Population aged } 65+ \\
\text { years }\end{array}$} & \multicolumn{2}{|c|}{$\begin{array}{l}\text { Mortality-adjusted } \\
\text { population aged } 65+ \\
\text { years }\end{array}$} & \multicolumn{2}{|c|}{$\begin{array}{c}\text { Population aged } 85+ \\
\text { years }\end{array}$} & \multicolumn{2}{|c|}{$\begin{array}{c}\text { Population with } \\
\text { disability aged } 65+\text { years }\end{array}$} \\
\hline & $\begin{array}{l}\text { Hours per } \\
\text { person }\end{array}$ & $\begin{array}{c}\text { Ratio of } \\
\text { area value } \\
\text { to national } \\
\text { value }\end{array}$ & $\begin{array}{l}\text { Hours per } \\
\text { person }\end{array}$ & $\begin{array}{c}\text { Ratio of } \\
\text { area value } \\
\text { to national } \\
\text { value }\end{array}$ & $\begin{array}{l}\text { Hours per } \\
\text { person }\end{array}$ & $\begin{array}{c}\text { Ratio of } \\
\text { area value } \\
\text { to national } \\
\text { value }\end{array}$ & $\begin{array}{c}\text { Hours per } \\
\text { person }\end{array}$ & $\begin{array}{c}\text { Ratio of } \\
\text { area value } \\
\text { to national } \\
\text { value }\end{array}$ \\
\hline Sligo & 34.5 & 1.43 & 33.5 & 1.39 & 251.0 & 1.13 & 91.5 & 1.43 \\
\hline Leitrim & 32.5 & 1.35 & 31.0 & 1.28 & 247.8 & 1.12 & 90.1 & 1.41 \\
\hline Kerry & 31.0 & 1.29 & 30.1 & 1.25 & 284.9 & 1.29 & 90.2 & 1.41 \\
\hline Dublin North & 30.5 & 1.26 & 30.5 & 1.26 & 298.9 & 1.35 & 75.7 & 1.18 \\
\hline Louth & 30.0 & 1.24 & 31.1 & 1.29 & 284.4 & 1.29 & 78.1 & 1.22 \\
\hline Meath & 30.0 & 1.24 & 32.6 & 1.35 & 323.5 & 1.46 & 86.5 & 1.35 \\
\hline Donegal & 29.8 & 1.23 & 30.2 & 1.25 & 248.5 & 1.12 & 76.0 & 1.19 \\
\hline Cork & 28.4 & 1.18 & 28.4 & 1.18 & 265.3 & 1.20 & 77.7 & 1.22 \\
\hline Roscommon & 28.2 & 1.17 & 28.0 & 1.16 & 203.9 & 0.92 & 74.8 & 1.17 \\
\hline Cavan & 28.1 & 1.17 & 25.6 & 1.06 & 212.9 & 0.96 & 77.8 & 1.22 \\
\hline Monaghan & 27.5 & 1.14 & 24.8 & 1.03 & 232.9 & 1.05 & 75.3 & 1.18 \\
\hline Tipperary North & 24.9 & 1.03 & 22.2 & 0.92 & 223.9 & 1.01 & 65.3 & 1.02 \\
\hline Galway & 24.8 & 1.03 & 26.2 & 1.08 & 204.6 & 0.92 & 68.8 & 1.08 \\
\hline Tipperary South & 24.7 & 1.02 & 24.7 & 1.02 & 219.9 & 0.99 & 63.0 & 0.99 \\
\hline Limerick & 23.1 & 0.96 & 21.0 & 0.87 & 241.2 & 1.09 & 60.6 & 0.95 \\
\hline Carlow & 23.0 & 0.95 & 21.3 & 0.88 & 234.3 & 1.06 & 59.8 & 0.94 \\
\hline Laois & 22.6 & 0.94 & 22.1 & 0.91 & 206.5 & 0.93 & 59.6 & 0.93 \\
\hline Wexford & 22.0 & 0.91 & 22.7 & 0.94 & 240.9 & 1.09 & 60.2 & 0.94 \\
\hline Mayo & 21.6 & 0.89 & 20.7 & 0.86 & 166.8 & 0.75 & 57.4 & 0.90 \\
\hline Kilkenny & 20.4 & 0.84 & 22.7 & 0.94 & 173.9 & 0.79 & 56.0 & 0.88 \\
\hline Wicklow & 20.3 & 0.84 & 22.1 & 0.91 & 221.6 & 1.00 & 54.9 & 0.86 \\
\hline Westmeath & 20.2 & 0.84 & 17.6 & 0.73 & 174.1 & 0.79 & 53.6 & 0.84 \\
\hline Offaly & 19.6 & 0.81 & 21.7 & 0.90 & 175.8 & 0.79 & 50.6 & 0.79 \\
\hline Longford & 18.3 & 0.76 & 18.3 & 0.76 & 180.3 & 0.81 & 49.5 & 0.77 \\
\hline Kildare & 17.2 & 0.71 & 19.0 & 0.79 & 191.6 & 0.87 & 45.1 & 0.71 \\
\hline Waterford & 16.9 & 0.70 & 16.8 & 0.70 & 166.2 & 0.75 & 45.2 & 0.71 \\
\hline Clare & 16.9 & 0.70 & 16.8 & 0.69 & 156.3 & 0.71 & 47.4 & 0.74 \\
\hline Dublin South & 15.4 & 0.64 & 15.4 & 0.64 & 137.1 & 0.62 & 38.9 & 0.61 \\
\hline Ireland & 24.1 & 1.00 & 24.1 & 1.00 & 221.3 & 1.00 & 63.9 & 1.00 \\
\hline Gini coefficient & 0.101 & & 0.122 & & 0.116 & & 0.129 & \\
\hline
\end{tabular}

Sources: Data on the supply of publicly financed home care were provided by the Social Care Division of the HSE.

Notes: (a) Mortality-adjusted area populations are calculated by multiplying the area's 2014 population estimate by: area crude mortality rate 2014/national crude mortality rate 2014. (b) Area populations with disability are calculated by applying area disability rates from Census 2011 to area population estimates 2014. (c) Area populations with morbidity are the proportion of people with a full Medical Card who are receiving a prescription for a chronic health condition in 2014 applied to the number of people with a full Medical Card at December 2014. (d) The Gini coefficient summarises inequality in the distribution of home care hours across areas, with 0 representing complete equality across areas and 1 representing complete inequality across areas. 
TABLE A4.11 CHANGE IN RELATIVE SUPPLY FROM HIGHER/LOWER THAN NATIONAL SUPPLY TO LOWER/HIGHER THAN NATIONAL SUPPLY AFTER ADJUSTMENT BY GEOGRAPHIC AREA, HEALTHCARE SERVICE AND ADJUSTMENT TYPE, IRELAND 2014 ${ }^{\mathrm{a}}$

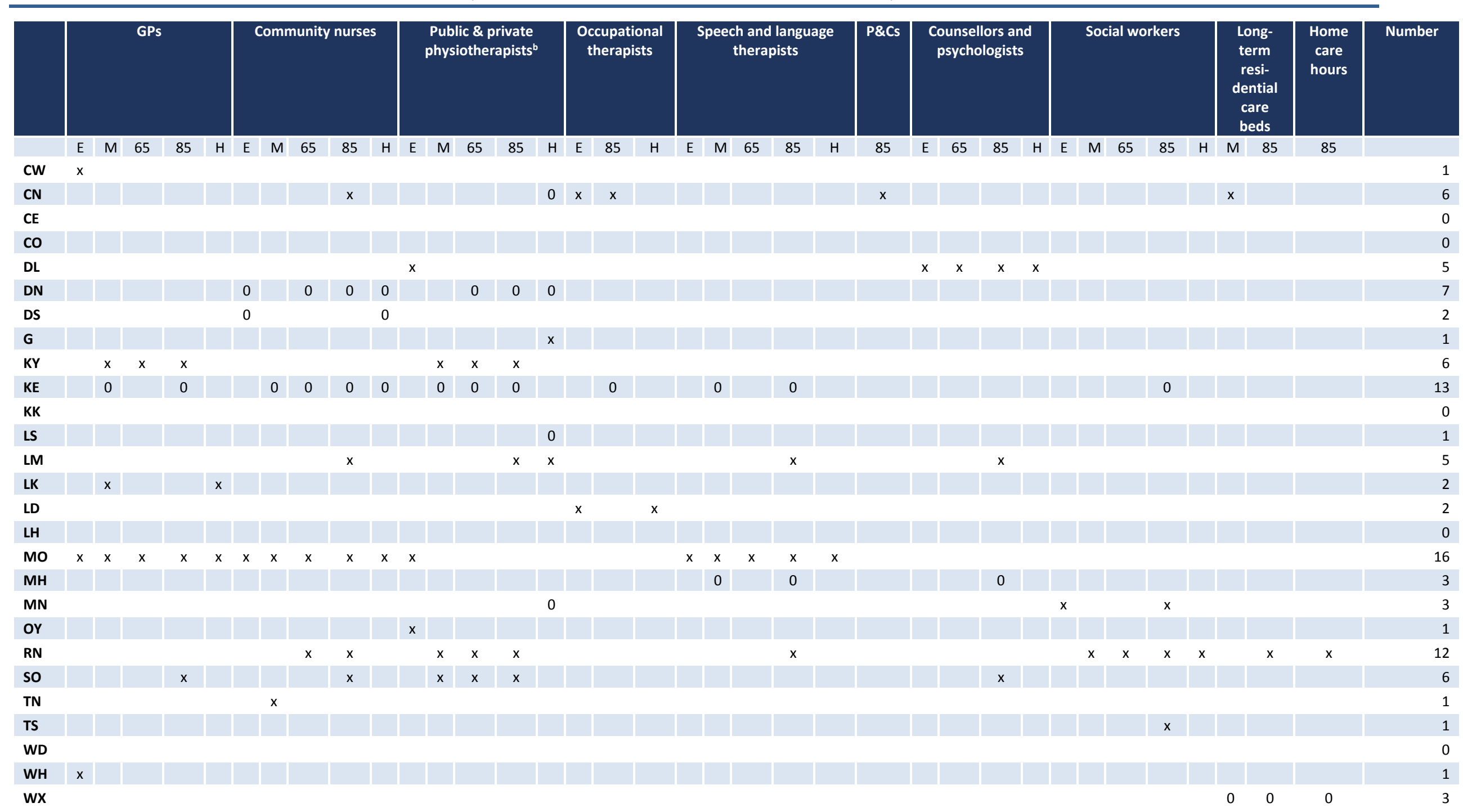



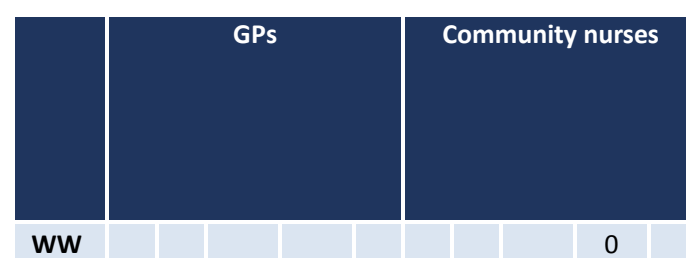

Public \& private
physiotherapists

Occupational
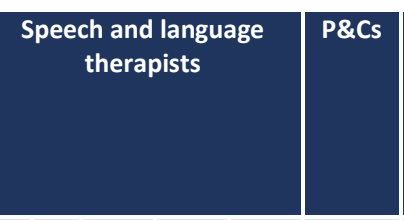

Counsellors and

psychologists

Social workers

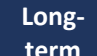

(E) Enabling: Population with a Medical Card (or GP Visit Card for GP services). (M) Mortality-adjusted population (mortality-adjusted population aged 65+ years for LTRC beds). (65) Population aged 65+ years. (85) Population aged 85+ years. (D) Population with disability (for LTRC beds: population aged 65+ years with disability). (H) Population with a Medical Card and a prescription

for a chronic health condition. (N) Number of times area's relative supply changes from higher/lower than national supply to lower/higher than national supply after adjustment (i.e. above national value before adjustment and below national value after adjustment, or vice versa). (x). Area is higher than national value before adjustment, lower than national value after adjustment. 
180 | Geographic Profile of Healthcare Needs and Non-Acute Healthcare Supply in Ireland 
Whitaker Square,

Sir John Rogerson's Quay, Dublin 2

Telephone +35318632000

Email admin@esri.ie

Web www.esri.ie

Twitter @ESRIDublin

ISBN 978-0-7070-498-3 